\title{
Evolución de los Balaenidae (MAMMALIA, CETACEA, MYSTICETI) del Mioceno de Patagonia: Sistemática, Filogenia y Aspectos Paleobiológicos
}

\section{Lic. Mónica R. Buono}

\author{
280
}

\section{Director}

Dra. Marta S. Fernández

Facultad de Ciencias Naturales y Museo

Universidad Nacional de La Plata CONICET

\section{Co-Director}

Dr. Mario A. Cozzuol

Universidade Federal de Minas Gerais Instituto de Ciencias Biológicas

Departamento de Zoología

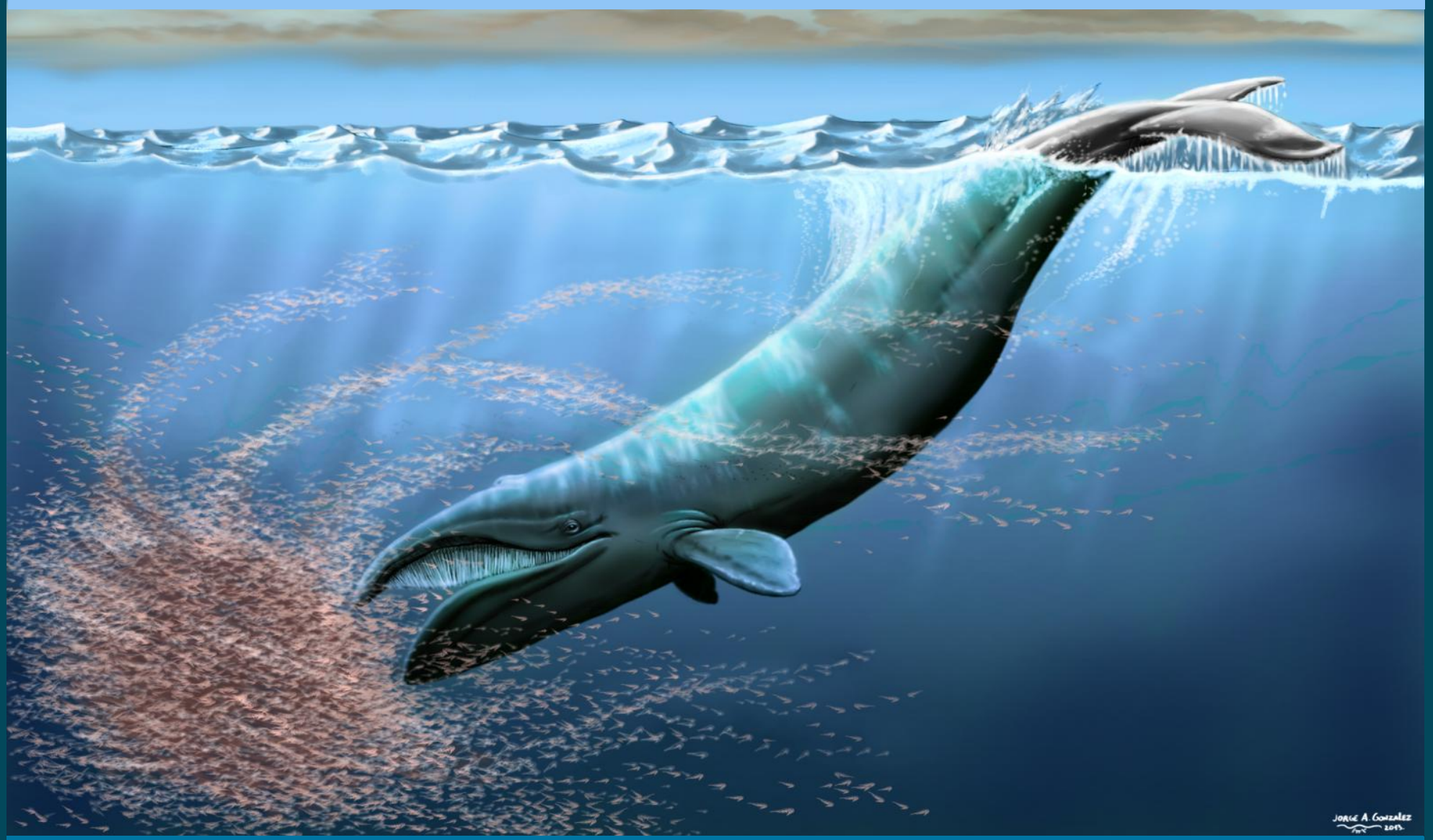

TRABAJO DE TESIS PARA OPTAR POR EL TÍTULO DE DOCTOR EN CIENCIAS NATURALES 
A mis viejos, Patricia y Rafael

A mis dos amores, Hugo y Tomás 


\section{Agradecimientos}

El desarrollo de esta tesis fue posible gracias al aporte y ayuda de muchas personas e instituciones, a las cuales quiero expresar mi gratitud.

Quiero agradecer en primer lugar a mis directores, la Dra. Marta Fernández y al Dr. Mario Cozzuol. A Marta por su apoyo incondicional y confianza a lo largo de estos años, por sus enseñanzas y motivaciones, por poner límites a mis propias exigencias y bajarme siempre a la realidad, pero, sobre todo, por ser la persona que es. A Mario por ofrecerme y confiarme este tema de tesis, y por permitirme continuar con una línea de trabajo que el inició hace muchos años. A ambos mi total gratitud.

A la Dra. Maria Teresa Dozo por toda la ayuda brindada durante el desarrollo de esta tesis y especialmente por ayudarnos en muchas instancias personales en nuestro establecimiento en la ciudad de Puerto Madryn.

A los miembros del jurado, los Drs. Diego Verzi, Marcelo Reguero y Ewan Fordyce por los comentarios y sugerencias realizadas, las cuales mejoraron este trabajo de tesis.

Al personal del Dpto. de Postgrado de la Facultad de Ciencias Naturales y Museo de La Plata por la celeridad y buena predisposición que mostraron en las instancias de presentación y defensa de esta tesis.

A los directivos del Centro Nacional Patagónico (Cenpat), Dra. Mirtha Lewis, Dr. Rolando González-José, por abrirme las puertas de la institución para el desarrollo de este trabajo de tesis. A Rolo especialmente por la ayuda brindada en varias ocasiones.

A todas las personas que me ayudaron durante estos años en los trabajos de campo: el personal de automotores y náutica del Cenpat (“Bocha”, “Bebote”, Andrés, Néstor y Fabián), Pablo Puerta, Magalí Cardenas, Leandro Canessa, Maria Teresa Dozo, Gastón Martinez, Lucas Cheme Arriaga y Lucio Ibiricu. A Bocha especialmente por su ayuda y apoyo en todas las campañas, por sus ricas comidas, por cuidarnos en el campo, y por todas las charlas en las camionetas de camino a algún lugar de Península Valdés. A Pablito por toda su ayuda y enseñanzas en el trabajo de campo y por todo lo que aún tenés que enseñarme, por los asados y cervezas en casa y en el campo, y por tu jeep que se banco muchas campañas. A Maga, por su apoyo y ayuda incondicional, por creer en mi siempre, por sus enseñanzas, y, por sobre todo, por tu generosa amistad.

A mi compañeros de trabajo y amigos, Gastón, Lucas y Lucio: se que muchas veces me “odiaron" por tener que ayudarme a mover mis "ballenitas"! pero de todo corazón les agradezco la ayuda que me brindaron en muchas oportunidades, gracias muchachos!

A Adrián Guillaume por su buena predisposición y por facilitar el desarrollo de los trabajos de 
campo.

A las personas que preparon en distintas instancias los materiales de esta tesis: Juanjo Moly, Leonel Acosta Burllaile, Pablo Puerta, Magalí Cardenas, Leandro Canessa y E. R. Gomez. Gracias a todos por el excelente trabajo que hicieron.

Quiero agradecer especialmente al personal del Programa de Monitoreo Sanitario de la Ballena Franca Austral en Península Valdés, Dr. Victoria Rowntree, Dr. Mariano Sironi, Dr. Luciano Valenzuela, Vet.Marcela Uhart, Vet. Andrea Chirife, Vet. Matías Di Martino y voluntarios, por facilitarme el acceso a los ejemplares de ballenas francas varados durante las temporadas de trabajo, por el aporte de muestras, datos, fotografias y bibliografía. A Andrea especialmente por todo que me enseñó y ayudó en mis primeras disecciones, y a Matias por continuar con esa tarea. También quiero agradecer a otras personas que me ayudaron en varias ocasiones en las disecciones en el campo y en el laboratorio: Hugo Ruiz (porque sin su ayuda no hubiera sido posible colectar y diseccionar el mejor ejemplar de ballena franca al que tuve acceso), Nadia Velasquez Barloa, Lucas Federico Britos, Marina Reparaz, Leonardo Hardtke, Joaquin Orgeira, Emilia González, Bocha, Jorge Briguglio, Gastón, Lucio, Lucas y Néstor. Sin la colaboración de todos ustedes este trabajo no hubiera sido posible, por ello gracias!

A las instituciones y personas que a lo largo de estos años me permitieron el acceso a las colecciones: Diego Pol y E. R. Gomez (Museo Paleontológico Egidio Feruglio, Trelew, Chubut, Argentina), Marcelo Reguero, Diego Verzi e Itatí Olivares ( Museo de La Plata, La Plata, Argentina); Lilian Giraldez (Museo Provincial de Ciencias Naturales y Oceanográfico, Puerto Madryn, Chubut, Argentina); Alejandro Kramarz, David Flores y Sergio Lucero ( Museo Argentino de Ciencias Naturales "Bernardino Rivadavia", Buenos Aires, Argentina); Enrique Crespo y Néstor García (Laboratorio de Mamíferos Marinos, Centro Nacional Patagónico, Puerto Madryn, Argentina); Nycholas Pyenson, Charles Potter, Dave Bohaska (National Museum of Natural History, USNM); Anton V. Helden (Museum of New Zealand Te Papa Tongarewa); y Eileen Westwig (American Museum of Natural History), Tom Demeré (San Diego Natural History Museum).

A Anton Van Helden y Ewan Fordyce por permitirme participar de la disección de una ballena franca pigmea en Nueva Zelanda.

A Joy Reidenberg por permitirme acceder y diseccionar varias muestras de ballenas y por las charlas sobre anatomía de misticetos.

A Guillermo Harris, Teresa Correa y Ariel Lazzari por colectar y donar para su estudio dos de los ejemplares fósiles que se describen en esta tesis.

A Norma Luján del Servicio de Histología del Cenpat por animarse a cortar y preparar ojos de ballenas.

A Néstor Garcia por su desinteresada ayuda todos estos años en la colecta de materiales de 
ballenas actuales, por aguantar todas mis visitas "molestas" a la colección buscando especímenes, números de colección, medidas; por eso y más, gracias totales Néstor!

A Flor Grandi y a Damián Vales por su asistencia, en varias ocasiones, en mis consultas de materiales en la colección de Mamíferos Marinos.

A Julia Desojo y Diego Verzi por toda la ayuda que me brindaron en los inicios de mi carrera y por impulsarme a trabajar con los cetáceos fósiles.

A Ewan Fordyce por la increíble experiencia en mi viaje de estudio a Nueva Zelanda: por las enseñanzas en la anatomía de los cetáceos, por la lectura crítica de manuscritos, por las fotografías de especímenes, y sobre todo por recibirme tan calurosamente entre sus estudiantes y familia. Especialmente quiero agradecer a Carolina Loch, Gabriel Aguirre, Felix Marx y Yoshi Tanaka por toda la ayuda que me brindaron durante mi estadía en Dunedin, me hicieron sentir como en casa.

A Felix Marx por las interesantes dicusiones e intercambios de información sobre la anatomía y filogenia de los misticetos, y por las fotografías de varios especímenes.

A Nick Pyenson por la ayuda brindada durante mi visita a la colección del National Museum of Natural History (Washington), por los aportes y discusiones en anatomía blanda y reconstrucción del tamaño corporal en los misticetos.

A Morgan Churchill por proveerme fotografías de Eubalaena glacialis y Eubalaena shinshuensis

A Alejandro Panes (IDECH-Puerto Madryn) por las tomografías y resonancias efectuadas sobre los ejemplares estudiados; por su estusiasmo, buena predisposición y por el tiempo dedicado para estos estudios.

A Constanza Figueroa Paz (Coni) por las reconstrucciones $3 \mathrm{D}$ y análisis del oído interno de los balénidos y por toda la ayuda brindada en la etapa final de esta tesis.

A Diego Pol y a Juliana Sterli por la ayudad brindada en los análisis filogenéticos.

A todas las personas que de una u otra manera me ayudaron en la preparación y diseño de este manucrito: Pame por el diseño de las tapas y carátulas; Anahí por la lectura de varios capítulos, la ayuda con el índice, los mapas, y el abstract, Coni, Patricia y Cami por la ayuda con la bibliografía, a Gaby Massaferro por la construcción de los perfiles, y a la Dra. Catalina Pastor por tomar las fotografías de los cortes histológicos.

A mis amigas ñoñas: Anahí, Caro, Ana, Flor y Marina, por apoyarme y preocuparse por mi todos estos años, sobre todo en los momentos más difíciles, gracias por su amistad.

A las instituciones que me brindaron apoyo financiero para el desarrollo de esta tesis: Conicet, Cetacean Society International (CSI), American Museum of Natural History (Lerner Gray Fund for Marine Research), Society for Marine Mammalogy (Grant In Aid of Research), y Smithsonian Institution (Remington Kellogg Fund). 
A mis viejos, Patricia y Rafael, y a mis hermanos, Pame, Cami y Hernán, por su apoyo y ayuda incondicional todos estos años; yo se que aún no entienden muy bien lo que hago pero me reconforta saber que a pesar de eso están ahí... Especialmente gracias por ser el soporte vital estos últimos meses de escritura de la tesis cuidando al pequeño Tomás; sin su ayuda este trabajo no hubiera sido posible.

Por último a mis dos amores:

Hugo, por ser el impulsor inicial de este trabajo y por seguir impulsándolo durante todos estos años, en los buenos y malos momentos, por tu paciencia, compañía y apoyo, y por creer en mi aún cuando ni yo puedo;

Tomás, hijo sos el motor de mi vida, este trabajo es por y para vos... 


\section{Índice}

\section{Tomo I}

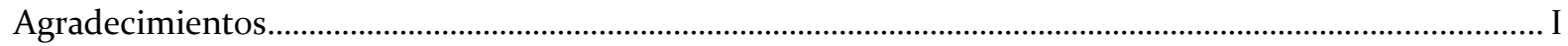

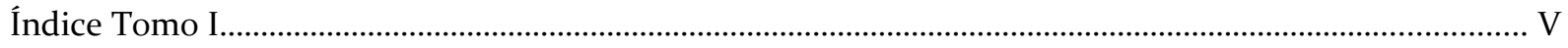

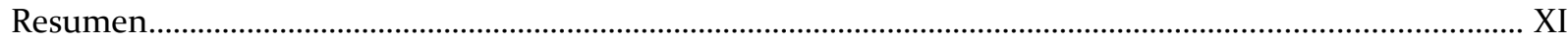

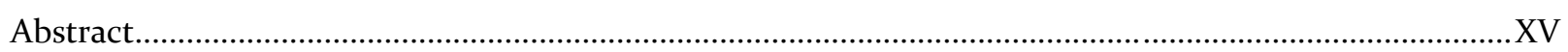

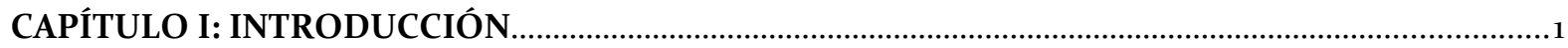

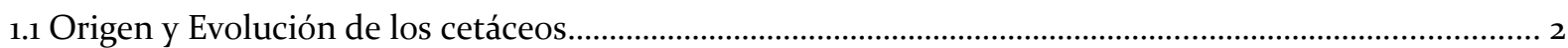

1.1.1 Los primeros cetáceos: "Archaeoceti”........................................................................................................ 2

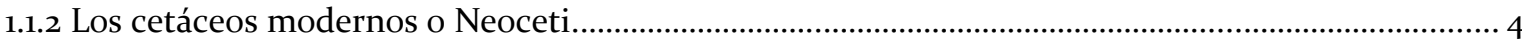

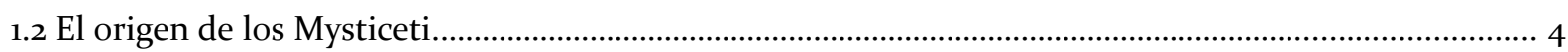

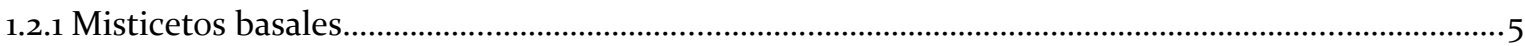

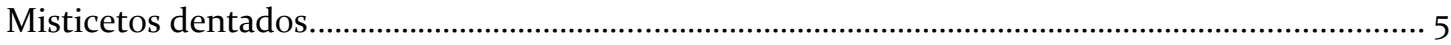

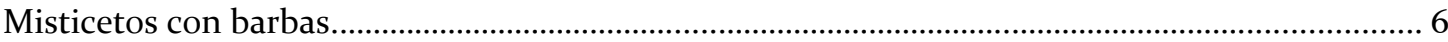

1.2.2 Misticetos modernos.................................................................................................................... 7

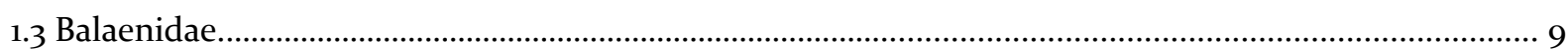

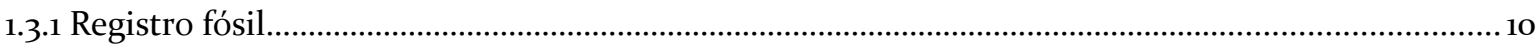

1.3.2 Relaciones filogenéticas ..........................................................................................................11

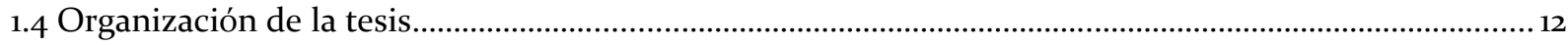

CAPÍTULO II: MATERIALES Y MÉTODOS............................................................................................ 14

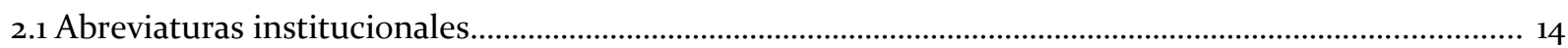

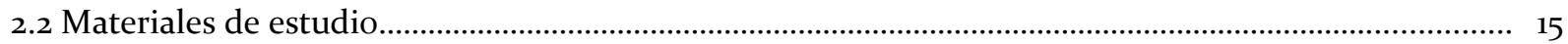

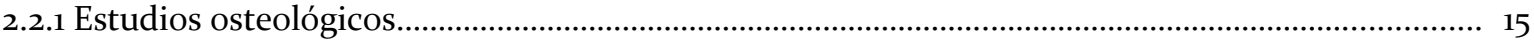

2.2.2 Estudios de anatomía blanda...................................................................................................... 19

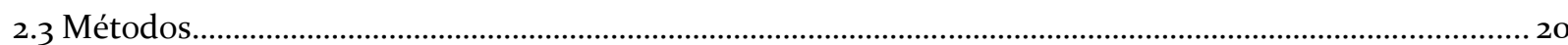

Eubalaena australis como modelo neontólogico de comparación................................................................ 20

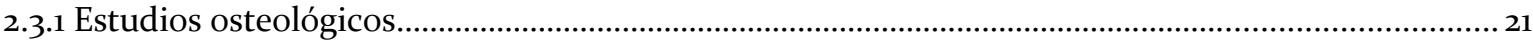

2.3.1.1 Terminología osteológica..........................................................................................................21

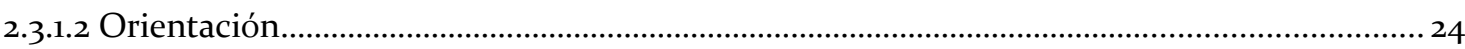

Términos para la orientación de estructuras anatómicas....................................................... 24

Orientación del cráneo de los balénidos extintos.......................................................................24

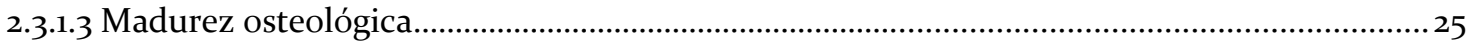

Estadios de edad en balénidos actuales...................................................................................25

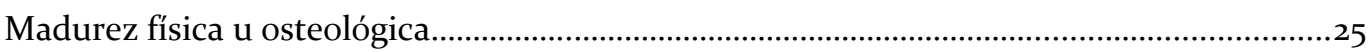




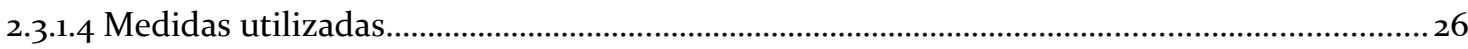

2.3.1.5 Tomografías helicoidales computadas................................................................................. 29

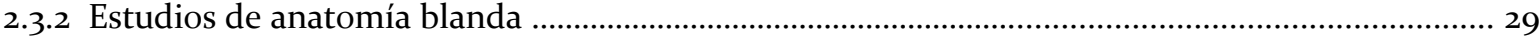

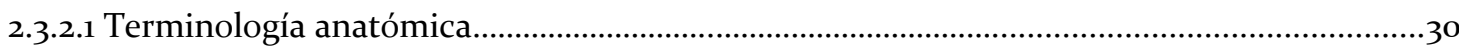

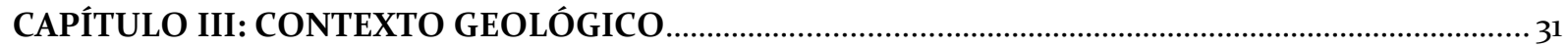

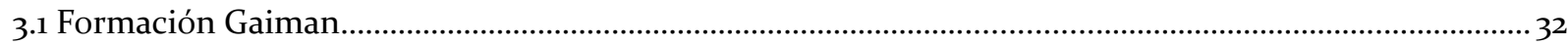

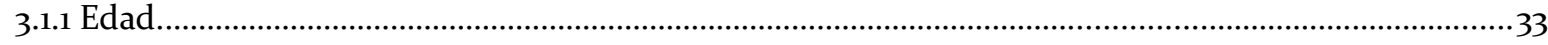

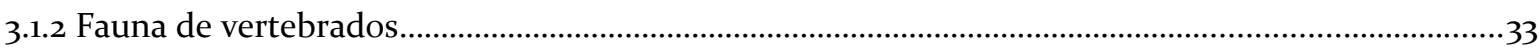

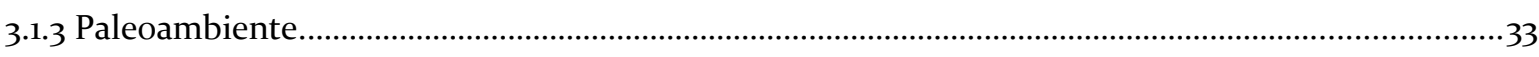

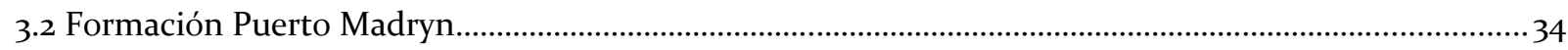

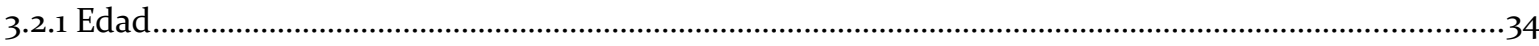

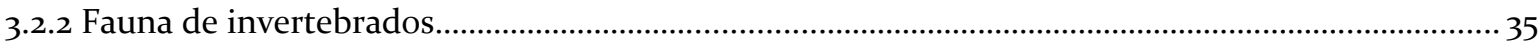

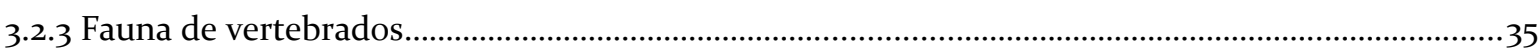

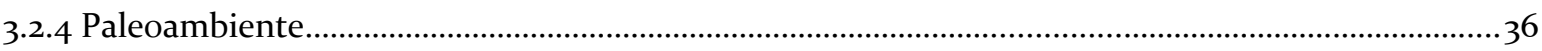

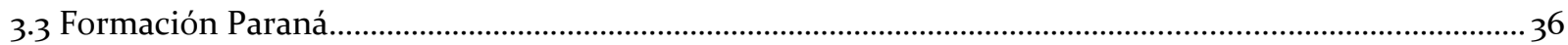

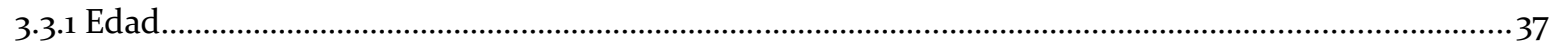

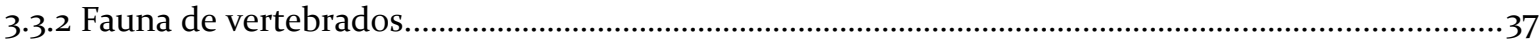

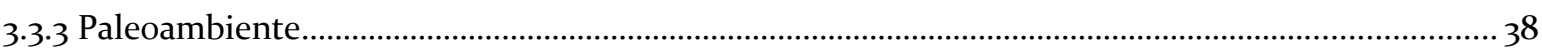

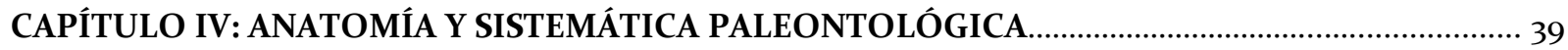

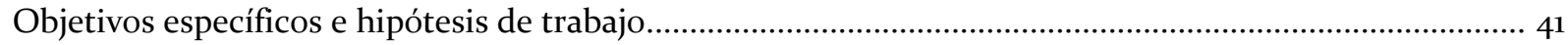

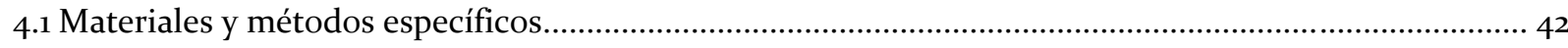

4.2 Modelo neontólogico de comparación: Eubalaena australis................................................................42

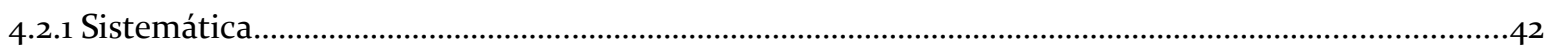

4.2.2 Anatomía craneana y mandibular de Eubalaena australis...........................................................45

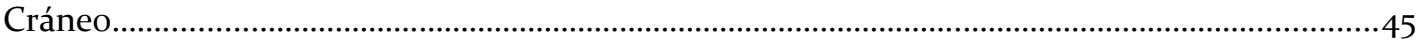

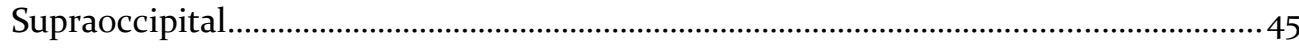

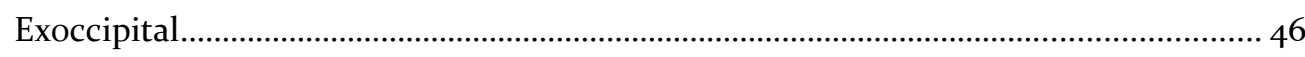

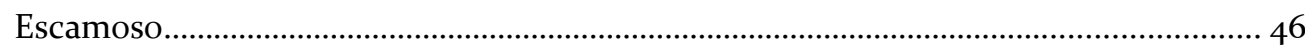

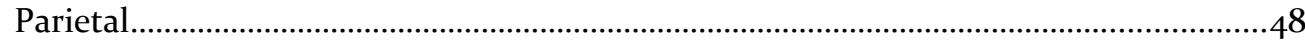

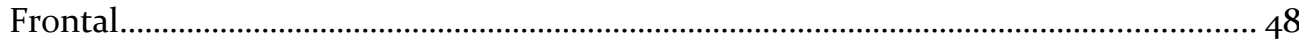

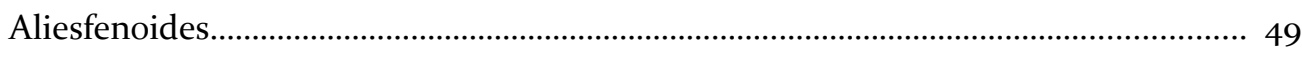

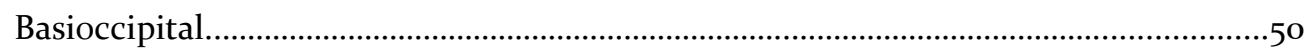

Basiesfenoides-Preesfenoides.......................................................................... 50

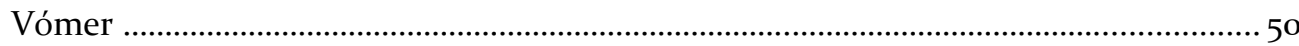

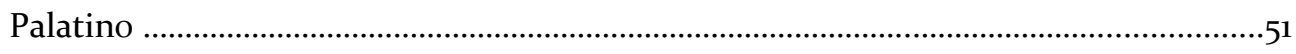

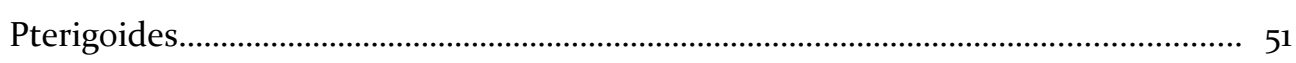

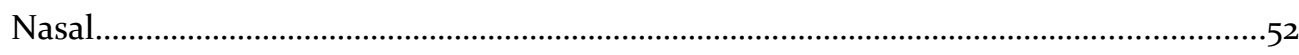

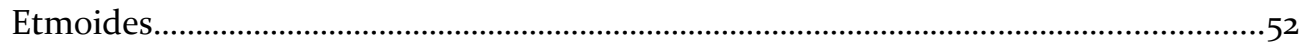




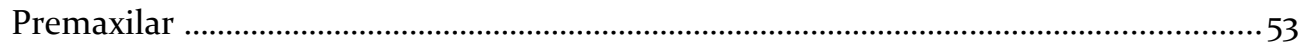

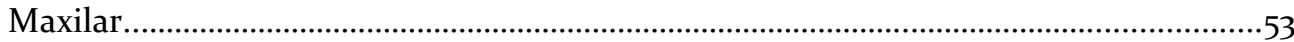

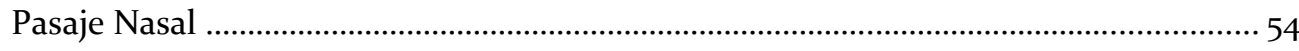

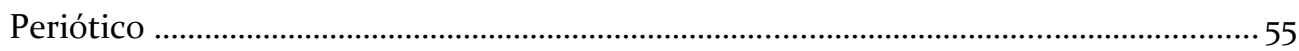

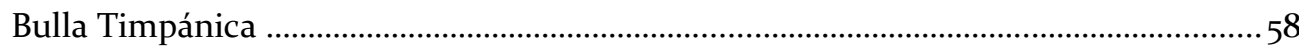

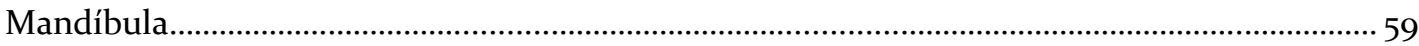

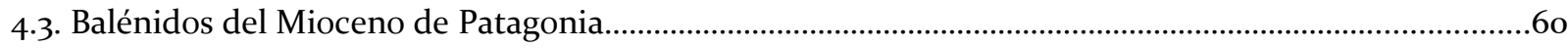

4.3.1 Balénido del Mioceno Temprano (Fm. Gaiman): Morenocetus parvus.............................................. 60

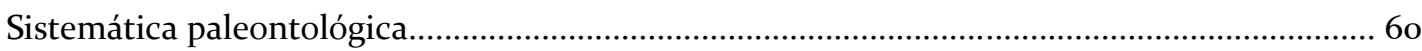

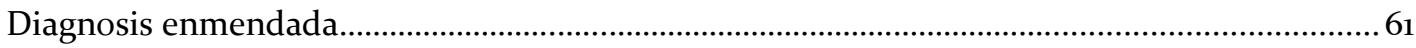

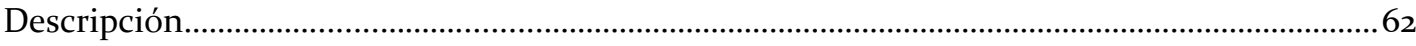

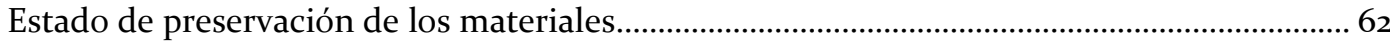

Características generales del cráneo........................................................................................... 62

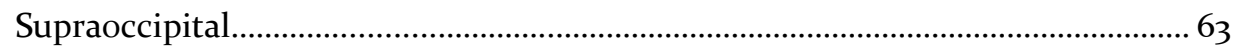

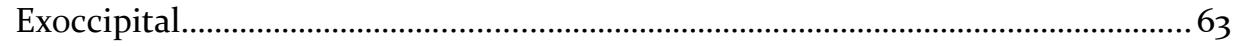

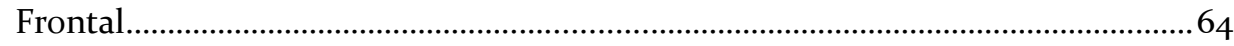

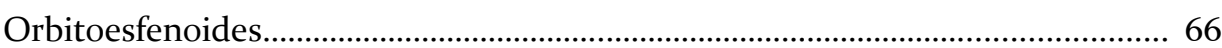

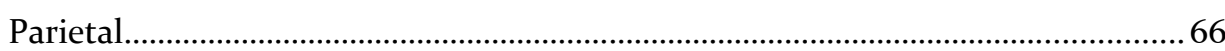

Escamoso

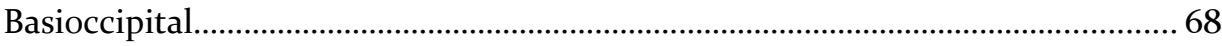

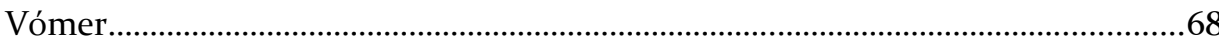

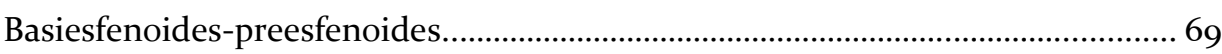

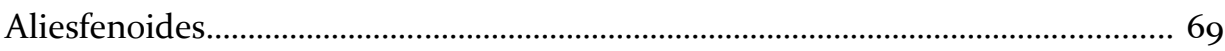

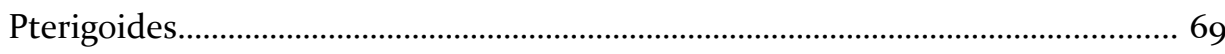

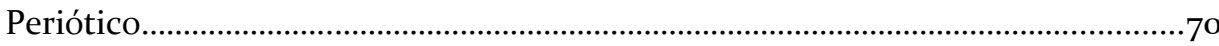

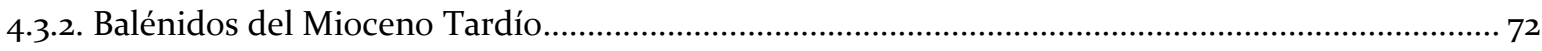

4.3.2.1 Balénido de la Formación Puerto Madryn: nuevo género y especie..........................................72

Sistemática paleontológica..................................................................................................... 72

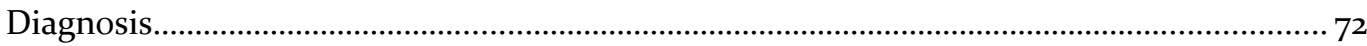

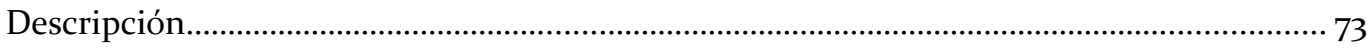

Estado de preservación de los materiales...................................................................74

Características generales del cráneo........................................................................74

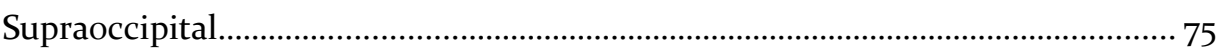

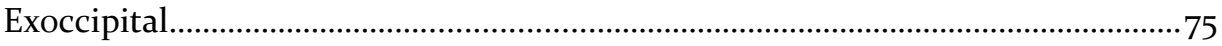

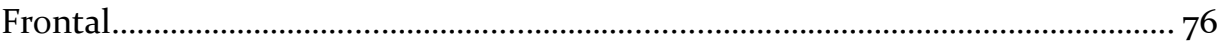

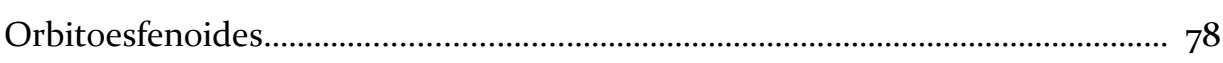

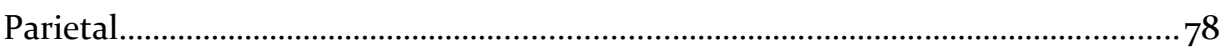

Escamoso 


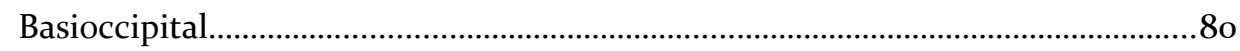

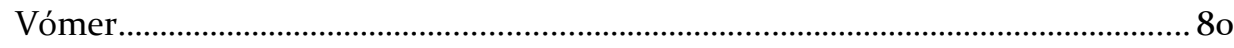

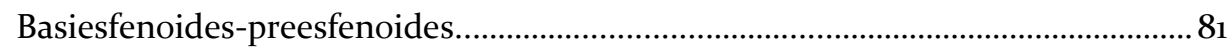

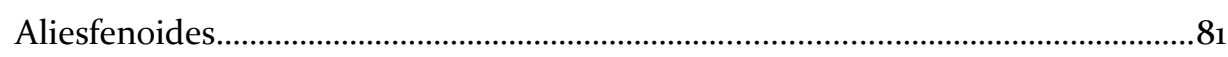

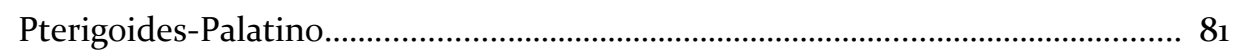

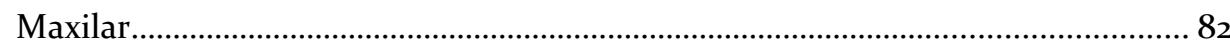

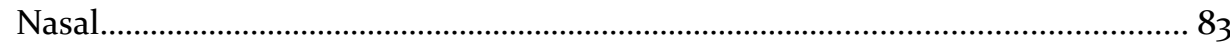

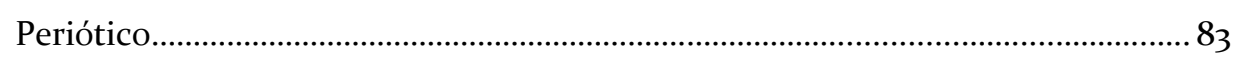

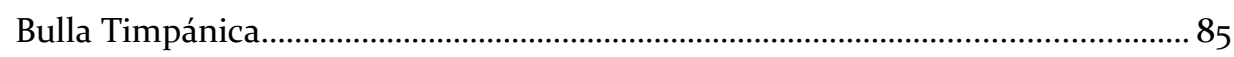

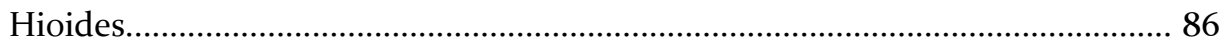

4.3.2.2 Balénido de la Formación Paraná .................................................................................................. 86

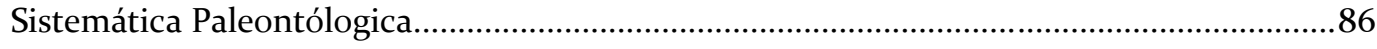

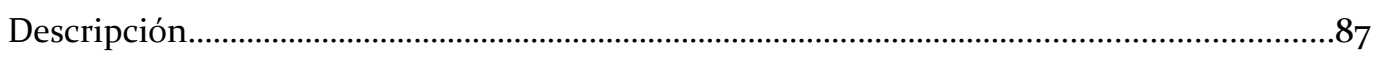

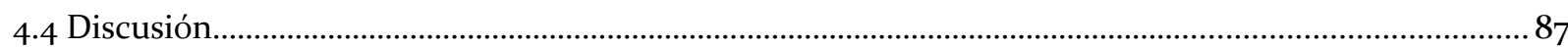

4.4.1 Variaciones ontogenéticas en la morfología del cráneo y mandíbula de Eubalaena australis .87

4.4.2 Madurez osteológica de los balénidos........................................................................................ 91

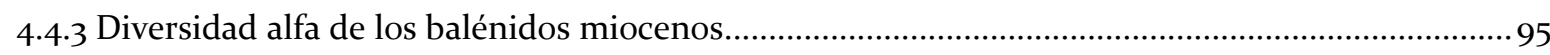

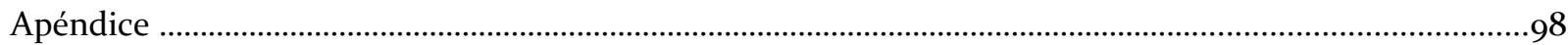

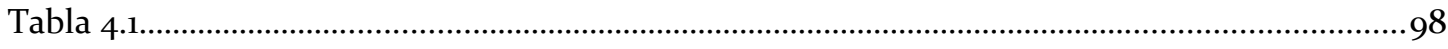

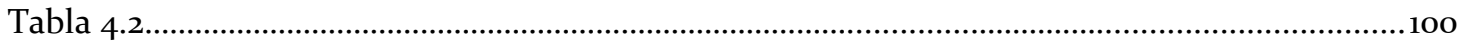

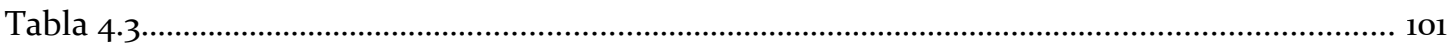

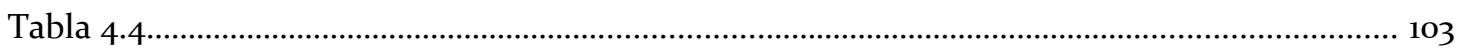

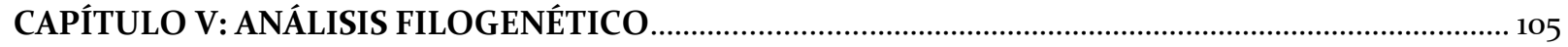

Objetivos específicos e hipótesis de trabajo............................................................................................. 106

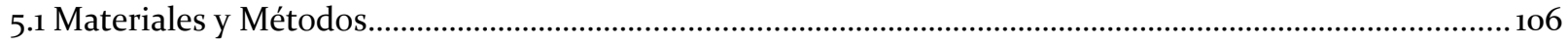

5.1.1 Taxones y caracteres incluidos en el análisis.......................................................................................... 106

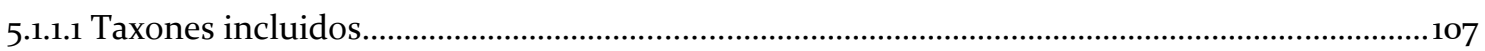

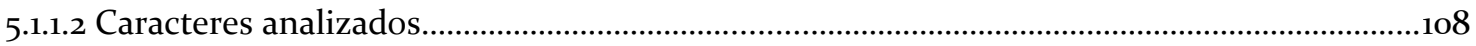

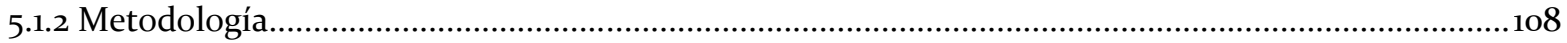

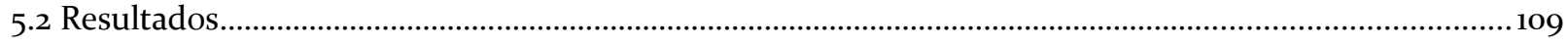

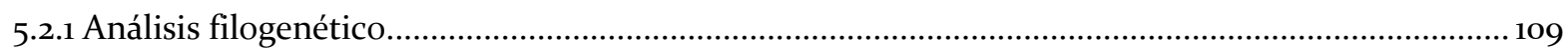

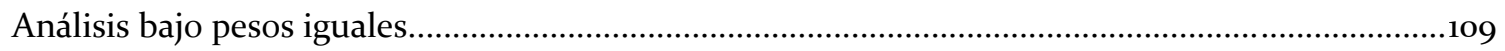

Análisis bajo pesos implicados............................................................................................... 113

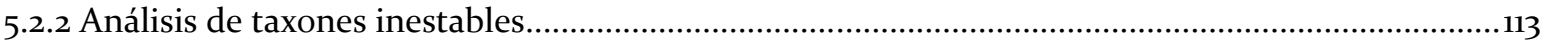

5.2.3 Ajuste estratigráfico................................................................................................................113

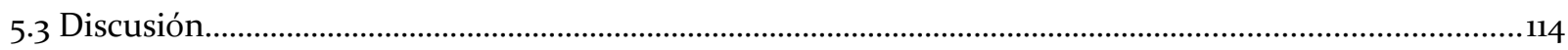

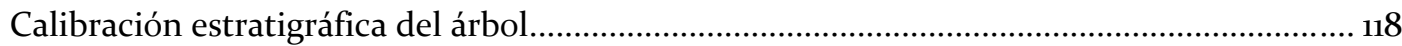


Apéndice.

5.1 Listado de caracteres .120

5.2 Matriz de datos

\section{CAPÍTULO VI: ASPECTOS PALEOBIOLÓGICOS DE LOS BALÉNIDOS MIOCENOS E} IMPLICANCIAS EN LA EVOLUCIÓN DE LOS MISTICETOS

6.1 Tamaño corporal.

6.1.1 Introducción.

Objetivo específico e hipótesis de trabajo.

6.1.2 Materiales y métodos específicos

6.1.3 Resultados.

6.1.4 Discusión

6.2 Morfología de la región nasal y respiración.......................................................................................

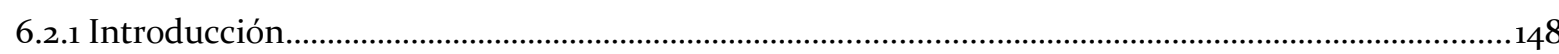

Objetivos específicos e hipótesis de trabajo...............................................................................149

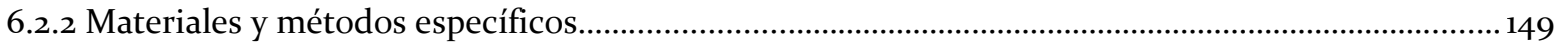

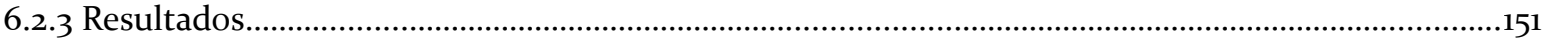

6.2.3.1 Anatomía de la región nasal en Eubalaena australis........................................................... 151

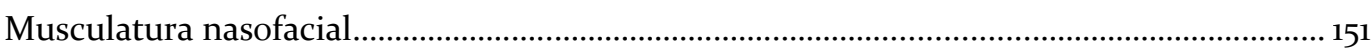

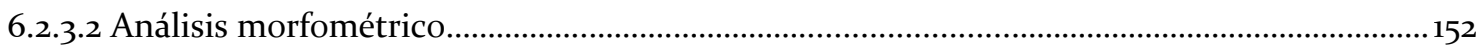

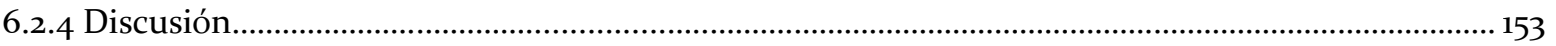

Aspectos morfológicos del complejo nasal en los misticetos....................................... 153

Aspectos evolutivos del complejo nasal de los misticetos.............................................155

Análisis morfométrico...................................................................................................... 157

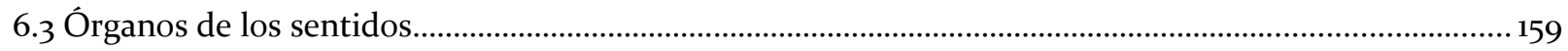

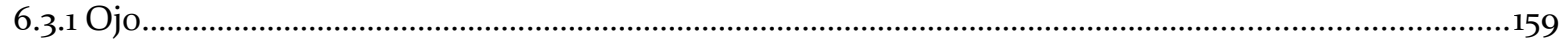

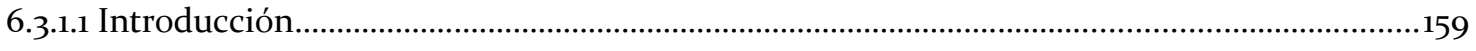

Objetivos específicos e hipótesis de trabajo....................................................................159

6.3.1.2 Materiales y métodos específicos...........................................................................................160

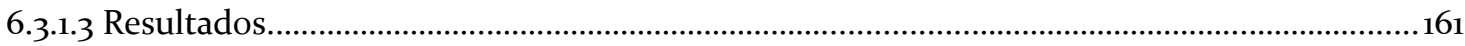

6.3.1.3.1 Anatomía del ojo y estructuras periorbitales de Eubalaena australis........................ 161

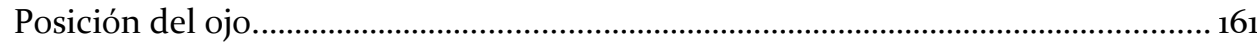

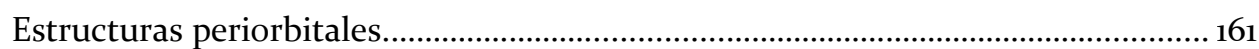

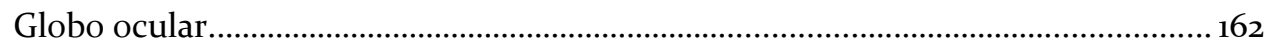

6.3.1.3.2 Análisis morfométrico....................................................................................... 165

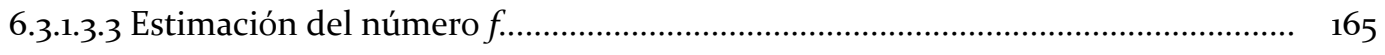

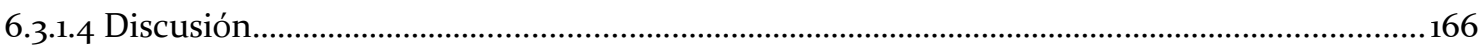

Aspectos morfológicos del ojo y estructuras periorbitales de Eubalaena australis. .166 
Análisis alométrico. .170

Estimación del parámetro $f$. 171

Reconstrucción del globo ocular y evolución de la visión en los misticetos

extintos 172

6.3.2 Oído 174

6.3.2.1 Introducción .174

Objetivos específicos e hipótesis de trabajo...................................................................176

6.3.2.2 Materiales y Métodos específicos........................................................................................176

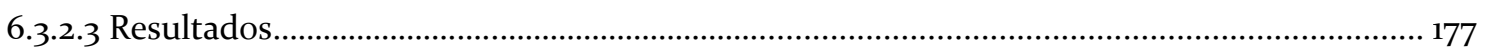

Morfología del oído de Eubalaena australis.......................................................................177

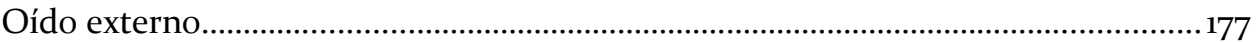

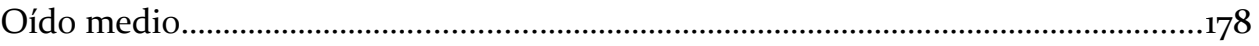

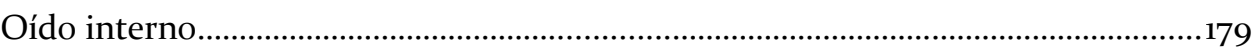

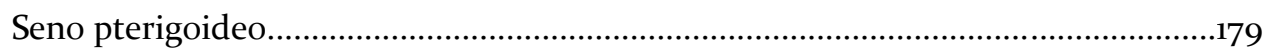

Reconstrucción del oído en balénidos extintos...............................................................179

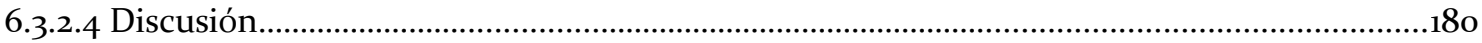

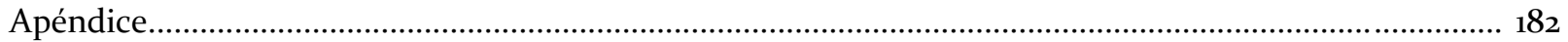

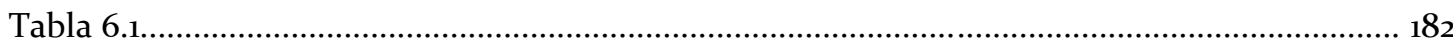

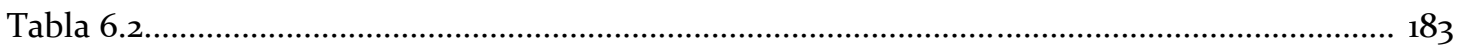

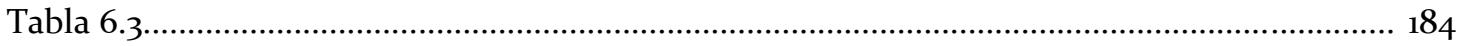

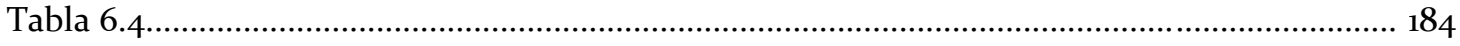

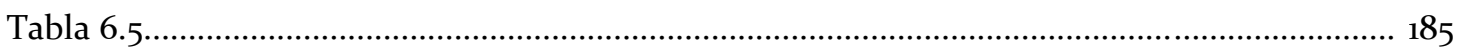

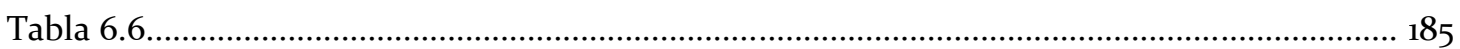

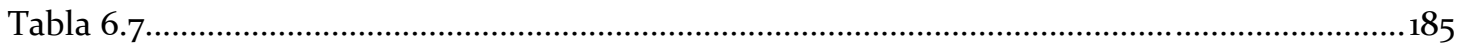

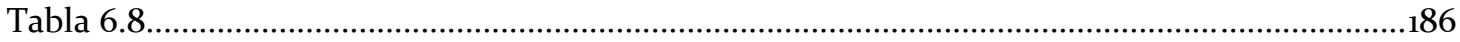

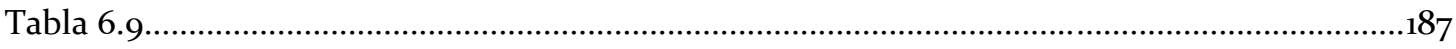

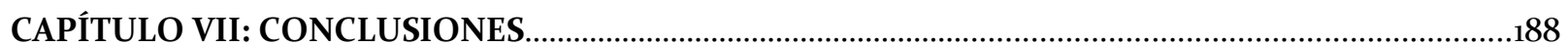

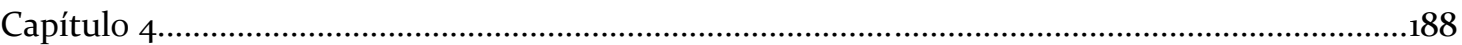

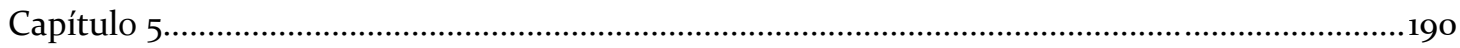

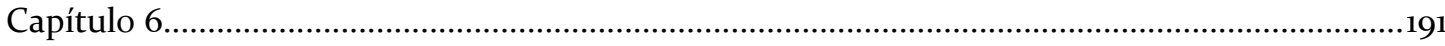

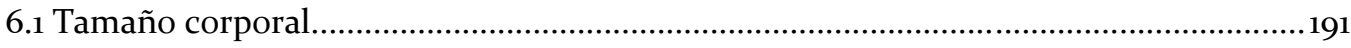

6.2 Morfología de la región nasal y respiración........................................................... 192

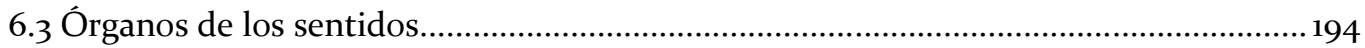

6.3.1 Ojo y estructuras periorbitales........................................................................ 194

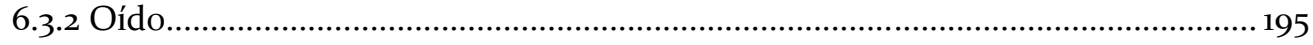

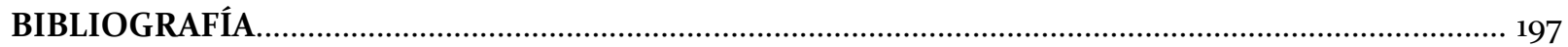




\section{Resumen}

Los Balaenidae (Cetacea: Neoceti) son un grupo de misticetos caracterizados por presentar, en el cráneo y de la mandíbula, una serie de especializaciones vinculadas al sistema de alimentación por filtración, tales como un rostro muy arqueado y angosto, huesos rostrales sin interdigitación con los huesos occipitales, mandíbula con un proceso coronoides y angular reducido y barbas largas. El patrón corporal de los balénidos actuales, especialmente su anatomía esqueletaria, es muy conservador y sólo se reconocen cuatro especies distribuidas en dos géneros: Balaena (B. mysticetus) y Eubalaena (E. australis; E. glacialis; E. japonica).

El registro fósil de los balénidos es temporalmente extenso (Mioceno temprano-actualidad) y, en algunos casos abundante (i.e. Plioceno, Pleistoceno,) pero está caracterizado por grandes discontinuidades estratigráficas y geográficas. En particular, el registro mioceno es extremadamente escaso y está restringido a la Patagonia argentina, con la presencia de Morenocetus parvus, el balénido más antiguo conocido (Mioceno temprano). Los registros de balénidos pliocenos y pleistocenos son, en cambio, abundantes aunque están restringidos al Hesmiferio Norte. Estos incluyen géneros extintos (Balaenella, Balaenula, Balaenotus) y otros con representantes actuales (Balaena y Eubalaena). Morenocetus parvus fue descripto y nominado por Cabrera (1926), en una monografía sobre cetáceos fósiles del Museo de La Plata, sobre la base de dos cráneos incompletos recuperados de la Formación Gaiman (Mioceno temprano, Chubut). Debido a que este taxón no fue re-estudiado luego de su descripción original, ha permanecido como una especie enigmática. Como resultado de trabajos paleontológicos en el sector de Península Valdés y alrededores, se han recuperado nuevos ejemplares de balénidos provenientes de la Formación Puerto Madryn (Mioceno tardío, Chubut). Estos ejemplares, junto con algunos restos aislados provenientes del Mioceno tardío de Entre Ríos (Formación Paraná) completan, en parte, los extensos hiatos del registro de balénidos Mioceno.

La familia Balaenidae es un linaje clave en la evolución de los misticetos ya que, según algunos estudios filogenéticos, es el grupo más basal y más antiguo de misticetos actuales. Este supuesto está basado en la ocurrencia temprana de los balénidos en el registro estratigráfico, y en datos de divergencia antiguos estimados a partir de estudios moleculares. Uno de los puntos más controvertidos sobre las relaciones filogenéticas de los balénidos es la posición de su representante más antiguo, Morenocetus parvus. La importancia de este taxón, así como la de los otros registros miocenos recuperados en de la Formación Puerto Madryn y aún no descriptos, ameritan el estudio en profundidad de los balénidos miocenos de Patagonia. En este contexto, el objetivo general de 
esta tesis fue adquirir un mejor entendimiento de la historia evolutiva de los balénidos, mediante el análisis de los miembros más tempranos de este grupo. Para ello se aplicó un protocolo general de trabajo basado en la exploración de Eubalaena australis como modelo neontológico de los balénidos. La integración de la información osteológica y blanda obtenida permitió interpretar la anatomía de los taxones extintos, identificar los caracteres útiles para los análisis filogenéticos y la búsqueda de correlatos óseos para la reconstrucción de estructuras blandas en los fósiles.

El estudio de individuos en distintos estadios madurativos de Eubalaena australis permitió identificar parámetros, independientes del tamaño y del cierre relativo de las suturas, que diferencian a los neonatos y crías de los adultos. Sobre la base de la información de los balénidos actuales, se procedió al estudio anatómico y posteriormente sistemático de los balénidos miocenos. Los resultados de los estudios sistemáticos indicaron que Morenocetus parvus es una entidad taxonómica válida y que está representado por dos ejemplares subadultos. Asimismo los 3 ejemplares de balénidos del Mioceno tardío de la Fm. Pto Madryn corresponden a un adulto, un subadulto y un juvenil de un mismo taxón que se propone como un nuevo género y especie (=Taxón A). La presencia en el ejemplar adulto del Taxón A de caracteres tales como, un proceso ascendente del maxilar aproximadamente triangular y corto ántero-posteriormente, una bulla timpánica de aspecto globoso sin una marcada compresión dorso-ventral, y superficie dorsal del periótico sin crestas ni surcos, se interpretan como rasgos paedomórficos. Por último, los balénidos de la Fm. Paraná (Mioceno tardío, Entre Ríos) están representados sólo por bullas timpánicas, las cuales no son asignables al Taxón A de la Fm. Puerto Madryn. La condición fragmentaria de los especímenes no permitió su identificación a niveles específicos ni genéricos, por lo cual se designaron como Balaenidae indet.

Los análisis filogenéticos, de pesos implicados y pesos iguales, desarrollados en esta tesis dieron resultados consistentes entre sí, tanto en la topología general de los árboles como en las relaciones internas de los grandes clados. Los Balaenidae constituyen un grupo bien soportado y hermano del clado formado por los Balaenopteroidea y Cetotheriidae. Caperea marginata se recuperó, con buenos valores de soporte, profundamente anidado dentro de los Cetotéridos y constituye, de esta forma, el único representante actual de este clado. Los balénidos miocenos (Morenocetus y Taxón A) se recuperaron en un clado basal dentro de los Balaenidae; el soporte de este clado es adecuado y ninguno de los dos taxones fue hallado como inestables. Balaenella y Balaenula se posicionaron como sucesivos taxones hermanos de los balénidos modernos (Balaena y Eubalaena). Las relaciones dentro de los clados modernos (Balaena y Eubalaena) no lograron resolverse.

La calibración estratigráfica del cladograma mostró un extenso linaje fantasma entre los balénidos miocenos y los balénidos más derivados (Balaenella, Balaenula, Balaena y Eubalaena). La extensión de este linaje fantasma ( 15 Ma) abarca desde el Mioceno temprano-tardío (Burdigaliense) 
hasta el Plioceno temprano (Zancliense). A esto se suma un extenso hiato temporal en el registro fósil de los balénidos que abarca más de la mitad de la historia evolutiva del grupo. El hallazgo del Taxón A del Mioceno tardío de la Fm. Puerto Madryn interrumpe el hiato temporal entre Morenocetus y los balénidos más derivados, pero no acorta el linaje fantasma previamente mencionado.

Los aspectos paleobiológicos de los balénidos miocenos indagados en esta tesis comprendieron los siguientes tópicos: la evolución de la longitud corporal y su relación con la tendencia al gigantismo, la reconstrucción de la morfología de la región nasal y su vinculación con el buceo y la exploración de correlatos óseos vinculados con los órganos de los sentidos (ojo y oído).

En relación con el primero de estos tópicos, las estimaciones efectuadas del largo corporal, y su mapeo sobre el árbol filogenético, sugieren que la condición primitiva para los misticetos es un largo corporal pequeño $(<6 \mathrm{~m})$, condición que retienen las formas basales de misticetos con barbas o Chaeomyticeti. En lo misticetos el incremento en el largo corporal o tendencia al gigantismo no siguió un patrón lineal y se adquirió al menos dos veces en forma independiente, una en los Balaenidae y otra en los Balaenopteridae-Eschrichtiidae. En lo que respecta a los balénidos, las formas más antiguas y más basales (i.e. Morenocetus y Taxón A) presentan un largo corporal pequeño $(<6 \mathrm{~m})$. Desde finales del Mioceno se registra en los balénidos una tendencia al aumento del largo corporal en el ancestro del clado Eubalaena-Balaena.

La exploración de la anatomía de la región nasal de los balénidos (Eubalaena australis), cetotéridos (Caperea) y balenoptéridos (Balaenoptera bonaerensis), indicó que comparten un patrón general, con diferencias menores en las estructuras para la deflexión del agua y en la organización de la musculatura nasal. El análisis de los correlatos entre las estructuras blandas y óseas de la región nasal mostró que en los balénidos, cetotéridos y balenoptéridos, el ancho máximo de la fosa nasal coincide y marca el emplazamiento de la narina blanda (=blowhole). En los misticetos, a diferencia de lo que ocurre en los amniotas, el blowhole se ubica en posición póstero-dorsal dentro de la fosa nasal. La exploración de este correlato en los grupos analizados sugiere que, la migración posterior de la narina externa ósea estuvo acompañada del desplazamiento póstero-dorsal del blowhole dentro de la fosa nasal, condición ya adquirida en los primeros cetáceos completamente acuáticos (basilosauridos). Por otro lado, el análisis morfométrico efectuado muestra que hay una correlación positiva entre el aumento del tamaño del cráneo (medido en ancho y largo) y el aumento del tamaño del blowhole. Se hipotetiza que el cambio en la posición y el aumento en el tamaño relativo del blowhole estaría vinculado con un aumento en la eficiencia de la respiración durante el buceo.

El estudio de la morfología de ojo y estructuras periorbitales de Eubalaena australis muestra que las mismas presentan un patrón morfológico similar al observado en otros misticetos actuales. El análisis morfométrico dio como resultado que en E. australis hay una correlación positiva entre el 
tamaño del globo ocular y el largo corporal. Las variables del tamaño del globo ocular (medidas en ancho, el alto y el largo) presentan un incremento alométrico negativo con el aumento del largo corporal. Por el contrario, la córnea presenta una baja correlación con el largo corporal, y la relación entre estas dos variables presenta una alometría negativa, lo cual sugiere que la córnea no aumenta mucho de tamaño durante el crecimiento del animal.

El análisis de correlatos óseos que permitieran la reconstrucción del globo ocular/nervio óptico y, de esta forma, la estimación de las capacidades visuales en los balénidos extintos, mostró que el tamaño de la órbita es un correlato muy grosero del tamaño del ojo. El globo ocular es mucho menor que la órbita, está protruido y rodeado de estructuras metabólicamente activas (grasa), cuyo desarrollo varía en la ontogenia y en distintos períodos del ciclo vital del animal. Asimismo, el canal y el foramen óptico no resultan buenos proxies, ya que el nervio óptico también está rodeado en su recorrido por estructuras blandas.

La exploración de la anatomía de la región auditiva de Eubalaena australis permitió identificar correlatos óseos de algunas estructuras blandas implicadas en la audición. En este sentido, se identificó que la depresión en el meato auditivo externo y los recesos en la superficie ventral del pterigoides y del basioccipital, marcan el punto de inserción de la membrana timpánica y la extensión posterior del seno pterigoideo respectivamente. La exploración de este correlato en Morenocetus y en el Taxón A indicó que, en los representantes más tempranos de los balénidos, la membrana timpánica tiene un desarrollo y posicionamiento comparable al de los balénidos actuales. Por otro lado, el análisis de la estructura de la cóclea de individuos de E. australis de diferentes estadios ontogenéticos indicó que la macroestructura de la misma (i.e. número de vueltas 2,5 y forma) no varía en la ontogenia. La cóclea del Taxón A presenta el mismo patrón morfológico general que el de E. australis (i.e. 2,5 vueltas y superposición entre las mismas), sugiriendo una adaptación a las bajas frecuencias, comparables con algunos balénidos actuales. 


\section{Abstract}

The Balaenidae (Cetacea: Neoceti) are mysticetes characterized by specializations related to filter feeding in their skull and mandible, such as, a very narrow and arched rostrum, rostral bones lacking of interdigitation with occipital bones, reduced angular and coronoid processes and long baleen. The body pattern of the extant balaenids, and specially their skeleton anatomy, is very conservative and they only include four species arranged in two genera: Balaena (B. mysticetus) and Eubalaena (E. australis; E. glacialis; E. japonica).

Balaenid fossil record is temporally extended (Early Miocene-Present) and, in some cases, it is also abundant (i.e. Pliocene, Pleistocene), but it is characterized by large geographic and stratigraphic gaps. In particular, the Miocene record is extremely rare and it is restricted to Argentinean Patagonia, with the presence of Morenocetus parvus, the oldest known balaenid (Early Miocene). However, Pliocene and Pleistocene balaenid records are abundant but restricted to the North Hemisphere. These records include extinct (Balaenella, Balaenula, Balaenotus) and extant genera (Balaena y Eubalaena). Morenocetus parvus was described and nominated by Cabrera (1926) on the basis of two incomplete skulls, collected from Gaiman Formation (Early Miocene, Chubut). Because of this taxon was not re-examined after its original description, it has remained as an enigmatic species. As a result of paleontological works in Peninsula Valdés and nearby, new balenid specimens were collected from Puerto Madryn Formation (Late Miocene, Chubut). These specimens, along with some isolated remains from the Late Miocene of Entre Rios (Paraná Formation) complete, partially, the extensive gaps in Miocene balaenid fossil record.

Balaenidae is a key lineage in the evolution of mysticetes, because of, according to some phylogenetic studies, it is the most basal and oldest group of extant mysticetes. This assumption is based on the early occurrence of balenids in the fossil record and on ancient divergence time estimated from molecular studies. One of the most controversial aspects of the phylogenetic relationships among balaenids is the position of their oldest member, Morenocetus parvus. The importance of this taxon, as well as other records collected from Puerto Madryn Formation (Late Miocene) and undescribed yet, justify the detailed study of the Miocene balaenids from Patagonia. In this context, the main goal of this thesis was to generate a better understanding of the evolutionary history of the balaenids, by analyzing the earliest members of this group. In this sense, we took as a basis the exploration of Eubalaena australis as a neontologic model of balaenids. The collection and integration of osteological and soft data allowed us to interpret the anatomy of extinct taxa, identify useful characters for phylogenetic analyzes and determinate osteological correlates of soft-tissue 
structures in order to reconstruct the soft tissues in fossils.

The study of individuals of Eubalaena australis in different age stages allowed the identification of parameters, with the independence of size and relative closure of sutures, which are different for neonates and calves and adults. On the basis of information obtained from extant balaenids, we studied the anatomy and later the systematics of miocene balaenids. The results of systematic studies showed that Morenocetus parvus is a valid taxon and it is represented by two subadult specimens. These results also showed that the three balaenid specimens from Late Miocene of Puerto Madryn Formation included an adult, a subadult and a young which corresponds to a new genus and species (=Taxon A). The presence in Taxon A of an ascending process of the maxilla nearly triangular and short anteroposteriorly, globular tympanic bullae without a dorso-ventral compression and a dorsal surface of periotic lacking of crests and grooves, were interpreted as pedomorphic features. Finally, balaenids from Paraná Formation (Late Miocene, Entre Ríos) are only represented by timpanic bullae, which are not referable to Taxon A from Puerto Madryn Formation. The fragmentary condition of these specimens did not allow their identification to species level, because of this reason they were assigned as Balaenidae indet.

Phylogenetic analysis, both of implied and equal weight, were consistent between them, in the general topology of trees and in the internal relationships of the major clades. Balaenids form a well supported group and sister to the clade of Balaenopteroidea and Cetotheriidae. Caperea marginata was recovered with high levels of branch supports, deeply nested within cetotheriids, and this is the only extant representative of this clade. Miocene balaenids (Morenocetus and Taxon A) form a basal clade within Balaenidae, with a well branch support and without unstable taxa. Balaenella and Balaenula were recovered as sister taxa of extant balaenids (Balaena and Eubalaena). Relationships among extant clades (Balaena and Eubalaena) remained unresolved.

Stratigraphic calibration of cladogram showed an extensive ghost lineage among miocene balaenids and those more derivated forms (Balaenella, Balaenula, Balaena and Eubalaena). The extension of this ghost lineage $(\sim 15 \mathrm{Ma})$ is from Late-early Miocene (Burdigaliense) to Early Pliocene (Zancliense). In addition, there is a large temporal gap in the fossil record of balaenids which covers more than half of their evolutionary history. The recover of Taxon A from Puerto Madryn Formation interrupts the temporal gap between Morenocetus and more derivated balaenids, but it does not reduce the ghost lineage mentioned above.

Paleobiological aspects on miocene balaenids analysed in this thesis comprised the following topics: evolution of body lenght and its relation to trend to gigantism, reconstruction of nasal morphology and its relation to diving; and exploration of osteological correlates associated with sense organs (eye and ear). 
In relation to the first topic, estimations carried out on body lenght and phylogenetic tree optimization, suggested that primitive condition of mysticetes was a short body lenght $(<6 \mathrm{~m})$, which remains in basal forms of baleen whales or Chaeomyticeti. Body lenght increase in mysticetes did not follow a lineal pattern and was at least twice acquired, once in the Balaenidae and other in Balaenopteridae-Eschrichtiidae. Since the end of the Miocene, balaenids increase in body lenght and the earliest record of a giant forms corresponds to Eubalaena-Balaena ancestor clade.

The exploration of nasal region of balaenids (Eubalaena australis), cetotheriids (Caperea) and balaenopterids (Balaenoptera bonaerensis) showed that they share a common pattern, with minor differences in structures for water deflection and nasal musculature arrangement. The analysis of osteological and soft tissues correlates of nasal region showed that in balaenids, cetotheriids and balaenopterids the maximun width of nasal fossa coincides and marks the soft nares location (=blowhole). In mysticetes, the blowholes overlie the posterior region of the nasal fossa. The exploration of this correlate in other whales groups suggest that the migration of the external bony nares toward the posterior region of the skull occurred at the same time than postero-dorsal migration of the blowhole inside of the nasal fossa, condition that have been acquired by the first fully acuatic whales (basilosaurids). On the other hand, morphometric analysis showed a positive correlation between skull size increase (width and lenght meassured) and blowhole size increase. We inferred that the change in position and blowhole size increase could be related to an increase of breathing efficiency during diving.

The analysis of eye and periorbital structures of Eubalaena australis showed a similar pattern to the other extant mysticetes. Morphometric analysis showed a positive correlation between eyeball size and body length. The variables of eyeball size (width, height and lenght meassured) showed a negative alometric increase in relation to body lenght increase. On the other hand, the cornea and body lenght reveal a low correlation, with negative alometry, suggesting that cornea does not increase in size during animal growth.

The analysis of osteological correlates that allowed eyeball and optic nerve reconstruction, and in this sense, the estimation of visual capacity of extinct balaenids, showed that orbit is a gross proxy of eyeball size. Eyeball is littler than orbit bone, it is outside of the orbit and surrounded by metabolically active estructures (fat), whose developement varies in onthogeny and different periods of life cycle. In addition, optic foramen and optic canal are not good proxies, due to optic nerve is surrounded in its path by soft structures.

The exploration of anatomy of auditory region of Eubalaena australis allowed the identification of osteological correlates of some soft structures involved in hearing. In this study, we found that the depression in external auditory meatus and in the ventral surface of pterygoid and basioccipital, indicate the insertion of the tympanic membrane and the posterior extension of 
pterygoid sinus, respectively. The exploration of this correlate in Morenocetus and Taxon A, showed that among earlier representatives of balaenids, the tympanic membrane had a development and location comparable to extant balaenids. On the other hand, the analysis of cochlea in different ontogenetic stages individuals of E. australis showed that its macrostructure (i.e. turn number 2,5 and shape) does no change in ontogeny. Taxon A cochlea presents the same morphology than $E$. australis (2,5 turns and superposition betweem them), suggesting an adaptation to low frequencies, similar to some extant balaenids. 


\section{Capítulo 1}

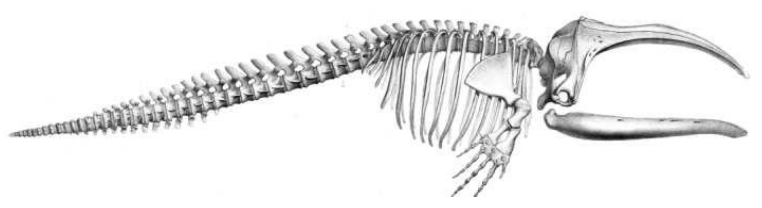

\section{Introducción}

Buono, M. Evolución de los Balénidos del Mioceno de Patagonia 


\section{Capítulo 1}

\section{Introducción}

A lo largo de la evolución de la vida en la tierra, la transición entre el ambiente terrestre y acuático fue un suceso poco frecuente en la mayoría de los clados de plantas y animales (Vermeij \& Dudley, 2000). Varios grupos de vertebrados tetrápodos, entre ellos los ictiosaurios, las tortugas, los plesiosaurios, los mosasaurios, los sirenios, los pinnípedos y los cetáceos, re-invadieron el ambiente acuático en diferentes oportunidades. Precisamente, el origen de los cetáceos (ballenas, delfines y marsopas) representa el ejemplo más reciente y exitoso de re-invasión del medio acuático por parte de los tetrápodos.

En la actualidad, con aproximadamente 600 especies nominadas organizadas en 38 familias (Uhen, 2013), los cetáceos son el grupo dominante de mamíferos acuáticos, tanto en términos de distribución geográfica y de diversidad taxonómica y ecológica. Los cetáceos modernos o Neoceti (Fordyce \& Muizon, 2001) comprenden dos clados: los Mysticeti (ballenas francas, ballena gris y rorcuales), cuyos representantes actuales poseen barbas, y los Odontoceti (delfines y marsopas) o cetáceos con dientes. Las formas de cetáceos más basales (stem Cetacea) son agrupadas informalmente con el término arqueocetos (Fordyce \& Muizon, 2001; Berta et al., 2006) (Fig. 1.1). La morfología de estas formas basales documentan los cambios excepcionales en el patrón corporal de los cetáceos, como resultado de la transición a un modo de vida estrictamente acuático (Uhen, 2010).

Los misticetos y los odontocetos presentan un cráneo telescopizado, esto es, los huesos rostrales están elongados en dirección posterior mientras que los huesos del occipucio están desplazados en dirección dorso-anterior. Como resultado de este diseño varios huesos están superpuestos. El patrón de telescopización es marcadamente distinto en ambos grupos: en los misticetos está caracterizado por la extensión ventro-posterior del maxilar, mientras que en los 
odontocetos el premaxilar y el maxilar están desplazados dorso-posteriormente (Miller, 1923) (Fig. 1.2). Por otro lado, los odontocetos presentan una dentición homodonta y una innovación clave en la evolución de este grupo fue el desarrollo del sistema de ecolocalización. Los misticetos actuales carecen de dientes en el estadio adulto y, en su lugar, presentan barbas, estructuras queratinizadas que penden del maxilar.

\subsection{Origen y Evolución de los cetáceos}

El origen de los cetáceos representa uno de los eventos macroevolutivos más importantes dentro de los mamíferos. La transición desde el ambiente terrestre al acuático implicó profundos cambios en la anatomía, fisiología y comportamiento de los cetáceos, lo cual dificulta el posicionamiento de este grupo dentro de los Eutheria. Los estudios filogenéticos efectuados durante el siglo XVIII y XIX vincularon a los cetáceos con varios grupos de mamíferos actuales, tales como los Pinnipedia, los Edentata, los Perissodactyla, los Sirenia y los Artiodactyla (Blainville, 1816; Gill, 1873; Flower, 1883a, b; Thompson, 189o; Anthony, 1926). Posteriormente, y sobre la base de nueva evidencia paleontológica y morfológica, se propusieron dos nuevas hipótesis: por un lado una estrecha relación con los condilartros Mesonychidae (Luo \& Gingerich, 1999; O'Learly \& Gatesy, 2008), y por otro con los Artiodactyla (e.g. Thewissen et al., 2001; Geisler \& Uhen, 2003, 2005; Thewissen et al., 2007). En la actualidad, existe un amplio consenso en considerar que los cetáceos y los artiodáctilos forman un clado, el cual ha sido nominado Cetartiodactyla (Montgelard et al., 1997). Esta hipótesis está respaldada por evidencia molecular, morfológica y combinada. En relación a cual es el grupo hermano de los cetáceos dentro de los Artiodactyla, hay dos líneas propuestas: una basada en evidencia morfológica y molecular que los vincula con los Hippopotamidae (Geisler \& Uhen, 2003, 2005; Geisler \& Theodor, 2009), y otra en evidencia morfológica que los relaciona con la familia extinta Raoellidae (Thewissen et al., 2007) (Fig. 1.3). Si bien el panorama evolutivo de los cetáceos se ha esclarecido en los últimos años, se necesitan estudios comparados más detallados de los artiodáctilos, especialmente de taxones extintos, para evaluar cual es el grupo más emparentado con los cetáceos.

\subsubsection{Los primeros cetáceos: "Archaeoceti”}

Los primeros cetáceos aparecen en el registro fósil durante el Eoceno temprano ( $\sim 53 \mathrm{Ma})$, y los cambios en la estructura y diversidad del registro fósil evidencian al menos tres radiaciones en la historia evolutiva del grupo (Fordyce, 2009a). La primera radiación se produjo en el Eoceno temprano-medio en el mar de Tethys e involucró a los "arqueocetos". La misma estuvo asociada con una migración desde un ambiente fluvial y/o costero marino, a un ambiente de océano abierto; y 
estuvo acompañada de cambios en patrón corporal (=bauplan). Estos cambios estuvieron vinculados con los mecanismos de locomoción, alimentación y audición de éstos cetáceos basales, asociados a una mayor independencia del ambiente continental. Los "Archaeoceti" incluyen 5 familias: Pakicetidae, Protocetidae, Ambulocetidae, Remingtonocetidae, y Basilosauridae (Thewissen, 1998; Uhen, 2013) (Fig. 1.4).

Los primeros cetáceos, los Pakicetidae, provienen del Eoceno temprano-medio de la región de Indo-Pakistán y se encuentran asociados a depósitos fluviales. Estos arqueocetos presentan, en el cráneo y en el esqueleto postcraneano, algunos caracteres de los artiodáctilos terrestres y otros típicos de los cetáceos. Entre los primeros se encuentran un foramen mandibular pequeño, vértebras cervicales largas, metapodio largo y vértebras sacras fusionadas y entre los segundos una bulla timpánica paquiosteosclerótica con involucro y proceso sigmoideo, molares y premolares (molariformes) modificados para actuar como cizallas, y región temporal del cráneo larga y angosta (Gingerich \& Russell, 1981; Bajpai \& Gingerich, 1998; O'Learly \& Uhen, 1999; Thewissen et al., 20o1; 2007) (Fig. 1.5 A). Sobre la base de la morfología del postcráneo se infiere que los pakicétidos presentaban cierta habilidad para desplazarse en ambientes de aguas someras (Madar, 2007).

Los Ambulocetidae provienen del Eoceno medio de la región de Indo-Pakistán, con un único taxón conocido a partir de un esqueleto completo: Ambulocetus natans. Ambulocetus presenta, a diferencia de los pakicétidos, el miembro anterior con el estilopodio reducido y el zeugopodio largo, y una cola bien desarrollada para desplazarse en el agua y en la tierra (Fig. 1.5 B). Ambulocetus presenta un foramen y canal mandibular agrandado, un carácter típico de los odontocetos vinculado con la recepción del sonido debajo del agua (Thewissen et al., 1994, 1996).

Los Remingtonocetidae son conocidos en el Eoceno medio de Indo-Pakistán. Están caracterizados por esqueletos largos con miembros relativamente cortos, órbitas pequeñas y cráneos con diferentes morfologías que han sido vinculadas a distintos tipos de dieta (Bajpai et al., 2011; Bebej et al., 2012) (Fig. 1.5C). En este grupo el oído es de mayor tamaño que el de los ambulocétidos, y muestra una mayor conexión con la mandíbula, sugiriendo una mayor especialización a la audición acuática (Bajpai et al., 2011). La morfología del esqueleto axial y apendicular indica que los remingtonocétidos podían caminar en tierra, así como también desplazarse en el agua (Bajpai \& Thewissen, 2000; Gingerich et al., 1995; Thewissen \& Hussain, 2000).

Los Protocetidae conforman un grupo muy diverso de formas semiacuáticas. Este grupo se originó en la región de Indo-Pakistán durante el Eoceno medio-temprano, y se diversificó y desplazó rápidamente hacia Europa, el norte de África, América del Norte y Sudamérica. Los protocétidos se diferencian de los "arqueocetos" más basales (i.e. pakicétidos, ambulocétidos y remingtonocétidos) por presentar órbitas grandes y ubicadas lateralmente, y narinas externas más 
retraídas (Uhen, 2010 y referencias allí incluidas). La morfología de los miembros sugiere que tenían hábitos similares a los pinnípedos actuales, con la capacidad de desplazarse en tierra para reproducirse y dar a luz, y en el agua para alimentarse (Gingerich et al., 2009) (Fig. 1.5D).

Los Basilosauridae son los primeros cetáceos completamente acuáticos, los cuales están bien documentados desde el Eoceno medio-tardío hasta el Eoceno tardío-temprano en todos los continentes. Los basilosáuridos presentan una serie de caracteres distintivos tales como molares y premolares con dentículos accesorios, miembros posteriores reducidos y sin conexión con la columna vertebral, rotación de la pelvis, un aumento en el número de vértebras lumbares, vértebras caudales rectangulares, cortas y comprimidas dorso-ventralmente, y ausencia del tercer molar superior (Fig. 1.5E). Algunos de estos caracteres, especialmente aquellos del postcráneo, han sido asociados con un estilo de vida completamente acuático (Uhen, 1998; 2008). La combinación de caracteres previamente mencionada es compartida con los cetáceos modernos o Neoceti, lo cual permitió la creación de un nuevo clado, los Pelagiceti (Basilosauridae y Neoceti) (Uhen, 2008).

\subsubsection{Los cetáceos modernos o Neoceti}

La segunda radiación en la historia evolutiva de los cetáceos ocurrió durante el Oligoceno temprano e involucró a los cetáceos modernos o Neoceti (Fordyce, 2009). Esta radiación, durante la cual misticetos y odontocetos se diversificaron rápidamente $(\sim 5 \mathrm{Ma})$, ha sido vinculada con la aparición de innovaciones clave. Entre éstas se encuentran el aumento del tamaño del cerebro, la ecolocalización en los odontocetos y la aparición de las barbas en los misticetos. Estas innovaciones permitieron el aprovechamiento de los nichos vacantes generados tras la extinción de los "arqueocetos" en el Oligoceno tardío (Fordyce \& de Muizon, 2001; Marino et al., 2004). Asimismo, estos sucesos ocurrieron en consonancia con eventos climáticos y geográficos, tales como la rotura final de Gondwana, la apertura del Océano del Sur, el descenso marcado de la temperatura de las aguas y cambios en la productividad primaria de los ecosistemas marinos (Fordyce, 2003a). Hacia finales del Oligoceno, los Neoceti estaban representados por alrededor de 16 familias y 50 especies.

La tercera y última radiación de los cetáceos ocurrió durante el Mioceno medio-tardío y marcó la diversificación de los grupos actuales de misticetos y odontocetos, y la desaparición de algunas familias de Neoceti basales.

\subsection{El origen de los Mysticeti}

El origen de los misticetos representa una de las mayores transiciones dentro de la historia evolutiva de los cetáceos (Demeré et al., 2008). Tradicionalmente se consideró la aparición de las barbas, y consecuentemente la aparición de la alimentación por filtración, como una innovación 
clave que permitió el origen y posterior diversificación de los misticetos (Fordyce 1980, 1989, 1992; Fordyce \& Muizon 2001; Berta et al., 2006). La identificación en el cráneo del misticeto basal Aetiocetus weltoni de estructuras (=correlatos óseos) vinculadas con la presencia de barbas (i.e. canales y forámenes nutricios) ha respaldado, en parte, la hipótesis planteada previamente (Demeré et al., 2008; Demeré \& Berta, 2008). Sin embargo, la interpretación de estos correlatos óseos como indicativos de la presencia de barbas ha sido cuestionada por algunos autores, lo cual permitió la elaboración de hipótesis alternativas (Fitzgerald, 2010; Marx, 2010).

Un escenario evolutivo distinto propuesto por Fitzgerald (2010) sugiere que, muchos caracteres vinculados con la alimentación por filtración (i.e. cráneo platirostro y quinético y un rostro elongado y ancho en la base), aparecieron previamente al surgimiento de este sistema de alimentación y que, por lo tanto, representan exaptaciones. Este autor propuso que, por el contrario, estos caracteres estaban vinculados a una alimentación por macrofagia o por succión. Estas modificaciones fueron posteriormente útiles, junto con el desarrollo de una sínfisis mandibular elástica, en la adquisición de la alimentación por filtración en los misticetos con barbas, representando de este modo un claro ejemplo de co-opción adaptativa (Fitzgerald, 2010, 2011). En este contexto, es probable que la historia evolutiva más temprana de los misticetos estuviera marcada por una diversidad de formas que explotaron distintos nichos ecológicos y desarrollaron diversas especializaciones morfológicas, antes de la aparición de las barbas y de la alimentación por filtración.

Los misticetos incluyen dos morfotipos: aquellos con dientes en el estadio adulto o misticetos dentados (todos taxones extintos), y aquellos con barbas (con representantes extintos y actuales) (Fig. 1.6). A continuación se presenta una breve introducción a cada grupo.

\subsubsection{Misticetos basales}

Misticetos dentados. Los primeros misticetos dentados aparecen hacia finales del Eoceno y se diversifican rápidamente durante el Oligoceno. Los misticetos dentados presentan una morfología craneana muy dispar en comparación con los "arqueocetos" y misticetos con barbas, lo cual ha sido vinculado con el desarrollo de diferentes estrategias de alimentación (e.g. succión, macrofagia). Estos misticetos presentan ciertos caracteres compartidos con los "arqueocetos" (i.e. dentición heterodonta, leve telescopización del cráneo con poca interdigitación de los elementos rostrales y occipitales y narinas externas moderadamente retraídas) (Fig. 1.7) y otros compartidos con los misticetos con barbas (expansión transversal del proceso lateral del maxilar, la pérdida de una sínfisis mandibular suturada, excepto Janjucetus, y un maxilar con márgenes laterales delgados) (Fitzgerald, 2006, 2010, 2011; Demeré \& Berta, 2008). 
Los misticetos dentados se organizan en tres familias, dos endémicas del Hemisferio Sur, Llanocetidae (Mitchell, 1989; Fordyce \& Muizon, 2001) y Mammalodontidae (Pritchard, 1939; Fitzgerald, 2006, 2010) y otra endémica del Pacífico Norte, Aetiocetidae (Barnes et al., 1995).

Los Llanocetidae incluyen a un único taxón, Llanocetus denticrenatus, proveniente del Eoceno tardío de Antártida (Fm. La Meseta), el cual es el misticeto más antiguo. Llanocetus fue descripto originalmente sobre la base de materiales fragmentarios (restos de mandíbulas con dientes asociados y fragmentos del basicráneo) y, por lo tanto, muchos aspectos de su anatomía son desconocidos (Mitchell, 1989). Los nuevos estudios que se están llevando a cabo en un ejemplar más completo de esta especie permitirán conocer más aspectos sobre la anatomía de este misticeto primitivo (Fordyce, 2003b).

Los Aetiocetidae son el linaje más diverso de misticetos dentados, con alrededor de 8 especies agrupadas en 4 géneros y cuyo registro fósil está circunscripto al Oligoceno. Los aetiocétidos son considerados un grupo transicional dentro de los misticetos, con una morfología intermedia entre los arqueocetos y los misticetos con barbas (Barnes et al., 1995; Demeré \& Berta, 2008).

Por último, los Mammalodontidae están integrados por sólo dos especies, Mammalodon colliveri y Janjucetus hunderi, ambas del Oligoceno tardío de Australia (Pritchard, 1939; Fitzgerald, 2006, 2010). Estos misticetos se caracterizan por una morfología craneana muy peculiar, que ha sido vinculada con el desarrollo de una alimentación por succión (Fitzgerald, 2011) (Fig. 1.7).

Misticetos con barbas. La adquisición de la alimentación por filtración utilizando las barbas (placas de queratina que cuelgan del paladar), representó una transición eco-morfológica clave en la evolución de los misticetos, que permitió el acceso a fuentes de alimento de bajos niveles tróficos (i.e zooplancton), con un alto valor energético (Werth, 2000; Fitzgerald, 2006; Slater et al., 2010). Este método de alimentación consiste en ingerir grandes cantidades de agua con alimento que, posteriormente, filtran a través de las barbas donde quedan atrapadas las presas (Pivorunas, 1979; Werth, 2000). Las innovaciones morfológicas presentes en los misticetos y vinculadas a este sistema de alimentación incluyen: pérdida de dentición en el estadio adulto, desarrollo de barbas, expansión de la cavidad bucal por el ensanchamiento del rostro, márgenes laterales del maxilar delgados, mandíbulas arqueadas lateralmente y sínfisis mandibular elástica (e.g. Demeré et al., 20o8; Fitzgerald 2010, 2011; Gatesy et al., 2013).

Dentro de los misticetos con barbas o Chaeomysticeti (Mitchell, 1989) se reconocen dos familias extintas, Eomysticetidae y Cetotheriidae, que aparecen en el Oligoceno tardío y se diversifican hacia el Mioceno. Los Eomysticetidae son formas basales representadas por dos especies, Eomysticetus whitmorei y E. carolinensis, y caracterizadas por nasales elongados, narinas externas poco retraídas, proceso coronoides muy desarrollado, pérdida de la dentición, rostro 
elongado y aplanado y mandíbulas arqueadas lateralmente (Sanders \& Barnes, 2002).

Los Cetotheriidae (sensu Simpson, 1945=sensu lato) son el grupo de misticetos con barbas extinto más diverso taxonómica y morfológicamente. El registro fósil de este grupo abarca desde el Oligoceno tardío hasta el Plioceno temprano, y es conocido en varias localidades del Hemisferio Norte y Sur. Tradicionalmente los Cetotéridos (sensu lato) han sido reconocidos como un grupo parafilético, pero estudios filogenéticos recientes sugieren un nuevo panorama. Los estudios de Bouetel \& Muizon (2006) proponen que Piscobalaena, Herpetocetus, Metopocetus, Cetotherium, Nannocetus y Mixocetus forman un clado, nominado como Cetotheriidae sensu stricto, resultados que coinciden, en gran medida, con los análisis filogenéticos de Marx (2010) y Fordyce \& Marx (2012). Por el contrario, los otros taxones considerados previamente como "cetotéridos" (e.g. Diorocetus, Pelocetus, Cophocetus, Parietobalaena) tienen una posición variable en los distintos estudios filogenéticos, con lo cual las relaciones de parentesco de los mismos son aún controversiales (e.g. Bouetel \& Muizon, 2006; Steeman, 2007; Marx, 2010; Fordyce \& Marx, 2012).

\subsubsection{Misticetos modernos}

Los misticetos modernos son formas exclusivamente filtradoras que desarrollaron diferentes estrategias adaptativas para la captura de presas, tales como la filtración activa o engullición (“engulfment"), la filtración pasiva (“skimming”) y la succión (Bouetel, 2005) (Fig. 1.8). Estas estrategias varían entre las cinco familias actuales: Balaenopteridae (rorcuales), Eschrichtiidae (ballena gris), Neobalaenidae (ballena franca pigmea) y Balaenidae (ballenas francas). Los Balaenoperidae o rorcuales son filtradores activos o engullidores. Este sistema de filtración consiste en la captura rápida de grandes volúmenes de agua con las presas, que luego es expulsada por el cierre de la boca, quedando las presas atrapadas en las barbas (Lambertsen et al., 1995). Entre las especializaciones vinculadas con este método de alimentación se encuentran la rotación y dislocación de las mandíbulas, el desarrollo de pliegues longitudinales en la superficie ventral de la cabeza, barbas cortas, la reducción de la lengua y la ausencia de una articulación temporomandibular sinovial (Lambertsen et al., 1995; Lambertsen \& Hintz, 2004; Bouetel, 2005). Los Balaenidae y Neobalaenidae son filtradores pasivos que nadan lentamente con la boca abierta a través de las agregaciones de kril, lo cual permite que el agua fluya unidireccionalmente. Posteriormente, cierran la boca y el agua es expulsada por la acción de la lengua, quedando el alimento retenido en las barbas (Pirovunas, 1979; Werth, 2004). Las especializaciones morfológicas vinculadas con este sistema de filtración son: leve interdigitación de los huesos rostrales y craneales, rostro muy arqueado y labios grandes que contribuyen a ampliar la cavidad bucal, proceso coronoides y angular reducido, largas y numerosas barbas y lengua muy desarrollada 
(Werth, 2004; Bouetel, 2005; Lambertsen et al., 2005). Los Eschrichtiidae o ballena gris utilizan la succión oral para filtrar presas del fondo marino. Las modificaciones morfológicas involucradas en este tipo de alimentación son algunas comunes con los balenoptéridos, y otras con los balénidos y neobalénidos. Con los balenoptéridos comparten barbas cortas y una marcada interdigitación de los elementos rostrales y craneales, mientras que con los balénidos comparten un rostro arqueado y un proceso coronoides y angular reducido (Bouetel, 2005; Johnston et al., 2009).

Los balenoptéridos (Fig. 1.9A-B) son el grupo más diverso y abundante de misticetos actuales. Está formado por 8 especies distribuidas en dos géneros: Balaenoptera (B. musculus; B. physalus; $B$. borealis; B. edeni; B. omurai; B. acutorostrata; B. bonaerensis) y Megaptera (Megaptera novaeangliae). Los rorcuales presentan cuerpos estilizados, una cabeza corta y plana, una aleta dorsal pequeña y, lo más característico, una serie de surcos ventrales en la garganta. Los balenoptéridos presentan un rango de tamaño corporal muy amplio, que abarca desde los $9 \mathrm{~m}$ (en B. acutorostrata) hasta los $33 \mathrm{~m}$ (en B. musculus). En cuanto a la morfología esqueletaria, presentan un rostro casi recto, huesos rostrales y de la caja craneana interdigitados, mandíbulas arqueadas lateralmente con un proceso coronoides y angular bien desarrollado, y vértebras cervicales no fusionadas (Bouetel, 2005; Bannister, 2009).

Los escríctidos están integrados por una única especie actual, Eschrichtius robustus o ballena gris (Fig. 1.9C), la cual es endémica del Pacífico Norte. La ballena gris presenta un rostro moderadamente arqueado, carece de aleta dorsal y, en su lugar, presenta una pequeña joroba dorsal seguida de una serie de protuberancias, tiene de 2 a 4 surcos en la garganta, y las barbas son pequeñas y de coloración amarilla. A nivel esqueletario, una de las características más conspicuas es la presencia de tuberosidades en la porción posterior del cráneo, para la inserción de la musculatura del cuello (Berta et al., 2006).

La familia Neobalaenidae es monotípica y está integrada por la especie Caperea marginata o la ballena franca pigmea, la cual es exclusiva del Hemisferio Sur (Fig. 1.9C). Esta especie presenta una aleta dorsal pequeña, un rostro moderadamente arqueado, y una serie de surcos longitudinales en la garganta. A nivel osteológico, C. marginata presenta una arquitectura única, muy diferente al resto de los misticetos, con algunos caracteres similares a los balénidos y otros a los balenoptéridos. Esto último, sumado al escaso registro fósil de esta familia, ha contribuido a que la posición filogenética de este taxón sea controversial (Capítulo 5). Recientemente, los análisis filogenéticos de Fordyce \& Marx (2012) proponen la asignación de Caperea a la familia Cetotheriidae (sensu stricto), siendo de esta forma el único representante actual de este linaje de misticetos.

Los balénidos son objeto de estudio del presente trabajo de tesis y se discuten en la siguiente sección. 


\subsection{Balaenidae}

Los Balaenidae son misticetos filtradores caracterizados por un cuerpo robusto, un rostro muy arqueado y largo, barbas numerosas y largas, una cabeza que ocupa aproximadamente un tercio del largo corporal y labios inferiores grandes y arqueados (Fig. 1.10) (McLeod et al., 1993). El patrón corporal de los balénidos, especialmente su anatomía esqueletaria, es muy conservador y sólo se reconocen cuatro especies distribuidas en dos géneros actuales: Balaena (B. mysticetus) y Eubalaena (E. australis; E. glacialis; E. japonica).

La Ballena de Groenlandia (Balaena mysticetus) es endémica del Hemisferio Norte, específicamente del Ártico y del Atlántico Norte. Esta especie está entre los misticetos de mayor tamaño corporal, con un largo total de 14-18m y con un peso de 75 toneladas (Rugh \& Shelden, 2009). La Ballena de Groenlandia presenta una cabeza muy grande (más de 1/3 el largo corporal) y arqueada, barbas largas y manchas blancas en la cabeza y en la base de la aleta caudal.

Las ballenas francas (Eubalaena spp.) (Fig. 1.10) se distribuyen en latitudes medias, entre los $20^{\circ}$ y los $60^{\circ}$, de ambos Hemisferios, y se reconocen tres especies: E. glacialis (en el Atlántico Norte), E. japonica (Pacífico Norte) y E. australis (en el Océano del Sur) (Rosenbaum et al., 200o; Gaines et al., 2005; Kaliszewska et al., 2005). La característica más conspicua de las ballenas francas es el patrón de callosidades que presentan en la cabeza (Payne et al., 1983). Estas callosidades están formadas por un tejido epidérmico queratinizado y engrosado que está ocupado por crustáceos anfípodos, conocidos como ciámidos (Rowntree, 1996; Kaliszewska et al., 2005). Las callosidades se distribuyen en el labio inferior, alrededor del ojo y del orificio respiratorio y en el extremo del rostro, y presentan un patrón único en cada individuo que es utilizado para identificarlos (Payne et al., 1983; Kraus et al., 1986).

En la actualidad, los tópicos en discusión en relación a la sistemática de los balénidos actuales son: la validez de Eubalaena y Balaena como géneros separados; y el estatus y número de especies de Eubalaena (Churchill et al., 2012 y referencias allí incluidas). En referencia al primer punto, algunos autores han propuesto que no hay suficiente evidencia para reconocer dos géneros y, por lo tanto, todas las especies actuales deberían incluirse en el género Balaena (Arnason \& Gullberg, 1994; Rice, 1998). Sin embargo, algunos estudios moleculares y morfológicos reconocen a Eubalaena como un género válido (Bisconti, 2000, 2005; Rosenbaum et al., 2000; Gaines et al., 2005; Churchill et al., 2012).

En relación con la validez o no de las tres especies de Eubalaena, el mayor inconveniente es la escasez de caracteres morfológicos para diferenciarlas. Concretamente sólo serían reconocibles sobre la base de la morfología del aliesfenoides y de la escápula, y del patrón de coloración y callosidades de la cabeza. Sobre esta base, en el siglo XIX todas las ballenas francas fueron asignadas 
a un único género y especie: Balaena glacialis (Flower, 1885; Turner, 1913; Norman \& Fraser, 1938; Tomilin, 1967). Sin embargo estudios filogenéticos recientes, basados en información morfológica, molecular y parásitológica, permitieron reconocer tres especies: E. australis, E. glacialis y E. japonica (Rosenbaum et al., 2000; Bisconti, 2005; Gaines et al., 2005; Kaliszewska et al., 2005; Churchill et al., 2012).

\subsubsection{Registro fósil}

Si bien el registro fósil de los balénidos es temporalmente extenso, y en algunos casos abundante (i.e. Plioceno, Pleistoceno), está caracterizado por grandes discontinuidades estratigráficas y geográficas. En particular, el registro de los balénidos miocenos presenta un extenso hiato temporal (que comprende la mayor parte del Mioceno). A esto se suma que este registro es extremadamente escaso y restringido a la Patagonia (Argentina). El balénido más antiguo conocido corresponde a Morenocetus parvus (Cabrera, 1926) del Mioceno temprano (Fm. Gaiman). Morenocetus fue descripto y nominado por Cabrera en una monografía sobre cetáceos fósiles del Museo de La Plata en el año 1926. La descripción se basó en dos cráneos incompletos, pero en buen estado de conservación, colectados en Cerro Castillo, Valle Inferior del Río Chubut (Chubut). La descripción original de este taxón es concisa y no incluye información de todo el material referido por Cabrera a esta especie. Debido a que este taxón no fue re-estudiado luego de su descripción original, ha permanecido, para la comunidad de cetólogos, como una especie enigmática. Como resultado de trabajos paleontológicos en el sector de Península Valdés y alrededores, se han sumado a este registro, nuevos ejemplares de balénidos provenientes del Mioceno tardío (Formación Puerto Madryn) (Cozzuol, 1993, 1996). Estos ejemplares, junto con algunos especímenes provenientes del Mioceno tardío de Entre Ríos (Formación Paraná) (Cozzuol, 1993; Agnolin \& Lucero, 2004) completan, en parte, los extensos hiatos del registro Mioceno.

Los registros de balénidos para el Plioceno y Pleistoceno son, en cambio, abundantes, e incluyen géneros extintos (Balaenella, Balaenula, Balaenotus) así como otros con representantes actuales (Balaena y Eubalaena).

Balaenella es un genéro monotípico, conocido sólo por el ejemplar tipo de la especie ( $B$. brachyrhynus, NMB 42001), proveniente del Plioceno temprano de Bélgica. El holotipo de esta especie, correspondiente a un cráneo completo, es hasta el momento, el balénido mejor preservado (Bisconti, 2005).

Con respecto al género Balaenula se reconocen dos especies, B. astensis y B. balaenopsis, provenientes del Plioceno temprano/tardío de Italia y Bélgica respectivamente. Balaenula ha sido un taxón problemático en la historia sistemática de los Balaenidae. Esto se debe a que las descripciones 
originales son incompletas (Van Beneden, 1872, 1880; Trevisan, 1941), y a la condición fragmentaria de algunos especímenes (e.g. holotipo de B. balaenopsis).

Dentro de Balaena se reconocen dos especies extintas: B. ricei y B. montalionis. B. ricei proviene del Plioceno tardío de Estados Unidos, y se conoce a partir de un único ejemplar correspondiente al holotipo (USNM 22553) correspondiente a un cráneo incompleto, mandíbulas y algunas vértebras (Westgate \& Whitmore Jr, 2002). B. montalionis también es conocida únicamente a partir del ejemplar holotipo (MSNT I12357), un cráneo muy incompleto, proveniente del Plioceno tardío de Italia (Capellini, 1904, Bisconti, 2000, 2003).

Balaenotus es un género monotípico conocido a partir de varios ejemplares de la especie tipo (B.insignis) provenientes del Plioceno de Europa (Van Beneden, 1872, 1878, 1880; Bisconti 2003). El estatus sistemático de este taxón es poco claro, debido a la poca información anatómica con la que se cuenta, dada por la condición fragmentaria de los espécimenes.

Eubalaena esta representada por dos especies extintas; E. shinshuensis y E. belgica. El registro fósil más temprano de este genéro corresponde al Mioceno tardío/Plioceno temprano, con la especie E. shinshuensis. Esta especie es conocida sólo a partir del ejemplar holotipo, correspondiente a un cráneo en buen estado de preservación proveniente de Japón (SFMCB-o024) (Kimura et al., 2007; Kimura, 2009). Durante el Plioceno tardío, Eubalaena esta representada en el registro fósil por E. belgica. Este taxón, descripto en el siglo XX por Abel (1941) y re-descripto posteriormente por Bisconti (2000, 2003), es conocido únicamente por el ejemplar holotipo (IRSNM CtM 879a-f), el cual corresponde a un cráneo muy incompleto.

\subsubsection{Relaciones filogenéticas}

La familia Balaenidae es considerada un linaje clave en la evolución de los misticetos ya que, según algunos estudios filogenéticos, es el grupo más basal de misticetos actuales (e.g. Kimura \& Ozawa, 2002; Steeman 2007; Bisconti, 2008; Marx, 2010) (Fig. 1.11). Asimismo los balénidos presentan, a diferencia de los restantes grupos de misticetos actuales, una ocurrencia temprana en el registro estratigráfico, lo cual es de gran importancia en el estudio de la historia evolutiva de los Mysticeti.

El estudio sistemático y filogenético de los balénidos adquirió en los últimos años mayor importancia y ha sido abordado por algunas contribuciones (e.g. McLeod, 1993; Bisconti, 2000, 2003, 2005; Churchill et al., 2012). En este sentido, el análisis de MacLeod et al. (1993) no incluye formas extintas, por lo cual no permite una interpretación acertada de la radiación de la familia. Los análisis filogenéticos efectuados por Bisconti (2003, 2005) y Churchill et al. (2012) son, en cambio, más completos ya que incluyen tanto taxones extintos como actuales. Estos estudios se centraron 
principalmente en los balénidos pliocenos de Europa, Estados Unidos y Japón y aclararon, en gran medida, el panorama evolutivo de la familia. Sin embargo, la posición filogenética de taxones claves, como Morenocetus, aún permanece sin resolverse. Esto se debe a que, desde su descripción original (Cabrera, 1926), no se han realizado nuevos estudios morfológicos en detalle de este taxón. Asimismo, la escasez de registros de balénidos miocenos acrecentó la incertidumbre sobre la historia evolutiva más temprana de este grupo. La importancia de Morenocetus, tanto para esclarecer las relaciones filogenéticas entre los balénidos así como el tiempo de divergencia de este clado con los restantes misticetos, y la escasez de materiales miocenos, ameritan el estudio en profundidad de los balénidos miocenos de Patagonia. En este sentido es importante incluir en este estudio los ejemplares colectados de la Formación Puerto Madryn (Mioceno Tardío) asignables a balénidos, que no han sido descriptos formalmente.

En este contexto, el objetivo general planteado en esta tesis fue adquirir un mejor entendimiento de la historia evolutiva de los balénidos, mediante el análisis de los miembros más tempranos de este grupo. El desarrollo de este objetivo implicó dos grandes aspectos: el sistemático y el paleobiológico. Para el desarrollo de éstos, y dada la escasez y/o ausencia de información anatómica de los balénidos actuales, se aplicó como protocolo general la elección y exploración de Eubalaena australis como modelo neontológico de los balénidos. La información obtenida fue utilizada para interpretar la de los taxones extintos. Los caracteres que no demostraron ser variables durante la ontogenia, fueron utilizados en los análisis filogenéticos. Sobre la base de los cladogramas, y su calibración estratigráfica, se elaboraron árboles filogenéticos utilizados para construir escenarios evolutivos que explicaran las observaciones. En paralelo, la exploración del modelo neontológico permitió identificar correlatos óseos para la reconstrucción de estructuras blandas en los taxones extintos. Estas reconstrucciones fueron utilizadas para indagar aspectos paleobiológicos optimizándolos sobre los árboles filogenéticos.

\subsection{Organización de la tesis}

El contenido de la tesis está organizado en 7 capítulos más la Bibliografía:

- Capítulo 1 Introducción

- Capítulo 2 Materiales y Métodos: en esta sección se incluye la metodología general de la tesis mientras que las metodologías específicas se detallan en cada capítulo.

- Capítulo 3 Contexto geológico: incluye una breve reseña y caracterización del marco geológico del cual provienen los materiales estudiados. 
- Capítulo 4 Anatomía y Sistemática Paleontológica: incluye las descripciones osteológicas y diagnosis de los balénidos miocenos analizados, así como también de Eubalaena australis.

- Capítulo 5 Análisis Filogenético: en esta sección se desarrolla el análisis filogenético de los balénidos, con énfasis en las formas del Mioceno de Patagonia, incluídos en una matriz de datos general de los misticetos.

- Capítulo 6 Aspectos paleobiológicos de los balénidos miocenos e implicancias en la evolución de los misticetos: en este capítulo se abordaron tres aspectos: el tamaño corporal, la morfología de la región nasal (como adaptación al buceo) y los órganos de los sentidos (ojo y oído).

- Capítulo 7 Conclusiones: aquí se plantean las conclusiones de esta tesis.

- Bibliografía

Los objetivos, hipótesis de trabajo y metodologías específicas así como la discusión de los resultados se detallan en cada capítulo. Las Tablas con medidas se encuentran dentro de un Apéndice al final de cada capítulo. En el Tomo II se incluyen las figuras. 


\section{Capítulo 2}

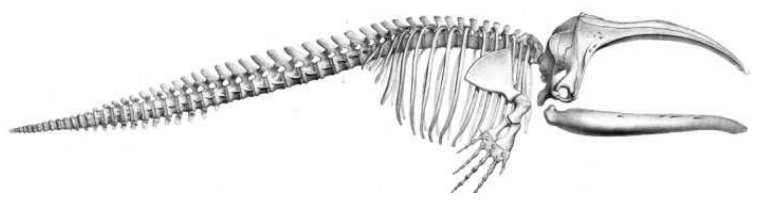

\section{Materiales y Métodos}

Buono, M. Evolución de los Balénidos del Mioceno de Patagonia 


\section{Capítulo 2}

\section{Materiales y Métodos}

Durante el desarrollo de esta tesis se analizó la anatomía, principalmente craneana y mandibular, de los balénidos. Para ello se seleccionaron especímenes pertenecientes a taxones extintos y actuales de la familia Balaenidae, depositados en distintas colecciones nacionales e internacionales. Para una mejor comprensión de la morfología ósea de los balénidos extintos se efectuó el estudio anatómico y re-descripción del cráneo de Eubalaena australis y, posteriormente, se recurrió a la búsqueda de correlatos óseos de estructuras blandas a través de disecciones anatómicas. Una vez explorada la diversidad primaria se analizaron las relaciones filogenéticas de los balénidos, con énfasis en los taxones del Mioceno de Patagonia.

En este capítulo se detallan los especímenes fósiles y actuales estudiados en esta tesis así como también la metodología general utilizada. Los materiales y métodos específicos se detallan en cada capítulo.

\subsection{Abreviaturas institucionales}

AMNH: American Museum of Natural History, Nueva York, E.E.U.U

ChM: The Charleston Museum, Charleston, E.E.U.U

CH-P: Registro paleontológico de la provincia del Chubut $(\mathrm{CH})$, colección Privada $(\mathrm{P}) \mathrm{N}^{\circ} 33$ (Ariel Lazzari)

CGM: Cairo Geological Museum, Cairo, Egipto.

CNPMAMM: Laboratorio de Mamíferos Marinos, Centro Nacional Patagónico, Puerto Madryn, Argentina.

GMNH-PV: Gunma Museum of Natural History, Tomioka, Gunma Prefecture, Japón. 
GSP-UM: Geological Survey of Pakistan-University of Michigan collection, Pakistán.

IRSNM: Institute Royal des Sciences Naturelles, Bruxelles, Bélgica.

MACN: Museo Argentino de Ciencias Naturales Bernardino Rivadavia, Buenos Aires, Argentina.

MLP: Museo de La Plata, La Plata, Argentina.

NMB: Natuurmuseum Brabant, Tilburg, Holanda.

NMNZ: Museum of New Zealand Te Papa Tongarewa, Wellington, Nueva Zelanda.

NMV: Museum Victoria, Melbourne, Australia.

MNHN: Museum National d 'Histoire Naturelle, Paris, Francia.

MPCNyO: Museo Provincial de Ciencias Naturales y Oceanográfico, Puerto Madryn, Chubut, Argentina.

MPEF: Museo Paleontológico "Egidio Feruglio”, Trelew, Argentina.

MPST: Museo Paleontologico di Salsomaggiore Terme, Salsomaggiore Terme, Italia.

MSNT: Museo di Storia Naturale e del Territorio, Universita di Pisa, Pisa, Italia.

OM: Otago Museum, Dunedin, Nueva Zelanda.

OU: Geology Museum, University of Otago, Dunedin, Nueva Zelanda.

PIN: Paleontological Institute, Moscú, Rusia.

SFM: Shinshushinmachi Fossil Museum, Shinshushinmachi, Nagano Prefecture, Japón.

SMNS: Staatliches Museum für Naturkunde, Stuttgart, Alemania.

UCMP: University of California Museum of Paleontology, Berkeley, E.E.U.U.

UM: University of Michigan Museum of Paleontology, Ann Arbor, Michigan, E.E.U.U.

USNM: National Museum of Natural History, Smithsonian Institution, Washington D.C., E.E.U.U.

\subsection{Materiales de estudio}

\subsubsection{Estudios osteológicos}

En los estudios osteológicos de Eubalaena australis se consultaron y analizaron los siguientes ejemplares:

Neonato: CNPMAMM 748 (cráneo y mandíbula).

Crías: CNPMAMM 746 (cráneo incompleto); CNPMAMM 742 (cráneo incompleto); CNPMAMM 747 (mandíbula); CNPMAMM s/n (varios perióticos y bullas timpánicas desarticulados); USNM 484901 (periótico y bulla timpánica).

Subadultos: ejemplar S/N (esqueleto completo) en exhibición en el Centro de Interpretación Istmo Ameghino (Península Valdes).

Adulto: USNM 267612 (cráneo, mandíbula, tímpano-perióticos); CNPMAMM 743 (cráneo 
incompleto); CNPMAMM 741 (mandíbula); S/N colección privada (esqueleto completo); USNM 484899 (perióticos y bulla timpánica izquierda); USNM 267612 (ambos perióticos y bulla timpánica derecha).

Estadio de edad desconocido: MLP 1508 (cráneo y mandíbula); MACN 54.119 (cráneo y mandíbula); CNPMAMM 774 (cráneo, mandíbula y perióticos); NMNZ 2239 (cráneo incompleto, perióticos y bulla timpánica izquierda); OU s/n (periótico); OU 226 (periótico y bulla timpánica); ejemplares S/N en colecciones privadas.

Los misticetos actuales utilizados en los estudios comparativos son:

Eubalaena glacialis: USNM 23077 (cráneo, bulla y perióticos); USNM 301637 (cráneo completo); USNM 500860 (cráneo incompleto).

Eubalaena japonica: USNM16434 (periótico); USNM 16435 (bulla timpánica y periótico).

Balaena mysticetus: USNM 257513 (cráneo completo y perióticos).

Caperea marginata: OM VT 227; AMNH 36692; MPCNyO 8172.

Balaenoptera bonaerensis: CNPMAMM 750 (esqueleto completo); CNPMAMM S/N (cráneo); MACN 20522 (cráneo y mandíbulas).

Balaenoptera acutorostrata: USNM 571487 (cráneo completo);

Balaenoptera borealis: USNM 504244 (cráneo y mandíbulas)

Balaenoptera musculus: USNM 124326 (cráneo)

Balaenoptera physalus: USNM 550467 (cráneo)

Megaptera novaeangliae: USNM 13656, 21492; AMNH 34869; OU 228.

Eschrichtius robustus: USNM 364973; AMNH 181374.

Los balénidos extintos estudiados corresponden a los siguientes ejemplares:

\section{Morenocetus parvus:}

Holotipo (MLP 5-11): cráneo incompleto, donde falta por completo la región rostral, con ambos perióticos articulados.

Procedencia geográfica y estratigráfica: Cerro Castillo, Barranca Sur en el Valle inferior del Río Chubut, provincia de Chubut; Formación Gaiman, Mioceno temprano.

Materiales referidos: MLP 5-15, cráneo incompleto, sin rostro, con periótico izquierdo articulado.

Otros materiales referidos por Cabrera (1926) a este taxón corresponden al MLP 5-21 (dos ramas mandibulares completas), y al MLP 5-30 (cinco vértebras cervicales). En el caso del MLP 5-21, un análisis de contenido de nitrógeno y de colágeno del ejemplar permitió determinar que estos materiales no son asignables a una edad Miocena. Por otro lado el MLP 5-30 no pudo ser localizado para su estudio. 
Procedencia geográfica y estratigráfica: Cerro Castillo, Barranca Sur en el Valle inferior del Río Chubut, provincia de Chubut; Formación Gaiman, Mioceno temprano.

Balaenidae indet.

MPEF-PV-1122: cráneo incompleto, con región rostral parcialmente preservada, perióticos y bulla.

Procedencia geográfica y estratigráfica: playa Punta Pardelas, al este de Puerto Pirámides, costa Norte del Golfo Nuevo; Península Valdés, Chubut; Formación Puerto Madryn, Mioceno tardío.

CH-P33-o1: cráneo incompleto, sin rostro, con ambos perióticos articulados.

Procedencia geográfica y estratigráfica: Puerto Pirámides, Golfo Nuevo, Península Valdés, Chubut; Formación Puerto Madryn, Mioceno tardío.

MPCNyO 290: cráneo incompleto, sin región rostral, con ambos tímpano-perióticos articulados.

Procedencia geográfica y estratigráfica: restinga de la costa Sur del Golfo San José, Lote 39, Península Valdés, Chubut; Formación Puerto Madryn, Mioceno tardío.

\section{Balaenidae indet.}

MACN 13221: bulla timpánica derecha.

Procedencia geográfica y estratigráfica: Paraná, Entre Ríos, Formación Paraná, Mioceno tardío.

Otros especímenes de balénidos extintos consultados y utilizados en los estudios comparativos son los siguientes:

\section{Balaenula astensis:}

Holotipo: MSNT I12555, Trevisan 1941, cráneo con parte de la región rostral preservada, periótico izquierdo y fragmentos de ambas mandíbulas.

Procedencia geográfica y estratigráfica: Portacomaro, Italia, Plioceno temprano.

\section{Balaenula balaenopsis:}

Holotipo: IRSNB M.853; Van Beneden (1872, 1880); esqueleto casi completo incluyendo porción posterior del cráneo, bulla timpánica, vértebras, fragmentos del esternón y costillas.

Procedencia geográfica y estratigráfica: Stuyvenberg, Bélgica, Plioceno temprano-tardío.

\section{Balaena montalionis:}

Holotipo: MSNT I12357; Capellini (1904), Bisconti (2000, 2003); cráneo incompleto, donde falta por completo la región rostral, y el complejo tímpano-periótico.

Procedencia geográfica y estratigráfica: Casina, Italia, Plioceno tardío. 


\section{Balaena ricei:}

Holotipo: USNM 22553, Westgate \& Whitmore Jr. (2002); cráneo incompleto con región rostral parcialmente preservada (maxilar derecho y vómer), periótico derecho, martillo, yunque y estribo, mandíbula, 7 vértebras cervicales, 3 torácicas, 2 lumbares, 16 caudales, chavrones, algunos elementos de la aleta derecha (escápula, húmero, radio, ulna, y 4 metacarpales), framento de esternón, y 8 costillas.

Procedencia geográfica y estratigráfica: Hampton, Virginia (EEUU), Yorktown Formation, Plioceno tardío.

\section{Balaenella brachyrhynus:}

Holotipo: NMB 42001, Bisconti (2005); cráneo casi completo, sin mandíbulas, con complejo tímpanoperiótico derecho.

Procedencia geográfica y estratigráfica: Antwerp, Bélgica, Plioceno temprano.

\section{Eubalaena belgica:}

Holotipo: IRSNM CtM 879a-f, Abel (1941); Bisconti (2000, 2003), cráneo incompleto, donde falta por completo la región rostral.

Procedencia geográfica y estratigráfica: Antwerpen, Bélgica, Plioceno tardío.

\section{Eubalaena shinshuensis:}

Holotipo: SFMCV-0024, Kimura et al., (2007), Kimura (2009), cráneo casi completo y vértebra lumbar.

Procedencia geográfica y estratigráfica: Nagano, Japón, Gonda Formation, Mioceno tardíoPlioceno temprano.

Los "arqueocetos" y misticetos extintos examinados para los estudios comparativos son:

Zygorhiza kochii: USNM 11962 (cráneo completo, mandíbulas y algunos elementos de la columna vertebral); USNM 4679 (escápula); USNM 468o (bulla timpánica izquierda); USNM 10857 (periótico). Procedencia geográfica y estratigráfica: Alabama, Estados Unidos, Eoceno medio.

Aetiocetus cotylalveus: USNM 25210 (holotipo).

Procedencia geográfica y estratigráfica: Oregon, Estados Unidos, Oligoceno temprano.

Aetiocetus weltoni: UCMP 122900 (holotipo).

Procedencia geográfica y estratigráfica: Oregon, Estados Unidos, Oligoceno tardío. 
Eomysticetus whitmorei: ChM PV 4253 (holotipo); Sanders \& Barnes, 2002.

Procedencia geográfica y estratigráfica: South Carolina, Estados Unidos, Chandler

Bridge Formation, Oligoceno tardío.

Pelocetus calvertensis: USNM 11976 (holotipo).

Procedencia geográfica y estratigráfica: Maryland, Estados Unidos; Mioceno tardío.

Diorocetus hiatus: USNM 16783 (holotipo).

Procedencia geográfica y estratigráfica: Maryland, Estados Unidos, Mioceno medio.

Los ejemplares utilizados en el análisis filogenético se detallan en el Capítulo 5 (sección 5.1.1.1).

\subsubsection{Estudios de anatomía blanda}

Los estudios de la anatomía blanda de la cabeza de Eubalaena australis se efectuaron a partir de disecciones anatómicas de 10 crías y un neonato varados en las costas de Península Valdés y Puerto Madryn en la temporada 2009-2011.

Para ejemplificar la condición de necropsia de los especímenes, se utilizaron las siguientes categorías (Programa de Monitoreo Sanitario Ballena Franca Austral):

1-Carcasa fresca: apariencia normal; generalmente pocas lesiones por carroñeros; olor fresco; piel levemente seca o arrugada, mucosas y ojos levemente secos; ausencia de hinchazón por gases; musculatura muy conservada y de coloración rojiza.

2-Moderada descomposición: Carcasa intacta; hinchazón por gases evidente; piel agrietada y desprendimiento en algunas zonas, posibles lesiones por carroñeros; mucosas secas; ojos hundidos o ausentes. La mayor parte de órganos y musculatura internos con estructura conservada, musculatura de coloración rosada.

3-Descomposición avanzada: carcasa intacta pero colapsada; piel agrietada, severos daños por carroñeros; fuerte olor, grasa y músculo que se desgarran fácilmente; huesos que se desprenden fácilmente; órganos internos y musculatura licuefactos.

4- Momificada o resto de esqueleto: Carcasa desecada; restos de piel y huesos.

Los ejemplares analizados fueron los siguientes:

Ejemplar o2-o9: macho, largo corporal=5,9om; condición de necropsia: 1

Ejemplar 03-o9: macho, largo corporal desconocido; condición de necropsia: 3

Ejemplar o4-o9: macho, largo corporal=5,25m; condición de necropsia: 2 
Ejemplar o1-10: macho, largo corporal=4,96m; condición de necropsia: 1

Ejemplar o2-10: macho; largo corporal=6,34m; condición de necropsia: 1

Ejemplar o3-10: macho; largo corporal=5,20m; condición de necropsia: 2

Ejemplar o4-10: hembra; largo corporal=4,9om; condición de necropsia: 1

Ejemplar: o5-10: macho; largo corporal=7,30m; condición de necropsia: 2

Ejemplar o1-11: macho; largo corporal= 5,10m; condición de necropsia: 2

Ejemplar o2-11: macho, largo corporal= 5,73m; condición de necropsia: 2

Ejemplar o3-11 (CNPMAMM 748): macho; largo corporal=3,64m; condición de necropsia: 1

Otras especies de misticetos diseccionadas y utilizadas en los estudios comparativos son:

Caperea marginata (NMNZ TMP o11345): la tesista participó en la disección de un ejemplar juvenil de esta especie en el Museum of New Zealand Te Papa Tongarewa, (Nueva Zelanda), donde se exploraron principalmente las estructuras blandas de la cabeza.

Balaenoptera spp.y Megaptera: se diseccionaron varias muestras de ojos y estructuras periorbitales, así como también estructuras blandas de la región nasal depositadas en el Icahn School of Medicine at Mount Sinai (Nueva York, E.E.U.U)

Balaenoptera bonaerensis (CNPMAMM 750): disección a campo de la cabeza de un ejemplar juvenil, (Puerto Madryn, Argentina).

\subsection{Métodos}

Eubalaena australis como modelo neontológico de comparación. Como se detalló en la introducción, la escasez de información anatómica de los balénidos actuales ocasionó que, en el marco de esta tesis, se efectuaran estudios previos en detalle de la anatomía blanda y ósea de los balénidos actuales. Para ello se realizó una primera exploración morfológica de E. australis. A esto se sumó el análisis de Balaenoptera bonaerensis y B. physalus como representantes de los balenoptéridos y Caperea marginata como único representante viviente de los cetotéridos. Como resultado de estas observaciones se determinó que los patrones morfológicos generales eran semejantes entre los tres grupos, y se seleccionó Eubalaena australis como modelo neontológico para esta tesis. Esta decisión estuvo basada en que, desde la década del '7o, esta población es objeto de estudio de varios grupos de investigación, con lo cual se ha recabado gran cantidad de información relacionada con aspectos biológicos, ecológicos, sociales y etológicos. A esto se suma que, todos los años se registran varamientos de esta especie en las costas de Península Valdés, especialmente de crías, los cuales son relevados por personal del "Programa de Monitoreo Sanitario de la Ballena Franca Austral". Esta situación brinda la ventaja única de acceder a ejemplares frescos y de pequeño tamaño, muy útiles 
para estudios de la anatomía blanda, así como también a varios esqueletos de distintas edades. En este contexto, y gracias a la colaboración de esta red de varamientos, se dispuso de abundante material osteológico y blando para diseccionar, efectuar tomografías y resonancias, que, junto con la abundante información publicada sobre su ciclo de vida, hacen de esta especie un excelente modelo neontológico de comparación con los balénidos miocenos. Complementariamente, esta información fue comparada con aquella disponible en la literatura de otros balénidos, como Eubalaena glacialis y Balaena mysticetus así como también de otras especies de misticetos. Las diferencias morfológicas observadas entre balénidos, cetotéridos y balenoptéridos fueron señaladas oportunamente.

\subsubsection{Estudios osteológicos}

El holotipo y especímenes referidos de Morenocetus parvus fueron preparados y acondicionados por el personal técnico del Departamento de Paleontología Vertebrados del Museo de La Plata para su re-descripción. En el caso de los ejemplares de balénidos del Mioceno tardío de Patagonia, los mismos fueron acondicionados y preparados por el personal técnico del Museo Paleontológico "Egidio Feruglio" (Trelew) y por la tesista. Los estudios anatómicos descriptivos incluyeron la toma de notas, fotografías digitales y medidas de los especímenes. En la toma de fotografías se utilizó una cámara Nikon D300o y un lente 18.0-55.0mm f/3.5. Por otro lado, para un estudio más detallado de las estructuras internas del cráneo, especialmente el oído, se efectuaron tomografías computadas helicoidales de los especímenes fósiles y actuales.

\subsubsection{Terminología osteológica}

En la descripción anatómica del cráneo de los balénidos se utilizó principalmente la terminología osteológica propuesta por Mead \& Fordyce (2009), Fraser \& Purves (1960) y Bisconti (2005). En particular, para la descripción del complejo tímpano-periótico se utilizó la terminología de Mead \& Fordyce (2009), Geisler \& Luo (1996) y Ekdale et al. (2011). Dada la diversidad de terminología osteológica presente en la literatura científica de los cetáceos, se efectuarán algunas aclaraciones con respecto a ciertas estructuras osteológicas del cráneo, especialmente del complejo tímpano-periótico de los cetáceos, con énfasis en los misticetos.

\section{Cráneo}

Caja craneana: está definido por los huesos que encierran el cerebro. Consiste en el escudo occipital (supraoccipital y exoccipitales) posteriormente, el interparietal dorsalmente, el parietal y escamoso lateralmente, el frontal y etmoide anteriormente y el basioccipital, tímpano-periótico y esfenoides ventralmente. 
Rostro: es definido como la porción anterior de la caja craneana y consiste en el maxilar, premaxilar, y vómer. Desde un punto de vista morfométrico, el rostro está delimitado posteriormente por una línea que atraviesa las muescas anterorbitales en el maxilar.

Cresta nucal (=cresta occipital o cresta lambdoidal). Se identifica como cresta nucal el contacto del exoccipital con el escamoso.

Cresta temporal: la cresta temporal es una continuación anterior de la cresta nucal. Ánterodorsalmente está formada por el frontal y póstero-dorsalmente por el parietal. La cresta temporal se desarrolla lateralmente sobre el proceso zigomático del escamoso donde se define como cresta supramastoidea.

Cresta orbitotemporal: corresponde a la porción anterior de la cresta temporal y en los misticetos se desarrolla en el margen posterior del proceso supraorbitario del frontal.

Canal infraorbitario: el canal infraorbitario lleva el nervio infraorbital, que es la rama infraorbitaria del nervio maxilar (segunda rama del trigémino, $V_{2}$ ). En los mamíferos no cetáceos, este canal comienza posteriormente dentro de la órbita en el foramen maxilar y termina anteriormente en el foramen infraorbitario. En los cetáceos, debido a la telescopización del cráneo, ha habido una confusión en la nomenclatura de las aperturas proximal y distal de este canal. La apertura proximal (posterior, orbital) se denomina foramen infraorbitario ventral mientras que la apertura distal (facial o anterior) del canal se denomina foramen infraorbitario dorsal.

Hiato craneal (=fisura basicapsular): es el espacio entre el periótico y el exoccipital, basioccipital, aliesfenoides, escamoso y parietal. En este espacio confluyen el foramen laceratum posterior, el foramen yugular y del meato auditivo interno, condición común a la mayoría de los cetáceos actuales.

Foramen carotídeo: en los cetáceos actuales la arteria carótida interna degenera durante el desarrollo, y la irrigación de la cavidad craneal es asumida en su mayor parte por la arteria carótida externa y por la red admirable espinal (Geisler \& Luo, 1998). La transmisión de vestigios de esta arteria hacia la cavidad craneal se produce a través del foramen carotídeo ventral, el cual se ubica sobre la superficie medial de la lámina dorsal del pterigoides. El foramen carotídeo dorsal abre en la superficie dorsal del basiesfenoides, el cual es visible en los neonatos pero se oblitera en los adultos (Ridewood 1923; Walmsley, 1938; Vogl \& Fisher, 1981). 
Foramen oval: en los mamíferos no cetáceos, el foramen oval corresponde a la salida de la rama mandibular del trigémino $\left(\mathrm{V}_{3}\right)$, el cual perfora únicamente el aliesfenoides. En los odontocetos se mantiene esa condición, mientras que en los misticetos adultos, debido a la reducción del aliesfenoide y a la superposición de otros huesos (escamoso y el pterigoides), el aliesfenoides no está perforado por el foramen oval. La salida del nervio $\mathrm{V}_{3}$ del cráneo se produce a través de un canal/surco en el aliesfenoide, localizado en el extremo anterior del hiato craneal. Desde allí el nervio $\mathrm{V}_{3}$ se dirige hacia la mandíbula a través de un foramen o muesca en el escamoso y/o pterigoides, el cual se denomina foramen pseudoval (ya que no es homólogo al foramen oval presente en los odontocetos y en los restantes mamíferos).

\section{Periótico}

Canal facial: en los mamíferos el canal facial transmite el nervio facial (VII) dentro del periótico. Este comprende el camino del nervio facial desde el meato auditivo interno (dorsalmente) hasta el foramen estilomastoideo (lateralmente). En la mayoría de los Neoceti, debido a que el foramen estilomastoideo está ausente, la apertura distal o ventral del canal facial es en el oído medio, en posición lateral y levemente anterior a la fenestra oval, a través de la apertura externa o distal del canal facial.

\section{Mandíbula}

Cuerpo mandibular: se define de esta forma a la región de la mandíbula que se extiende desde el extremo anterior hasta el proceso coronoides.

Rama mandibular: constituye aquella porción de la mandíbula posterior al proceso coronoides.

Surco milohioideo: se ubica en la superficie ventro-medial del cuerpo mandibular y constituye un vestigio del canal que ocupa el cartílago de meckel durante la ontogenia (Eschricht \& Reinhardt, 1866; Novacek, 1993). Dicho canal es el sitio de inserción del músculo milohioideo.

Complejo del seno pterigoideo: una de las modificaciones más notables del basicráneo de los cetáceos es el desarrollo de una extensión anterior del tubo de Eustaquio, la cual forma una serie de senos aéreos conocidos como complejo del seno pterigoideo. Estos senos son plexos fibro-venosos asociados a espacios de aire, que excavan la superficie de los huesos formando cavidades o senos. En los misticetos este complejo está formado por los siguientes senos:

1) Seno pterigoideo: es la cavidad que se ubica enteramente en la lámina dorsal del pterigoides, entre la lámina media y la lámina lateral del pterigoides. 
2) Seno peribullar: está asociado al oído medio, y se desarrolla entre el complejo tímpano-periótico y las crestas basioccipitales, sobre la superficie lateral de las crestas basioccipitales. A diferencia del seno pterigoideo, este seno carece de una fosa en el hueso.

3) Seno posterior o póstero-lateral: es una extensión del seno peribullar que se desarrolla sobre los procesos paraoccipitales.

\subsubsection{Orientación}

Términos para la orientación de estructuras anatómicas. Los términos utilizados para la orientación del cuerpo y esqueleto de los balénidos son los siguientes (Fig. 2.1; 2.2):

* Plano sagital: refiere a un plano vertical que se ubica a lo largo de la línea media y longitudinal del cuerpo y divide el cuerpo en una mitad derecha y otra izquierda.

* Plano transversal: refiere a un plano vertical que corta a través del eje longitudinal del cuerpo y lo separa en una sección anterior y otra posterior.

* Plano horizontal: refiere a un plano horizontal que se ubica en posición perpendicular al plano sagital y transversal y separa el cuerpo en una porción dorsal y otra ventral.

* Dorsal/ventral: refiere a un eje longitudinal vertical que designa las direcciones hacia arriba (hacia el lomo) o hacia abajo (hacia el vientre) respectivamente.

* Anterior/posterior: referidas a un eje longitudinal horizontal que designa las direcciones hacia la cabeza o hacia la aleta caudal respectivamente.

* Medial/Lateral: refiere a una dirección longitudinal hacia la línea media o sagital del cuerpo o hacia afuera de ese plano respectivamente.

Orientación del cráneo de los balénidos extintos. En los balénidos actuales el rostro es muy arqueado y la caja craneana presenta una orientación predominantemente vertical para permitir el anclaje de los huesos del rostro. En los balénidos el arqueamiento del rostro y la orientación vertical del escudo occipital implica que el largo cóndilo basal del cráneo (LCB; tomado en línea recta desde el margen posterior de los cóndilos occipitales hasta el extremo más anterior del rostro) no sea homólogo al de los restantes cetáceos y, además, el largo total del cráneo resultada subestimado. La orientación anatómica del cráneo en los balénidos extintos es conflictiva ya que en la mayoría de los especímenes no se conserva el rostro, por lo cual es difícil determinar el grado de inclinación de la caja craneana. Esto tiene un impacto muy importante en la interpretación de muchos caracteres (e.g. la orientación del supraoccipital). Con el objetivo de orientar el cráneo de los balénidos extintos, se exploraron en Eubalaena australis puntos anatómicos (y estructuras blandas asociadas) que brindaran información sobre la posición anatómica del cráneo in vivo. Los puntos anatómicos que brindan un buen marco de referencia para orientar el cráneo son: 
1. Orientación del proceso postglenoideo: en E. australis la orientación del proceso postglenoideo es ventro-posterior, lo cual define la posición de la fosa glenoidea para la articulación témporo-mandibular (Fig. 2.3A).

2. Posición del foramen magnum: este punto anatómico permite orientar el cráneo en relación a la columna vertebral. En E. australis la espina neural sale del cráneo a través del foramen magnum en posición dorsal; en consecuencia el foramen magnum está orientado formando un ángulo agudo con respecto al plano horizontal del cráneo (Fig. 2.3B).

3. Posición de la fosa nasal: la fosa nasal se ubica en la región póstero-dorsal del cráneo, y su porción más posterior (lugar donde se emplaza el blowhole o narina blanda) se ubica en forma perpendicular al plano transversal del cráneo (Fig. 2.3 A).

\subsubsection{Madurez osteológica}

Estadios de edad en los balénidos actuales. El establecimiento de categorías de edad en los misticetos es un tema difícil de abordar dada la falta de caracteres externos diagnósticos para cada edad y la dificultad para realizar un seguimiento de la historia de vida de los individuos. Una aproximación interesante para resolver esta problemática fue efectuada por Sironi y colaboradores (2005) en la ballena franca del Norte (Eubalaena glacialis). En este estudio determinaron que el largo de la cabeza crece en una determinada proporción con respecto al largo corporal (Sironi et al., 2005). De este modo, en las crías el largo de la cabeza (medido desde el extremo del rostro hasta el espiráculo) representa un 15\% del largo corporal, mientras que en adultos es del 21\%. Esta proporción combinada con el largo corporal, permitió establecer las siguientes categorías (Sironi comm.pers., 2013):

Cría: hasta 9m (largo de la cabeza representa entre un 15-16\% del largo corporal)

Juvenil/Subadulto: entre 9 y $12 \mathrm{~m}$ (largo de la cabeza entre un 17-19\% del largo corporal)

Adulto: 12 m o más (largo de la cabeza representa un 20\% o más del largo corporal)

El esquema anteriormente planteado para E. glacialis es consistente con la información biológica y/o del ciclo de vida conocido por el "Programa de Monitoreo Sanitario de la Ballena Franca Austral" en E. australis. Esto da una base empírica importante para examinar las formas actuales y extintas, y es el esquema que se utilizará en esta tesis.

Madurez física u osteológica. La madurez osteológica en los balénidos fue evaluada sobre la base del patrón de cierre de las suturas del basicráneo: basioccipital/basiesfenoides, basioccipital/exoccipital y supraoccipital/ exoccipital. Este patrón de suturas fue previamente explorado en los balenoptéridos y para su análisis se propusieron cuatro categorías (Walsh \& Berta, 2011): 
Estadio SR1: suturas abiertas

Estadio SR2: suturas parcialmente cerradas

Estadio SR3: suturas cerradas, pero aún se observa la línea de unión entre los huesos

Estadio SR4: sutura fuertemente cerrada, sin observarse la línea de unión entre los huesos.

Dichas categorías serán utilizadas para caracterizar el grado de cierre de las suturas anteriormente mencionadas.

\subsubsection{Medidas utilizadas}

Las medidas craneanas, del complejo tímpano-periótico y de la mandíbula utilizadas fueron tomadas de diferentes fuentes bibliográficas (Bisconti, 2005, 2010, 2012; Steeman, 2009). A estos parámetros se adicionaron otras medidas desarrolladas en esta tesis (marcadas por un asterisco). Las medidas fueron obtenidas en Eubalaena australis y en los balénidos miocenos, y se incluyen en el Apéndice del capítulo 4.

Las medidas se detallan a continuación:

\section{CRÁNEO}

1. Largo condilobasal

2. Ancho bizigomático

3. Largo del rostro

4. Ancho del rostro en la base (a nivel de las muescas antorbitales)

5. Ancho del cráneo entre los procesos postorbitarios del frontal*

6. Ancho del cráneo entre los procesos preorbitarios del frontal*

7. Ancho del cráneo a nivel de los exoccipitales*

8. Alto del cráneo a nivel del vértex

\section{SUPRAOCCIPITAL}

9. Ancho del supraoccipital por delante del foramen magnum*

10. Ancho del supraoccipital a la mitad del largo*

11. Ancho del supraoccipital en el extremo anterior (a $10 \mathrm{~cm}$ del borde anterior)*

12. Largo del supraoccipital

\section{EXOCCIPITAL}

13. Diámetro transverso del cóndilo

14. Diámetro dorso-ventral del cóndilo occipital

15. Diámetro transverso del foramen magnum

16. Diámetro dorso-ventral del foramen magnum 
17. Distancia entre el borde lateral del exoccipital y el margen lateral del cóndilo

18. Ancho de los cóndilos occipitales más el foramen magnum

\section{FRONTAL}

19. Ancho ántero-posterior del proceso supraorbitario del frontal en el extremo*

20. Ancho transversal del proceso supraorbitario del frontal

21. Ancho del proceso supraorbitario del frontal en la constricción*

22. Ancho del canal óptico en su porción medial*

23. Ancho del canal óptico en su porción lateral*

24. Largo de la región interorbitaria

25. Largo del canal óptico

26. Largo del margen dorsal de la órbita entre los procesos pre y postorbitario

27. Altura dorso-ventral de la órbita

\section{FOSA TEMPORAL}

28. Diámetro ántero-posterior de la fosa temporal

29. Diámetro transverso de la fosa temporal

\section{NASALES}

30. Largo de los nasales a lo largo de la línea media

31. Ancho máximo de ambos nasales

32. Ancho máximo del nasal derecho en la línea media

33. Ídem izquierdo

34. Ancho máximo del nasal derecho en el extremo posterior*

35. Ídem Izquierdo*

36. Ancho máximo de la fosa nasal

37. Largo de la fosa nasal*

\section{MAXILAR}

38. Largo linear del maxilar

39. Ancho posterior del maxilar

\section{PREMAXILAR}

40. Largo del premaxilar

\section{PERIÓTICO}

41. Largo del proceso posterior

42. Ancho en la mitad medial del proceso posterior*

43. Ancho en la mitad lateral del proceso posterior*

44. Largo del proceso anterior del periótico

45. Ancho del proceso anterior del periótico excluyendo la proyección lateral 
46. Ancho del proceso anterior del periótico incluyendo la proyección lateral

47. Largo de la proyección lateral de la tuberosidad lateral

48. Ancho de la proyección lateral de la tuberosidad lateral

49. Largo ántero-posterior de la pars coclearis

50. Diámetro transverso de la pars coclearis

51. Diámetro dorso-ventral de la fenestra coclear

52. Diámetro transverso de la fenestra coclear

53. Diámetro máximo de la fenestra oval

54. Diámetro mínimo de la fenestra oval

55. Diámetro dorso-ventral del meato auditivo interno (sensu lato)

56. Diámetro ántero-posterior del meato auditivo interno (sensu lato)

57. Diámetro máximo de la apertura interna del canal facial

58. Diámetro máximo del meato auditivo interno sensu stricto

59. Diámetro máximo del foramen endolinfático

6o. Diámetro máximo del foramen perilinfático

\section{BULLA TIMPÁNICA}

61. Largo ántero-posterior máximo

62. Ancho posterior en vista ventral

63. Ancho anterior en vista ventral

64. Ancho a nivel del proceso sigmoideo (incluyendo el proceso) en vista ventral

65. Ancho a nivel del proceso cónico

66. Alto a nivel del proceso sigmoideo

67. Alto a nivel del proceso cónico

68. Ancho transverso de la apertura de Eustaquio

\section{MANDÍBULA}

69. Largo de la mandíbula (lineal)

7o. Largo de la mandíbula (curvilíneo)

71. Altura de la rama mandibular a $500 \mathrm{~mm}$ del extremo anterior

72. Altura de la rama mandibular a $1000 \mathrm{~mm}$ del extremo anterior

73. Altura del cóndilo mandibular

74. Ancho del cóndilo mandibular

75. Alto del foramen mandibular

76. Ancho del foramen mandibular

77. Altura de la rama mandibular a nivel del proceso coronoides

78. Distancia entre el proceso coronoides y el cóndilo mandibular 
79. Altura del cóndilo mandibular

\subsubsection{Tomografías helicoidales computadas}

Para un estudio osteológico más detallado de los balénidos extintos y actuales, especialmente de la región auditiva, se efectuaron tomografías computadas helicoidales y una resonancia magnética. Asimismo se tomografió el oído de un balenoptérido (Balaenoptera sp.) a los fines comparativos. Las tomografías de los ejemplares de Eubalaena australis y del ejemplar MPEF-PV-1122 (balénido del Mioceno tardío de Patagonia) se efectuaron en el Instituto del Diagnóstico del Este del Chubut (Idech; Puerto Madryn), mientras que la tomografía de Morenocetus se efectuó en el Sanatorio IPENSA (La Plata). A continuación se detallan los especímenes tomografiados:

a) Morenocetus parvus (MLP 5-11): cráneo completo y región auditiva, espesor de los cortes 1 mm.

b) Balaenidae indet. (MPEF-PV-1122): periótico derecho, espesor de corte $1 \mathrm{~mm}$; $120 \mathrm{Kv}, 100 \mathrm{~mA}$; matriz 512; separación de imágenes 0.5.

c) Eubalaena australis (ejemplar 03-11; neonato): tomografía del lado izquierdo de la cabeza, espesor del corte $10 \mathrm{~mm}$ y $3 \mathrm{~mm}(80 \mathrm{~mA}, 120 \mathrm{Kv})$; tomografía de la región del oído de $1 \mathrm{~mm}$ de espesor (120 Kv, $90 \mathrm{~mA})$. Resonancia magnética de la cabeza del lado izquierdo.

d) E. australis (cría, $\mathrm{S} / \mathrm{N}$, colección del CNPMAMM): tomografía de complejo tímpano-periótico izquierdo, espesor del corte $1 \mathrm{~mm}(120 \mathrm{Kv}, 40 \mathrm{~mA})$.

e) E. australis (adulto, $\mathrm{S} / \mathrm{N}$, colección del CNPMAMM): tomografía del periótico izquierdo, espesor de corte $1 \mathrm{~mm}$.

f) Balaenoptera spp. (adulto, $\mathrm{S} / \mathrm{N}$, colección del CNPMAMM): tomografía de periótico derecho, espesor de corte $1 \mathrm{~mm}(8 \mathrm{o} \mathrm{mA,} 120 \mathrm{Kv})$.

g) B. bonaerensis (cría, CNPMAMM 750): tomografía del complejo tímpano-periótico derecho, espesor de corte $1 \mathrm{~mm}(60 \mathrm{~mA}, 120 \mathrm{Kv})$.

\subsubsection{Estudios de anatomía blanda}

Para efectuar los estudios descriptivos de la anatomía blanda de Eubalaena australis, así como también de las otras especies de misticetos analizadas, se efectuaron disecciones en el campo y en laboratorio siguiendo los protocolos estándar de disección de cetáceos (Geraci \& Lounsbury, 1993). Se tomó un registro fotográfico y videográfico detallado junto con notas, medidas y dibujos, además de la toma de muestras para estudios histológicos. Para el estudio de las estructuras in situ se utilizó la tomografía computada y la resonancia magnética del ejemplar 03-11.

Para complementar los estudios macro-anatómicos, se efectuaron cortes histológicos de distintas estructuras blandas de ejemplares de E. australis que fueron procesados en el Laboratorio de 
Histología del Centro Nacional Patagónico. Las muestras fueron fijadas en formol (8\%), deshidratadas en etanol, embebidas en parafina, cortadas en secciones de $7 \mu \mathrm{m}$ con un micrótomo y montadas en portaobjetos. La tinción se realizó con hematoxilina-eosina y tricrómico de Masson y fueron estudiadas bajo microscopio óptico.

\subsubsection{Terminología anatómica}

Para la identificación y denominación de las estructuras blandas se utilizaron referencias bibliográficas anatómicas generales (e.g. Nómina Anatómica Veterinaria, 2012) y otras más especializadas en cetáceos como Carte \& Macalister (1868), Eschricht \& Reinhardt (1866), Shulte (1916), Henry et al., (1983), Heyning \& Mead (1990), Lillie (1910) y Johnston et al., (2009). En particular, para la identificación y nominación de los músculos nasales y faciales descriptos se utilizó el criterio topológico (i.e. correspondencia en la posición relativa de los músculos) siguiendo la descripción de Carte \& Macalister (1868). Para la identificación y descripción de estructuras en los cortes histológicos se utilizó Dellmann (1994) y Bacha \& Wood (1991). 


\section{Capítulo 3}

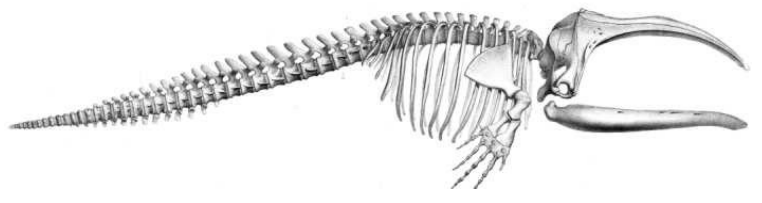

\section{Contexto Geológico}

Buono, M. Evolución de los Balénidos del Mioceno de Patagonia 


\section{Capítulo 3 \\ Contexto Geológico}

La historia geológica de la Patagonia extraandina estuvo marcada por una serie de ingresiones marinas del Océano Atlántico durante el Terciario, lo cual produjo la depositación de secuencias marinas alternadas con secuencias continentales (Mallumián, 1999). Estos afloramientos, bien expuestos en el este y oeste de la Patagonia, representan importantes yacimientos fosilíferos del Paleoceno, el Eoceno tardío, el Oligoceno-Mioceno temprano-medio, y el Mioceno tardío temprano.

Durante el Mioceno hubo al menos dos ingresiones marinas que cubrieron gran parte de la Patagonia y la región Chacopampeana. La primera ingresión, conocida como "Patagoniense", ocurrió durante el Oligoceno tardío-Mioceno temprano, donde el mar ocupó gran parte de la Patagonia sin afectar la región chacopampeana (Fig.3.1). Una segunda y última ingresión, conocida como "Entrerriense o Paranaense" ("Mar Entrerriense”), se produjo durante el Mioceno medio-tardío y afectó a la Argentina (la llanura Chacopampeana y la parte noroeste de la Patagonia) Uruguay y el Sur de Brasil (Feruglio, 1949; Scasso \& del Río, 1987; Uliana \& Biddle, 1988) (Fig. 3.2).

Tradicionalmente, los sedimentos marinos terciarios correspondientes a estas ingresiones han sido nominados en unidades cronoestratigráficas informales, como "Patagoniense", "Entrerriense" y "Rionegrense" (D'Orbigny, 1842; Darwin, 1846; Ameghino, 1906; Frenguelli, 1927; 1935; Simpson, 1935; Feruglio, 1949). Esta designación se efectuó en base a la naturaleza de las rocas constituyentes, sus relaciones estratigráficas y la fauna que incluyen (Cione \& Tonni, 1995). Posteriormente, estos niveles fueron asignados a unidades litoestratigráficas formales. De este forma los sedimentos "Patagonienses", que afloran en la región del Valle inferior del Río Chubut, Puerto Madryn e Istmo Ameghino, fueron asignados en la Formación Gaiman (Haller \& Mendia, 1980) (Fig. 3.3), mientras que los afloramientos del "Entrerriense" y "Rionegrense", en el área de Península 
Valdés y alrededores de la ciudad de Puerto Madryn, se asignaron a la Formación Puerto Madryn (Haller, 1978) (Fig. 3.4). Asimismo, los afloramientos "Entrerrienses" en los alrededores de la ciudad de Paraná (Entre Ríos), fueron asignados a la Formación Paraná (Yrigoyen, 1969).

Scasso \& del Río (1987) efectuaron un análisis paleoambiental de los afloramientos miocenos del área de Peninsula Valdés y alrededores, y sugirieron la presencia de un único ciclo sedimentario. Este ciclo fue de carácter regresivo, abarcó al "Patagoniense", al "Entrerriense" y al "Rionegrense", y la retirada del mar se produjo desde el oeste y sudoeste hacia el este y noreste. El modelo paleoambiental propuesto por estos autores indica que los sedimentos iniciales ("Patagoniense") se habrían depositado en un ambiente de plataforma de poca profundidad y baja energía, mientras que los sedimentos del "Entrerriense" se habrían depositado en un ambiente somero dominado por tormentas y por la acción de mareas. Las secuencias del "Rionegrense" corresponderían a depósitos en ambientes de planicies de marea con menor influencia de tormentas (Scasso \& del Río, 1987).

\subsection{Formación Gaiman}

Los primeros estudios de los sedimentos terciarios marinos aflorantes en la región del valle inferior del río Chubut, fueron efectuados por Frenguelli (1935) y Feruglio (1949) y, más recientemente, por Haller \& Mendia (1980), Mendia \& Bayarsky (1981) y Scasso \& Castro (1999). En particular, Haller \& Mendía (1980) asignan los sedimentos "patagonianos" de este sector a la Formación Gaiman, y designan como localidad tipo Loma Blanca (Bryn Gwyn), frente a la localidad de Gaiman.

La Fm. Gaiman, de aproximadamente 140m de espesor, se compone de materiales piroclásticos finos, los cuales provendrían de las erupciones volcánicas producidas en el Macizo Norpatagónico (Ardolino, 1981). La litología predominante son lutitas, tobas pelíticas y arenosas, de coloración gris, blanco-amarillenta, areniscas tobáceas grises y coquinas (Scasso \& Castro, 1999). La parte inferior de la Fm. Gaiman tiene 2om de grosor y está formada por una alternancia de estratos gruesos, de arenas gruesas con ondas y estructuras de tormenta, y estratos finos, de limolitas tobáceas con fuerte bioturbación. Estas estructuras sugieren un ambiente de sedimentación de alta energía alternado con uno de baja energía. Los niveles inferiores de la Fm. Gaiman son portadores de restos de vertebrados, moldes de bivalvos, y niveles muy delgados de Ostrea. La parte superior de la Fm. Gaiman presenta 3om de grosor, es de coloración blanquecina a gris claro y levemente más oscura que la porción inferior. Se compone de limolitas tobáceas intercaladas con lutitas, algunas coquinas y conglomerados fosfáticos (Scasso \& Castro, 1999).

En el valle inferior del río Chubut, la Fm. Gaiman suprayace a la Formación Sarmiento, la cual está compuesta de sedimentos continentales de coloración amarillo-grisáceo, portadores de 
abundante fauna de mamíferos de edad colhuehuapense. En este sector la Fm. Gaiman infrayace discordantemente a la Formación Puerto Madryn (Mendía \& Bayarski, 1981).

\subsubsection{Edad}

La edad de la Fm. Gaiman ha sido ampliamente discutida en la literatura. La fauna de moluscos de los géneros Venericor y Monophoraster, presente en las facies de la localidad de Barranca Blanca, sugiere una edad Eoceno tardío (Camacho \& Fernández, 1956). Por otro lado, Mendía \& Bayarsky (1981) propusieron una edad Oligoceno tardío-Mioceno temprano para esta formación en base a la fauna de mamíferos ("Colhué-Huapí") de la Formación Sarmiento (Oligoceno tardío; Simpson, 1935). Sin embargo, posteriormente esta fauna fue asignada al Mioceno temprano (Flynn \& Swisher, 1995). La fauna de vertebrados marinos, principalmente peces y cetáceos, sugiere una edad Mioceno temprano (Burdigalian) (Cione et al., 2011; Hilgen et al., 2012), edad que es aceptada en este trabajo de tesis.

\subsubsection{Fauna de vertebrados}

Los vertebrados marinos asociados a la Fm. Gaiman corresponden a peces, cetáceos y aves (Fig. 3.5). Entre los peces, se destaca una abundante fauna de condrictios elasmobranquios (e.g. Isurus, Carcharocles, Hemipristis, Galeocerdo, Squalus, etc.), holocéfalos y teleósteos (e.g. Cione, 1978, 1986; Arriata \& Cione, 1996; Cione \& Azpelicueta, 2002). Las aves marinas más abundantes son los Spheniscidae, con al menos 4 especies (Acosta Hospitaleche, 2007; Acosta Hospitaleche et al., 2008). El registro más antiguo de anseriformes no voladores (Cayaoa bruneti) también proviene de la Fm. Gaiman (Noriega et al., 2008). Los cetáceos están representados por los misticetos y los odontocetos. Dentro de los misticetos, se registra la familia Balaenidae, con Morenocetus parvus, y otros misticetos de afinidades inciertas (Aglaocetus moreni y Plesiocetus dyticus) (Lydekker, 1894; Cabrera, 1926). En relación a los odontocetos, se registran varias familias extintas, tales como Squalodelphidae (con el cetáceo más abundante de la formación, Notocetus vandebedeni), Eurhinodelphidae (Argyrocetus patagonicus), Squalodontidae (Phoberodon arctirostris, Cabrera, 1926), Prosqualodontidae (Prosqualodon australis, Cabrera, 1926), Kentriodontidae (Kentriodon; Cione \& Cozzuol, 1990) y Physeteridae (Diaphorocetus pouchetti e Idiorophus patagonicus; Moreno, 1892; Lydekker, 1893).

\subsubsection{Paleoambiente}

Los niveles inferiores de la Fm. Gaiman fueron depositados en un ambiente de plataforma 
poco profundo, por debajo del tren de olas, con tasas de sedimentación bajas y fuerte bioturbación (Scasso \& del Río, 1987; Scasso \& Castro, 1999). Hacia los niveles superiores, se observa un cambio a un ambiente de sedimentación dominado por tormentas y, finalmente, depósitos fluviales y de marea. El análisis de los depósitos fosfáticos y la fauna de vertebrados marinos presentes en la Fm. Gaiman sugieren cambios en los ambientes de depositación, desde uno de aguas frías (en la base de la formación) a uno de aguas más cálidas (hacia la parte superior de la secuencia). Este evento estaría vinculado con la formación del arco volcánico en la región de las Islas Sandwich, lo cual impidió la libre circulación de la corriente circumpolar Antártica en el extremo sur de la Patagonia (Scasso \& del Río, 1987; Scasso \& Castro, 1999), ocasionando el calentamiento de las aguas del Atlántico sudoccidental hacia el Mioceno medio.

\subsection{Formación Puerto Madryn}

La Formación Puerto Madryn aflora en los alrededores de la ciudad de Puerto Madryn hasta la latitud del Eje Tentativo en el Istmo Ameghino (Fig. 3.4) y en los alrededores de la Península Valdés. La Fm. Puerto Madryn, de aproximadamente $200 \mathrm{~m}$ de espesor, está formada por una intercalación de areniscas finas de color gris o amarillo, pelitas, limolitas blanquecinas y coquinoideos con matriz arenosa o limosa (Scasso \& del Río, 1987; del Río, 200o). La Fm. Puerto Madryn suprayace a la Fm. Gaiman e infrayace a los "Rodados Patagónicos”. Estos últimos corresponden a depósitos de grava arenosa de edad Plioceno - Pleistoceno temprana, que coronan la superficie de la Fm. Puerto Madryn (Haller et al., 2001).

\subsubsection{Edad}

La edad de la Fm. Puerto Madryn ha sido ampliamente discutida. Los primeros estudios en relación a este tema, asignaron a la Fm. Puerto Madryn una edad de Mioceno tardío sobre la base de la información proveniente de los invertebrados ostrácodos y los foraminíferos (e.g. García, 1970; Malumian \& Masiuk, 1973). Por el contrario, y sobre la base de la correlación efectuada con las sedimentitas del pozo YPF Ch.P.V. es-1, se asignó a estos sedimentos una edad Mioceno medio/tardío (Masiuk et al., 1976).

Por otro lado, sobre la base de la evidencia paleontológica, paleogeográfica y paleoclimática provista por la fauna de moluscos, se propuso una edad Mioceno medio tardío (del Río, 1988, 1990, 1991) y, posteriormente, Mioceno tardío (Martínez, 1994) para estos sedimentos. Asimismo, sobre la base del contenido de algunos vertebrados marinos, se propuso también una edad Mioceno medio para la Fm. Puerto Madryn (Cione, 1978; Cozzuol, 1993, 1996; Cione et al., 2005; Riva Rossi et al., 
2000)

Las dataciones isotópicas de K/Ar, a partir de tobas volcánicas (9.41 Ma; Zinsmeister et al., 1981), y de $\mathrm{Sr}^{87} / \mathrm{Sr}^{86}$, a partir de valvas de pectínidos (10 Ma \pm 0.3 Ma; Scasso et al., 2001), sugieren para la Fm. Puerto Madryn una edad Mioceno tardío (Tortoniano temprano; Hilgen et al., 2012). Esta edad es soportada también por evidencia palinológica (Palazzesi \& Barreda, 2004; Barreda \& Palazzesi, 2007) y aquella proveniente de la fauna de moluscos (Martínez \& del Río, 2002; del Río, 2004), y es aceptada en esta tesis.

\subsubsection{Fauna de invertebrados}

Los invertebrados son la fauna más común de la Fm. Puerto Madryn, y los más abundantes, son los ensambles de moluscos bivalvos (pectínidos, ostreas, venéridos y arcoideos), acompañados de briozoos, braquiópodos, equinodermos y artrópodos (e.g. del Rio, 1990, 2000, 2004). En particular, los ensambles de bivalvos del Mioceno tardío presentaban una composición distinta a los de la actualidad, ya que estaban caracterizados por una fauna de carácter tropical coincidente con un mar entrerriense de tipo cálido. Hacia finales del Mioceno tardío, se observa una fuerte renovación faunística con respecto a las asociaciones que se encuentran durante el Paleógeno, no sólo de los bivalvos sino también de los otros grupos de invertebrados. Esta renovación implicó la extinción y aparición de varios taxones, y el desplazamiento hacia el norte de otros (del Río, 2000). Los cambios en la composición de la fauna se vinculan, por un lado, a un enfriamiento de las aguas del Atlántico Sur por el establecimiento de la Corriente de Malvinas (ocurrido hacia finales del Mioceno tardío) y por otro, a cambios en la productividad primaria de las aguas (Martinez \& del Río, 2002).

\subsubsection{Fauna de vertebrados}

A diferencia de lo que sucede con los invertebrados, los vertebrados no son abundantes en la Fm. Puerto Madryn, pero son excepcionales en cuanto al buen estado de preservación que presentan. Esto ha sido vinculado a condiciones rápidas de sedimentación, caracterizadas por un entierro rápido ocasionado por grandes cantidades de sedimentos depositados en un corto período de tiempo (Cione et al., 2011).

La fauna de vertebrados registrada en esta formación corresponde a peces, aves y mamíferos

(Fig. 3.6). A diferencia de la Fm. Gaiman, los peces elasmobranquios son poco abundantes (e.g. Carcharocles, Carcharias, Squatina y Myliobatis; e.g. Cione, 1978; Arratia \& Cione, 1996) mientras que los osteictios aparecen en muy buen estado de preservación, con esqueletos completos y articulados (Cozzuol et al., 1990; Riva Rossi, 1997; Riva Rossi et al., 2000). Las aves están representadas por los Sphenicidae, que son poco abundantes en la Fm. Puerto Madryn y sólo se conocen por ejemplares 
fragmentarios, excepto por Madrynornis mirandus (Acosta Hospitaleche, 2003; Acosta Hospitaleche et al., 2007a). Otras aves conocidas para la Fm. Puerto Madryn son los Anseriformes (Acosta Hospitaleche et al., 2007b) y a una nueva especie de Ciconiidae (Noriega \& Cladera, 2008). En lo que respecta a los mamíferos marinos, los cetáceos encontrados en la Fm. Puerto Madryn corresponden a linajes más modernos que los presentes en la Fm. Gaiman (Cozzuol, 1996). De este modo, dentro de los odontocetos se registran los Ziphiidae (con una nueva especie, Notoziphius bruneti; Buono \& Cozzuol, 2013), Physeteridae (con dos especies Preaulophyseter gualichensis y Aulophyseter rionegrensis (Caviglia \& Jorge, 1980; Gondar, 1975) y Eurhinodelphidae (restos fragmentarios; Cozzuol, 1996). Los misticetos corresponden a los Balaenidae (nuevos ejemplares que se describirán en el capítulo 4) y Cetotheridae sensu stricto (mandíbula gen.et sp. indet; Buono et al., 2013). Otro grupo de mamíferos marinos registrado en esta formación corresponde a los pinnípedos, con el Phocinae Kawas benegasorum, que constituye el primer y el más antiguo registro de este grupo para el Hemisferio Sur (Cozzuol, 2001).

Asimismo en los últimos años, se dio a conocer el primer ensamble de vertebrados continentales provenientes de los niveles superiores de la Fm. Puerto Madryn. El mismo está compuesto por peces osteíctios; aves Gruiformes, Anseriformes y Falconiformes; y mamíferos xenartros, roedores y ungulados litopternos, y representa el primer ensamble de vertebrados continentales del Mioceno tardío registrado al sur de Río Negro (Cione et al., 2005; Vucetich et al., 2005; Picasso et al., 2009; Dozo et al., 2010).

\subsubsection{Paleoambiente}

La Fm. Puerto Madryn es una secuencia regresiva, con alternancia de facies depositadas en un ambiente de plataforma, por debajo de la base del tren de olas en ambientes de baja energía, y de facies más someras depositadas en un ambiente con dominio de mareas y tormentas (Scasso \& del Río, 1987). El análisis de los ensambles de invertebrados sugieren la presencia de un mar subtropical a tropical, con temperaturas superiores a las registradas en la actualidad, que oscilarían entre los $18^{\circ}$ $20^{\circ} \mathrm{C}$ en invierno y los $24^{\circ} \mathrm{C}$ o superior en verano (del Río, 1988, 1990; Martínez \& del Río, 2002 y referencias allí incluidas).

\subsection{Formación Paraná}

En el área de la Mesopotamia, la ingresión del "Mar Entrerriense" depositó los sedimentos de la Fm. Paraná. Estos sedimentos afloran en una amplia región que se extiende desde la margen derecha del río Nogoyá hasta la desembocadura del río Feliciano, en las inmediaciones de la ciudad de 
Paraná. La Fm. Paraná está compuesta por limolitas verdes y areniscas con bancos de ostras (Aceñolanza, 200o) (Fig. 3.7).

La retirada del "Mar Entrerriense" ocasionó una red hidrográfica que depositó valles de sedimentos, la cual suprayace a la Formación Paraná, y es designada como Fm. Ituizangó. Esta última está formada por un conglomerado basal ("conglomerado Osífero"), compuesto de arenas blanquecinas, ocres y amarillento-rojizas y clastos de arcillas y portador de abundantes restos de vertebrados (Aceñolaza, 200o).

\subsubsection{Edad}

La edad de la Fm. Paraná está basada principalmente en la correlación estratigráfica de la fauna de vertebrados. La fauna de peces sugiere una edad Mioceno medio-Plioceno, mientras que los cetáceos sugieren una edad Mioceno tardío (Tortoniano) (Cione et al., 2000).

La edad de la Fm. Ituizangó ha sido objeto de controversias y ha fluctuado entre el Mioceno, el Plioceno y el Cuaternario (Herbst, 2000 y referencias allí incluidas). La fauna de mamíferos presente en la base de la Formación Ituizangó ("Conglomerado Osífero") es de edad huayqueriense en la escala de edades-mamífero Sudamericana (Cione et al., 200o) y correspondería a un Mioceno tardío (Tortoniano).

\subsubsection{Fauna de vertebrados}

La Fm. Paraná incluye vertebrados marinos y de agua dulce, pero no incluye vertebrados continentales. La fauna de esta formación corresponde a peces, cetáceos, sirenios y pinnípedos. El ensamble de peces, muy distinto a la fauna de Patagonia, está representado por elasmobranquios y osteíctios (e.g Arratia \& Cione, 1996; Cione et al., 2000, Cione et al., 2005; Cione et al., 2008). Los cetáceos están representados por linajes más modernos y similares a los actuales que aquellos presentes en la Fm. Gaiman y Puerto Madryn. Entre los odontocetos se encuentran los Pontoporiidae y los Physeteridae, mientras que los misticetos están representados por los Balaenidae y Balaenopteridae (Cozzuol, 1993, 1996; Agnolin \& Lucero, 2004; Noriega et al., 2007; Perez et al., 2011). En referencia a los sirenios, se encuentran restos fragmentarios asignados al género Dioplotherium (Vélez-Juarbe et al., 2012). Los pinnípedos están representados por una especie de fócido de la subfamilia Monachinae (Cozzuol, 1985, 1993, 1996).

En el "conglomerado osífero" se encuentran peces, cocodrilos, tortugas, aves y diferentes grupos de mamíferos terrestres y acuáticos. En el caso de los mamíferos acuáticos, se registran al menos tres especies de cetáceos de la familia Iniidae y Pontoporiidae, mientras que los sirenios están 
representados por los Trichechidae (Cione et al., 2000).

\subsubsection{Paleoambiente}

En relación con la Fm. Paraná, la fauna de pinnípedos, cetáceos, sirenios, peces e invertebrados sugieren un ambiente de aguas cálidas. En el "Conglomerado Osífero" de la Fm. Ituizangó, la diversidad taxonómica de reptiles, aves y mamíferos, sugiere una variedad de paleoambientes. Entre éstos últimos se encontrarían tierras bajas, pantanosas y arboladas, así como también una fragmentación del ambiente boscoso en áreas más abiertas, de tipo sabana y humedales, en las adyacencias de las márgenes ribereñas (Cione et al., 20oo; Noriega \& Agnolin, 2008). 


\section{Capítulo 4}

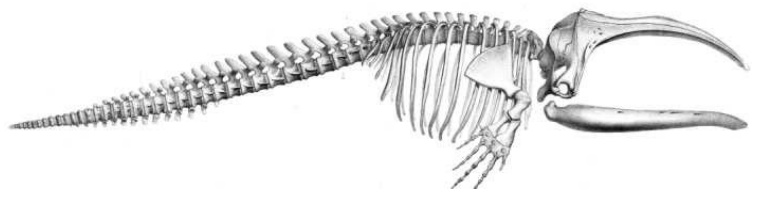

\section{Anatomía y Sistemática Paleontológica}

Buono, M. Evolución de los Balénidos del Mioceno de Patagonia 


\section{Capítulo 4}

\section{Anatomía y Sistemática Paleontológica}

En los misticetos la anatomía esqueletaria, especialmente del cráneo y mandíbula, presenta una serie de especializaciones que han sido asociadas con los métodos de alimentación empleados por cada grupo (Bouetel, 2005). En particular, en los balénidos, las especializaciones observadas en el cráneo y mandíbula están vinculadas con el incremento del tamaño de la cavidad bucal, aumentando la capacidad de filtrar mayor cantidad de presas. De esta forma el cráneo presenta un rostro muy arqueado y angosto transversalmente, huesos rostrales sin interdigitación con los huesos occipitales y mandíbula con un proceso coronoides y angular reducido (Bouetel, 2005).

La anatomía esqueletaria de los balénidos actuales es muy conservadora y sólo se reconocen 4 especies actuales distribuidas en dos géneros: Balaena (B. mysticetus) y Eubalaena (E. australis; E. glacialis; E. japonica). En general los estudios anatómicos, no sólo osteológicos sino también de estructuras blandas, son más abundantes en Balaena mysticetus que en Eubalaena, si bien ambas han sido objeto de estudio desde principios del siglo XIX (e.g. Cuvier, 1823; van Beneden \& Gervais, 1880; Eschricht \& Reinhardt, 1866; True, 1904; Allen, 1908). Por ejemplo, en el caso de Eubalaena australis, desde su descripción original en el siglo XIX, su anatomía esqueletaria no ha sido revisada (Gray, 1825).

Balaena se diferencia de Eubalaena, a nivel de la morfología del cráneo, por poseer: un cráneo más grande (>1/3 del largo corporal), un rostro y caja craneana más arqueados y un escamoso y proceso supraorbitario del frontal orientados posteriormente (McLeod et al., 1993; Bisconti, 2003; Churchill et al., 2012). Las tres especies de Eubalaena se diferencian principalmente a nivel molecular, y existen muy pocos caracteres morfológicos útiles para diagnosticarlas. Entre éstos últimos está la morfología del aliesfenoides y de la escápula, el patrón de coloración y de 
callosidades de la cabeza (Rosenbaum et al., 2000; Bisconti, 2005; Gaines et al., 2005; Kaliszewska et al., 2005; Churchill et al., 2012).

El marco geográfico donde se desarrolló este proyecto de tesis brindó la posibilidad de acceder a varios materiales esqueletarios de Eubalaena australis, principalmente cráneos y mandíbulas, de individuos de distintos estadios ontogenéticos, circunstancia muy difícil de encontrar en colecciones científicas nacionales e internacionales. Esto permitió el estudio osteológico del cráneo y mandíbula en detalle y, además, identificar en forma preliminar algunos caracteres que varían en la ontogenia de los individuos. En este contexto, como parte del desarrollo de este capítulo se presentará la descripción anatómica del cráneo y mandíbula de E. australis, que servirá como modelo neontológico de comparación con los balénidos miocenos.

La baja diversidad taxónomica de los balénidos en la actualidad contrasta con su diversidad en el pasado. McLeod et al. (1993) y posteriormente Bisconti (2000, 2003) efectuaron una revisión sistemática de los taxones de esta familia, muchos de ellos nominados y descriptos en el siglo XIX y XX por Van Beneden $(1872,1878,1880)$, Capellini $(1872,1904)$ y Abel (1941). Sobre la base del reestudio de estos materiales, McLeod et al. (1993) y Bisconti (2003) determinan la invalidez de varios taxones, entre ellos Balaena paronai, Balaena etrusca, Balaena primigenius y Balaenula praediolensi. En la actualidad se reconocen 9 especies extintas organizadas en 6 géneros: Balaena (B. ricei, $B$. montalionis), Balaenula (B. astensis, B. balaenopsis), Balaenotus (B. insignis), Balaenella (B. brachyrhynus), Morenocetus (M. parvus) y Eubalaena (E. belgica, E. shinshuensis).

El registro fósil de los balénidos es temporalmente extenso (Mioceno temprano-actualidad) y, en algunos casos abundante (i.e. Plioceno, Pleistoceno,) pero está caracterizado por grandes discontinuidades estratigráficas y geográficas. En particular el registro mioceno es extremadamente escaso y está restringido a la Patagonia (Argentina), con la presencia de Morenocetus parvus, el balénido más antiguo conocido (Mioceno temprano, Chubut). Los registros de balénidos para el Plioceno y Pleistoceno son, en cambio, abundantes y restringidos al Hemisferio Norte, e incluyen géneros extintos (Balaenella, Balaenula, Balaenotus) así como otros con representantes actuales (Balaena y Eubalaena).

Morenocetus parvus fue descripto y nominado por Cabrera en una monografía sobre cetáceos fósiles del Museo de La Plata en el año 1926. La descripción original fue concisa, y no incluyó información y figuras de todos los ejemplares referidos a esta especie. La descripción se basó en dos cráneos incompletos, pero en buen estado de conservación, colectados en Cerro Castillo, Valle Inferior del Río Chubut (Chubut), de los cuales sólo el holotipo es figurado. Asimismo Cabrera (1926) refiere a esta especie una mandíbula y vértebras cervicales, procedentes de la misma localidad y de los mismos niveles estratigráficos que los otros ejemplares. Sin embargo, el re-estudio de la mandíbula permitió determinar que no corresponden a una edad miocena y las vértebras no 
pudieron ser localizadas para su estudio. Debido a que la descripción es poco informativa y a que los materiales de Morenocetus no han sido re-estudiados luego de su descripción original, este taxón ha permanecido como una especie enigmática dentro de la comunidad de cetólogos por mucho tiempo. A pesar de los re-estudios y nuevos análisis que se han efectuado en los últimos años de la sistemática de los balénidos, la posición filogenética de Morenocetus permanece aún sin resolverse (Bisconti, 2002, 2005; Churchill et al., 2012). Por otro lado como resultado de trabajos paleontológicos en el área de Península Valdés, se suman a este registro Mioceno nuevos ejemplares de balénidos extintos colectados en niveles de la Formación Puerto Madryn (Mioceno tardío temprano) (Cozzuol, 1993, 1996). Estos ejemplares, junto con algunos especímenes provenientes del Mioceno tardío de Entre Ríos (Formación Paraná) (Cozzuol, 1993; Agnolin \& Lucero, 2004) completan, en parte, los extensos hiatos del registro Mioceno. En este contexto, estos materiales requieren una descripción y análisis taxonómico detallado, que es parte de los objetivos de este capítulo.

Los objetivos específicos e hipótesis de trabajo de este capítulo son:

1) Efectuar la descripción osteológica del cráneo y mandíbula de ejemplares de distintos estadios ontogenéticos del balénido actual Eubalaena australis, que se utilizará como modelo neontológico para efectuar comparaciones con los balénidos miocenos.

Hipotesis de trabajo 1: la morfología craneal y mandibular brinda parámetros no vinculados al tamaño que permiten diferenciar estadios ontogenéticos relativos.

2) Analizar los caracteres diagnósticos de la familia Balaenidae así como también del género Eubalaena y de la especie E. australis

Hipótesis de trabajo 2: Los caracteres identificados como diagnósticos de la familia Balaenidae, y particularmente del género Eubalaena y de la especie E. australis, en publicaciones anteriores son insuficientes.

3) Realizar el estudio y re-descripción del holotipo y material referido de Morenocetus parvus Cabrera (1926) del Mioceno temprano de Chubut (Formación Gaiman).

Hipótesis de trabajo 3: El ejemplar MLP 5-15 y el holotipo (MLP 5-11) de Morenocetus parvus son asignables a la misma entidad taxonómica.

4) Estudio anatómico detallado y de taxonomía alfa de los nuevos registros de balénidos recuperados de la Formación Puerto Madryn (Mioceno Tardío; Península Valdés; Chubut). Hipótesis de trabajo 4: Los ejemplares MPEF-PV-1122, CH-P33-01, y MPCNyO 290 colectados 
en niveles de la Formación Puerto Madryn (Mioceno tardío) representan un nuevo taxón.

5) Descripción de los ejemplares de balénidos del Mioceno de Paraná (Entre Ríos).

Hipótesis de trabajo 5: en la Formación Paraná (Mioceno tardío) se registran los mismos taxones que en la Formación Gaiman y Puerto Madryn.

\title{
4.1 Materiales y métodos específicos
}

Los estudios osteológicos de Eubalaena australis se efectuaron sobre la base de los siguientes ejemplares:

Neonato y crías: CNPMAMM 742, 746, 747, 748.

Subadultos: ejemplar S/N (esqueleto completo)

Adultos: USNM 267612, 484899, CNPMAMM 741.

La re-descripción del cráneo, complejo tímpano-periótico y mandíbulas de E. australis se efectuó sobre la base de los individuos adultos y se efectúan algunos comentarios particulares sobre la anatomía en las crías. Específicamente, las variaciones ontogenéticas observadas entre neonatos, crías y adultos se discuten en la sección 4.4.1.

La metodología aplicada en este capítulo en relación a la terminología osteológica, la orientación del cráneo y la madurez osteológica fue detallada en el Capítulo 2 (sección 2.3.1).

Las tablas con las medidas tomadas de los especímenes se detallan en el apéndice al final de este capítulo.

\subsection{Modelo neontológico de comparación: Eubalaena australis}

\subsubsection{Sistemática}

\author{
Orden CETACEA Brisson, 1762 \\ Rango no determinado NEOCETI Fordyce \& Muizon, 2001 \\ Suborden MYSTICETI Gray, 1864 Sensu Cope, 1869 \\ Rango no determinado CHAEOMYSTICETI Mitchell, 1989 \\ Familia BALAENIDAE Gray, 1825
}

Género tipo: Balaena Linnaeus, 1758

Géneros incluídos: Balaena Linnaeus, 1758; Balaenotus Van Beneden, 1872; Balaenula Van Beneden, 1872; Balaenella Bisconti, 2005, Eubalaena Gray, 1864, y Morenocetus Cabrera, 1926. 
Diagnosis enmendada: La familia Balaenidae se diferencia de las restantes familias de misticetos en la siguiente combinación única de caracteres: rostro arqueado dorso-ventralmente; extremo anterior del proceso supraorbitario del frontal orientado posteriormente; margen dorsal de la órbita localizado ventralmente al margen lateral del rostro; ventana maxilar en el borde posterior de la placa infraorbitaria del maxilar; margen posterior del proceso zigomático del escamoso y extremo lateral del exoccipital confluentes formando un borde lateral del cráneo continuo; parietales más altos dorso-ventralmente que largos ántero-posteriormente; extremo anterior del supraoccipital en línea con la mitad anterior o con el margen anterior del proceso supraorbitario del frontal; escamoso más alto dorso-ventralmente que largo ántero-posteriormente; proceso zigomático orientado ántero-lateralmente; extremo anterior del proceso zigomático del escamoso ubicado ventralmente al proceso postorbitario del frontal y separado de este por una distancia dorso-ventral; largo de la fosa escamosa menor a $3 / 4$ el ancho de la fosa temporal; cresta occipital externa poco desarrollada o ausente; foramen pseudoval localizado dentro del escamoso y abriendo posteriormente; crestas basioccipitales divergentes en dirección posterior; proceso anterior del periótico redondeado; presencia de una cresta delimitando la superficie de inserción del músculo tensor timpánico; proceso caudal timpánico triangular y orientado póstero-ventralmente; surco lateral de la bulla timpánica orientado ántero-ventralmente; cresta del involucro retraída lateralmente; extremo anterior de la cresta del involucro posterior al margen anterior de la bulla timpánica; superficie dorso-lateral del involucro formando un anillo continuo; y superficie ántero-ventral de la bulla timpánica plana o levemente cóncava.

\section{Eubalaena Gray, 1864a}

1864a Eubalaena Gray, p.201

1864a Macleayius Gray, p. 589

1865 Eubalaena; Flower, p.390

1866 Hunterius Gray, p.98

1867 Eubalaena; Flower, p. 115

1871 Eubalaena; Gill, p.126

1872 Eubalaena; Brandt, p.119

1872 Macleayius; Brandt, p. 119

1873 Halibalaena Gray, p.140

1904 Macleayius; Palmer, p. 391

1904 Eubalaena; Palmer, p. 272

1923 Eubalaena; Miller, p.40 
1945 Eubalaena; Simpson, p. 105

1951 Eubalaena; Ellerman \& Morrisson-Scott, p.717

1977 Eubalaena; Barnes, p. 323

1999 Eubalaena; Bergqvist et al., p. 31

2003 Eubalaena; Bisconti, p. 34

2005 Eubalaena; Mead \& Brownell, p. 723

2006 Eubalaena; Bouetel \& Muizon, p. 387

2007 Eubalaena; Steeman, p. 880

2011 Eubalaena; Ekdale et al., p. 39

2012 Eubalaena; Churchill et al., p. 19

Especie tipo: Eubalaena australis Desmoulins, 1822

Diagnosis enmendada: Eubalaena se diferencia de todos los restantes balénidos en la siguiente combinación única de caracteres: nasales cortos en comparación con el ancho bizigomático (menor al 25\%); extremo anterior de proceso zigomático del escamoso en posición ventral y próximo al proceso postorbital; cresta escamosa lateral bien desarrollada obstruyendo parcialmente la sutura parietal-escamoso; depresión cóncava en posición ántero-medial a la apertura del tubo de Eustaquio en la bulla timpánica; ausencia de olecranon en el húmero; presencia de callosidades en la cabeza; escamoso orientado perpendicular al eje sagital del cráneo; superficie dorsal del cráneo con una curvatura leve en el extremo anterior del rostro y plana a nivel del vértex; proceso supraorbitario del frontal no inclinado posteriormente en vista lateral, largos transversalmente y desarrollados principalmente en dirección ventral; presencia del proceso narial del frontal el cual separa la porción posterior de los nasales; márgenes laterales del supraoccipital convexos; exoccipitales extendidos posteriormente al margen posterior de los cóndilos occipitales en vista ventral; gran exposición del escamoso en posición lateral al exoccipital en vista posterior; pared posterior de la fosa temporal cóncava; alineamiento ántero-posterior de la apertura dorsal o interna del canal facial, el meato auditivo interno sensu stricto y del foramen perilinfático; foramen perilinfático de menor tamaño que el foramen endolinfático; fosa glenoidea posterior al proceso postorbital; y presencia de proceso piramidal en el periótico.

Eubalaena australis Desmoulins, 1822

1822 Eubalaena australis Desmoulins, p. 186

1776 Balaena glacialis Muller, p. 7

1822 Balaena australis Desmoulins, p. 161 
1828 Balaena antarctica Lesson, p. 391

1841 Balaena mysticetus antarcticus Schlegel, p. 37

1843 Balaena antipodum Gray, p. 183

1864b Hunterus temminckii Gray, p. 349

1865 Macleayius australiensis Gray, p. 589

1866 Eubalaena capensis Gray, p. 91

1868 Balaena capensis Gray, p. 91

1874 Balaena hectori Gray, p. 56

1962 Eubalaena glacialis australis Tomilin, p. 86

1963 Balaena glacialis australis Scheffer \& Rice, p. 9

2012 Eubalaena australis; Churchil et al., p. 15

Lectotipo: MNHN (esqueleto completo) sin número.

Diagnosis enmendada: Eubalaena australis se diferencia de las restantes especies de Eubalaena en la siguiente combinación única de caracteres: extremo anterior del proceso supraorbitario del frontal orientado posteriormente, proceso coracoides de la escápula reducido a una rugosidad, acromion de la escápula reducido y presencia de una mancha ventral en el cuerpo.

\subsubsection{Anatomía craneana y mandibular de Eubalaena australis}

Las medidas del cráneo, complejo tímpano-periótico y mandíbula de Eubalaena australis (crías y adultos) se detallan en la Tabla 4.1. y 4.2 (Apéndice).

\section{Cráneo}

\section{SUPRAOCCIPITAL}

El supraoccipital se extiende anteriormente hasta aproximadamente la mitad del proceso supraorbitario del frontal en vista dorsal (Fig. 4.1). El margen anterior, que contacta con el frontal, es de forma semicircular. Los márgenes laterales, los cuales contactan con el escamoso y el parietal, son convexos y marcadamente elevados en dirección posterior debido al desarrollo de la cresta temporal (Fig. 4.2; 4.3). Posteriormente, el supraoccipital contacta con el exoccipital a través de una sutura completamente cerrada (estadio $\mathrm{SR}_{4}$ ). Sobre la superficie dorsal del supraoccipital se observa una cresta occipital externa, sólo detectable al tacto, dentro de una depresión longitudinal pronunciada que no alcanza el margen anterior del supraoccipital (Fig. 4.3). En vista lateral la superficie dorsal del supraoccipital es cóncava en la línea media por la profundización de la fosa longitudinal. 


\section{EXOCCIPITAL}

El exoccipital forma parte de la pared posterior de la caja craneana y el cóndilo occipital. Contacta anteriormente con el supraoccipital, látero-ventralmente con el escamoso y ventralmente con el basioccipital.

En vista posterior (Fig. 4.3) el exoccipital es ancho transversalmente y representa un $44 \%$ del ancho bizigomático del cráneo (Tabla 4.1). El margen lateral del exoccipital es convexo, y en vista póstero-lateral la superficie dorsal próxima a los cóndilos occipitales es levemente cóncava. El margen ventral del exoccipital forma el proceso paraoccipital y la muesca yugular. El proceso paraoccipital es corto dorso-ventralmente, de contorno redondeado y se ubica lateralmente a la muesca yugular. La muesca yugular es una escotadura profunda y en forma de "V" que se ubica lateralmente a los procesos basioccipitales. La cresta exoccipital medial es una proyección ventral corta que se ubica en posición medial a la muesca yugular. Los cóndilos occipitales delimitan el foramen magnum látero-ventralmente, son de forma ovalada, y en vista lateral son marcadamente convexos. Ventro-medialmente, ambos cóndilos están separados por un canal intercondilar profundo. En la cría CNPMAMM 748, la superficie externa de los cóndilos está recubierta por un capuchón cartilaginoso grueso que forma la superficie de contacto con el atlas (Fig. 4.5); en crías en estados más avanzados de su desarrollo y en los adultos la persistencia de este capuchón cartilaginoso es evidente porque la superficie externa de los cóndilos presenta un patrón rugoso. El ancho máximo de los cóndilos occipitales representa $\sim 15 \%$ del ancho bizigomático del cráneo (Tabla 4.1). El foramen magnum es de contorno circular. Las fosas condiloidea dorsal y ventral son excavaciones poco profundas, pero claramente diferenciables, en el margen dorso-lateral y ventrolateral respectivamente de cada cóndilo occipital.

En vista ventral (Fig. 4.4; 4.6), sobre la superficie póstero-lateral de los procesos paraoccipitales y en posición posterior a la bulla timpánica, se observa una depresión de contorno aproximadamente circular que corresponde a la fosa para el seno posterior. El estilohial articula con los procesos paraoccipitales a través de una unión móvil y cartilaginosa. El foramen hipogloso, lugar de salida del nervio hipogloso (XII), se ubica entre la porción anterior de la cresta basioccipital y el proceso paraoccipital, y desde allí se desarrolla un canal profundo que marca el recorrido de este nervio en dirección posterior hasta la muesca yugular. Dicha muesca también marca el sitio de salida de la vena yugular y los nervios IX, X y XI. El exoccipital se extiende posteriormente sobrepasando el margen posterior del cóndilo occipital.

\section{ESCAMOSO}

El escamoso forma parte de la pared lateral del cráneo, la pared medial y posterior de la fosa temporal, el proceso zigomático y posglenoideo y la fosa glenoidea para la articulación temporo- 
mandibular.

En vista lateral (Fig. 4.2; 4.7) el escamoso está desarrollado en dirección dorso-ventral con respecto al plano sagital del cráneo (i.e. es más alto dorso-ventralmente que largo ánteroposteriormente), y está orientado en forma perpendicular al plano sagital del cráneo. Contacta anteriormente con el parietal, dorsalmente con el supraoccipital y póstero-dorsalmente con el exoccipital. La sutura parieto-escamosal se desarrolla dorso-ventralmente y es de forma sinusoidal, y, a diferencia de Balaena mysticetus y de Eubalaena japonica, no forma una cresta. La sutura escamoso-supraoccipital es convexa y forma parte de la cresta temporal, mientras que la sutura escamoso-exoccipital es recta y se desarrolla ántero-posteriormente. Lateralmente, el margen dorsal del escamoso forma una fuerte convexidad anterior, la cresta escamosa lateral. En vista lateral el desarrollo de esta cresta obstruye la visión de la pared posterior de la fosa temporal. Ventroanteriormente el escamoso forma el proceso zigomático y ventro-posteriormente el proceso postglenoideo; la superficie de unión entre ambos es cóncava y constituye la zona de articulación con la mandíbula, la fosa glenoidea. El proceso zigomático está orientado ántero-lateralmente, es corto, de contorno redondeado y se ubica en posición ventral y en proximidad al proceso postorbitario del frontal. El proceso postglenoideo está orientado ventro-posteriormente, es corto dorso-ventralmente y de contorno redondeado. En vista lateral dicho proceso se extiende en posición ventral al margen ventral del exoccipital. En vista posterior el proceso postglenoideo está orientado ventro-medialmente, y el margen lateral y medial son cóncavos. A diferencia de Balaena mysticetus, el proceso postglenoideo no está rotado en vista ventral y se orienta transversalmente con respecto al plano sagital del cráneo. En las crías, el proceso zigomático y postglenoideo están recubiertos por un capuchón cartilaginoso y el hueso tiene un aspecto muy esponjoso en este sector.

En vista dorsal (Fig. 4.1) la fosa temporal es más ancha transversalmente que larga ánteroposteriormente, con el margen anterior (formado por el proceso supraorbitario del frontal) y posterior (formado por el escamoso) cóncavo. La pared medial de la fosa temporal no es visible en vista dorsal.

En vista posterior (Fig. 4.3) el escamoso está ampliamente expuesto en la pared posterior del cráneo, en posición lateral al exoccipital (el ancho transversal del escamoso lateral al exoccipital representa más del 15\% de la distancia entre el plano sagital y el margen lateral del exoccipital).

En vista ventral (Fig. 4.6A) el escamoso forma la pared dorsal y anterior de la fosa periótica, el proceso falciforme y el meato auditivo externo. El proceso falciforme es una proyección en forma de placa, delgada transversalmente y orientada en dirección ántero-posterior. En posición medial al proceso falciforme se observa una escotadura que corresponde al foramen pseudoval. Dicho foramen permanece abierto posteriormente y es el lugar de salida de la rama mandibular del nervio trigémino $\left(V_{3}\right)$. El meato auditivo externo es una excavación profunda en el margen póstero-lateral del cráneo, 
en posición dorsal al proceso postglenoideo. En el extremo medial del meato, y sobre la superficie ventral, se observa una depresión de forma ovalada cuyo textura lisa difiere notoriamente del tejido óseo circundante, que corresponde al sitio de emplazamiento de la membrana timpánica (Capítulo 6, sección 6.3.2.3). La fosa glenoidea es ancha transversalmente, levemente cóncava y, en vista lateral, se ubica posteriormente al proceso postorbitario.

\section{PARIETAL}

El parietal forma parte de la pared lateral de la caja craneana y la pared medial de la fosa temporal.

En vista lateral (Fig. 4.2; 4.7) el parietal es más alto dorso-ventralmente que largo ánteroposteriormente y marcadamente cóncavo. Contacta anteriormente con el frontal, a través de la sutura coronal, posteriormente con el escamoso, dorsalmente con el supraoccipital y ventralmente con el aliesfenoides. La sutura coronal se desarrolla dorso-ventralmente y es de forma sinusoidal. La sutura parietal-supraoccipital protruye lateralmente y contribuye a la formación de la cresta temporal. La porción dorsal del parietal se proyecta anteriormente y se superpone sobre la base del proceso supraorbitario del frontal.

En vista dorsal (Fig. 4.1) el parietal está totalmente excluido del vértex del cráneo y sólo ocupa una posición lateral, condición ya presente en las crías.

En vista ventral (Fig. 4.4) el parietal está expuesto en la región orbito-temporal y delimita el canal óptico en su región póstero-medial.

\section{FRONTAL}

El frontal forma la región interorbitaria y los procesos supraorbitarios del frontal.

En vista dorsal (Fig. 4.1) el frontal está expuesto en el vértex del cráneo formando la región interorbitaria. En direción ántero-medial forma una proyección, el proceso narial del frontal, el cual separa sagitalmente la porción posterior de los nasales. Anteriormente, el frontal contacta con los nasales y con los premaxilares a través de una sutura aserrada, y posteriormente contacta con el supraoccipital a través de una sutura curvilínea. En dirección lateral contacta con los maxilares a través de una superficie definida por numerosas crestas y surcos. Desde el vértex craneal, el frontal desciende suavemente y forma el proceso supraorbitario, el cual presenta el margen anterior orientado anteriormente. Dicho proceso es grácil, más ancho transversalmente que largo ánteroposteriormente, y presenta una constricción ántero-posterior marcada aproximadamente a la mitad de su largo. El margen anterior es recto y contacta anteriormente con el proceso lateral del maxilar en toda su extensión, superponiéndose a este último en el extremo látero-ventral. El margen posterior es cóncavo y delimita anteriormente la fosa temporal. En vista lateral el proceso 
supraorbitario está desarrollado en dirección ventral y no está inclinado posteriormente como en Balaena mysticetus.

En vista lateral (Fig. 4.2; 4.7) la superficie dorsal del proceso supraorbitario es convexa y sobre la superficie dorsal presenta una cresta orbitotemporal baja. La posición de dicha cresta indica que el origen del músculo temporal es póstero-dorsal. La órbita se ubica en posición marcadamente ventral en el cráneo, a 2/3 de altura de la distancia entre el vértex del cráneo y la base del proceso postglenoideo, y está orientada en forma paralela al plano sagital del cráneo. El largo ánteroposterior de la órbita (LO) representa el $\sim 8 \%$ del ancho bizigomático (ABZ) (LO/ABZ; Tabla 4.1). La órbita es de contorno aproximadamente circular, está formada dorsalmente por el proceso supraorbitario del frontal, y ventralmente por el jugal, el maxilar y el proceso zigomático del escamoso. El margen dorsal es marcadamente cóncavo y está delimitado anteriormente por el proceso preorbitario y posteriormente por el proceso postorbitario. Dicho margen está cubierto en las crías por un capuchón cartilaginoso. El proceso preorbitario es más corto dorso-ventralmente que el postorbitario y este último está casi en contacto con el proceso zigomático del escamoso. El margen ventral está definido en su mayor parte por el yugal, el maxilar y el proceso zigomático.

En vista ventral (Fig. 4.4) sobre la superficie ventral del proceso supraorbitario del frontal, se desarrolla el canal óptico, por donde se transmite el nervio óptico (II) y otras estructuras blandas asociadas al ojo (capítulo 6). Medialmente dicho canal se desarrolla en la mitad posterior del proceso supraorbitario, donde es angosto y profundo. En dirección lateral el canal óptico es más ancho y menos profundo y ocupa casi todo el ancho ántero-posterior del proceso supraorbitario. El canal óptico está cerrado parcialmente en su porción medial por proyecciones del frontal y del parietal y en dirección lateral está cerrado por cartílago. La superficie dorsal de proceso supraorbitario presenta pequeños forámenes correspondientes a los forámenes frontales. Sobre la superficie ventral del frontal, en posición medial al proceso supraorbitario, hay dos fosas profundas y simétricas.

\section{ALIESFENOIDES}

El aliesfenoides está ampliamente expuesto, en vista ventral, en la pared orbitotemporal del cráneo, y forma parte del extremo póstero-medial del canal óptico (Fig. 4.4). Es de forma cuadrangular, con una proyección lateral corta que se superpone al parietal y alcanza el margen lateral del cráneo. El aliesfenoides contacta anteriormente con el parietal y el frontal, medialmente con el palatino y el pterigoides, posteriormente con el escamoso y lateralmente con el parietal y el escamoso, y se fusiona con el basiesfenoides en estadios muy tempranos del desarrollo.

En vista lateral, una pequeña porción del aliesfenoides es visible en la porción ventral de la pared lateral del cráneo, contactando con el frontal y el parietal a través de una sutura aserrada. 


\section{BASIOCCIPITAL}

El basioccipital se ubica en la región ventro-posterior del cráneo y está cubierto ventralmente por los palatinos, los pterigoides y el vómer (Fig. 4.4). Está formado por dos porciones: una horizontal, correspondiente a la porción basilar que forma parte del piso de la caja craneana, y otra látero-ventral que corresponde a las crestas basioccipitales. La porción basilar es marcadamente cóncava y contacta, anteriormente, con el basiesfenoides y, posteriormente, con el exoccipital. La sutura basioccipital-basiesfenoides está completamente cerrada (estadio SR4).

En vista posterior (Fig. 4.3) la cresta basioccipital se proyecta ventro-lateralmente en posición medial a la muesca yugular. En vista ventral, la cresta basioccipital contacta anteriormente con la lámina media del pterigoides y látero-posteriormente con el exoccipital (Fig. 4.6). La cresta basioccipital es bulbosa, ancha transversalmente y alta dorso-ventralmente, y de contorno romo. La superficie póstero-medial es levemente cóncava y rugosa; esta región es el sitio de inserción de la musculatura flexora del cuello. En vista ventral ambas crestas basioccipitales divergen posteriormente.

\section{BASIESFENOIDES-PREESFENOIDES}

El basiesfenoides se ubica en la porción póstero-ventral de la caja craneana. Contacta lateralmente con la lámina media del pterigoides, posteriormente con el basioccipital y anteriormente con el preesfenoides, a través de una sutura abierta que forma la fisura basiesfenoidespreesfenoides. Esta fisura está ocupada por cartílago en las crías (Fig. 4.5) y posiblemente también en los adultos ya que la fisura permanece abierta.

En vista dorsal la superficie dorso-medial del basiesfenoides presenta una depresión marcada correspondiente a la silla turca, donde apoya la hipófisis (Fig. 4.5). En cada margen póstero-lateral se observan sendas acanaladuras que corresponderían a la salida de la arteria carótida interna.

El preesfenoides es de forma triangular y contacta posteriormente con el basiesfenoides y lateralmente con el frontal. Medialmente, delimita la fisura óptica.

La presencia del orbitoesfenoides en el canal óptico es dificil de determinar ya que se fusiona muy tempranamente al frontal y al preesfenoides.

\section{VÓMER}

El vómer es el único hueso impar del rostro y se desarrolla ántero-posteriormente a lo largo de la línea sagital del cráneo (Fig. 4.4). Consiste en dos partes, una porción sagital y una porción horizontal. La porción sagital está formada por dos láminas laterales que se unen ventralmente y forman un surco, correspondiente al canal mesorostral. Sobre la pared ventral del canal mesorostral se apoya el cartílago mesorostral, el cual permanece cartilaginoso aún en estado adulto. En vista 
dorsal el canal mesorostral es angosto en su porción anterior y está cerrado dorsalmente, aunque en forma parcial, por los premaxilares. En dirección posterior el canal es más ancho y permanece abierto dorsalmente formando parte del piso de la fosa nasal.

En vista ventral (Fig. 4.4) el vómer tiene una leve exposición en la región palatal y forma, junto con el maxilar, una quilla que se desarrolla a lo largo de la línea media del rostro. La porción posterior del vómer se ubica ventral al basiesfenoides, cubriendo la sutura basiesfenoidesbasioccipital, y dorsal a los palatinos, formando la pared ventro-lateral del pasaje nasal y la pared dorsal de las narinas internas. Debido a la extensión posterior de los palatinos, el margen pósteroventral del vómer no es visible en vista ventral. Sobre la superficie ventro-posterior del vómer se desarrolla la cresta vomerina, la cual es pronunciada y separa el pasaje nasal derecho e izquierdo. La porción horizontal o alas del vómer son estructuras pares en la porción póstero-lateral del vómer.

\section{PALATINO}

El palatino se ubica en la región póstero-ventral de la caja craneana y debido a su extensión posterior cubre casi toda la superficie ventral de los pterigoides (incluyendo los hamulus pterigoideos) y la región posterior del vómer, una característica que distingue a los balénidos de otros misticetos (Fig. 4.4). El palatino forma parte de la región palatal del cráneo y delimita la porción póstero-ventral del pasaje nasal.

En vista ventral (Fig. 4.4)el palatino es de contorno cuadrangular. El margen anterior contacta con el maxilar definiendo una sutura en forma de " $\mathrm{V}$ " invertida, el margen posterior es redondeado y forma parte del margen anterior de las narinas internas. La superficie ventral es casi plana, a diferencia de la superficie dorsal que es levemente cóncava.

\section{PTERIGOIDES}

El pterigoides se ubica en la región póstero-ventral de la caja craneana y contacta ventralmente con el palatino, medialmente con el vómer y el basiesfenoides, anteriormente con el aliesfenoides, lateralmente con el escamoso y el exoccipital y posteriormente con el basioccipital. En los cetáceos la configuración de este hueso está afectada por el desarrollo del seno pterigoideo, una extensión de la cavidad del oído medio, que es una característica exclusiva de este grupo. Debido al desarrollo de este seno, el pterigoides está dividido en una serie de láminas: la media, la lateral, la dorsal y la ventral.

En vista ventral (Fig. 4.6). la lámina media se desarrolla ántero-posteriormente y contacta medialmente con el vómer y el basiesfenoides. La lámina lateral se extiende en dirección mediolateral y contacta lateralmente con el escamoso y anteriormente con el aliesfenoides. La lámina dorsal está desarrollada en dirección dorso-ventral y está poco extendida en dirección posterior; 
como consecuencia una porción del aliesfenoides es visible en la pared dorsal de la fosa pterigoidea. La lámina ventral es corta ántero-posteriormente y junto con el hamulus pterigoideos cubren ventralmente la fosa pterigoidea. El hamulus pterigoideos es una placa delgada, levemente más ancha tranversalmente que larga ántero-posteriormente, y en vista ventral está orientado medialmente. La fosa pterigoidea se desarrolla como una excavación profunda en dirección dorsoventral sobre la lámina dorsal, ventral y lateral del pterigoides y se extiende anteriormente hasta el nivel del margen anterior del foramen pseudoval. Póstero-medialmente en la lámina dorsal se ubica el foramen carotídeo ventral, el cual es de contorno circular y bien conspicuo (Fig. 4.6b).

\section{NASAL}

El nasal se ubica en la región póstero-dorsal del rostro y cubre parcialmente la fosa nasal. Es de forma cuadrangular, más largo ántero-posteriormente que ancho transversalmente. El largo del nasal representa menos del 25\% del ancho bizigomático, a diferencia de Balaena mysticetus donde los nasales son relativamente más largos (el largo es más del 25\% del ancho bizigomático) (Tabla 4.1). La superficie dorsal de los nasales es plana. La sutura entre ambos nasales en la línea media es recta. El margen anterior de los nasales es marcadamente cóncavo y en forma de "W" (Fig. 4.1). El nasal contacta posteriormente con el proceso narial del frontal a través de una sutura aserrada (estadio $\mathrm{SR}_{3}$ ). Dicho proceso separa la porción posterior de ambos nasales a lo largo de la línea media. Lateralmente el nasal contacta con el premaxilar a través de una sutura sin fusionar (estadio SR3). En sección sagital se observa que el nasal es alto dorso-ventralmente, y contacta ventralmente con el maxilar (Fig. 4.5).

\section{ETMOIDES}

El etmoide comprende 3 partes: el ectecmoide (dos proyecciones laterales) y la placa cribiforme. El centro de osificación del mesetmoide no fue identificado en el ejemplar neonato y su presencia en los adultos no pudo verificarse; la ausencia del mesetmoides parece ser una condición común a los cetáceos (Ichishima, 2011). El ectecmoides se fusiona tempranamente a la porción posterior del vómer, si bien en las crías aún se observa la línea de sutura entre ambos huesos. En sección sagital, cuando el cartílago mesorostral es removido, se observa la cámara nasal, la cual alberga los etmoturbinales (Fig. 4.5). Se identificaron tres etmoturbinales que corresponden topográficamente al I, II y III identificados en Balaenoptera physalus (Schulte, 1916), siendo el I el más grande de la serie. La porción póstero-dorsal de la cámara nasal está formada por la placa cribiforme. La placa cribiforme es una lámina pequeña que separa la fosa craneal anterior de la cámara nasal y está perforada por numerosos forámenes que transmiten el nervio olfatorio (I). 


\section{PREMAXILAR}

El premaxilar es un hueso par que forma parte de la región rostral del cráneo y de la fosa nasal.

En vista lateral (Fig. 4.2) el premaxilar está marcadamente arqueado en dirección dorsoventral y se ubica dorsalmente al maxilar. A diferencia de Balaena mysticetus, el arco formado por el premaxilar en el rostro no es continuo, en su lugar la porción más posterior es relativamente plana y se curva en mayor medida en dirección anterior. El premaxilar se extiende anteriormente sobrepasando el margen anterior del maxilar.

En vista dorsal (Fig. 4.1) el premaxilar es angosto en su extremo anterior, donde está casi en contacto en su línea media con el otro premaxilar. En este sector contacta lateralmente con el maxilar y medialmente con el vómer. En dirección póstero-dorsal la superficie medial está excavada y forma la superficie látero-ventral de la fosa nasal, la cual es de contorno oval. Hacia el vértex, el premaxilar es más angosto y forma el proceso ascendente del premaxilar. Dicho proceso contacta posteriormente con el frontal a través de una sutura aserrada (aunque en algunos ejemplares de $E$. australis el proceso ascendente del premaxilar no contacta con el frontal), medialmente con el nasal, y lateralmente con el maxilar; en ambos casos la sutura entre los huesos es recta.

En vista ventral, el premaxilar tiene una exposición muy corta en la región palatal del rostro ya que está cubierto por el maxilar ventralmente.

\section{MAXILAR}

El maxilar, junto con el premaxilar, forma parte de la región rostral del cráneo.

En vista lateral (Fig. 4.2) el maxilar está fuertemente arqueado en dirección dorso-ventral y, debido a la compresión transversal que presenta la superficie dorsal, la superficie ventral está ampliamente expuesta en vista lateral.

En vista dorsal (Fig. 4.1) la superficie dorsal del maxilar está comprimida transversalmente y como resultado es más alto dorso-ventralmente que ancho látero-medialmente. Los márgenes laterales del maxilar son rectos y en dirección póstero-lateral forma la muesca antorbital. En su porción anterior el maxilar es angosto y se ensancha en dirección posterior donde forma, láteroventralmente, el proceso lateral del maxilar y, póstero-dorsalmente, el proceso ascendente del maxilar. El proceso lateral del maxilar es de contorno triangular, ancho medialmente y angosto en dirección lateral. El proceso lateral del maxilar está solapado parcialmente a lo largo de su margen posterior, por el proceso supraorbitario del frontal. En vista lateral el extremo lateral del proceso lateral del maxilar se ubica en posición anterior al proceso supraorbitario del frontal, a diferencia de Balaena mysticetus donde este se ubica por debajo. En Eubalaena australis así como también en otros balénidos actuales, debido a la extensión anterior del supraoccipital, el proceso ascendente del 
maxilar está reducido. Posteriormente sobre la superficie dorsal del maxilar se ubican los forámenes infraorbitarios dorsales, que corresponden al lugar de salida de la rama maxilar del nervio trigémino (V2). Estos forámenes son numerosos y se disponen, algunas sobre la superficie póstero-dorsal, y otras sobre la superficie póstero-ventral del maxilar (Fig. 4.2).

En vista ventral (Fig. 4.4) el maxilar forma la mayor parte de la región palatal del cráneo. Se ubica en posición ventral al premaxilar, al cual cubre totalmente, y junto al vómer forma una quilla que se desarrolla a lo largo de la línea sagital del paladar. Sobre la superficie ventral del maxilar se ubican los forámenes y surcos nutricios por donde corren los vasos sanguíneos que irrigan las barbas. Los forámenes se ubican principalmente en la región posterior del maxilar y presentan una disposición irregular, mientras que los surcos o canales nutricios se disponen en forma paralela al eje sagital del cráneo, sobre la superficie lateral. En algunos ejemplares estos surcos confluyen en un único surco longitudinal. Póstero-medialmente, el maxilar contacta con el palatino a través de una sutura en forma de "V" invertida. Lateralmente a dicha sutura, se desarrolla una escotadura profunda y ancha que corresponde a la ventana maxilar. La placa infraorbitaria del maxilar, se ubica en posición lateral a la ventana maxilar y ventralmente al proceso supraorbitario del frontal. En posición dorsal a la placa infraorbitaria la superficie del maxilar es levemente cóncava y presenta numerosos canales. Este sector está ocupado in vivo por una masa de vasos sanguíneos que se desarrollan en dirección anterior y que se distribuyen a lo largo de la superficie ventral del maxilar para irrigar las barbas.

\section{PASAJE NASAL}

El pasaje nasal se define como todo el corredor de aire entre el blowhole (apertura blanda en la piel del aparato respiratorio) y las narinas óseas internas (apertura interna o posterior del pasaje nasal formada por el pterigoides y el vómer). El pasaje nasal está asociado a una serie de estructuras blandas que se describirán en detalle en el capítulo 6 (sección 6.1.1.1), mientras que las estructuras óseas se describirán a continuación.

La fosa nasal es una excavación profunda en la superficie dorsal del rostro, de contorno oval, que se ubica entre la mitad del rostro (considerado desde la base del rostro a nivel de las muescas antorbitales y el extremo más anterior del rostro) y el margen anterior de los nasales (Fig. 4.1). Dicha fosa está formada látero-ventralmente por los premaxilares y maxilares, ventro-medialmente por el vómer, y alberga los músculos nasales, los cartílagos nasales y las válvulas nasales (capítulo 6). La fosa nasal está dividida en su línea media por el septo nasal (formado por el vómer y el cartílago mesorostral), el cual separa el pasaje nasal derecho e izquierdo (Fig. 4.5). El cartílago mesorostral se extiende ántero-posteriormente a lo largo de la línea media del cráneo como una estructura cilíndrica que se angosta en dirección anterior, y llena el canal mesorostral formado por el vómer y 
los premaxilares. Es probable que el cartílago mesorostral permanezca cartilaginoso en los adultos, ya que no hay evidencia de una estructura mesorostral osificada en los esqueletos preparados y depositados en colecciones. La fosa nasal continúa póstero-ventralmente en el pasaje nasal óseo y par formado por los maxilares, los premaxilares, el vómer, los palatinos y los pterigoides. Pósteroventralmente dentro del pasaje nasal, en posición ventral al frontal y al nasal, se ubica la cámara nasal. La pared póstero-dorsal de la cámara nasal está formada por la placa cribiforme. Pósteroventralmente el pasaje nasal óseo termina en las narinas internas óseas las cuales están delimitadas por los palatinos y los pterigoides látero-ventralmente y por el vómer dorsalmente (Fig. 4.5).

Cartílagos nasales: dentro de la cavidad nasal hay un complejo de dos pares de cartílagos (uno por cada orificio nasal) que corresponden al cartílago nasal medial y lateral, donde se insertan los músculos nasales (capítulo 6 sección 6.2).

\section{PERIÓTICO}

Debido a que el periótico está altamente modificado en los cetáceos, se procederá a describir en primer término cada estructura dentro de un contexto general para los cetáceos y luego se hará hincapié en las peculiaridades de dicha estructura en Eubalaena australis. Las medidas del periótico y de la bulla timpánica se presentan en la Tabla 4.2.

\section{Vista ventral (Fig. 4.8A).}

Proceso anterior: el proceso anterior es, en su estado elongado, una estructura neomórfica de muchos "arqueocetos" y de los cetáceos modernos o Neoceti. Se define como aquella estructura anterior a una línea transversal a través del margen anterior de la pars coclearis. Los estudios embriológicos indican que el proceso anterior es una extensión anterior del tegmen timpánico de los mamíferos no cetáceos (Mead \& Fordyce, 2009). En Eubalaena australis el proceso anterior es aproximadamente del mismo largo que la pars coclearis o levemente mayor y el extremo anterior es de contorno redondeado. En posición lateral al proceso anterior se encuentra un surco oblicuo que corresponde al surco ántero-externo.

\section{Proyección lateral de la tuberosidad ventrolateral del proceso anterior: es una} estructura típica de los misticetos que consiste en una expansión lateral de la tuberosidad ventrolateral del proceso anterior del periótico, ubicada en posición lateral a la fosa para el martillo (Geisler \& Luo, 1996). En los adultos de Eubalaena australis, como en otros balénidos, la proyección lateral es de contorno aproximadamente triangular y está hipertrofiada.

Pedicelo anterior y posterior: en los misticetos el periótico está unido a la bulla timpánica a través de dos conexiones óseas, correspondientes al pedicelo anterior y al posterior. En Eubalaena australis el pedicelo anterior se ubica en la superficie ventral del proceso anterior mientras que el 
pedicelo posterior se ubica sobre la superficie ventro-medial del proceso posterior compuesto.

Pars coclearis: es una estructura que contiene la cóclea, el meato auditivo interno y estructuras asociadas dentro del meato, la apertura para el acueducto coclear o foramen perilinfático y el acueducto vestibular o foramen endolinfático. En Eubalaena australis la pars coclearis es globosa: más alta dorso-ventralmente que ancha transversalmente. En posición lateral a la fenestra coclear y medial a la fosa para el músculo estapedial se desarrolla el proceso caudal timpánico, el cual está orientado póstero-ventralmente. Dicho proceso es elongado, de contorno triangular y forma parte de la pared ventral de la fosa para el músculo estapedial. La superficie ventral de la pars coclearis o promontorio es convexa, a diferencia de lo que ocurre en los balenoptéridos donde es plana. En vista ventral el surco promontorial se ubica en la cara medial de la pars coclearis y se desarrolla ántero-medialmente. Las estructuras que alberga la pars coclearis (e.i. la cóclea y los canales semicirculares) serán descriptas en el Capítulo 6 (sección 6.3.2)

Fosa para el martillo: en algunos misticetos la cabeza del martillo articula con el petroso a través de una pequeña fosa, la fosa para el martillo. Dicha fosa se ubica en la superficie ventral del proceso anterior, en posición medial a la proyección lateral de la tuberosidad ventro-lateral. En Eubalaena australis dicha fosa es indistinguible y sólo se detecta al tacto.

Hiatus fallopii: esta incisura es la apertura anterior del canal petrosal y representa la salida del nervio petrosal o rama palatina del nervio facial (VII), que inerva el ganglio pterigo-palatino. En Eubalaena australis se ubica en la superficie ventral del promontorio, en posición medial a un surco entre el proceso anterior y el promontorio, condición similar a la observada en los mamíferos terrestres (Cifelli, 1982).

Fosa para el músculo tensor timpánico: El músculo tensor timpánico es muy pequeño en los Neoceti a diferencia de lo que ocurre en la mayoría de los mamíferos, por lo cual la identificación de la fosa donde se inserta este músculo ha sido muy confusa en la literatura de los cetáceos. En muchos misticetos (i.e. en el taxón extinto y basal Eomysticetus whitmorei y en la mayoría de los balenoptéridos), si bien este músculo está presente, no deja una impronta en el periótico. En Eubalaena australis el origen del músculo tensor timpánico se identifica en una depresión delimitada por una cresta baja, en posición medial al proceso anterior, mientras que la inserción es sobre el martillo. La contracción de este músculo tira del martillo, lo cual ocasiona la tensión de la membrana timpánica.

Proceso posterior compuesto: en los misticetos la mayor parte de la superficie ventral del proceso posterior del periótico está cubierta por el proceso posterior del timpánico, y forman el proceso posterior compuesto (Kasuya, 1973; Geisler \& Luo 1996). Estas dos estructuras están totalmente fusionadas en los adultos. In situ el proceso posterior compuesto está orientado formando un ángulo recto con el eje longitudinal del proceso anterior. El proceso es de forma 
cilíndrica y es más alto dorso-ventralmente en comparación con los balenoptéridos. El proceso posterior se fusiona completamente al escamoso a lo largo de su superficie dorsal.

Fenestra coclear (fenestra rotunda=ventana coclear=ventana redonda): se ubica en el extremo póstero-lateral de la pars coclearis y constituye la vía de conexión entre la cavidad del oído medio y el oído interno. En Eubalaena australis la fenestra coclear es grande y de forma ovalada, más alta dorso-ventralmente que ancha transversalmente. Como en otros balénidos actuales, la fenestra coclear está ampliamente separada de foramen perilinfático por un septo óseo (a diferencia de lo que ocurre en Eschrichtius robustus donde ambos forámenes confluyen).

\section{Vista dorsal (Fig. 4.8B)}

Proceso piramidal: La unión del tegmen timpánico y la pars coclearis forma una proyección denominada proceso piramidal, que en Eubalaena australis no es tan pronunciada como en Balaena mysticetus.

\section{Vista dorsomedial (Fig. 4.8C)}

Meato auditivo interno (sensu lato): El meato auditivo interno sensu lato contiene el canal para el nervio vestibulococlear (VIII) y para el nervio facial (VII). En Eubalaena australis el meato auditivo interno está separado por un septo óseo transversal, la cresta transversa, en dos forámenes: uno correspondiente a la salida del nervio vestibulococlear (VIII) o meato auditivo interno sensu estricto y otro correspondiente a la apertura interna o dorsal del canal facial (VII). El foramen para la salida del nervio VIII es de mayor tamaño que el foramen para el nervio VII; esta condición difiere de la observada en Balaena mysticetus donde la apertura dorsal del canal facial es de mayor tamaño.

Foramen endolinfático o acueducto vestibular: constituye la apertura del acueducto vestibular, el cual lleva el ducto endolinfático. En Eubalaena australis el foramen endolinfático se ubica posteriormente al meato auditivo interno y dorsalmente al foramen perilinfático. Es de contorno oval y de mayor tamaño que el foramen perilinfático.

Foramen perilinfático o acueducto coclear: constituye la apertura del acueducto coclear, el cual contiene el ducto perilinfático. En Eubalaena australis el foramen perilinfático es pequeño y se ubica posteriormente al meato auditivo interno sensu estricto. A diferencia de Balaena mysticetus, el meato auditivo interno sensu lato y el foramen perilinfático están alineados ántero-posteriormente

Fosa estilomastoidea: La fosa estilomastoidea es una depresión cuadrangular en la superficie póstero-dorsal de la pars coclearis, dorsal a la fosa estapedial. En Eubalaena australis dicha fosa está bien desarrollada y está confinada a la pars coclearis, sin extenderse en el proceso posterior compuesto. Fraser \& Purves (1960) indican que esta fosa es ocupada por parte del seno peribullar o 
del seno posterior. La disección de esta fosa muestra que in vivo está ocupada por un tejido de tipo fibro-cartilaginoso y no se observó la presencia del seno peribullar.

\section{Vista lateral (Fig. 4.8D)}

Fenestra oval (=ventana o fenestra vestibular=ventana oval): la fenestra oval se ubica ántero-lateralmente a la fenestra coclear y lateral de la pars coclearis, y constituye el sitio de acomodación del estribo. En Eubalaena australis la fenestra oval es de contorno circular y más pequeña que la fenestra coclear.

Fosa para el músculo estapedial: en Eubalaena australis la fosa para el músculo estapedial se ubica en posición inmediatamente posterior a la fenestra oval, en posición lateral al surco o canal facial, entre la pars coclearis y el proceso posterior. La fosa es grande, profunda y ovalada, y se continúa en la superficie dorsal del proceso caudal timpánico.

Canal facial: es el canal encargado de transmitir el nervio facial (VII) dentro del periótico. En mamíferos no cetáceos, el canal facial comprende el recorrido del nervio facial desde el meato auditivo interno (dorsalmente) hasta el foramen estilomastoideo (ventralmente) en la región temporal del cráneo (Mead \& Fordyce, 2009). En Eubalaena australis como en otros cetáceos, la apertura dorsal del canal facial se ubica en el area nervus facialis del meato auditivo interno mientras que la apertura ventral del canal facial se produce en el oído medio, en posición lateral a la fenestra oval (ya que el foramen estilomastoideo está ausente en los Neoceti). Desde este punto el nervio facial se transmite a través del surco facial, el cual es profundo y se ubica en posición medial a la fosa para el músculo estapedial, y continua póstero-lateralmente en la superficie ventral del proceso posterior compuesto.

\section{BULLA TIMPÁNICA}

La bulla timpánica alberga la cavidad timpánica donde se encuentran los huesecillos del oído medio.

En vista dorsal (Fig. 4.9A) el margen ántero-medial de la bulla es rectangular con el extremo redondeado. El margen medial es marcadamente convexo. El involucro está expandido dorsoventralmente, lo cual le otorga a la cara ventral de la bulla un aspecto inflado, y presenta numerosas y bien definidas crestas transversales en la superficie dorsal. La cresta del involucro se extiende hacia el margen medial, pero no confluye con la cresta medial o principal de la bulla. El extremo anterior de la cresta del involucro es posterior al margen anterior de la bulla timpánica. La superficie dorsolateral del involucro forma un arco continuo, sin mediar ningún escalón que separe la superficie en una porción anterior y en otra posterior (como lo observado por ejemplo en Caperea marginata). La apertura del tubo de Eustaquio es una escotadura ancha y profunda que se extiende medialmente en 
el extremo anterior del involucro. El proceso cónico es delgado, corto y de contorno redondeado (Fig. 4.9D).

En vista ventral (Fig. 4.9B) la superficie ventral de la bulla está comprimida dorsoventralmente, y presenta un surco longitudinal que se desarrolla ántero-posteriormente. El surco lateral es profundo, se orienta ántero-ventralmente y está ubicado en los 2/3 posteriores del largo ántero-posterior de la bulla. La fisura sigmoidea es corta y poco profunda.

En vista anterior (Fig. 4.9C) es evidente la compresión dorso-ventral de la bulla y el aspecto convexo del involucro.

En vista lateral (Fig. 4.9D) el surco lateral y la fisura sigmoidea definen dos lóbulos, uno anterior y otro posterior. El lóbulo anterior es más corto que el lóbulo posterior y, sobre su superficie ventro-lateral, se encuentra la base del pedicelo anterior para la articulación con el periótico. La base del pedicelo posterior se ubica posteriormente, en el margen ventro-lateral del lóbulo posterior. El proceso sigmoideo se ubica entre el surco lateral y la fisura sigmoidea y se proyecta láteroventralmente. Es robusto y ancho transversalmente.

En vista medial (Fig. 4.9E), la cresta medial de la bulla timpánica se desarrolla ánteroposteriormente en la cara medial de la bulla y es de contorno convexo.

El anillo timpánico es el sitio de inserción de la membrana timpánica en la superficie externa de la bulla. Está formado por el proceso sigmoideo, el proceso cónico y el pedicelo posterior de la bulla timpánica. Internamente, el sitio de inserción de la membrana timpánica está formado por un surco profundo y semicircular, el surco timpánico, que se extiende desde el extremo posterior del proceso sigmoideo hasta el extremo posterior del proceso cónico.

\section{MANDÍBULA}

En vista dorsal el cuerpo mandibular está fuertemente arqueado en dirección lateral. En sección transversal, la cara lateral es marcadamente convexa, a diferencia de la cara medial que es plana. El tercio anterior del cuerpo mandibular presenta una torsión en dirección medial; como resultado la cara medial está orientada dorsalmente mientras que la cara lateral está orientada ventralmente. La porción posterior de la rama mandibular presenta una trayectoria curva, a diferencia de los balenoptéridos donde este sector es de forma sigmoidal.

En vista lateral (Fig. 4.2) la altura dorso-ventral de la mandíbula es aproximadamente constante a todo su largo. En posición anterior al proceso coronoides se observan varios (5-6) forámenes mentonianas orientados anteriormente a lo largo del margen dorsal del cuerpo mandibular. El cuello mandibular se ubica entre el margen posterior del proceso coronoides y el extremo anterior del cóndilo mandibular. El margen dorsal del cuello mandibular es cóncavo. La superficie ventral al proceso coronoides es cóncava, y forma una fosa para la inserción de uno de los 
músculos masetéricos. El cóndilo mandibular está ubicado póstero-dorsalmente al proceso coronoides y forma un ángulo obtuso con el eje longitudinal del cuerpo mandibular. La superficie de articulación está orientada dorsalmente.

En vista medial el extremo anterior del cuerpo mandibular presenta una serie de estructuras vinculadas con tejidos blandos de la sínfisis mandibular: el surco alveolar y el surco y la superficie sinfisial. El surco alveolar es un surco que corre ántero-posteriormente en el margen dorsal del cuerpo mandibular. El surco sinfisial es un surco más pequeño y poco profundo que se desarrolla ántero-posteriormente en el margen ventral, sin alcanzar el extremo anterior de la mandíbula. La superficie sinfisial es plana y presenta algunas crestas y surcos. En el margen ventral del cuerpo mandibular se observa un surco, el surco milohioideo, que se extiende, posteriormente, desde el margen posterior del foramen mandibular hasta desaparecer antes del extremo anterior de la mandíbula. El foramen mandibular se ubica en el extremo póstero-dorsal de la rama mandibular, en posición posterior al proceso coronoides. Dicho foramen está desarrollado dorso-ventralmente y está orientado en forma oblicua con respecto al plano horizontal del cuerpo mandibular. El margen anterior es semicircular y se ubica posterior al cóndilo mandibular. Ántero-dorsalmente al foramen mandibular, se desarrolla en dirección medial una elevación redondeada que corresponde a la elevación postcoronoidea (sensu Kimura, 2002). El proceso angular está reducido en los balénidos y fusionado al cóndilo mandibular. El proceso coronoides está reducido y sólo se conserva como una cresta baja y ancha ántero-posteriormente en la superficie dorsal de la rama mandibular (Fig. 4.2; 4.10).

\title{
4.3 Balénidos del Mioceno de Patagonia
}

\subsubsection{Balénido del Mioceno Temprano (Fm. Gaiman): Morenocetus parvus}

\author{
SISTEMÁTICA PALEONTOLÓGICA \\ Orden CETACEA Brisson, 1762 \\ Rango no determinado NEOCETI Fordyce \& Muizon, 2001 \\ Suborden MYSTICETI Gray, 1864 Sensu Cope, 1869 \\ Rango no determinado CHAEOMYSTICETI Mitchell, 1989 \\ Familia BALAENIDAE Gray, 1825
}

Morenocetus Cabrera, 1926

Especie tipo y única conocida por monotipia-Morenocetus parvus Cabrera, 1926

Diagnosis-igual a la de la especie tipo y única conocida.

Morenocetus parvus Cabrera, 1926 
Diagnosis enmendada-Balénido caracterizado por la siguiente combinación única de caracteres: fenestra coclear en forma de riñón $\left(^{*}\right)$; proceso supraorbitario del frontal no inclinado pósteroventralmente en vista lateral; extremo anterior del proceso supraorbitario del frontal orientado posteriormente; proceso supraorbitario del frontal desarrollado principalmente en dirección transversal con una moderada inclinación ventral; proceso supraorbitario del frontal corto transversalmente; nasales no separados posteriormente a lo largo de la línea sagital por el proceso narial del frontal; pared posterior de la fosa temporal plana; escamoso orientado en forma perpendicular al eje sagital del cráneo; cresta escamosa lateral bien desarrollada y sin obliterar la visión lateral del escamoso y del parietal; proceso zigomático del escamoso en posición ventral al proceso postorbital y separado por una distancia dorso-ventral amplia; pequeña exposición del escamoso en posición lateral al exoccipital; ausencia de tubérculo nucal en la unión de la sutura parietal-escamoso-supraoccipital; sutura parieto-escamosal no forma una cresta; proceso postglenoideo orientado transversalmente con respecto al eje sagital del cráneo en vista ventral; fosa glenoidea en posición posterior al proceso postorbital; fosa pterigoidea extendida anteriormente al foramen pseudoval; márgenes laterales del supraoccipital rectos; proceso anterior más corto que la pars coclearis; extremo posterior del exoccipital extendido posteriormente a los cóndilos occipitales; ausencia de proceso piramidal; proyección lateral de la tuberosidad ventro-lateral del proceso anterior poco desarrollada y bulbosa; proceso posterior compuesto del periótico orientado pósterolateralmente con respecto el eje longitudinal del proceso anterior; apertura dorsal o interna del canal facial de menor tamaño que el meato auditivo interno (sensu stricto); y surco facial en el proceso posterior compuesto del timpánico poco profundo y definido por bordes anteriores y posteriores. *autapomorfías.

Holotipo-MLP 5-11, cráneo incompleto donde se preservó gran parte de la caja craneana con ambos perióticos articulados y falta por completo la región rostral. (Fig. 4.13-4-18; Tabla 4.3; 4.4).

Espécimen referido-MLP 5-15, cráneo incompleto con periótico izquierdo articulado, sin región rostral (Fig. 4.19; Tabla 4.3). En el caso del ejemplar MLP 5-21, correspondiente a dos ramas mandibulares originalmente referidas por Cabrera (1926) a esta especie, las mismas fueron sometidas a un estudio analítico del contenido de nitrógeno y de colágeno. Este estudio permitió determinar que presentan un contenido de colágeno muy elevado en comparación con el ejemplar holotipo, con lo cual estos materiales no son asignables a una edad Miocena temprana.

Localidad tipo y procedencia estratigráfica-Todos los materiales referidos a Morenocetus parvus fueron colectado en la localidad de Cerro Castillo, Barranca Sur en el Valle inferior del Río Chubut, provincia de Chubut, Argentina (Cabrera, 1926; P: 364) (Fig. 4.11). La localidad de Cerro Castillo corresponde a una elevación de terreno que representa la exposición de sedimentos marinos terciarios referidos por Cabrera (1926) como "Formación Patagónica marina". Estos sedimentos 
corresponden a una unidad informalmente conocida en la literatura del siglo XIX como Patagoniano o Patagoniense (D'Orbigny, 1842; Darwin, 1846; Ameghino, 1906; Frenguelli, 1927; 1935; Simpson, 1935; Feruglio, 1949). Las sedimentitas del Patagoniano que afloran en el valle inferior del Río Chubut fueron asignadas a la Formación Gaiman (Mioceno temprano) (Mendia \& Bayarsky, 1981) (Fig. 4.12). Desafortunadamente Cabrera (1926) no precisa el nivel estratigráfico exacto en el cual estos materiales fueron colectados.

\section{DESCRIPCIÓN}

Estado de preservación de los materiales: El ejemplar MLP 5-11 consiste en un cráneo bien preservado donde falta la región rostral; el proceso supraorbitario derecho del frontal (está roto a 180 mm aproximadamente del plano sagital del cráneo); los yugales; el proceso zigomático y postglenoideo derecho; los palatinos; gran parte de los pterigoides y del preesfenoides, la porción anterior del vómer, el aliesfenoides derecho y las bullas timpánicas. El supraoccipital presenta una pequeña porción faltante por delante del foramen magnum. La superficie ventral del cráneo está deteriorada en su mayor parte, sin embargo la región ótica presenta ambos perióticos asociados a la caja craneana. El periótico derecho está incompleto en la región coclear a diferencia del izquierdo que está completo. El ejemplar MLP 5-15 presenta un estado de conservación similar al holotipo, con excepción del proceso supraorbitario izquierdo que está incompleto en su porción lateral y del proceso zigomático izquierdo que está completo.

El grado de fusión de las suturas entre el basioccipital/exoccipital y supraoccipital/exoccipital en ambos ejemplares corresponde al estadio SR4.

Características generales del cráneo: una de las características más llamativas del cráneo es su pequeño tamaño: el ancho bizigomático es de $+560 \mathrm{~mm}$ (Tabla 4.3), el cual corresponde a un $\sim 25 \%$ del ancho bizigomático del cráneo de un balénido actual, como por ejemplo Eubalaena o Balaena. En vista dorsal, el escudo occipital es elongado ántero-posteriormente, de forma triangular con el margen anterior redondeado y se extiende anteriormente sobrepasando la órbita y excluyendo a los parietales de la vista dorsal del cráneo. Las órbitas se ubican dorso-lateralmente en el cráneo. Los procesos supraorbitarios del frontal descienden suavemente desde el vértex craneal, son cortos transversalmente y anchos ántero-posteriormente, están desarrollados principalmente en el plano transversal y están levemente orientados en dirección póstero-ventral. La porción ántero-dorsal del parietal está sobreimpuesta a la porción póstero-dorsal del frontal, y se extiende anteriormente hasta el nivel del margen anterior del escudo occipital. La cresta escamosa lateral está bien desarrollada y, 
en vista lateral, no impide la visualización del parietal y de la pared posterior de la fosa temporal.

\section{SUPRAOCCIPITAL}

El supraoccipital, en vista dorsal, se extiende ántero-dorsalmente sobrepasando el proceso preorbitario del frontal (Fig. 4.13). Es de contorno triangular con el margen anterior redondeado. Los márgenes laterales son rectos formando la sutura con el parietal y con el escamoso. La preservación de los márgenes laterales no es completa, estando el margen izquierdo erosionado casi en toda su extensión, mientras que el derecho está incompleto en la mitad anterior. La mitad posterior del margen derecho conserva una cresta temporal baja y redondeada, la textura del hueso en esta área sugiere la probable persistencia de cartílago. En el ejemplar MLP 5-15 el margen lateral izquierdo del supraoccipital está completo y forma una cresta temporal pronunciada. El margen anterior del supraoccipital contacta con el frontal a través de una sutura incompleta (estadio $\mathrm{SR}_{3}$ ) y no está elevado como en Balaenella. La superficie dorso-medial del supraoccipital presenta una depresión poco profunda, triangular y que se desarrolla ántero-posteriormente (Largo=90 $\mathrm{mm}$ ) sin alcanzar el margen anterior del supraoccipital (se extiende a $75 \mathrm{~mm}$ de dicho margen). Dentro de esta fosa hay una cresta, correspondiente a la cresta occipital externa, sólo evidente al tacto. La superficie pósterodorsal del supraoccipital está incompleta, faltando una porción por delante del foramen magnum donde el hueso es muy delgado.

En vista lateral (Fig. 4.14) el supraoccipital es convexo y está orientado oblicuamente formando un ángulo agudo con respecto al eje sagital del cráneo.

En vista posterior (Fig. 4.15) el supraoccipital no está expuesto ampliamente sobre el margen dorsal del foramen magnum (la exposición del supraocccipital es dos veces la altura del foramen magnum). La sutura con el exoccipital no es observable (estadio SR4).

\section{EXOCCIPITAL}

El exoccipital contacta anteriormente con el supraoccipital, a través de una sutura no visible (estadio SR4), y látero-ventralmente con el escamoso a través de la sutura occipito-escamosal, la cual presenta un estadio de fusión incompleto ( $\mathrm{SR}_{3}$ ) (Fig. 4.15). La sutura occipito-escamosal se extiende desde el margen lateral del exoccipital, donde es convexa, y luego se curva ventralmente y continúa dentro de la fosa periótica donde no puede distinguirse.

En vista dorsal (Fig. 4.13) la superficie posterior del exoccipital es levemente cóncava y el margen posterior está orientado lateralmente formando un ángulo casi recto con el plano sagital del cráneo.

En vista posterior (Fig. 4.15) los exoccipitales son anchos transversalmente (representan el $84 \%$ del ancho bizigomático) y forman la mayor parte del escudo occipital. Los cóndilos occipitales 
forman el margen látero-ventral del foramen magnum y son grandes en comparación con el tamaño de la caja craneana: el ancho máximo de los cóndilos occipitales representa el $28 \%$ del ancho bizigomático (Tabla 4.3). Ambos cóndilos occipitales están bien preservados, son de forma ovoide, no marcadamente convexos como en Eubalaena australis y están orientados formando un ángulo agudo con el plano sagital del cráneo. Los cóndilos están separados en su porción ventro-medial por una muesca intercondilar angosta y poco profunda (Largo $=60 \mathrm{~mm}$; ancho mínimo= $4 \mathrm{~mm}$ ). El foramen magnum tiene un contorno circular $(75 \times 75 \mathrm{~mm})$. En posición posterior a la cresta temporal y en el margen dorso-lateral de cada exoccipital se observan surcos bien definidos y orientados transversalmente. La fosa condiloidea dorsal es una depresión marcada en el margen ántero-dorsal de cada cóndilo (Fig. 4.13). La fosa condiloidea ventral no se observa. El margen lateral del exoccipital es convexo y el margen ventral forma una muesca yugular profunda y los procesos paraoccipitales. En posición medial a la muesca yugular, el exoccipital forma una proyección ventral pequeña y de contorno redondeado (cresta exoccipital medial sensu Mead \& Fordyce, 2009) similar a la observada en Eubalaena australis así como también en el misticeto extinto Aetiocetus weltoni (Demeré \& Berta, 2008; P: 327). El proceso paraoccipital es pequeño, se ubica lateralmente a la muesca yugular y dorsalmente a la cresta basioccipital, y está mejor preservado del lado derecho. El proceso paraoccipital es triangular, corto dorso-ventralmente y la superficie posterior es plana.

En vista ventral (Fig. 4.16; 4.17) el proceso posterior compuesto del periótico contacta con el exoccipital a través de una sutura visible (estadio $\mathrm{SR}_{3}$ ), recta y orientada póstero-lateralmente. Anteriormente el exoccipital contacta con el basioccipital a través de una sutura completamente fusionada (estadio SR4). La contribución del exoccipital a la formación de la cresta basioccipital no pudo ser determinada debido al avanzado estado de fusión que presenta la sutura exoccipitalbasioccipital. El proceso paraoccipital se ubica anteriormente a los cóndilos occipitales, la superficie ventro-medial es lisa y de contorno triangular indicando la presencia de la fosa para el seno posterior; el sitio de articulación del estilohial no pudo determinarse. En posición medial a los procesos paraoccipitales se observa un surco profundo y orientado ántero-posteriormente que corresponde a la muesca yugular, lugar de salida de los nervios hipogloso (XII), glosofaríngeo (IX), vago (X) y espinal (XI), la vena yugular y la arteria carótida externa. El margen posterior del exoccipital se extiende en posición posterior a los cóndilos occipitales (Fig. 4.16).

\section{FRONTAL}

Los frontales forman la región interorbitaria, los procesos supraorbitarios del frontal y parte de la pared orbital.

En vista dorsal (Fig. 4.13), la exposición de los frontales en el vértex es amplia y se extiende ántero-posteriormente por $52 \mathrm{~mm}$. La región anterior del frontal, zona de articulación de 
los elementos del rostro, está expuesta debido a la ausencia de los nasales, maxilares y premaxilares. En la superficie ántero-dorsal del frontal hay una fosa medial profunda para la recepción de los nasales, la cual está flanqueada lateralmente por un complejo de crestas y surcos longitudinales que corresponden a la zona de recepción de los premaxilares y maxilares (Fig. 19). Posterior a esta región, la exposición dorsal del frontal presenta el margen anterior semicircular. Medialmente, el contacto entre el frontal derecho e izquierdo, la sutura interfrontalis, se infiere por la presencia de una superficie rugosa y elevada. El frontal desciende gradualmente desde el vértex craneal en dirección látero-ventral formando los procesos supraorbitarios del frontal, y se desarrollan principalmente en el plano transversal y a diferencia de Eubalaena australis presenta poca inclinación ventral. Dichos procesos son cortos transversalmente y anchos ántero-posteriormente en comparación con $E$. australis: el ancho transversal es aproximadamente el doble del largo ántero-posterior (Tabla 4.3). El margen anterior del proceso supraorbitario es recto y forma un ángulo agudo con el plano sagital del cráneo $\left(67^{\circ}\right)$, mientras que el margen posterior es levemente cóncavo. La superficie dorsal del proceso es aproximadamente plana.

En vista lateral (Fig. 4.14) el margen dorsal de la órbita se ubica lateralmente en el cráneo en posición dorsal al proceso zigomático del escamoso; la distancia vertical entre el margen dorsal de la órbita y el margen ventral del proceso postglenoideo es $185 \mathrm{~mm}$. El largo ántero-posterior de la órbita (medida entre el ápex del proceso preorbitario y postorbitario) en comparación con el ancho bizigomático es de un 23\% (LO/ABZ, Tabla 4.3), un valor cercano al misticeto extinto Aetiocetus weltoni (27\% Demeré \& Berta, 2008 P: 323) y comparativamente mayor a Eubalaena australis (LO/ABZ=8\%, Tabla 4.1). El margen dorsal de la órbita está formado anteriormente por el proceso preorbitario del frontal, el cual está incompleto, y posteriormente por el proceso postorbitario del frontal. El proceso postorbitario es robusto, de contorno redondeado y está orientado pósteroventralmente. En vista lateral, el eje ántero-posterior de la órbita es paralelo al plano sagital del cráneo. El margen ventral de la órbita no se conservó debido a la ausencia del yugal y el maxilar. En vista dorsal el margen dorsal de la órbita es levemente recto mientras que en vista lateral es levemente cóncavo. La superficie externa del frontal es lisa en la región interorbitaria y en la superficie dorsal del proceso supraorbitario, a diferencia del margen dorsal de la órbita donde el hueso presenta un aspecto rugoso/poroso sugiriendo la presencia de cartílago.

En vista ventral (Fig. 4.16) el foramen óptico, lugar de salida del nervio óptico (II), es una muesca que se ubica en posición lateral a la fisura basiesfenoides-preesfenoides. A partir de allí se desarrolla el canal óptico en dirección lateral a lo largo del margen póstero-ventral del proceso supraorbitario. A diferencia de la condición observada en Eubalaena australis, la mitad lateral del canal óptico no ocupa todo el margen ántero-posterior de la superficie ventral del proceso supraorbitario, sino que está ubicado en los $2 / 3$ posteriores (representa cerca de un $70 \%$ del largo 
ántero-posterior total del proceso). En su porción medial el canal óptico está delimitado anteriormente por el frontal y posteriormente por el parietal. Dicho canal es profundo y angosto en su porción medial (Ancho=35 mm) y se ensancha en dirección lateral (Ancho=50 mm). El margen anterior del canal óptico está preservado sólo en su mitad lateral, lo cual permite inferir que el canal permanece abierto ventralmente a todo su largo. La pared dorsal del canal óptico está perforada por el foramen etmoidal, para la salida del nervio etmoidal y vasos sanguíneos, y por pequeños forámenes frontales. La superficie ventral del frontal presenta dos fosas profundas y simétricas ubicadas entre la sutura del preesfenoides y el frontal, en posición dorsal al proceso supraorbitario del frontal, similar a la observada en E. australis.

\section{ORBITOESFENOIDES}

La presencia del orbitoesfenoides en el canal óptico es difícil de determinar debido a que probablemente este fusionado al frontal y al preesfenoides.

\section{PARIETAL}

Los parietales, en vista dorsal, no están en contacto en la línea media del vértex del cráneo debido a la extensión anterior del supraoccipital y sólo una pequeña porción es visible lateralmente al vértex (Fig. 4.13).

En vista lateral (Fig. 4.14) el parietal forma parte de la pared lateral de la caja craneana y contacta anteriormente con el frontal a través de la sutura coronal. Dicha sutura se inicia a nivel del margen anterior del supraoccipital, continúa en dirección posterior sobre el margen póstero-dorsal del frontal, luego se curva ventralmente y termina en una muesca bien definida. Posteriormente el parietal contacta con el escamoso a través de la sutura parieto-escamosal, la cual se desarrolla dorsoventralmente en la pared medial de la fosa temporal, está curvada posteriormente y no forma una cresta. Dorsalmente el parietal contacta con el supraoccipital y contribuye a la formación de la cresta temporal, la cual protruye lateralmente. La porción ántero-dorsal del parietal se proyecta anteriormente y se superpone sobre el extremo póstero-dorsal del proceso supraorbitario del frontal, hasta aproximadamente la mitad del largo del proceso. En esta región la superficie del parietal es marcadamente cóncava y lisa. No hay evidencia de la presencia de cresta orbitotemporal.

En vista ventral (Fig. 4.16; 4.17) el parietal tiene una pequeña exposición en la porción póstero-medial del canal óptico donde contacta anteriormente con el frontal y posteriormente con el escamoso. En esta región el parietal está parcialmente solapado por el aliesfenoides y forma anteriormente una muesca bien definida, y posteriormente una proyección lateral triangular. 


\section{ESCAMOSO}

El escamoso es un hueso masivo que forma parte de la pared lateral de la caja craneana y de la pared medial y posterior de la fosa temporal. Asimismo forma el proceso zigomático y postglenoideo, la fosa glenoidea para la articulación temporo-mandibular y la fosa periótica.

En vista lateral (Fig. 4.14) el escamoso está desarrollado en sentido dorso-ventral con respecto al plano sagital del cráneo y está orientado en forma perpendicular al eje horizontal del cráneo. Contacta dorsalmente con el supraoccipital formando la cresta temporal, anteriormente con el parietal y póstero-lateralmente con el exoccipital a través de una sutura redondeada. Lateralmente a la sutura escamoso-exoccipital, el escamoso forma la cresta escamosa lateral la cual es robusta, convexa anteriormente y está orientada ántero-lateralmente. El desarrollo de esta cresta oblitera la visión de la pared póstero-dorsal de la fosa temporal pero no la sutura escamoso-parietal. El proceso zigomático es corto, con un ápex redondeado y está orientado ántero-lateralmente. El proceso postglenoideo izquierdo está mejor preservado que el derecho, sin embargo el margen ventral y lateral están incompletos tanto en el holotipo como en el ejemplar MLP 5-15. El proceso postglenoideo es alto dorso-ventralmente, está orientado póstero-ventralmente en vista lateral y ventralmente en vista posterior. La superficie externa del proceso zigomático y postglenoideo tiene una textura rugosa sugiriendo la persistencia de cartílago. En vista dorsal, el escamoso forma póstero-lateralmente la pared posterior de la fosa temporal. Dicha fosa es elíptica, más ancha que larga $(A / L=190 / 90=2.11$; Tabla 4.3) y la pared medial es plana mientras que la posterior es cóncava. No presenta hendidura escamosal como la observada en Caperea marginata. La fosa glenoidea se ubica anteriormente al ápex posterior de la cresta nucal.

En vista ventral (Fig. 4.16; 4.17) el escamoso forma la pared anterior, dorsal y lateral de la fosa donde se aloja el periótico. Dicha fosa es profunda, se extiende desde la base del proceso falciforme hasta el margen ántero-medial del meato auditivo externo. El meato auditivo externo es una excavación profunda localizada en el margen póstero-lateral del cráneo, dorsal al proceso postglenoideo. El margen posterior es casi recto y está definido por la cresta meatal posterior, la cual contacta con el proceso posterior compuesto del periótico a través de una sutura recta y sin fusionar (estadio $\mathrm{SR}_{3}$ ). El margen medial forma el proceso espinoso del escamoso el cual se extiende ánteromedialmente. La superficie ventral del meato auditivo externo es cóncava, y en posición medial presenta una fosa profunda la cual in vivo está ocupada por la membrana timpánica en forma de saco característica de los misticetos (Capítulo 6). En posición dorso-medial a la base del proceso falciforme hay un surco ancho y poco profundo para el pasaje de la rama mandibular del trigémino $\left(V_{3}\right)$; dicho surco termina en la superficie ventral del escamoso y forma la muesca para la salida del nervio $V_{3}$ hacia la mandíbula (foramen pseudoval) (ancho=12 mm) (Fig. 4.17). El proceso falciforme está roto en la base. La fosa glenoidea es plana a levemente cóncava y ancha como en Eubalaena 
australis. La posición dorsal de la órbita con respecto al proceso postglenoideo sugiere que la posición de la fosa glenoidea debía ser posterior al proceso postorbitario del frontal (Fig. 4.14).

\section{BASIOCCIPITAL}

El basioccipital está completamente preservado y ubicado en la región póstero-ventral del cráneo. El mismo consta de una porción medial horizontal o parte basilar, la cual forma el piso de la caja craneana, y dos proyecciones látero-ventrales que forman las prominentes crestas basioccipitales (Fig. 4.16; 4.17). La porción basilar es levemente cóncava en vista posterior y el contacto anterior con el basiesfenoides está encubierto por la extensión posterior del vómer. Sin embargo, la superficie dorsal del basioccipital presenta una superficie rugosa que corresponde a la sutura basiesfenoidesbasioccipital. En el ejemplar MLP 5-15 como el vómer no se preservó, la sutura basioccipitalbasiesfenoides es visible en vista ventral (estadio SR3). Posteriormente, el contacto entre el basioccipital y el exoccipital es evidente por el cambio en la textura de ambos huesos, desde una superficie lisa del basioccipital a una superficie esponjosa de los cóndilos occipitales.

En vista posterior (Fig. 4.15) la cresta basioccipital es bulbosa y está engrosada medio-lateral y dorso-ventralmente. La superficie medial es convexa anteriormente y plana posteriormente, el margen ventral presenta la superficie del hueso de una textura rugosa, sugiriendo la presencia de cartílago. En el MLP-5-15 la superficie medial de la cresta basioccipital presenta surcos y crestas que corresponden al sitio de inserción de la musculatura flexora del cuello. La cresta basioccipital contacta anteriormente con la lámina pterigoidea media a través de una sutura cerrada (estadio $\mathrm{SR}_{3}$ ) (Fig. 4.17).

\section{VÓMER}

Sólo la porción posterior del vómer está preservada. Debido a que los palatinos y hamulus pterigoideos no se preservaron, la porción posterior del vómer está expuesta en la pared ventral del cráneo (Fig. 4.16; 4.17). La porción preservada del vómer corresponde a la pared dorsal y dorsomedial del pasaje nasal interno. El vómer está orientado en forma horizontal con respecto al eje sagital del cráneo y se ubica ventralmente al basiesfenoides y al basioccipital obstruyendo la visión de la sutura basioccipital/basiesfenoides. El vómer se extiende desde el margen anterior de la fosa pterigoidea hasta 2/3 el largo de la lámina pterigoides media, sin embargo la extensión posterior final del vómer no pudo determinarse ya que el margen posterior no se preservó. El vómer es ancho anteriormente y se angosta en dirección posterior. La superficie ventral presenta una cresta medial, la cresta vomerina, la cual no alcanza el margen posterior preservado del vómer. La cresta vomerina está flanqueada lateralmente por dos superficies cóncavas. 


\section{BASIESFENOIDES-PRESFENOIDES}

El basiesfenoides contacta posteriormente con el basioccipital, lateralmente con la lámina media del pterigoides y anteriormente con el preesfenoides (Fig. 4.17). El foramen carotídeo dorsal no es evidente en la superficie dorsal del basiesfenoides. El preesfenoides es elongado ánteroposteriormente y contacta lateralmente con el frontal y posteriormente con el basiesfenoides a través de la fisura basiesfenoides-preesfenoides (ancho $=73 \mathrm{~mm}$, largo $=7 \mathrm{~mm}$ ). La sutura con el orbitoesfenoides no se observa. La mayor parte de la superficie ventral del preesfenoides está erosionada, sin embargo parte de los márgenes laterales están preservados lo cual permite inferir que este presenta un contorno triangular como en otros balénidos. La porción póstero-lateral del preesfenoides contribuye a la delimitación de la fisura orbital y del foramen óptico.

\section{ALIESFENOIDES}

El aliesfenoides está bien preservado en la superficie ventral del cráneo en el lado izquierdo mientras que el lado derecho no es visible.

En vista ventral (Fig. 4.16; 4.17) el cuerpo principal del aliesfenoides está interpuesto entre el pterigoides, el parietal, y el escamoso. Está solapado ventralmente en su sector póstero-medial por la porción anterior de la lámina lateral del pterigoides y póstero-lateralmente por el escamoso a través de una sutura bien definida (en ambos casos). El aliesfenoides es pequeño (ancho máximo $\sim 41 \mathrm{~mm}$; largo $\sim 56 \mathrm{~mm}$ ) y presenta una proyección lateral triangular bien definida que se extiende por $\sim 28$ mm sobre el parietal sin alcanzar el margen lateral de la caja craneana, por esta razón el aliesfenoides no está expuesto en la pared medial de la fosa temporal. La superficie anterior del aliesfenoides es vertical y levemente cóncava mientras que la superficie posterior es plana; ambas superficies están separadas por una cresta pronunciada que se desarrolla medio-lateralmente siguiendo la proyección lateral del parietal. La proyección lateral del aliesfenoides delimita medialmente el margen pósteroventral del canal óptico. El aliesfenoides contacta anteriormente con el parietal a través de una sutura visible que se extiende medio-lateralmente. La proyección lateral del aliesfenoides solapa la proyección lateral del parietal dejando un espacio libre entre ambos huesos. Póstero-lateralmente, el aliesfenoides contacta con el escamoso a través de una sutura convexa y póstero-medialmente con el pterigoides. El foramen pseudoval no perfora el aliesfenoides externamente, sino que está confinado al escamoso.

\section{PTERIGOIDES}

La porción preservada del pterigoides corresponde a la lámina media, lateral y dorsal. Los hamulus pterigoideos y la mayor parte de la lámina ventral no se preservaron; como consecuencia la lámina media, dorsal y lateral están expuestas en la superficie ventral del cráneo (Fig. 4.16; 4.17). La 
lámina media está orientada ántero-posteriormente y contacta medialmente por $\sim 80 \mathrm{~mm}$ con el basioccipital, anteriormente con el basiesfenoides y posteriormente con la superficie medial y lateral de la cresta basioccipital. La lámina lateral se extiende medio-lateralmente y contacta lateralmente con el escamoso a través de una sutura visible e irregular $(+40 \mathrm{~mm})$ y anteriormente con el aliesfenoides (esta sutura no es evidente). La fosa para el seno pterigoideo está excavada en la lámina dorsal y lateral del pterigoides y se extiende ántero-lateralmente por $\sim 44 \mathrm{~mm}$ y póstero-lateralmente por $\sim 22 \mathrm{~mm}$ dentro del hiato craneal. El eje principal de la fosa para el seno pterigoideo es oval y está desarrollada en dirección ántero-posterior $(\mathrm{L}=77 \mathrm{~mm})$. Más de un tercio de la fosa para el seno pterigoideo está ubicada anteriormente al foramen pseudoval. Posteriormente dicha fosa se extiende hasta el nivel de la sutura pterigoides-basioccipital. Sobre la superficie ventral de la lámina dorsal se observa un canal que comunica con el foramen carotídeo ventral (ubicado a $\sim 51 \mathrm{~mm}$ de la sutura pterigoides-basioccipital) para la transmisión de la arteria carótida interna hacia la cavidad craneal. La cresta faríngea, que separa la región faríngea y ótica del cráneo, está formada anteriormente por la lámina media del pterigoides y posteriormente por la cresta basioccipital. La cresta faríngea es más baja dorso-ventralmente que en Eubalaena australis.

\section{PERIÓTICO}

Se conservaron ambos perióticos in situ fusionados a la caja craneana a través del escamoso. El periótico izquierdo se conservó completamente a diferencia del derecho que está roto a nivel del proceso anterior y lateral (Fig. 4.16). Las bullas timpánicas no se preservaron.

En vista ventral (Fig. 4.18A-B), el proceso anterior es más corto que el largo ántero-posterior de la pars coclearis y presenta el extremo anterior redondeado. El pedicelo anterior para la articulación de la bulla timpánica está ubicado en la superficie ventral del proceso anterior, y está definido por una cresta flanqueada por dos surcos. En posición lateral al proceso anterior, se ubica la tuberosidad ventrolateral del proceso anterior que es pequeña y de contorno redondeado, y no presenta una proyección lateral hipertrofiada como la observada en individuos adultos de Eubalaena australis (Fig. 4.8). Póstero-medialmente, en el cuerpo del periótico, la fosa para el martillo es una depresión leve y poco definida. La pars coclearis está orientada ántero-posteriormente formando un ángulo agudo con el plano sagital del cráneo. La superficie medial de la pars coclearis presenta pequeñas proyecciones del hueso que le otorgan un perfil irregular. El promontorio está bien diferenciado de la superficie ventral de la pars coclearis, es marcadamente convexo y más largo que ancho $(\mathrm{A} / \mathrm{L}=\mathrm{0.58})$. La superficie ventral del promontorio es convexa, lo cual está asociado con la elongación dorso-ventral de la pars coclearis. La fenestra coclear se ubica posteriormente en la pars coclearis y en posición medial a la cresta coclear posterior. El surco del promontorio es un surco poco profundo que se observa en la superficie ventral de la pars coclearis en dirección ántero-medial. 
Entre la porción anterior de la pars coclearis y el proceso anterior se observa una depresión leve delimitada por una cresta que corresponde al sitio de inserción del músculo tensor timpánico. El hiato de fallopii, lugar de salida de la rama petrosa del nervio facial (VII), es un foramen pequeño y oval que se ubica en la superficie ventral del surco para el tensor timpánico. El proceso posterior compuesto es cilíndrico y está orientado póstero-lateralmente formando un ángulo obtuso con el eje longitudinal de la pars coclearis. Ventro-medialmente presenta el pedicelo posterior para la articulación con la bulla timpánica. La superficie dorsal del proceso posterior compuesto está fusionada con el escamoso en toda su extensión, anteriormente contacta con el escamoso a través de la cresta meatal posterior formando un surco, posteriormente con el exoccipital a través de una sutura visible (estadio SR4) y lateralmente con el escamoso formando un sutura interdigitada. El margen medial del proceso posterior compuesto es cóncavo y sobre la superficie dorso-medial se desarrolla una fosa estilomastoidea profunda.

En vista posterior (Fig. 4.18 C-D), la fenestra coclear es más alta que ancha y presenta forma de riñón con el margen medial convexo y el margen lateral cóncavo. En el margen medial de la fenestra coclear se observa un surco anterior y posterior bien definidos separados por una cresta redondeada. Dentro de la fenestra es visible la impronta de la parte basal del espacio interlaminar donde se ancla la membrana basilar (Geisler \& Luo, 1996; P: 1054). La cresta coclear posterior se ubica posteriormente a la pars coclearis, lateralmente a la fenestra coclear y medialmente al surco facial. Dicha cresta es delgada, de forma triangular, con la superficie dorsal cóncava y orientada póstero-ventralmente. La superficie dorsal de la cresta coclear posterior forma el piso de la fosa para el músculo estapedial.

En vista lateral, la fenestra oval preserva in situ parte del estribo. La fosa para el músculo estapedial está bien definida, es profunda y de forma oval y se ubica lateralmente a la cresta coclear posterior. El surco facial, por donde corre ventralmente el nervio facial (VII), se desarrolla como un surco poco profundo en la superficie ventro-medial del proceso posterior compuesto del periótico (Fig. 4.18 A-B).

En vista dorso-medial, los forámenes endocraneales se ubican en el extremo dorso-medial elevado del promontorio. Anteriormente se ubica el meato auditivo interno el cual está dividido por la cresta transversa baja que se ubica por debajo del anillo del meato y separa la apertura interna o dorsal del canal facial para la salida del nervio facial (VII) y el meato auditivo interno sensu stricto para la salida del nervio vestíbulococlear (VIII). Ambos forámenes están alineados ánteroposteriormente. La apertura interna del canal facial es de contorno circular y de menor tamaño que la apertura para la salida del nervio VIII. Posteriormente, y alineado con el meato auditivo interno, se ubica el foramen perilinfático. El foramen endolinfático se infiere en posición lateral al foramen perilinfático, donde se observa una depresión que está parcialmente obstruida por sedimento. 
Dorso-lateralmente al meato auditivo interno se encuentra una fosa poco profunda pero bien definida, la fosa suprameatal. Dicha fosa está delimitada lateralmente por una cresta bien desarrollada que corresponde al proceso superior. A diferencia de los balénidos actuales, el periótico de Morenocetus no presenta proyección piramidal.

\title{
4.3.2 Balénidos del Mioceno Tardío
}

\section{4·3.2.1 Balénido de la Formación Puerto Madryn: nuevo género y especie}

\author{
SISTEMATICA PALEONTOLOGICA \\ Orden CETACEA Brisson, 1762 \\ Rango no determinado NEOCETI Fordyce \& Muizon, 2001 \\ Suborden MYSTICETI Gray, 1864 Sensu Cope, 1869 \\ Rango no determinado CHAEOMYSTICETI Mitchell, 1989 \\ Familia BALAENIDAE Gray, 1825 \\ Gen. nov.
}

Diagnosis—como la de la especie tipo y única conocida.

\section{Sp. nov.}

Diagnosis - Balénido caracterizado por la siguiente combinación única de caracteres: maxilar no comprimido transversalmente; margen anterior de los nasales convexo y formando una "M"; estilohial aplanado; basihial no fusionado al tirohial y con el margen anterior formando una proyección medial en punta mientras que el margen posterior es marcadamente cóncavo; presencia de lóbulo medial en la bulla timpánica, proceso supraorbitario del frontal corto transversalmente y desarrollado principalmente en el plano transversal con una moderada inclinación ventral; porción posterior de los nasales no separada a lo largo del plano sagital por el proceso narial del frontal; márgenes laterales del supraoccipital rectos; tuberosidad ventrolateral del proceso anterior del periótico pequeña y bulbosa; surco lateral de la bulla timpánica ubicado dentro del tercio anterior de la bulla timpánica; crestas transversales en el involucro de la bulla timpánica poco desarrolladas; surco facial en el proceso posterior compuesto del periótico poco profundo y definido por un margen anterior y otro posterior; ausencia de proceso piramidal; proceso posterior compuesto del periótico orientado póstero-lateralmente con respecto al eje longitudinal del proceso anterior del periótico; fosa pterigoidea extendida anteriormente al foramen pseudoval; pared posterior de la fosa temporal plana o levemente cóncava; escamoso orientado en forma perpendicular al eje sagital del cráneo; proceso supraorbitario del frontal inclinado póstero-ventralmente en vista lateral; nasales cortos en comparación con el ancho bizigomático del cráneo; exoccipital extendido posteriormente al margen 
posterior de los cóndilos occipitales; extremo anterior del proceso zigomático del escamoso ubicado en posición ventral al proceso postorbitario y separado por una distancia dorsoventral; superficie dorsal del cráneo forma un arco suave interrumpido por el vértex craneal; extremo anterior del proceso supraorbitario del frontal orientado posteriormente; sutura parieto-escamosal no forma una cresta; fenestra coclear elíptica; proceso cónico bien desarrollado y dorsalmente convexo; cresta escamosa lateral bien desarrollada pero no oblitera la visión lateral del escamoso y del parietal; proceso postglenoideo transversal al eje sagital del cráneo en vista ventral; fosa glenoidea en posición posterior al proceso postorbital; ausencia de tubérculo nucal en la unión de la sutura parietalescamoso-supraoccipital; apertura dorsal o interna del canal facial de menor tamaño que el meato auditivo interno sensu stricto; y superficie medial al tubo de Eustaquio plana o levemente cóncava.

Holotipo-MPEF-PV-1122, cráneo incompleto, con región rostral parcialmente preservada, ambos perióticos, bulla timpánica izquierda, e hioides (basihial y tirohial) (Fig. 4.22; 4.23; 4.25; 4.28; 4.29; 4.30; $4.31 ; 4.32$; Tabla 4.3 y 4.4 ).

Paratipo-CH-P33-01, cráneo incompleto con periótico derecho articulado (Fig.4.24; 4.26; 4.30; Tabla 4.3 y 4.4), sin bullas timpánicas ni región rostral.

Espécimen referido-MPCNyO 290, cráneo incompleto con ambos perióticos y bullas timpánicas articuladas (Fig. 4.47; Tabla 4.3 y 4.4).

Localidad tipo y procedencia estratigráfica-el ejemplar MPEF-PV-1122 proviene de la playa Punta Pardelas, al este de Puerto Pirámides, costa Norte del Golfo Nuevo; Península Valdés, Chubut. El CH-P33-or proviene de Puerto Pirámides, Golfo Nuevo, Península Valdés, Chubut. El ejemplar MPCNyO 290 fue colectado en la restinga de la costa Sur del Golfo San José, Lote 39, Península Valdés, Chubut (Fig. 4.20).Todos los materiales provienen de los niveles inferiores de la Formación Puerto Madryn (Mioceno tardío) (Fig. 4.21).

Comentarios: esta especie fue descripta originalmente por Cozzuol (1993) en su tesis doctoral sobre la base de los especímenes MPEF-PV-1122 y MPCNyO 290, aunque no ha sido hasta la fecha publicado formalmente. Como resultado de los trabajos paleontológicos efectuados en los últimos años y de la revisión de colecciones privadas de residentes de la ciudad de Puerto Pirámides se logró colectar un nuevo espécimen el cual complementará la descripción original de Cozzuol (1993) y permitirá efectuar una nueva diagnosis de la especie.

Durante el desarrollo de esta tesis se utilizará el nombre de “Taxón A” para hacer referencia a este nuevo taxón. 


\section{DESCRIPCIÓN}

Estado de preservación de los materiales: El ejemplar MPEF-PV-1122 es un cráneo casi completo, donde se preservaron elementos del rostro, tales como los maxilares, el nasal derecho, y fragmentos del premaxilar, los cuales están desarticulados de la caja craneana (Fig. 4.28, 4.31, 4.35). El escudo occipital está deteriorado y falta una porción por delante del foramen magnum; el proceso zigomático izquierdo está mejor preservado que el derecho; falta gran parte del proceso supraorbitario del frontal derecho mientras que el izquierdo presenta una porción faltante en el margen ántero-dorsal. De la región ótica se conservó una bulla timpánica izquierda y ambos perióticos desarticulados de la caja craneana. El periótico izquierdo está completo a diferencia del derecho donde falta el proceso posterior compuesto y parte del cuerpo del periótico. De los huesos hioides se preservó el tirohial completo y el basihial (esté último no está fusionado al tirohial)

El CH-P33-o1 es un cráneo incompleto, de tamaño similar al MPFE-PV-1122, donde faltan por completo la región rostral y los procesos supraorbitarios del frontal. La caja craneana está bien preservada, con el periótico derecho articulado y faltan las bullas timpánicas. El escudo occipital también presenta una porción faltante por delante del foramen magnum.

El espécimen MPCNyO 290 consiste en un cráneo incompleto con ambos perióticos y bullas timpánicas articulados a la caja craneana. Faltan los procesos supraorbitarios del frontal, el escudo occipital está roto en su mayor parte y, de la región rostral, sólo se conservaron los nasales. El cráneo está deformado por procesos tafonómicos y presenta numerosas perforaciones e incrustaciones efectuadas por invertebrados.

En el ejemplar MPEF-PV-1122 el grado de fusión de las suturas del cráneo entre el basioccipital/exoccipital y supraoccipital/exoccipital corresponde al estadio SR4. En el CH-P33-01 dichas suturas también presentan un estadio de fusión completa (SR4), sin embargo algunas suturas en la caja craneana (escamoso/pterigoides; aliesfenoides/escamoso/frontal) no están completamente fusionadas (estadio $\mathrm{SR}_{3}$ ). En el ejemplar MPCNyO 290 el grado de fusión entre las suturas basioccipital/exoccipital y supraoccipital/exoccipital no pueden determinarse ya que dichos huesos no se preservaron.

Características generales del cráneo: El tamaño de la caja craneana (considerando el ancho bizigomático) es, en todos los ejemplares excepto MPCNyO 290, similar a Morenocetus (Tabla 4.3). En el ejemplar MPEF-PV-1122, donde se conservó parte del rostro, se puede estimar que la caja craneana representa aproximadamente el 45\% del largo total del cráneo (Tabla 4.3). En vista dorsal, el escudo occipital es elongado ántero-posteriormente, de contorno triangular con el margen 
anterior redondeado (Fig. 4.22). En vista lateral, el perfil dorsal del cráneo es levemente convexo. El proceso supraorbitario del frontal está inclinado póstero-ventralmente en forma más acentuada que en Morenocetus. Dicho proceso es ancho ántero-posteriormente y corto transversalmente. La órbita está ubicada en posición dorsal al proceso zigomático del escamoso y en vista dorsal y lateral, el margen dorsal es marcadamente cóncavo. En vista dorsal, el rostro, representado por los maxilares y por una pequeña porción de los premaxilares, es de contorno triangular y no presenta la marcada compresión transversal observada en Eubalaena australis.

\section{SUPRAOCCIPITAL}

El supraoccipital forma en vista dorsal la pared dorsal y póstero-dorsal de la caja craneana (Fig. 4.22). Se extiende anteriormente excluyendo a los parietales del vértex del cráneo y sobrepasando el proceso preorbitario del frontal. Es de contorno triangular y presenta el margen anterior redondeado. En todos los especímenes analizados falta la porción anterior al foramen magnum. En MPCNyO 290 se observa una pequeña proyección triangular correspondiente al interparietal? visible en el vértex del cráneo, lo cual sugiere que la superposición del supraoccipital es incompleta en este espécimen (Fig. 4.27). Asimismo, la superficie dorsal del supraoccipital presenta un aspecto más esponjoso, lo cual está relacionado con la condición juvenil del ejemplar. Los márgenes laterales no están completamente preservados en el ejemplar MPEF-PV-1122 (Fig. 4.22) y en MPCNyO 290 (Fig. 4.27) a diferencia del CH-P33-01 donde se conservaron completamente. Los márgenes laterales son rectos y contactan lateralmente con el parietal y el escamoso, formando una cresta temporal poco acentuada. Anteriormente, contacta con el frontal a través de una sutura visible (estadio SR3) y, en el ejemplar MPCNyO 290 también contacta con la porción expuesta del interparietal?. En la superficie dorsal del supraoccipital se observa una cresta baja, la cresta occipital externa, de contorno triangular que se desarrolla ántero-posteriormente sin alcanzar el margen anterior del supraoccipital, flanqueada por dos depresiones longitudinales. En todos los ejemplares se observa una porción faltante del supraoccipital, de contorno aproximadamente circular, por delante del foramen magnum. En vista lateral (Fig. 4.23), la superficie dorsal del supraoccipital es convexa y está orientado oblicuamente formando un ángulo agudo con respecto al plano horizontal del cráneo. En vista posterior, la sutura con el exoccipital no es observable (estadio SR4) (Fig. 4.25).

\section{EXOCCIPITAL}

El exoccipital forma la pared posterior de la caja craneana, el cóndilo occipital y la porción ventro-posterior de la fosa periótica. En vista posterior contacta anteriormente con el supraoccipital a través de una sutura no visible (estadio $\mathrm{SR}_{4}$ ), lateralmente con el escamoso a través de una sutura visible (estadio SR3), la sutura occipito-escamosal, la cual se continúa ventralmente dentro de la fosa 
periótica (Fig. 4.25). El exoccipital es ancho transversalmente (representan el $81 \%$ del ancho bizigomático, ejemplar MPEF-PV-1122, Tabla 4.3) y forma la mayor parte de la porción posterior del escudo occipital. Los cóndilos occipitales delimitan el foramen magnum en su porción látero-ventral y el ancho total de los mismos representa el 23\% del ancho bizigomático del cráneo (MPEF-PV-1122, Tabla 4.3). El cóndilo es de forma ovoide y en vista lateral la superficie es convexa, aunque de forma menos acentuada que en Eubalaena australis, y está orientado formando un ángulo agudo con el plano sagital del cráneo. Ambos cóndilos están separados en su porción ventro-medial por un surco ancho que se desarrolla dorso-ventralmente, correspondiente a la muesca intercondilar (Largo=70 $\mathrm{mm}$; Ancho máximo=32 mm). El tamaño del foramen magnum no puede determinarse en ninguno de los ejemplares analizados ya que falta el margen dorsal del mismo. La fosa condiloidea dorsal se observa como una depresión marcada en el margen dorsal de cada cóndilo, la fosa condiloidea ventral no es evidente (Fig. 4.22). El margen lateral del exoccipital es convexo y el margen ventral forma la muesca yugular y los procesos paraoccipitales. La muesca yugular es una escotadura profunda $(35 \mathrm{~mm})$ en forma de "V". El proceso paraoccipital se ubica lateralmente a la muesca yugular y dorsalmente a la cresta basioccipital. Es corto dorso-ventralmente y de contorno triangular con la superficie posterior plana. Entre la muesca yugular y la cresta basioccipital, se observa una proyección ventral corta y de contorno irregular que corresponde a la cresta exoccipital medial.

En vista ventral el exoccipital contacta con el proceso posterior compuesto del timpánico a través de una sutura visible (estadio $\mathrm{SR}_{3}$ ), recta y orientada póstero-lateralmente (Fig. 4.24). Anteriormente el exoccipital contacta con el basioccipital a través de una sutura completamente fusionada (SR4). La contribución del exoccipital a la formación de la cresta basioccipital no pudo ser determinada debido al avanzado estado de fusión que presenta la sutura exoccipital-basioccipital en todos los ejemplares estudiados. Los procesos paraoccipitales se ubican anteriormente a los cóndilos occipitales y la superficie ventro-medial presenta una depresión leve, de forma aproximadamente ovalada que corresponde a la fosa para el seno posterior. El sitio de articulación del estilohial se infiere sobre la superficie lateral del proceso paraoccipital. En posición medial al proceso paraoccipital se observa un surco profundo, orientado ántero-posteriormente que termina posteriormente en la muesca yugular, correspondiente al lugar de salida de los nervios hipogloso (XII), glosofaríngeo (IX), vago (X) y espinal (XI), la vena yugular y la arteria carótida externa.

En vista látero-posterior, la región próxima a los cóndilos es levemente cóncava a diferencia de la región lateral que es convexa (Fig. 4.25).

\section{FRONTAL}

El frontal forma la región interorbitaria, el proceso supraorbitario del frontal y parte de la pared orbital. 
En vista dorsal (Fig. 4.22) el frontal está expuesto por delante del escudo occipital formando la región interorbitaria $\left(\mathrm{L}=50 \mathrm{~mm}\right.$, en $\left.\mathrm{CH}-\mathrm{P}_{33}-\mathrm{o1}\right)$. La sutura entre el frontal izquierdo y derecho, la sutura interfrontalis, se evidencia como un surco ántero-posterior a lo largo de la línea media del frontal. En posición anterior el frontal presenta la superficie de contacto con el nasal, el premaxilar y el maxilar. En posición ántero-medial se observa una fosa profunda (Ancho máximo 48 mm; L 61 $\mathrm{mm}$ ) con el margen anterior en forma de "V" que corresponde al lugar de recepción de los nasales, la cual está flanqueada lateralmente por un complejo de crestas y surcos donde articulan el premaxilar y el maxilar. El frontal desciende gradualmente desde el vértex craneal en dirección látero-ventral y forma el proceso supraorbitario del frontal. Ambos procesos sólo se conservaron en el ejemplar MPEF-PV-1122, estando el proceso supraorbitario izquierdo mejor preservado que el derecho. Dicho proceso está desarrollado principalmente en el plano transversal y levemente en dirección ventral en comparación con Eubalaena australis y Balaena mysticetus; presenta una apariencia más robusta que en Morenocetus, siendo levemente más ancho ántero-posteriormente y largo transversalmente (Tabla 4.3). La porción preservada del margen anterior es recta mientras que el margen posterior es marcadamente cóncavo. El margen anterior está orientado póstero-ventralmente formando un ángulo agudo $\left(\sim 45^{\circ}\right)$ con el plano sagital del cráneo. La superficie dorsal es plana anteriormente mientras que posteriormente se observa una cresta orbitotemporal baja.

En vista lateral (Fig. 4.23) el proceso supraorbitario está inclinado en dirección posterior en forma similar a lo observado en Balaena mysticetus y a diferencia de Morenocetus donde el proceso no presenta una inclinación posterior. Como resultado, el eje ántero-posterior de la órbita está orientado oblicuamente con respecto al plano sagital del cráneo y está ubicado en posición dorsal al proceso zigomático del escamoso pero separado por una distancia dorso-ventral menor (distancia vertical entre el margen dorsal de la órbita y el margen ventral del proceso postglenoideo es de 100 $\mathrm{mm}$ ). El largo ántero-posterior de la órbita representa el 23\% del ancho bizigomático (LO/ABZ), un valor similar a Morenocetus, pero mayor al de Eubalaena australis (Tabla 4.3). El margen dorsal de la órbita está delimitado anteriormente por el proceso preorbitario y posteriormente por el postorbitario. El proceso preorbitario es más pequeño que el postorbitario, está orientado ventralmente y es de contorno redondeado. El proceso postorbitario es más robusto, está orientado póstero-ventralmente y se ubica dorsalmente al proceso zigomático del escamoso sin estar en contacto con éste. En vista lateral y dorsal el margen dorsal de la órbita es cóncavo y el margen ventral de la órbita no se conservó en ninguno de los ejemplares.

En vista ventral (Fig. 4.24) el foramen óptico se ubica en posición lateral a la fisura preesfenoides-basiesfenoides y está delimitado por el frontal, el preesfenoides, el orbitoesfenoides (fusionado al frontal) y el aliesfenoides. El canal óptico se desarrolla desde el foramen óptico en dirección lateral sobre el margen póstero-ventral del proceso supraorbitario del frontal. En su 
porción medial dicho canal es profundo y angosto; en dirección lateral es más ancho, menos profundo y no ocupa todo el ancho del proceso supraorbitario del frontal, sino que se ubica en los 2/3 posteriores. En su porción medial el canal óptico está delimitado anteriormente por el frontal y posteriormente por el aliesfenoides y en menor medida por el parietal. En dirección lateral el canal óptico está formado únicamente por el frontal y, la porción preservada del margen anterior y posterior, permite inferir que el canal permanece abierto ventralmente en toda su extensión. El foramen etmoidal es grande y circular y se ubica en la pared dorsal del canal óptico, en su extremo ántero-medial. No se observan forámenes frontales. La superficie ventral de cada frontal presenta una fosa profunda y simétrica ubicada entre la sutura del preesfenoides y el frontal, en posición dorsal al proceso supraorbitario del frontal al igual que las observadas en Morenocetus y en Eubalaena australis.

\section{ORBITOESFENOIDES}

El orbitoesfenoides no puede individualizarse dentro del canal óptico ya que probablemente este fusionado al frontal y al preesfenoides.

\section{PARIETAL}

El parietal forma en vista lateral parte de la pared lateral de la caja craneana y contacta anteriormente con el frontal a través de la sutura coronal (Fig. 4.23). Dicha sutura se inicia a nivel del margen anterior del supraoccipital, continúa en dirección posterior sobre el margen póstero-dorsal del frontal y luego se curva ventralmente. Posteriormente, el parietal contacta con el escamoso a través de la sutura parieto-escamosal, la cual se desarrolla dorso-ventralmente en la pared medial de la fosa temporal y está curvada posteriormente. Dorsalmente, el parietal contacta con el supraoccipital y contribuye a la formación de la cresta temporal, la cual protruye lateralmente en forma leve. La porción ántero-dorsal del parietal se superpone sobre el extremo póstero-dorsal del proceso supraorbitario del frontal y la superficie del parietal es fuertemente cóncava en este sector.

En vista dorsal (Fig. 4.22), el parietal está excluido del vértex craneal por la extensión y superposición anterior del supraoccipital, por lo cual sólo es visible en vista lateral.

En vista ventral, el parietal está cubierto en su mayor parte por el aliesfenoides y sólo una pequeña porción es visible lateralmente en la región orbitotemporal (Fig. 4.24).

\section{ESCAMOSO}

El escamoso forma parte de la pared lateral de la caja craneana, la pared medial y posterior de la fosa temporal, el proceso zigomático y postglenoideo, la fosa glenoidea y la fosa periótica. 
En vista lateral (Fig. 4.23) está desarrollado en dirección dorso-ventral con respecto al plano sagital del cráneo y contacta anteriormente con el parietal, dorsalmente con el supraoccipital y póstero-lateralmente con el exoccipital a través de una sutura redondeada. La cresta escamosa lateral se desarrolla como una acentuada convexidad anterior sobre la superficie lateral del escamoso y dorsalmente al proceso zigomático. Al igual que en Morenocetus, el desarrollo de esta cresta impide en vista lateral la visualización de la pared póstero-dorsal de la fosa temporal, pero no la sutura escamoso-parietal. Dicho proceso es corto y de contorno triangular y está orientado ánterolateralmente. El proceso zigomático se ubica en posición ventral al proceso postorbitario del frontal y separado por una distancia dorso-ventral de $54 \mathrm{~mm}$. El proceso postglenoideo está erosionado tanto en el holotipo como en el paratipo, a diferencia del ejemplar MPCNyO 290 donde se preservó en forma completa (Fig. 4.27 B-C). Dicho proceso es corto dorso-ventralmente ( $\sim 52 \mathrm{~mm}$; ejemplar MPCNyO 290), de aspecto bulboso con el margen ventral redondeado y está orientado láteroventralmente en vista posterior. En vista lateral la fosa glenoidea es posterior al proceso postorbital y anterior al ápex posterior de la cresta nucal y, en vista ventral, es plana a levemente cóncava (Fig. 4.27C). El escamoso no presenta hendidura en el escamoso (squamosal cleft). En vista dorsal el escamoso diverge lateralmente formando la pared posterior de la fosa temporal, la cual es levemente cóncava (Fig. 4.22).

En vista ventral el escamoso forma la pared dorsal, anterior y lateral de la fosa que aloja el periótico, la fosa periótica. Dicha fosa es una depresión profunda, de contorno ovalado, en la superficie dorsal del escamoso que se extiende desde la base del proceso falciforme hasta el margen ántero-medial del meato auditivo externo. El meato auditivo externo es un canal ancho ( 32 $\mathrm{mm}$ ) y largo ( $147 \mathrm{~mm}$ ) que se extiende póstero-lateralmente (Fig. 4.27B), dorsalmente al proceso postglenoideo y anteriormente al proceso posterior compuesto. El margen medial del meato forma una proyección triangular, que se extiende ántero-medialmente y corresponde al proceso espinoso del escamoso. El margen posterior es recto y forma la cresta meatal posterior, la cual es bien pronunciada y contacta con el proceso posterior compuesto a través de una sutura visible (SR3). En la superficie ventro-medial del meato hay una fosa profunda, cóncava ocupada in vivo por la membrana timpánica (capítulo 6) (Fig. 4.26). El proceso falciforme está incompleto en el holotipo y paratipo, pero está presente en el ejemplar MPCNyO 290. Es una proyección plana, larga ánteroposteriormente y delgada transversalmente, que se desarrolla en dirección posterior y contacta con el margen anterior de la bulla timpánica. El foramen pseudoval, lugar de salida de la rama mandibular del nervio trigémino $\left(\mathrm{V}_{3}\right)$, se infiere en una muesca profunda (Ancho=12 $\mathrm{mm}$ ) en la superficie ventral del escamoso entre el proceso falciforme y la lámina lateral del pterigoides (Fig. 4.26). No fue posible confirmar si el pterigoides cierra esta muesca formando un foramen, ya que dicho hueso no se preservó en forma completa en ninguno de los ejemplares analizados. La fosa 
glenoidea es levemente cóncava y se ubica posteriormente al proceso postorbitario del frontal. A nivel de la región orbitotemporal, el escamoso contacta anteriormente con el aliesfenoides a través de una sutura visible (estadio $\mathrm{SR}_{3}$ ), de configuración aserrada que se desarrolla medio-lateralmente. Medialmente, contacta con la lámina lateral del pterigoides a través de una sutura recta que se desarrolla ántero-posteriormente (estadio $\mathrm{SR}_{3}$ ).

\section{BASIOCCIPITAL}

El basioccipital se ubica en la región póstero-ventral del cráneo y forma parte de la pared ventral del mismo (Fig. 4.24). En el paratipo la porción horizontal o basilar del basioccipital esta levemente expuesto en la pared ventral de la caja craneana debido a la superposición del vómer, el cual cubre la sutura basioccipital-basiesfenoides. En vista dorsal dicha sutura está completamente fusionada (estadio SR4). En el holotipo, donde el vómer no está preservado, dicha sutura no es evidente en vista ventral y dorsal (estadio SR4). Posteriormente, el basioccipital contacta con el exoccipital a través de una sutura completamente fusionada (estadio SR4).

En vista posterior la porción basilar del basioccipital es cóncava. Las crestas basioccipitales se proyectan ventro-lateralmente, en posición medial a la cresta medial del exoccipital. Dichas crestas son robustas, anchas transversalmente $(\sim 53 \mathrm{~mm})$ y cortas dorso-ventralmente $(48 \mathrm{~mm})$ (Fig. 4.25).

En vista ventral (Fig. 4.26) la superficie medio-posterior de la cresta basioccipital es levemente cóncava y la superficie medial es lisa, y no se observan crestas y surcos para la inserción de la musculatura flexora del cuello. En el paratipo la cresta basioccipital contacta anteriormente con la lámina media del pterigoides a través de una sutura visible (estadio $\mathrm{SR}_{3}$ ), mientras que en el holotipo esta sutura no es visible (estadío SR4).

\section{VÓMER}

El vómer se conservó, en forma parcial, sólo en el paratipo y la porción preservada es la posterior la cual, debido a la ausencia de los palatinos, está expuesta en vista ventral (Fig. 4.24; 4.26). La porción posterior del vómer se ubica en posición ventral al basiesfenoides y basioccipital, obstruyendo la sutura basiesfenoides/basioccipital, y contacta lateralmente con la lámina media del pterigoides. La extensión final del vómer no pudo determinarse ya que el margen posterior no se preservó. Sobre la superficie ventral y en posición medial se ubica la cresta vomerina que se desarrolla ántero-posteriormente, la cual está flanqueada por dos superficies cóncavas. En el ejemplar MPCNyO 290 se conservó parte de la región anterior del vómer que está deformada por procesos tafónomicos. 


\section{BASIESFENOIDES-PREESFENOIDES}

El basiesfenoides contacta en vista ventral lateralmente con la lámina media del pterigoides y posteriormente con el basioccipital. Anteriormente entre el preesfenoides y el basiesfenoides, se encuentra la fisura basiesfenoides-preesfenoides de configuración aproximadamente oval (Ancho=96 $\mathrm{mm}$; Largo máximo= $27 \mathrm{~mm}$ ), como resultado ambos huesos están en contacto sólo en su extremo lateral. En vista dorsal el basiesfenoides presenta una depresión leve correspondiente a la silla turca. No se observa el foramen carotídeo dorsal.

El preesfenoides se desarrolla ántero-posteriormente a lo largo de la línea media del cráneo y contacta lateralmente con el frontal (Fig. 4.24). El margen posterior es triangular medialmente y cóncavo lateralmente.

\section{ALIESFENOIDES}

El aliesfenoides se preservó sólo en el paratipo y delimita el canal óptico en su porción póstero-medial (Fig. 4.24; 4.26). El aliesfenoides está ampliamente expuesto en la región orbitotemporal del cráneo, y dado que los palatinos no están completamente preservados, no puede determinarse si éstos cubrian originalmente al aliesfenoides. Este último es de forma cuadrangular, con un ancho transversal de $\sim 34 \mathrm{~mm}$ y un largo ántero-posterior de $\sim 46 \mathrm{~mm}$. Presenta una proyección lateral que se extiende por $\sim 27 \mathrm{~mm}$ hacia el margen lateral del cráneo, cubriendo la proyección lateral del parietal, y definida anteriormente por una cresta pronunciada. Contacta anteriormente con el frontal, posteriormente con el escamoso, lateralmente con el parietal y medialmente con el palatino y el pterigoides. La sutura aliesfenoides-frontal se extiende transversalmente dentro del canal óptico por $\sim 53 \mathrm{~mm}$. La sutura aliesfenoides-parietal es aserrada y se extiende por $\sim 40 \mathrm{~mm}$ ántero-posteriormente. La sutura aliesfenoides-escamoso también es de aspecto aserrado y se desarrolla transversalmente por $\sim 37 \mathrm{~mm}$. La sutura aliesfenoides-pterigoides es visible en la región orbitotemporal por $\sim 18 \mathrm{~mm}$ y se extiende ántero-posteriormente. En superficie ventro-lateral el aliesfenoides presenta una depresión bien definida en forma semicircular que no se observa en Eubalaena australis. El foramen pseudoval no perfora el aliesfenoides externamente.

En vista lateral el aliesfenoides no está expuesto en la pared medial de la fosa temporal.

\section{PTERIGOIDES-PALATINO}

La porción preservada del pterigoides corresponde a la lámina media, lateral y dorsal; los hamulus pterigoideos y la mayor parte de la lámina ventral no se preservaron (Fig. 4.24; 4.26). La lámina media es elongada ántero-posteriormente y contacta anteriormente con el palatino y el basiesfenoides, medialmente con el vómer, y posteriormente con el basioccipital. En dirección posterior la lámina media se extiende sobre el basioccipital y contribuye a la formación de la cresta 
basioccipital. La lámina lateral se desarrolla medio-lateralmente hasta el foramen pseudoval y contacta lateralmente con el escamoso a través de una sutura visible (estadío $\mathrm{SR}_{3}$ ) e irregular ( $\mathrm{L}=40$ mm; espécimen $\mathrm{CH}-\mathrm{P}_{33-01)}$ y anteriormente con el aliesfenoides. La lámina dorsal del pterigoides forma la pared dorsal de la fosa para el seno pterigoideo y se extiende ántero-lateralmente por 30 mm y póstero-lateralmente por $22 \mathrm{~mm}$ dentro del hiato craneal; como resultado el aliesfenoides no es visible en la pared dorsal de la fosa pterigoidea. El eje principal de la fosa para el seno pterigoideo es oval y está desarrollada principalmente en dirección dorso-ventral. El foramen carotídeo ventral es pequeño y abre en la superficie ventral de la lámina dorsal, a $\sim 27 \mathrm{~mm}$ de la sutura pterigoidesbasioccipital (Fig. 4.26).

Se conservó una pequeña porción de ambos palatinos. Posteriormente se ubican en posición ventral a la porción preservada de la lámina ventral del pterigoides y anteriormente sobre el frontal y el preesfenoides. La extensión final posterior de los palatinos no puede determinarse (Fig. 4.26).

\section{MAXILAR}

El maxilar forma parte de la región rostral del cráneo. El maxilar derecho se conservó en mayor medida que el izquierdo faltando en ambos casos parte del extremo anterior y posterior de los mismos (Fig. 4.28). Se preservó parte del proceso descendente del maxilar derecho. El largo de los maxilares representan aproximadamente la mitad del largo total preservado del cráneo $(\mathrm{L}=+560$ $\mathrm{mm})$.

En vista dorsal (Fig. 4.28 A) el maxilar tiene un contorno triangular y, a diferencia de lo que ocurre en Eubalaena australis así como también en otros balénidos, no está comprimido transversalmente. Posteriormente el maxilar es ancho (Tabla 4.3) y plano. En dirección anterior es más angosto y de contorno triangular, con la cara lateral oblicua (orientada látero-ventralmente) y la cara medial recta (orientada ventralmente). El margen medial es recto en el maxilar derecho y con una leve curvatura en el izquierdo, y la porción preservada del margen lateral permite inferir que también era recto. A lo largo de la superficie dorso-medial del maxilar se observan acanaladuras que posiblemente forman el sitio de articulación con el premaxilar. La porción preservada del proceso descendente del maxilar derecho corresponde a la porción medial del mismo. En el margen posterior se observa una acanaladura profunda rodeada por dos superficies laterales planas que se desarrollan medio-lateralmente y que corresponde a la zona de articulación con el frontal. El margen anterior de dicho proceso es cóncavo mientras que el margen posterior está incompleto.

En vista ventral (Fig. 4.28B) la superficie del maxilar es levemente cóncava y presenta dos acanaladuras profundas y angostas, una de posición medial y otra lateral, orientadas ánteroposteriormente que se interpretan como los canales vasculares nutricios para las barbas. No se observan forámenes nutricios. 
En vista lateral (Fig. 4.28C) los maxilares no están marcadamente arqueados en dirección ventral como sucede en Eubalaena australis.

\section{NASAL}

En el ejemplar MPEF-PV-1122 se conservó el nasal izquierdo mientras que en el MPCNyO 290 se preservaron ambos nasales articulados a la caja craneana, pero en forma incompleta, faltando la porción anterior (Fig. 4.27A; 4.29). En comparación con el ancho bizigomático del cráneo, los nasales son relativamente cortos (el largo de los nasales representan $\sim 25$ del ancho bizigomático en ambos ejemplares). En vista dorsal el nasal es elongado ántero-posteriormente y con un ancho máximo en su porción medial de $59 \mathrm{~mm}$ (Tabla 4.3). El margen medial es recto y la superficie medial de articulación con el nasal izquierdo es plana. El margen lateral es cóncavo posteriormente, donde presenta una superficie de articulación, luego marcadamente convexo y nuevamente cóncavo. El margen anterior es convexo, a diferencia del margen posterior que es triangular, lo cual determinaría una forma de "M" si ambos nasales estuvieran preservados. En vista ventral, se observa hacia el margen lateral una profunda acanaladura.

\section{PERIÓTICO}

En el holotipo se conservaron ambos perióticos desarticulados del cráneo. El periótico izquierdo está mejor preservado que el derecho donde falta el proceso posterior compuesto. En el paratipo sólo se conservó en forma completa el periótico izquierdo articulado a la caja craneana y en el ejemplar MPCNyO 290 se conservaron ambos perióticos articulados a la caja craneana.

En vista ventral (Fig. 4.30A-B) el proceso anterior es largo ántero-posteriormente y el extremo anterior es de contorno redondeado. Sobre la superficie ventral del cuerpo del periótico se ubica el pedicelo anterior para la articulación con la bulla timpánica, el cual es una cresta bien definida ( $\mathrm{L}=17 \mathrm{~mm} ; \mathrm{A}=8 \mathrm{~mm}$ ). La tuberosidad ventro-lateral del proceso anterior es pequeña y presenta proyecciones/crestas en el hueso que le otorgan a la superficie un aspecto irregular. Al igual que en Morenocetus no se observa una proyección lateral hipertrofiada de la tuberosidad ventro-lateral como la presente en Eubalaena australis. La fosa para el martillo es una depresión poco evidente pero detectable al tacto, de forma aprox. circular, que se ubica en la región pósteromedial del cuerpo del periótico, en posición lateral a la pars coclearis. La pars coclearis es elongada ántero-posteriormente y está levemente orientada en dirección lateral, formando un ángulo agudo con el plano sagital del cráneo (Tabla 4.4). El promontorio se desarrolla como una estructura convexa en la superficie ventral de la pars coclearis y es más largo que ancho $(A / L=0.69)$. El surco promontorial es poco profundo y se desarrolla sobre la superficie ventral de la pars coclearis en posición ántero-medial. El proceso posterior compuesto está orientado póstero-lateralmente con 
respecto al eje longitudinal del proceso anterior (Fig. 4.26; 4.27). En el paratipo, el proceso posterior compuesto está fusionado al escamoso a lo largo de su superficie dorsal, y contacta anteriormente con la cresta meatal posterior del escamoso a través de una sutura recta y visible (estadio $\mathrm{SR}_{3}$ ), posteriormente con el exoccipital (estadio SR3) y lateralmente con el escamoso. El proceso posterior compuesto es largo, angosto en su extremo medial y se más ancho en dirección lateral (Tabla 4.4); el margen lateral es convexo. En el ejemplar MPCNyO 290 se observa una línea de unión entre lo que podría corresponder al proceso posterior del periótico y el proceso posterior del timpánico. En la superficie ventro-medial del proceso posterior compuesto se ubica el pedicelo posterior para la articulación con la bulla timpánica, el cual es una cresta bien desarrollada.

En vista posterior (Fig. 4.3oE-F) la fenestra coclear se ubica en el extremo posterior de la pars coclearis y en posición medial a la cresta coclear posterior (Fig. 38). La fenestra coclear es grande, de forma oval, más alta dorso-ventralmente $(7 \mathrm{~mm})$ que ancha transversalmente $(3.5 \mathrm{~mm})$ y está orientada oblicuamente en dirección medio-lateral con respecto al plano sagital del cráneo. En el paratipo el margen medial presenta una serie de estriaciones longitudinales. Dentro de la fenestra es visible la impronta de la parte basal del espacio interlaminar donde se ancla la membrana basilar. La cresta coclear posterior se ubica posteriormente a la pars coclearis, lateralmente a la fenestra coclear y medialmente al surco facial. Es delgada, de contorno triangular, ligeramente más corta que en Morenocetus $(\mathrm{L}=5 \mathrm{~mm})$, y está orientada póstero-ventralmente. La superficie dorsal de la cresta coclear posterior forma el piso de la fosa para el músculo estapedial. La fosa estilomastoidea se ubica dorso-posteriormente a la pars coclearis, es una depresión profunda que se desarrolla dorsoventralmente hasta la base del proceso posterior compuesto del periótico.

En vista lateral el foramen oval es elíptico $(\mathrm{L}=5 \mathrm{~mm} ; \mathrm{A}=3 \mathrm{~mm})$, más pequeño que la fenestra coclear y se ubica en posición medial al surco para la salida del nervio facial (VII) y a la fosa estapedial (Fig. 4.30 E). La fosa para el músculo estapedial es grande y profunda, de contorno elíptico ( $\mathrm{L}=11 \mathrm{~mm} ; \mathrm{A}=6 \mathrm{~mm}$ ) y se ubica póstero-lateralmente al foramen oval. En posición lateral y separado por una cresta baja de la fosa estapedial, se encuentra el surco para la salida del nervio facial (VII) el cual se desarrolla póstero-lateralmente sobre la superficie ventro-medial del proceso posterior compuesto.

En vista dorso-medial (Fig. 4.30 C-D) se ubican los forámenes endocraniales. El meato auditivo interno está dividido por una cresta transversa baja, que no alcanza la superficie de la pars coclearis, en dos forámenes: anteriormente la apertura dorsal o interna del canal facial (VII) y póstero-medialmente el meato auditivo interno sensu estricto (salida del nervio VIII). La apertura interna del canal facial es de contorno circular y de menor tamaño que el meato auditivo interno sensu estricto. Posteriormente al meato auditivo interno y separado por una cresta transversal se encuentra el foramen perilinfático o acueducto coclear de contorno oval. El meato auditivo interno 
(sensu lato) y el foramen perilinfático están alineados ántero-posteriormente. En posición medial al foramen perilinfático y separado por un septo, se ubica en una depresión el foramen endolinfático o acueducto vestibular, el cual es de mayor tamaño que el perilinfático. La superficie entre la pars coclearis y el tegmen timpánico es plana al igual que en Balaena mysticetus. El proceso superior forma una cresta que delimita lateralmente la fosa suprameatal.

En vista dorsal el surco ántero-externo es un surco profundo, vertical, que se desarrolla en posición lateral a la tuberosidad ventro-lateral y lateral al proceso anterior. Al igual que en Morenocetus no presenta proyección piramidal.

\section{BULLA TIMPÁNICA}

En el holotipo se preservó la bulla timpánica izquierda desarticulada del cráneo, mientras que en el ejemplar MPCNyO 290 se preservaron ambas bullas timpánicas articuladas a la caja craneana (Fig. 4.27; 4.31; Tabla 4.4.). En el holotipo el margen ventro-lateral de la bulla está incompleto y en el ejemplar MPCNyO 290 falta el margen medial de las mismas.

La bulla es de forma rectangular y está comprimida dorso-ventralmente pero no en forma tan marcada como en Eubalaena australis. El tamaño de la bulla es pequeño en comparación con $E$. australis: el largo ántero-posterior es $78 \mathrm{~mm}$ y el ancho transversal es $\sim 40 \mathrm{~mm}$. La bulla en posición articulada está unida anteriormente al cuerpo del periótico a través de un pedicelo anterior corto, y, posteriormente, a través de un pedicelo posterior más largo, que está ubicado en el proceso posterior compuesto. El eje axial de la bulla está orientado ántero-posteriormente y levemente en dirección lateral con respecto al plano sagital del cráneo.

En vista dorsal (Fig. 4.31 A) el involucro está dividido por un surco medio-lateral poco profundo en un sector posterior grueso y un sector anterior más delgado. Este surco no está presente en Eubalaena australis, pero un surco de morfología similar se observa en el misticeto extinto Mammalodon (Fitzgerald, 2010; P: 405). A diferencia de E. australis el involucro presenta pocas y levemente marcadas crestas transversales en la superficie dorsal. La cresta del involucro es un engrosamiento marcado y rugoso de la superficie dorsal del involucro que no alcanza el margen anterior de la bulla. Dicha cresta está retraída lateralmente y no confluye con la cresta medial posteriormente. La morfología de la apertura de Eustaquio no puede determinarse en ninguno de los ejemplares ya que el margen ántero-lateral no se preservó.

En vista ventral (Fig. 4.31 B) la bulla presenta el margen anterior recto, el extremo ánteromedial redondeado y el margen medial convexo. La compresión dorso-ventral de la cara ventral de la bulla no es pronunciada en el Taxón A como en Eubalaena australis, y como resultado el surco longitudinal es muy poco acentuado. Esto le otorga a la bulla un aspecto más globoso en comparación con E. australis. En el margen látero-ventral se encuentra el proceso sigmoideo 
flanqueado anteriormente por el surco lateral y posteriormente por la fisura sigmoidea. El proceso sigmoideo es largo $(13 \mathrm{~mm})$ y de contorno convexo. El surco lateral es un surco poco profundo que se desarrolla oblicuamente en dirección ántero-ventral por $\sim 21 \mathrm{~mm}$. La fisura sigmoidea es un incisura corta, $(\sim 9 \mathrm{~mm})$ y menos profunda que el surco lateral. En vista lateral la superficie ventral de la bulla es convexa. La morfología del surco o anillo timpánico no pudo determinarse ya que el margen medial de la bulla no se preservó en ninguno de los ejemplares.

En vista medial (Fig. 4.31 C) la cresta medial se desarrolla ántero-posteriormente y forma el margen medial y ántero-medial de la bulla timpánica. La cresta medial es moderadamente ancha y de contorno convexo. La ligera compresión dorso-ventral de la bulla es evidente en vista medial. Sobre la superficie póstero-dorsal del involucro se desarrolla una prominencia convexa que corresponde al lóbulo medial, carácter no observado en otros balénidos. Dicho lóbulo no se extiende posteriormente hasta el nivel alcanzado por el lóbulo lateral. A diferencia de algunos misticetos extintos basales (tales como Aetiocetus y Eomysticetus) no se observa una cresta conectando dichos lóbulos.

En vista lateral (Fig. 4.31 D), el lóbulo anterior de la bulla es más corto ántero-posteriormente $(\mathrm{L}=21 \mathrm{~mm})$ que el lóbulo posterior $(42 \mathrm{~mm})$ y representa el $15 \%$ del largo total de la bulla. El proceso cónico es delgado, más largo ántero-posteriormente $(15 \mathrm{~mm})$ que alto dorso-ventralmente $(\sim 8 \mathrm{~mm})$ y es convexo dorsalmente. La cavidad timpánica es de contorno aproximadamente ovalado, debido al engrosamiento posterior del involucro es más angosta en dirección posterior y presenta el margen ventral convexo y el margen dorsal aproximadamente recto.

\section{HIOIDES}

Los hioides, específicamente el basihial y el tirohial, se preservaron en el ejemplar MPEF-PV1122 en forma completa (Fig. 4.32). El basihial presenta la superficie dorsal plana y la ventral convexa. El margen anterior forma una proyección medial en punta mientras que el margen posterior es marcadamente cóncavo y el estilohial no se preservó fusionado a este elemento. El tirohial es, a diferencia de Eubalaena y de Balaena, aplanado dorso-ventralmente.

\section{4·3.2.2 Balénido de la Formación Paraná}

\section{SISTEMÁTICA PALEONTOLÓGICA}

Orden CETACEA Brisson, 1762

Rango no determinado NEOCETI Fordyce \& Muizon, 2001

Suborden MYSTICETI Gray, 1864 Sensu Cope, 1869 
Rango no determinado CHAEOMYSTICETI Mitchell, 1989

Familia BALAENIDAE Gray, 1825

Gen. et sp. indet.

Espécimen referido-MACN-PV 13221, bulla timpánica derecha, donde falta el margen lateral y parte de la superficie ventral.

Localidad y procedencia estratigráfica-Paraná (Entre Ríos), Formación Paraná (Mioceno Tardío) Comentarios-Este material fue descripto por Cozzuol (1993) y posteriormente por Agnolin \& Lucero (2004).

Descripción-La bulla timpánica (MACN-PV 13221) es levemente más larga y ancha que en el Taxón A (Tabla 4.4). En vista dorsal (Fig. 4.33A) el involucro está dividido por un surco medio-lateral poco profundo que separa una porción gruesa y posterior del involucro, de una porción anterior más delgada. La superficie presenta crestas transversales moderadamente marcadas. La cresta del involucro está retraída lateralmente. El margen anterior y posterior de la bulla es de contorno redondeado.

En vista ventral (Fig. 4.33B) el margen anterior es recto mientras que el margen medial es convexo y ambos forman entre si un ángulo casi recto. El surco longitudinal es más pronunciado que en el Taxón A.

En vista medial (Fig. 4.33C) la cresta medial se desarrolla ántero-posteriormente y no confluye con la cresta del involucro. La cresta medial es moderadamente ancha y de contorno convexo. La compresión dorso-ventral de la bulla es evidente en esta vista presentando un estado intermedio entre el Taxón A y Eubalaena australis.

\subsection{Discusión}

\subsubsection{Variaciones ontogenéticas en la morfología del cráneo y mandíbula de Eubalaena australis}

Los estudios ontogenéticos en misticetos, y en particular en los balénidos, son escasos en la literatura y se limitan a los realizados en el siglo XIX y XX donde la actividad de caza comercial posibilitaba el acceso a especímenes de distintas edades (Eschricht \& Reinhardt, 1866; Carte \& Macalister, 1868; Andrews, 1914, 1916; Schulte, 1916). Con las restricciones a la caza comercial, el acceso a individuos de distintas edades se volvió dificultoso, lo cual impidió el desarrollo de este tipo de estudios. Sin embargo, en los últimos años, la comunidad científica ha puesto nuevamente su interés y esfuerzo en este tipo de estudios, los cuales son muy valiosos para abordar aspectos evolutivos y morfológicos de los misticetos (e.g. Walsh \& Berta, 2011; Roston et al., 2013; Marx et al., 
2013). En los balénidos, la morfología del cráneo y mandíbula de los neonatos y crías es prácticamente desconocida, excepto por los estudios de Eschricht \& Reinhardt (1866) en Balaena mysticetus y las descripciones que se presentan en esta tesis.

Como resultado de los estudios comparativos entre los individuos neonatos, crías y adultos de Eubalena australis en la morfología del cráneo, complejo tímpano-periótico y mandíbula, se observaron las siguientes diferencias (Fig. 4.34):

Cráneo:

1. Maxilar: En el neonato y en las crías (CNPMAMM 746, 748) el proceso ascendente del maxilar es corto ántero-posteriormente, de contorno aproximadamente triangular y confluye con el margen posterior del maxilar. Esto se diferencia de los adultos, donde el desarrollo anterior del supraoccipital resulta en una compresión ántero-posterior del vértex y, por lo tanto, en una reducción del proceso ascendente del maxilar (Marx et al., 2013).

Por otro lado en el neonato y en las crías la ventana maxilar está más cerrada transversalmente en comparación con los adultos (Fig. 4.34A-B).

2. Supraoccipital: en los neonatos y crías en estados tempranos de su desarrollo, el supraoccipital tiene un desarrollo predominantemente horizontal con respecto al plano horizontal del cráneo (considerando el cráneo en posición anatómica, Fig. 4.34C). En los adultos este presenta una orientación más vertical con respecto al plano horizontal del cráneo y el ángulo agudo formado entre ambos es menos pronunciado que en los neonatos y crías. Por otro lado, en sección sagital, el supraoccipital es grueso en su porción anterior (14 mm; CNPMAMM 746) y muy delgado en dirección posterior (por delante del foramen magnum) (3 mm; CNPMAMM 746) (Fig. 4.5), a diferencia de los adultos donde el sector posterior está más engrosado. Otra variación observada en el supraoccipital es la forma de los márgenes laterales: en los neonatos son rectos y en las crías levemente cóncavos, a diferencia de los adultos donde son marcadamente cóncavos. Esto último puede estar relacionado con el mayor desarrollo de la cresta temporal en los adultos (formada por el supraoccipital/escamoso/parietal) en comparación con los neonatos y crías.

3. Exoccipital: la cresta exoccipital medial está muy poco desarrollada en las crías, a diferencia de los adultos donde es bien conspicua.

4. Posición de la fosa glenoidea: en los neonatos la fosa glenoidea se ubica en posición anterior al ápex posterior de la cresta nucal, a diferencia de los adultos donde dichas estructuras están alineadas dorso-ventralmente (Fig. 4.34C).

5. Rostro: en neonatos y crías se observa una curvatura menos marcada del rostro (maxilar y premaxilar) en comparación con los adultos.

\section{Periótico:}


6. Proyección lateral del proceso anterior: en los neonatos y en las crías en etapas tempranas de su desarrollo, la proyección lateral del proceso anterior es corta y está poco desarrollada en comparación con los adultos donde dicha estructura está hipertrofiada (Fig. 4.35A).

7. Proceso posterior compuesto del periótico: este proceso es más corto en las crías que en los adultos (en las crías el largo del proceso posterior representa aproximadamente la mitad del largo total observado en los adultos) (Fig. 4.35A).

8. Fosa para el martillo: en las crías la fosa para el martillo es una concavidad bien definida delimitada por bordes laterales, a diferencia de los adultos donde dicha fosa sólo se detecta al tacto.

9. En los neonatos y crías la superficie dorsal del periótico presenta un aspecto más liso y carece de las crestas y surcos que se observan en el periótico de los adultos. Asimismo, en los neonatos y crías no se observan las proyecciones óseas en forma de punta alrededor de los forámenes endocraneales que presentan los adultos.

Bulla timpánica:

10. En vista ventral el margen ántero-medial de la bulla es redondeado y no rectangular como en los adultos. Asimismo la compresión dorso-ventral de la bulla timpánica es menos acentuada y presenta un surco longitudinal poco marcado. Todas estas características le otorgan a la bulla de las crías un aspecto globoso, a diferencia de los adultos donde es de forma romboidal (Fig. 4.35B)

\section{Mandíbula}

11. En los neonatos y crías de Eubalaena australis el proceso coronoides es una estructura conspicua que se ubica en el margen dorsal de la rama mandibular. Dicho proceso presenta un contorno aproximadamente triangular, es más largo ántero-posteriormente que alto dorso-ventralmente y, en vista dorsal, el ápex del proceso está alineado con el margen dorsal del cuerpo mandibular. En los adultos el proceso coronoides está notablemente reducido (Fig. $4 \cdot 35 \mathrm{C}$ ).

En este contexto, se acepta la hipótesis 1 y se establece que, dentro del patrón corporal general del cráneo de los balénidos, se verifican variaciones entre crías y adultos, algunas de las cuales son parámetros independientes del tamaño y permiten establecer indicadores relativos del estadio ontogenético. Cabe destacar que observaciones preliminares en crías y adultos de la especie estrechamente emparentada E. glacialis, sugieren el mismo tipo de variaciones entre ambos estadios de la serie ontognética.

Entre las variaciones que se observan, y que se identifican como dependientes del tamaño, se encuentran: cambio en la orientación y en el engrosamiento del supraoccipital, mayor desarrollo de crestas en el cráneo para la inserción muscular, incremento en la curvatura del rostro, cambio en la 
posición de la fosa glenoidea, y el aumento de tamaño de la proyección ventro-lateral del proceso anterior y del proceso posterior compuesto del periótico. La variación ontogenética en la inclinación del supraoccipital y en el engrosamiento de la porción anterior del supraoccipital, fue previamente mencionada por otros autores para las especies estrechamente emparentadas Eubalaena glacialis y Balaena mysticetus (Van Beneden \& Gervais, 1880; Eschricht \& Reinhardt, 1866; Bisconti, 2005). Estas variaciones fueron asociadas al aumento del tamaño del cráneo producido durante la ontogenia de estas especies. El engrosamiento de la porción anterior del supraoccipital se vinculó con un reforzamiento de este sector del cráneo, no necesariamente para proteger el encéfalo, sino más bien para brindar un buen punto de anclaje a los elementos del rostro, los cuales se vuelven más grandes y más pesados a medida que el animal crece (Eschricht \& Reinhardt, 1866). Asimismo el cambio en la orientación del supraoccipital y en la posición de la fosa glenoidea podría estar vinculado a un reposicionamiento de la caja craneana como consecuencia del incremento en la longitud y curvatura del rostro.

La reducción del proceso ascendente del maxilar y del proceso coronoides de la mandíbula se interpretan como variaciones inversamente relacionadas con el aumento del tamaño corporal. Las variaciones en la morfología del proceso ascendente del maxilar y del proceso coronoides de la mandíbula, han sido exploradas en otros taxones (i.e. Caperea) además de Eubalaena, y utilizadas para abordar problemáticas en las relaciones filogenéticas de los misticetos (Marx et al., 2013). Estos estudios, en crías y adultos del balénido Eubalaena spp. y de Caperea marginata, brindaron una nueva línea de evidencia que podría ayudar a resolver las relaciones filogenéticas de estos dos grupos de misticetos, lo cual ha sido tema de extensos debates en el terreno morfológico y molecular (e.g. Demeré et al., 2008; Geisler et al., 2011; Marx, 2010; Churchill et al., 2012). Los balénidos y Caperea marginata presentan ciertas semejanzas en la anatomía del cráneo y de la mandíbula, entre las que se encuentran un proceso coronoides de la mandíbula y un proceso ascendente del maxilar reducido (Bisconti, 2005). Sin embargo, al igual que lo observado en Eubalaena australis, la morfología del proceso ascendente del maxilar y del proceso coronoides de la mandíbula muestra un patrón diferente en los neonatos y crías de $C$. marginata. En estos últimos el proceso ascendente del maxilar presenta, a diferencia de los crías de Eubalaena australis, los márgenes paralelos, los cuales forman con el margen posterior del maxilar un ángulo de $90^{\circ}$. Asimismo el proceso coronoides de la mandíbula es bajo pero de contorno claramente triangular, y no está alineado con el margen dorsal de la rama mandibular como en E. australis (Marx et al., 2013). La exploración de estos caracteres muestra que el proceso coronoides de la mandíbula y el proceso ascendente del maxilar de las crías, tanto de Eubalaena como de Caperea, difieren de la de los adultos; y además diferen entre sí. Es interesante destacar que la morfología del proceso ascendente del maxilar de las crías de Eubalaena se asemeja a la de Morenocetus y algunos misticetos extintos (i.e. Diorocetus, Parietobalaena), 
mientras que la morfología del proceso coronoides es similar a la de algunos misticetos basales (e.i. Mammalodon y Eomysticetus) y stem Cetacea (i.e. Zyghoriza). Por otro lado la morfología del proceso ascendente del maxilar y del proceso coronoides de las crías de Caperea se asemeja a Miocaperea (taxón hermano de Caperea; Bisconti, 2012), balenopteroideos (e.g. Balaenoptera spp.; Archaeobalaenoptera) y algunos cetotéridos (i.e. Piscobalaena; Herpetocetus). Esta información sugiere que la similitud observada en algunas estructuras de la mandíbula y del maxilar de dos formas no estrechamente emparentadas (Capítulo 5), esto es los adultos de Eubalaena y Caperea, son resultado de una evolución convergente.

Por otro lado, las variaciones que se consideran independientes del tamaño son: apertura transversal de la ventana maxilar, fosa para el martillo poco acentuada, desarrollo de crestas y surcos en la superficie dorsal del periótico y bulla timpánica comprimida transversalmente.

En este contexto, este tipo de estudios ponen en evidencia la relevancia de estudiar series ontogenéticas en la comprensión de la historia evolutiva de un grupo, y por lo tanto este tipo de información no debería ser desestimada.

\subsubsection{Madurez osteológica de los balénidos}

Tradicionalmente en los mamíferos se utiliza el patrón de cierre de las suturas del cráneo para establecer la edad relativa de los ejemplares (e.g. Wyss, 1994; Landon et al., 1998), metodología que también se utiliza en los cetáceos odontocetos (Perrin, 1975). En los odontocetos las suturas de la caja craneana y del rostro completan el cierre cuando el animal alcanza la madurez sexual (Brunner, 1998), con lo cual el análisis de estas suturas es muy útil para determinar la madurez osteológica y, por lo tanto, la edad relativa de los ejemplares. En los misticetos el panorama es diferente ya que los estudios disponibles sobre el patrón de fusión de los huesos del cráneo son extremadamente escasos. Recientemente Walsh \& Berta (2011) analizaron la secuencia de fusión de las suturas de la caja craneana en balenoptéridos y escrictidos, el cual muestra que dichas suturas completan su cierre antes del año de edad cuando los individuos son crías.

En lo referente al análisis de la madurez osteológica de los balénidos no hay estudios previos que analicen el patrón de suturas y/o otros aspectos del cráneo que sirvan como proxy para determinar la edad de los individuos (e.g. grado de esponjosidad del hueso). Las observaciones preliminares realizadas en los cráneos de Eubalaena australis (efectuadas en neonatos, crías, subdultos y adultos) brindan un punto de partida para abordar esta problemática.

En los neonatos y crías las suturas de la caja craneana son cartilaginosas entre el exoccipital y el supraoccipital (se observa una abundante tejido cartilaginosos entre ambos huesos), entre el basioccipital/basiesfenoides (el tejido cartiloginoso es más delgado) y entre el 
basiesfenoides/preesfenoides (el tejido cartilaginoso es de mayor grosor). En todos los casos estas suturas presentan un estadio de fusión que varia entre SR1 y SR2 (Fig. 4.5). En crías en estados más avanzados de su desarrollo al menos la sutura exoccipital/supraoccipital presenta un estado de fusión completo (estadio SR4) (las otras suturas no pudieron visualizarse ya que estaban cubiertas por el vómer). En los subadultos y adultos las suturas entre el exoccipital/supraoccipital y entre el basioccipital/basiesfenoides están fusionados completamente (estadio SR4), mientras que la sutura entre el basiesfenoides/preesfenoides permanece abierta formando la fisura basiesfenoideapreesfenoidea. Por otro lado, en las crías de Eubalaena australis la sutura entre el proceso posterior del periótico y el proceso posterior de la bulla timpánica es evidente, mientras que estas dos estructuras que ya están fusionadas completamente en los adultos.

En los neonatos y crías el aspecto de los huesos es marcadamente esponjoso, de textura rugosa y muy delicada (se desgrana con facilidad), lo que evidencia su carácter de hueso en remodelación. Asimismo en el neonato se observa cartílago recubriendo la superficie de algunas estructuras tales como el proceso zigomático y postglenoideo del escamoso, la órbita y la superficie externa de los cóndilos occipitales. En los subadultos los huesos de la caja craneana presentan un aspecto más compacto en comparación con las crías, pero aún se observa cierta rugosidad del hueso al tacto, especialmente en el escamoso, la superficie ventral del exoccipital y del basioccipital. En los adultos los huesos del cráneo presentan un aspecto compacto y una textura lisa, excepto por las zonas de articulación (e.g. fosa glenoidea) y de inserción de estructuras blandas (e.g. superficie de las crestas basioccipitales).

Cabe destacar que observaciones preliminares en el cierre de las suturas y esponjosidad del hueso en crías, subadultos y adultos de la especie estrechamente emparentada E. glacialis, muestran el mismo patrón que el observado en E. australis.

Las observaciones previamente mencionadas en relación al grado de cierre de las suturas y el grado de esponjosidad de los huesos del cráneo de E. australis, brindan un punto de partida para analizar los estadios de madurez osteológica de esta especie. En referencia al patrón de cierre de las suturas, los resultados sugieren que al menos una de las suturas de la caja craneana (e.i. supraoccipital/exoccipital) está fusionada completamente en las crías en estados avanzados del desarrollo. Esto se corresponde con lo observado en balenoptéridos y escrictidos, donde dicha sutura es la última en completar su cierre (Walsh \& Berta, 2011). El cierre temprano de las suturas del basicráneo ha sido vinculado a un desarrollo y cierre rápido de la caja craneana, ante la elevada tasa de crecimiento que presentan estos misticetos durante el primer año de vida (Eschricht \& Reinhardt, 1866; Kenney, 2009). Esto ayudaría, no sólo a brindar contención y protección al encéfalo, sino también otorgaría sostén y anclaje a los huesos del rostro. El patrón de porosidad/esponjosidad del hueso varía entre crías, subadultos y adultos, lo cual brinda información complementaria sobre el 
estadio de edad relativo de los individuos. Las crías presentan un cráneo muy esponjoso con restos de cartílago, mientras que en los subadultos la mayor parte de los huesos tienen una estructura compacta, (excepto por algunos sectores que muestran todavía signos de remodelación), mientras que en los adultos los huesos son de aspecto compacto.

El testeo final de estas hipótesis requiere profundizar el estudio ontogenético del cráneo de los balénidos actuales incluyendo un mayor número de ejemplares, y complementarlo con información histológica de los huesos. Esto permitirá por un lado determinar cómo es el patrón de cierre de las suturas y la edad exacta a la cual se produce, y a su vez correlacionarlo con el estado de remodelación que presentan los huesos del cráneo. Sin embargo estos análisis escapan a los objetivos de esta tesis.

En lo referente a la madurez osteológica de los balénidos miocenos, como resultado de los estudios descriptivos de los ejemplares MPEF-PV-1122, MPCNyO 290 y CH-P33-01 asignados al Taxón A , se observaron diferencias entre éstos ejemplares que estarían indicando la presencia de al menos tres estadios ontogenéticos. El ejemplar MPCNyO 290 además de presentar un tamaño menor en comparación con los otros ejemplares, exhibe una serie de caracteres que pueden interpretarse como juveniles, debido a su gran semejanza con las crías de Eubalaena australis. En primer lugar, la sutura supraoccipital/exoccipital está abierta (estadio SR1) y los bordes preservados de esta región son naturales lo cual sugiere la presencia de abundante cartílago entre ambos huesos (Fig. 4.27), como en las crías de E. australis. El grado de fusión entre las suturas basioccipital/exoccipital y basioccipital/basiesfenoides no pudo determinarse ya que estos huesos no se preservaron. La sutura entre el supraoccipital/exoccipital está abierta (estadio SR1). La estructura de los huesos de la caja craneana es notablemente esponjosa (e.g. supraoccipital, parietal, escamoso, exoccipital y frontal). Por otro lado la sutura entre el proceso posterior del periótico y de la bulla timpánica presenta un estadio de fusión incompleto ( $\left.\mathrm{SR}_{3}\right)$. La cresta temporal y escamosa lateral son muy bajas y de aspecto esponjoso. Asimismo hay una porción faltante del supraoccipital, por delante del foramen magnum, la cual corresponde topológicamente con el sector más delgado de hueso observado en las crías de $E$. australis. Por último se observa un menor grado de telescopización anterior del supraoccipital, evidenciado por la presencia del interparietal? o el parietal? en el vértex del cráneo (Fig. 4.27).

En el ejemplar MPEF-PV-1122 la caja craneana presenta las suturas basioccipital/basiesfenoides, basioccipital/exoccipital y supraoccipital/exoccipital completamente fusionadas (estadio SR4) (Fig. 4.25). La sutura pterigoides-basioccipital no está fusionada (estadio $\mathrm{SR}_{3}$ ), y otras suturas son difíciles de observar ya que la superficie ventral está algo erosionada y faltan varios huesos. La cresta temporal y escamosa lateral son bajas y poco pronunciadas, mientras que la cresta occipital externa es incipiente. La superficie de los huesos de la caja craneana es de tipo compacto con excepción del escamoso. En el CH-P33-01 las suturas basioccipital/exoccipital, 
supraoccipital/exoccipital y basioccipital/basiesfenoides están fusionadas (SR4). Otras suturas de la caja craneana, tales como pterigoides-escamoso/vómer, aliesfenoides-escamoso/pterigoides/parietal, proceso posterior compuesto del timpánico-escamoso/exoccipital presentan un estadio de fusión incompleto ( $\left.\mathrm{SR}_{3}\right)$ (Fig. 4.24). La superficie del hueso es esponjosa en el escamoso y en la superficie ventral del exoccipital, del basioccipital y del pterigoides. Tanto en el ejemplar MPEF-PV-1122 y en CH-P33-O1 la superficie dorsal del supraoccipital presenta una porción faltante por delante del foramen magnum, donde el hueso es muy delgado.

Estas observaciones sugieren que:

1) el ejemplar MPCNyO 290 (Taxón A) presenta caracteres relacionadas con un estadio de inmadurez osteológica comparable al de las crías de Eubalaena australis, tales como suturas de la caja craneana sin fusionar, huesos de aspecto y textura esponjosa, junto con un menor tamaño del cráneo en comparación con los otros especímenes. Estas observaciones sugieren que se trata de una cría;

2) el ejemplar MPEF-PV-1122 muestra un estadio de madurez osteológica más avanzado, evidenciado por la presencia de suturas completamente fusionadas en la caja craneana y huesos de aspecto compacto y textura lisa, condición comparable a los adultos de E. australis, sugiriendo que se trata de un adulto;

3) el ejemplar $\mathrm{CH}-\mathrm{P}_{33-01}$ presenta un estadio de madurez osteológica menos avanzado en comparación con MPEF-PV-1122, evidenciado por una mayor esponjosidad de algunos huesos y la presencia de suturas sin fusión completa en casi todos los huesos del basicráneo. Esta condición se asemeja, en parte, a la observada en subadultos de E. australis lo cual sugiere que se trata de un individuo subadulto.

En el caso del balénido Morenocetus parvus, el análisis de los ejemplares MLP 5-11 y MLP 5-15 muestra que las suturas entre el basioccipital/exoccipital y supraoccipital/exoccipital están completamente cerradas, y corresponden al estadio SR4 (Fig. 4.13; 4.15; 4.16; 4.19). En el MLP5-11 la sutura basioccipital/basiesfenoides está cubierta ventralmente por el vómer, pero se puede observar en vista dorsal y la misma está cerrada pero aún es visible (estadio SR3). En el MLP 5-11 las suturas pterigoides-escamoso/vómer y aliesfenoides-escamoso/pterigoides/parietal presentan un estadio de fusión incompleto (estadio SR3). En el MLP 5-15 el vómer está ausente, lo cual permite determinar que la sutura basioccipital/basiesfenoides está completamente fusionada (estadio SR4). En MLP 5-15 la sutura pterigoides-basioccipital (la única que puede visualizarse en la caja craneana ya que la superficie ventral está muy erosionada) presentan un estadio de fusión incompleto (estadio SR3). Por otro lado, en ambos ejemplares la superficie de los huesos de la caja craneana es de aspecto compacto y textura lisa, con excepción del escamoso (proceso zigomático y postglenoideo), la superficie ventral del exoccipital, la cresta temporal, la cresta escamosa lateral, y la superficie dorsal 
del supraoccipital, las cuales presentan un aspecto y textura esponjosa.

En este contexto estas observaciones sugieren que:

1) los ejemplares referidos a Morenocetus parvus (MLP 5-11, MLP 5-15) presentan un estadio de madurez osteológica comparable al observado en el CH-P33-01 (Taxón A), evidenciado por la presencia de algunos huesos en remodelación y de algunas suturas del basicráneo en un estadio de fusión incompleto $\left(\mathrm{SR}_{3}\right)$; esto sugiere que son individuos subadultos.

Uno de los aspectos más interesantes de los resultados del análisis de las variaciones ontogenéticas en Eubalaena australis, es la semejanza que se observa en algunas estructuras del cráneo entre los neonatos y crías de E. australis y el ejemplar MPEF-PV-1122 (individuo adulto del Taxón A). Entre estas similitudes, considerando aquellas independientes del tamaño corporal, se encuentran: bulla timpánica de aspecto globoso sin una marcada compresión dorso-ventral, y superficie dorsal del periótico sin crestas ni surcos. Asimismo otras similitudes observadas, consideradas como dependientes del tamaño corporal, son: proceso ascendente del maxilar aprox. triangular y corto ántero-posteriormente supraoccipital orientado principalmente en el plano horizontal y muy delgado por delante del foramen magnum, rostro poco arqueado, fosa glenoidea ubicada en posición anterior al ápex posterior de la cresta nucal, proyección ventro-lateral del proceso anterior poco desarrollada, y proceso posterior compuesto del periótico más corto.

Estas evidencias sugieren que durante el desarrollo del Taxón A ocurrieron procesos heterocrónicos, específicamente de tipo paedomórficos. En el caso de Morenocetus se observan las mismas similitudes mencionadas para el Taxón A (con excepción de la bulla timpánica que no esta preservada), pero debido a que los ejemplares conocidos representan subadultos, no es posible contrastar si operó el mismo proceso. Sin embargo, el análisis de los subadultos de Eubalaena australis muestra que ya en este estadio se observan las morfologías que caracterizan a los adultos (en lo que respecta a los caracteres que han sido señalados anteriormente que muestran variación). Por lo tanto, puede hipotetizarse que este proceso también pudo haber ocurrido en Morenocetus. Nuevos hallazgos de ejemplares miocenos adultos permitirán poner a prueba esta hipótesis.

\subsubsection{Diversidad alfa de los balénidos miocenos}

El registro fósil de los balénidos presenta un hiato temporal, correspondiente al Mioceno, donde el registro de este grupo es extremadamente escaso (Bisconti, 2003; 2005; Churchill et al., 2012). Previo al desarrollo de esta tesis el único balénido mioceno formalmente descripto y nominado a niveles bajos era Morenocetus parvus, cuya descripción original sólo incluyó información y figuras de uno de los ejemplares. Posteriormente Cozzuol (1993) propone la creación de un nuevo taxón de Balaenidae sobre la base de dos especímenes colectados de la Formación Puerto Madryn (Mioceno 
tardío), pero el mismo no fue publicado formalmente. Otros balénidos miocenos conocidos incluyen materiales fragmentarios de la Formación Paraná (Mioceno tardío; Entre Ríos) los cuales no pueden determinarse a nivel específico (Cozzuol, 1996; Agnolin \& Lucero, 2004).

Los resultados de esta sección indican la existencia de al menos dos géneros (ambos monotípicos) en el Mioceno de Patagonia: M. parvus (del Mioceno temprano) y Taxón A (del Mioceno tardío). El re-estudio de los materiales referidos a Morenocetus parvus indica que es una entidad taxonómica válida representada por dos ejemplares, lo cual permite aceptar la hipótesis de trabajo 3 propuesta al inicio de este capítulo. Morenocetus fue asignado a la familia Balaenidae sobre la base de los siguientes caracteres: escamoso más alto dorso-ventralmente que largo ánteroposteriormente; crestas basioccipitales que divergen posteriormente en vista ventral; extremo anterior del proceso supraorbitario del frontal orientado en dirección posterior; margen posterior del proceso zigomático del escamoso y extremo lateral del exoccipital confluyen formando un borde lateral continuo; parietales más altos dorso-ventralmente que largos ántero-posteriormente; extremo anterior del supraoccipital en línea con la mitad anterior del proceso supraorbitario del frontal; proceso zigomático orientado ántero-lateralmente; extremo anterior del proceso zigomático del escamoso ubicado ventralmente al proceso postorbitario del frontal y separado de este por una distancia dorso-ventral; largo de la fosa escamosal menor a $3 / 4$ el ancho de la fosa temporal; cresta occipital externa poco desarrollada; foramen pseudoval localizado dentro del escamoso y ubicado posteriormente; extremo anterior del proceso anterior del periótico de contorno redondeado; presencia de una cresta delimitando la superficie de inserción del músculo tensor timpánico; y proceso caudal timpánico triangular y orientado póstero-ventralmente.

Por otro lado, el estudio de los balénidos del Mioceno tardío de Patagonia efectuado por Cozzuol (1993) se amplió debido a la re-descripción de MPEF-PV-1122 y de MPCNyO 290, y al hallazgo de un nuevo espécimen ( $\left.\mathrm{CH}_{-} \mathrm{P}_{33}-\mathrm{O1}\right)$. Estos ejemplares fueron asignados a la familia Balaenidae sobre la base de la presencia de la siguiente combinación de caracteres: escamoso más alto dorso-ventralmente que largo ántero-posteriormente; crestas basioccipitales divergen posteriormente en vista ventral; rostro arqueado dorso-ventralmente; extremo anterior del proceso supraorbitario del frontal orientado en dirección posterior; margen dorsal de la órbita localizado ventralmente al margen lateral del rostro; presencia de una ventana maxilar en el borde posterior de la placa infraorbitaria del maxilar; margen posterior del proceso zigomático del escamoso y extremo lateral del exoccipital confluyen formando un borde lateral continuo; parietales más altos dorsoventralmente que largos ántero-posteriormente; extremo anterior del supraoccipital en línea con la mitad anterior del proceso supraorbitario del frontal; proceso zigomático orientado ánterolateralmente; extremo anterior del proceso zigomático del escamoso ubicado ventralmente al proceso postorbitario del frontal y separado de este por una distancia dorso-ventral; largo de la fosa 
escamosal menor a $3 / 4$ el ancho de la fosa temporal; cresta occipital externa poco desarrollada; foramen pseudoval localizado dentro del escamoso y abriendo posteriormente; extremo anterior del proceso anterior del periótico de contorno redondeado; proceso caudal timpánico triangular y orientado postero-ventralmente; surco lateral de la bulla timpánica orientado ántero-ventralmente; cresta del involucro retraída lateralmente; extremo anterior de la cresta del involucro posterior al margen anterior de la bulla timpánica; superficie dorso-lateral del involucro formando un anillo continuo; y superficie ántero-ventral de la bulla timpánica plana o levemente cóncava. Dentro de los Balaenidae la combinatoria única de caracteres que presenta este taxón no permite referirlo a ninguno conocido, con lo cual se acepta la hipótesis de trabajo 4 y se propone un nuevo género y especie.

Finalmente el ejemplar MACN-PV 13221 (bulla timpánica derecha) proveniente de la Formación Paraná fue asignado a la familia Balaenidae sobre la base de la siguiente combinatoria de caracteres: cresta del involucro retraída lateralmente; extremo anterior de la cresta del involucro posterior al margen anterior de la bulla timpánica; superficie dorso-lateral del involucro formando un anillo continuo, y superficie ántero-ventral de la bulla timpánica plana o levemente cóncava.

El estudio comparativo de este espécimen con el Taxón A (MPEF-PV-1122 y MPCNyO 290), muestra que MACN-PV 13221 presenta un tamaño ligeramente mayor (Largo= 100 mm), un involucro más bajo látero-medialmente con crestas transversales más marcadas y una mayor compresión dorso-ventral de la bulla (con lo cual el surco longitudinal es más pronunciado). Morenocetus no pudo ser incluido en el análisis comparativo ya que las bullas timpánicas no se preservaron. Las diferencias entre la bulla que este espécimen y las del Taxón A, no permitieron asignarlos a un mismo taxón, por lo cual se rechaza la hipótesis de trabajo 5 planteada. Sin embargo, debido a la condición fragmentaria del espécimen no resulta conveniente asignarle un nuevo nombre, y se designa como Balaenidae indet. 


\section{APÉNDICE}

Tabla 4.1 Medidas del cráneo y de la mandíbula de Eubalaena australis (adultos y crías) en cm. Abreviaturas: e: estimado; +: estructura incompleta.

\begin{tabular}{|c|c|c|c|c|c|c|}
\hline Listado de medidas & $\begin{array}{l}\text { USNM } \\
26762\end{array}$ & CH-P33-01 & $\begin{array}{c}\text { CNPMAMM } \\
774\end{array}$ & $\begin{array}{l}\text { MLP } \\
1508\end{array}$ & $\begin{array}{c}\text { CNPMAMM } \\
748\end{array}$ & $\begin{array}{c}\text { CNPMAMM } \\
746\end{array}$ \\
\hline Largo condilobasal & 319 & 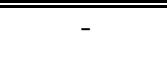 & 344 & & 88 & - \\
\hline Ancho bizigomático & 216 & 236 & 256 & & 54 & e95 \\
\hline Largo del rostro & 240 & - & - & & 57 & - \\
\hline $\begin{array}{l}\text { Ancho del rostro en la base (a nivel } \\
\text { de las muescas antorbitales) }\end{array}$ & - & - & - & & 26 & - \\
\hline Ancho del cráneo a nivel de los & - & 113 & 110 & & +32 & +44 \\
\hline
\end{tabular}

exoccipitales

Alto del cráneo a nivel del vértex

\section{SUPRAOCCIPITAL}

Ancho del supraoccipital por

delante del foramen magnum

Largo del supraoccipital

\section{EXOCCIPITAL}

Diámetro látero-lateral del cóndilo

occipital izquierdo

Diámetro dorso-ventral del cóndilo

occipital izquierdo

Diámetro látero-lateral del

foramen magnum

Diámetro dorso-ventral del

foramen magnum

Distancia entre el borde lateral del

exoccipital y el margen lateral del

cóndilo izquierdo.

Ancho de los cóndilos occipitales

más el foramen magnum

\section{FRONTAL}

Largo ántero-posterior del proceso

supraorbitario del frontal en el

extremo

Ancho transversal del proceso 
Largo de la región interorbitaria

Largo del canal óptico

de la órbita entre el extremo de los

procesos pre y postorbitario

Altura dorso-ventral de la órbita

\section{FOSA TEMPORAL}

Diámetro ántero-posterior de la

fosa temporal

Diámetro transversal de la fosa

temporal

\section{NASALES}

Largo de los nasales a lo largo de la

línea media

Ancho máximo de ambos nasales

Ancho máximo de la fosa nasal

Largo de la fosa nasal

\section{MAXILAR}

Largo linear del maxilar izq.

Ancho posterior del maxilar izq.

\section{PREMAXILAR}

Largo del premaxilar

\section{MANDIBULA}

Largo de la mandíbula izq. (lineal)

Largo de la mandíbula izq.

(curvilíneo)

Altura de la rama mandibular izq. a

$500 \mathrm{~mm}$ del extremo anterior

Altura de la rama mandibular izq.

A $1000 \mathrm{~mm}$ del extremo anterior

Altura del cóndilo mandibular izq.

Ancho del cóndilo mandibular izq.

Alto del foramen mandibular izq.

Ancho del foramen mandibular izq.

Altura de la rama mandibular a

nivel del proceso coronoides

Distancia entre el proceso

coronoides y el cóndilo mandibular

(izq.)

Altura del cóndilo mandibular 
Tabla 4.2 Medidas del periótico y de la bulla timpánica de ejemplares de Eubalaena australis (adultos y crías) en mm.

\begin{tabular}{ccccc}
\hline \hline Listado de medidas & USNM & CNPMAMM & CNPMAMM & CNPMAMM \\
& 267612 & S/N & $(\mathrm{S} / \mathrm{N})$ o1 & $(\mathrm{S} / \mathrm{N})$ o2 \\
\hline \hline
\end{tabular}

\section{PERIOTICO}

Largo del proceso posterior

167

Ancho en la mitad medial del proceso posterior

Ancho en la mitad lateral del proceso posterior

Largo del proceso anterior del periótico

Ancho del proceso anterior del periótico

excluyendo la proyección lateral

Ancho del proceso anterior del periótico

incluyendo la proyección lateral

Largo de la proyección lateral de la tuberosidad lateral

Ancho de la proyección lateral de la tuberosidad lateral

Largo ántero-posterior de la pars coclearis

Diámetro látero-lateral de la pars coclearis (sin

incluir las proyecciones de hueso)

Diámetro dorso-ventral de la fenestra coclear

Diámetro transversal de la fenestra coclear

Diámetro máximo de la fenestra oval

Diámetro mínimo de la fenestra oval

Diámetro dorso-ventral del meato auditivo interno (sensu lato)

Diámetro ántero-posterior del meato auditivo

interno (sensu lato)

Diámetro máximo de la apertura

interna del canal facial

Diámetro máximo del meato auditivo interno

sensu stricto (salida VIII)

Diámetro máximo del foramen endolinfático

Diámetro máximo del foramen perilinfático

\section{BULLA TIMPÁNICA}

Largo ántero-posterior máximo

Ancho posterior en vista ventral

Ancho anterior en vista ventral

Ancho a nivel del proceso sigmoideo (incluyendo el proceso) en vista ventral

$\begin{array}{lll}125 & 70 & 73\end{array}$

$\begin{array}{lll}38 & 53 & 53\end{array}$

6


Alto a nivel del proceso sigmoideo

Alto a nivel del proceso cónico

Ancho látero-medial de la apertura de Eustaquio
Ancho a nivel del proceso cónico

$\begin{array}{lll}- & 72 & 94 \\ - & 83 & 86 \\ - & 75 & 92 \\ - & 49 & 54\end{array}$

Tabla 4.3. Medidas craneales de los balénidos miocenos (Morenocetus parvus y Taxón A) en mm.

Abreviaturas: e: estimado; valor aproximado; +: estructura incompleta.

\begin{tabular}{|c|c|c|c|c|c|}
\hline Listado de medidas & $\begin{array}{l}\text { M. parvus } \\
\text { MLP 5-11 }^{-11}\end{array}$ & $\begin{array}{l}\text { M. parvus } \\
\text { MLP 5-15 }^{-15}\end{array}$ & $\begin{array}{c}\text { Taxón A } \\
\text { MPEF-PV } 1122\end{array}$ & $\begin{array}{c}\text { Taxón A } \\
\text { CH-P33-o1 }\end{array}$ & $\begin{array}{c}\text { Taxón A } \\
\text { MPCNyO } 290\end{array}$ \\
\hline Largo condilobasal & - & 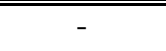 & 1020 & - & - \\
\hline Ancho bizigomático & +570 & +530 & +580 & +570 & +450 \\
\hline $\begin{array}{l}\text { Ancho del cráneo entre los procesos } \\
\text { postorbitarios del frontal }\end{array}$ & & - & e68o & - & - \\
\hline $\begin{array}{l}\text { Ancho del cráneo entre los procesos } \\
\text { preorbitarios del frontal }\end{array}$ & & - & e674 & - & - \\
\hline $\begin{array}{l}\text { Ancho del cráneo a nivel de los } \\
\text { exoccipitales }\end{array}$ & 470 & +385 & 470 & 440 & +348 \\
\hline SUPRAOCCIPITAL & & & & & \\
\hline $\begin{array}{l}\text { Ancho del supraoccipital por delante del } \\
\text { foramen magnum }\end{array}$ & 320 & +340 & 370 & 330 & - \\
\hline $\begin{array}{l}\text { Ancho del supraoccipital a la } \\
\text { mitad del largo }\end{array}$ & 220 & 220 & 215 & 220 & 164 \\
\hline $\begin{array}{l}\text { Ancho del supraoccipital en el extremo } \\
\text { anterior (a } 10 \mathrm{~cm} \text { del borde anterior) }\end{array}$ & 195 & 185 & 160 & 170 & 147 \\
\hline $\begin{array}{l}\text { Largo del supraoccipital } \\
\text { EXOCCIPITAL }\end{array}$ & 270 & 280 & 300 & 300 & $\sim 234$ \\
\hline $\begin{array}{l}\text { Diámetro látero-lateral del } \\
\text { cóndilo occipital izquierdo }\end{array}$ & 65 & 75 & 60 & 62 & 52 \\
\hline Îdem derecho & 65 & 75 & 60 & 63 & 49 \\
\hline $\begin{array}{l}\text { Diámetro dorso-ventral del } \\
\text { cóndilo occipital izquierdo }\end{array}$ & 130 & 140 & 135 & 120 & 86 \\
\hline Ídem derecho & 130 & 145 & 135 & 125 & +78 \\
\hline $\begin{array}{l}\text { Diámetro látero-lateral del } \\
\text { foramen magnum }\end{array}$ & 75 & 70 & - & - & - \\
\hline $\begin{array}{l}\text { Distancia entre el borde lateral del } \\
\text { exoccipital y el margen lateral del } \\
\text { cóndilo Izquierdo. }\end{array}$ & 155 & 130 & 145 & 140 & 93 \\
\hline Ídem derecho & 155 & - & +110 & 140 & +77 \\
\hline Ancho de los cóndilos occipitales & 155 & 200 & 180 & 150 & - \\
\hline
\end{tabular}

FRONTAL 
Largo ántero-posterior del proceso

supraorbitario del frontal en el extremo

Ancho transversal del proceso

supraorbitario del frontal

Largo del proceso supraorbitario del

frontal en la constricción

Ancho del canal óptico

en su porción medial

Ancho del canal óptico en su

porción lateral

Largo de la región interorbitaria

Largo del canal óptico

Largo del margen dorsal

de la órbita entre el extremo de los

procesos pre y postorbitario

\section{FOSA TEMPORAL}

Diámetro ántero-posterior de la fosa

temporal

Diámetro látero-lateral de la

fosa temporal

\section{NASALES}

Largo de los nasales a lo largo

de la línea media

Ancho máximo del nasal derecho

en la línea media

Ancho máximo del nasal izquierdo en la

línea media

Ancho máximo del nasal derecho

en el extremo posterior

Ancho máximo del nasal izquierdo en el extremo posterior

Ancho máximo de ambos nasales

\section{MAXILAR}

Largo linear del maxilar izquierdo

Ídem derecho

Ancho posterior del maxilar derecho

\begin{tabular}{lcccc}
- & - & & - & - \\
- & -500 & - & - \\
- & - & 606.5 & - & - \\
\hline
\end{tabular}


Tabla 4.4. Medidas del periótico y de la bulla timpánica de los balénidos miocenos de Patagonia (Morenocetus parvus y Taxón A) en mm. Abreviaturas: +: estructura incompleta.

\begin{tabular}{cccccc}
\hline \hline Listado de medidas & M.parvus & Taxón A & Taxón A & Taxón A & MACN \\
& $($ MLP 5-11 $)$ & MPEF-PV & CH-P33-01 \\
& & MPCNyO 290 $^{\ddagger}$ & 13221 $^{*}$ & & \\
\hline \hline
\end{tabular}

\section{PERIOTICO}

Largo del proceso posterior

Ancho en la mitad medial del proceso posterior

Ancho en la mitad lateral del proceso posterior Largo del proceso anterior del periótico

Ancho del proceso anterior del periótico

excluyendo la proyección lateral

Ancho del proceso anterior del periótico incluyendo la proyección lateral

Largo ántero-posterior de la pars coclearis

Diámetro látero-lateral de la pars coclearis

Diámetro dorso-ventral de la fenestra coclear

Diámetro transversal de la fenestra coclear

Diámetro máximo de la fenestra oval

Diámetro mínimo de la fenestra oval

Diámetro dorso-ventral del meato auditivo

interno (sensu lato)

Diámetro ántero-posterior del meato auditivo interno (sensu lato)

Diámetro máximo de la apertura

interna del canal facial

Diámetro máximo del meato auditivo interno sensu stricto (salida VIII)

Diámetro máximo del foramen endolinfático

Diámetro máximo del foramen perilinfático

\section{BULLA TIMPÁNICA}

Largo ántero-posterior máximo

Ancho posterior

Ancho a la mitad del largo

Ancho anterior (por delante del proceso cónico)

Ancho a nivel del proceso sigmoideo

Ancho a nivel del proceso cónico

Alto a nivel del proceso sigmoideo

Alto a nivel del proceso cónico
118

$-$

31

12

40

43

40

36

21

7

4

$-$

(1)

$-$

10

15

6

9

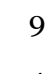

4

78

69

97

$+49$

$+39$

42

$+41$

$+49$

$+37$

$+35$

50 
*Las medidas corresponden al periótico izquierdo que está mejor preservado que el derecho y a la bulla timpánica izquierda. \# Las medidas corresponden al periótico derecho.

łLas medidas corresponden al periótico izquierdo (la mayoría de las estructuras están inaccesibles ya que el periótico está articulado a la bulla timpánica y al cráneo) y a la bulla timpánica izquierda. 


\section{Capítulo 5}

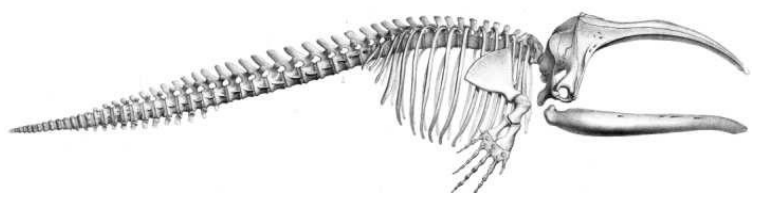

\section{Análisis Filogenético}

Buono, M. Evolución de los Balénidos del Mioceno de Patagonia 


\section{Capítulo 5}

\section{Análisis Filogenético}

La familia Balaenidae es considerada un linaje clave en la evolución de los misticetos ya que, según algunos estudios filogenéticos, es el grupo más basal de misticetos actuales (e.g. Kimura \& Ozawa, 2002; Steeman 2007; Bisconti, 2008; Marx, 2010) (Fig. 1.11). Asimismo los balénidos presentan, a diferencia de los restantes grupos de misticetos con representantes actuales, una ocurrencia temprana en el registro estratigráfico, lo cual es de gran importancia en el estudio de la historia evolutiva de los Mysticeti.

Actualmente uno de los mayores debates, en lo que respecta a las relaciones filogenéticas de los balénidos y también de los misticetos, es la relación de parentesco entre los Balaenidae y Neobalaenidae (familia integrada por el género monotípico Caperea marginata). Tradicionalmente, y sobre la base de estudios morfológicos, estas dos familias se reconocieron como grupos hermanos formando un clado conocido como Balaenoidea (Gray, 1825) (e.g. Bisconti, 2005, 2012; Ekdale et al., 2011; Churchill et al., 2012 y citas allí incluidas). Sin embargo algunos autores sugieren, por un lado, una interpretación errónea de algunos caracteres propuestos como sinapomorfías de este clado, y por otro lado, que muchos de los caracteres compartidos por este grupo son producto de convergencias como resultado de las modificaciones producidas en el cráneo relacionadas con la filtración pasiva (Fordyce, 2009b; Marx, 2010; Fordyce \& Marx, 2012). En contraposición a esta postura, otros estudios sobre la base de evidencia molecular (Sasaki et al., 2005; McGowen et al., 2009) morfológica (Marx, 2010) y análisis combinados (Demeré et al., 2008; Geisler et al., 2011; Fordyce \& Marx, 2012) sugieren que los balénidos y los neobalénidos no son grupos hermanos, y que por el contrario este último está estrechamente emparentado con los Cetotheriidae y con los Balaenopteroidea (Fig. 5.1). 
En lo que respecta a las relaciones filogenéticas de los balénidos, uno de los puntos más controvertidos es la posición del balénido más antiguo: Morenocetus parvus. Uno de los primeros análisis sobre las relaciones filogenéticas de los balénidos fue el de MacLeod et al. (1993), el cual no incluyó taxones extintos, por lo cual no permite una interpretación acertada de la radiación de la familia. Entre los estudios más recientes, se incluyen los de Bisconti (2000, 2005) y los de Churchill et al., (2012), los cuales son más completos ya que incluyen tanto taxones extintos como actuales. Sus estudios se centraron principalmente en las formas pliocenas de Europa, Estados Unidos y Japón y aclararon, en gran medida, el panorama evolutivo de la familia en el hemisferio norte. Sin embargo, no lograron resolver las relaciones filogenéticas de Morenocetus parvus (Fig. 5.2). Por otro lado, los estudios efectuados por Fordyce \& Marx (2012) proponen que Morenocetus es un balénido basal y taxón hermano de los restantes balénidos (Fig. 5.2). Sin embargo la codificación de este taxón en la matriz se efectuó sólo sobre la base del ejemplar holotipo, y la información proveniente del otro ejemplar referido a esta especie no fue incluida en su análisis. Asimismo, este estudio no incluye todas las especies de balénidos, por lo cual sólo permite una interpretación parcial de las relaciones filogenéticas de esta familia.

Morenocetus es un taxón clave no sólo para esclarecer las relaciones filogenéticas dentro de los balénidos, sino también para determinar el tiempo de divergencia de los Balaenidae y la relación con los restantes misticetos. En este contexto adquiere importancia el re-estudio de Morenocetus y un análisis filogenético exhaustivo donde se incluya toda la información disponible sobre este taxón. Asimismo, es importante incluir en el análisis la nueva especie de balénido (Taxón A), colectada en niveles inferiores de la Formación Puerto Madryn, la cual aportará nueva información a la relaciones filogenéticas de los balénidos.

Los objetivos específicos e hipótesis de trabajo de este capítulo son:

1) Analizar la posición filogenética de los Balaenidae dentro de los Mysticeti.

Hipótesis de trabajo 1: los balénidos son un grupo monofilético y hermano del clado formado por los Cetotheriidae y los Balaenopteroidea.

2)Analizar la posición filogenética de los balénidos del Mioceno de Patagonia dentro de los Balaenidae.

Hipótesis de trabajo 2: Morenocetus y el nuevo Taxón A forman un clado basal de balénidos.

\subsection{Materiales y Métodos}

\subsubsection{Taxones y caracteres incluidos en el análisis}

Para analizar las relaciones filogenéticas de los Balaenidae se utilizó como base la matriz de 
datos de Fordyce \& Marx (2012) la cual fue modificada por la inclusión/exclusión de algunos taxones y caracteres. El muestreo taxonómico se amplió con la inclusión de las siguientes 8 especies de balénidos (extintos y actuales): Balaenula balaenopsis, Eubalaena belgica, E. japonica, E. shinshuensis, Balaena ricei, B. montalionis y el balénido Taxón A descripto en la presente tesis. Asimismo se excluyó Metopocetus durinasus, ya que este taxón no está estrechamente vinculado con los balénidos y, por otra parte, debido a su pobre estado de preservación del holotipo y único ejemplar conocido muchos caracteres no pueden codificarse. La matriz resultante (de 30 taxones y 168 caracteres) fue enraizada usando al taxón Zygorhiza kochii como raíz.

\subsubsection{Taxones incluidos}

Todos los ejemplares utilizados en el análisis filogenético, y la correspondiente codificación de sus caracteres, están basadas en la observación de primera mano de los materiales, excepto por: Balaena montalionis, Balaenula astensis, B. balaenopsis, Balaenella brachyrhynchus, Eubalaena shinshuensis, E. belgica, Eomysticetus whitmorei, Piscobalaena nana, Cetotherium rathkii, Herpetocetus bramblei y Plesiobalaenoptera quarantelli.

A continuación se listan los taxones incluidos y entre paréntesis los números de colección correspondientes:

"Archaeoceti":

-Pakicetidae: Zygorhiza kochii (USNM 11962)

Odontoceti:

-Physeteridae: Physeter catodon (USNM 253051)

Mysticeti:

-Aetiocetidae: Aetiocetus cotylalveus (USNM 25210).

-Eomysticetidae: Eomysticetus whitmorei (Sanders \& Barnes, 2002, ChM PV 4253).

-Balaenidae: Morenocetus parvus (MLP 5-11, MLP 5-15); Taxón A (MPEF-PV-1122; CH-P33-01; MPCNyO 290); Balaena mysticetus (USNM 257513); B.ricei (USNM 22553); B. montalionis (MSNT I12357; Capellini, 1904; Bisconti, 2000, 2003); Balaenula astensis (MSNT I12555; Trevisan 1941); $B$. balaenopsis (IRSNB M.853; Van Beneden 1872, 1880); Balaenella brachyrhynchus (NMB 42001; Bisconti, 2005); Eubalaena australis (USNM 267612; CNPMAMM 743; CNPMAMM 741; S/N colección privada; USNM 484899; USNM 267612), E. glacialis (USNM 23077; USNM 301637; USNM 500860); E. japonica (USNM16434; USNM 16435); E. shinshuensis (SFMCV-oo24, Kimura et al., 2007; Kimura, 2009); E. belgica (IRSNM CtM 879a-f; Abel, 1941; Bisconti, 2000, 2003).

-Cetotheriidae: Caperea marginata (OM VT 227; AMNH 36692; MPCNyO 8172); Cetotherium rathkii (PIN 1840/1); Herpetocetus bramblei (UCMP 82465); Herpetocetus transatlanticus (USNM 182962, 299653, 312543); Nannocetus eremus (UCMP 26502); Piscobalaena nana (MNHN SAS 1617; Bouetel \& 
Muizon, 2006).

-Balaenopteroidea: Balaenoptera bonaerensis (CNPMAMM 750; CNPMAMM S/N; MACN 20522); Diorocetus hiatus (USNM 16783); Eschrichtius robustus (USNM 364973); Megaptera miocaena (USNM 23690, 10300); Megaptera novaeangliae (USNM 13656, 21492; AMNH 34869); Pelocetus calvertensis (USNM 11976); Plesiobalaenoptera quarantelli (MPST/SBAER 240505).

\subsubsection{Caracteres analizados}

Para el análisis filogenético se utilizaron 168 caracteres morfológicos del cráneo, postcráneo y caracteres blandos tomados de Fordyce \& Marx (2012) Churchill et al. (2012) y Bisconti (2005) y referencias allí incluidas, los cuales se detallan en el Apéndice 5.1

\subsubsection{Metodología}

La matriz de caracteres utilizada en este análisis se detalla en el Apéndice 5.2. Con respecto a la codificación original de los caracteres de Morenocetus parvus, en la matriz de Fordyce \& Marx (2012) se efectuaron las siguientes modificaciones: carácter 90: se cambió de 1 a o; carácter 81: se cambió de o a 1. Los caracteres fueron tratados como desordenados o no aditivos. El análisis filogenético se llevó a cabo en el programa TNT versión 1.1. usando una búsqueda tradicional bajo pesos iguales y pesos implicados (Goloboff, 1993; Goloboff et al., 2008 a, b, c). En el caso del análisis con pesos implicados se realizó con una constante $\mathrm{K}=3, \mathrm{~K}=6$ y $\mathrm{K}=10$ para evaluar cambios en la topología del árbol. El análisis heurístico se efectuó con 1000 réplicas usando secuencias de adición de taxones al azar seguida por un análisis de permutación de ramas (TBR o tree bisectionreconnection) guardando 100 árboles por réplica. La información contenida en los árboles más parsimoniosos obtenidos fue combinada en un árbol de consenso estricto.

El soporte del árbol fue evaluado utilizando remuestreo simétrico (symmetric resampling; Goloboff et al., 2003), el cual no es distorsionado por el peso de los caracteres, y el mismo será expresado en términos de diferencias de frecuencias (group differences, GC). Este análisis se llevó a cabo utilizando 1000 réplicas.

Con el objetivo de detectar taxones inestables sobre todo el set de árboles más parsimoniosos, se implementó el procedimiento de IterPCR propuesto por Pol \& Escapa (2009) en el programa TNT. Este procedimiento permite, además, identificar aquellos caracteres que soportan posiciones alternativas de un taxón inestable, así como también los caracteres codificados con entradas faltantes que, si fueran codificados, contribuirían a resolver la posición del taxón inestable (Pol \& Escapa, 2009; Escapa \& Pol, 2011).

La calibración del árbol filogenético se efectuó sobre la base del dato de primera aparición en 
el registro fósil, a partir de información de la literatura y de la disponible en Paleobiology database (Uhen, 2013). Para evaluar el grado de ajuste entre el registro estratigráfico y la filogenia obtenida se calculó el índice MSM (Manhattan Stratigraphic Measure), propuesto inicialmente por Sidall (1998) y modificado posteriormente por Pol \& Norell (2001), y el GER (Gap Excess Ratio) (Wills, 1999) para todos los árboles más parsimoniosos obtenidos y para el consenso estricto.

\subsection{Resultados}

\subsubsection{Análisis filogenético}

El análisis bajo pesos iguales y bajo pesos implicados (incluso explorando las distintas constantes K) mostró los mismos resultados en la topología del árbol.

Análisis bajo pesos iguales. El análisis filogenético bajo pesos iguales produjo 5 árboles más parsimoniosos con un largo de 448 pasos. El árbol de consenso estricto se presenta en la Fig 5.3 con los valores de soporte de remuestreo simétrico. El índice de consistencia para el árbol de consenso es de 0.50 y el índice de retención es de 0.71 .

En todos los árboles más parsimoniosos se recuperan los siguientes grandes clados: Neoceti (Odontoceti + Mysticeti), Mysticeti, Chaeomysticeti, Balaenidae, Cetotheriidae y Balaenopteroidea.

El clado Mysticeti tiene un valor de soporte relativamente alto $(\mathrm{GC}=72)$ lo cual concuerda con estudios filogenéticos previos (e.g. Fitzgerald, 2010; Marx, 2010; Geisler et al., 2011; Fordyce \& Marx, 2012), y Aetiocetus cotylalveus es su taxón más basal. Este grupo está diagnosticado por 7 sinapomorfías ambiguas: presencia de un proceso lateral del maxilar formando la muesca antorbital (carácter $15_{1}$ ); presencia de surcos y forámenes nutricios en el paladar (carácter $2 \mathbf{1}_{1}$ ); presencia de la placa infraorbitaria del maxilar (carácter 331); cresta orbitotemporal ausente o ubicada en la superficie dorsal del proceso supraorbitario del frontal y con el músculo temporal originándose póstero-dorsalmente o dorsalmente (carácter $4 \mathbf{1}_{1}$ ); presencia de una cresta sagital en el escudo occipital (carácter $7 \mathrm{O}_{1}$ ); extremo anterior de la fosa del seno pterigoideo aproximadamente en línea con el margen anterior del foramen pseudoval (carácter $\mathbf{7 2}_{\mathbf{1}}$ ); crestas basioccipitales anchas y bulbosas (carácter 79) ) y crestas basioccipitales paralelas o subparalelas sin formar un ángulo entre sí (carácter $\left.8 \mathrm{o}_{1}\right)$.

Los Chaeomysticeti, o ballenas con barbas, forman un grupo cuyo taxón más basal es Eomysticetus whitmorei, resultado consistente con estudios previos (e.g. Fitzgerald, 2006, 2010; Marx, 2010; Churchill et al., 2012; Fordyce \& Marx, 2012). El clado Chaeomysticeti tiene un valor de soporte bajo $(\mathrm{GC}=19)$ y está diagnosticado por cuatro sinapomorfías ambiguas: rostro con un contorno suave, no abruptamente deprimido en vista lateral (carácter 231); ausencia de dientes en el estadio adulto (carácter 241); proceso zigomático orientado anteriormente (carácter $52_{1}$ ); y márgenes laterales del 
supraoccipital rectos o cóncavos (carácter 691).

Dentro de los Chaeomysticeti se recuperan dos grandes clados: Balaenidae y otro formado por los Cetotheriidae y los Balaenopteroidea. Esta relación es consistente con lo propuesto por Fordyce \& Marx (2012), y presenta un valor de soporte relativo alto (GC=100). Las sinapomorfías que lo sustentan son: proceso supraorbitario del frontal proyectado gradualmente desde el vértex del cráneo (carácter 271); yugal y proceso zigomático del escamoso con una leve superposición o sin ella (carácter 32 1 ); fosa temporal más ancha que larga (carácter 431); proceso postglenoideo extendido ventralmente al margen ventral del exoccipital en vista lateral (carácter 631); proceso postglenoideo de forma parabólica con el margen medial y lateral paralelos o cóncavos (carácter $65_{1}$ ); ausencia de fosa en el escamoso para la recepción del proceso sigmoideo de la bulla timpánica (carácter $76_{1}$ ); extremo posterior del exoccipital extendido a nivel de o posterior al margen posterior de los cóndilos occipitales (carácter $81_{1}$ ); articulación entre el proceso anterior del periótico y la bulla timpánica a través del osículo accesorio o región homóloga en el periótico (carácter 891); ausencia de un septo dividiendo el meato auditivo interno en dos forámenes para la salida del nervio vestibular y del nervio coclear (carácter 991); proceso posterior del periótico y de la bulla timpánica fusionado en los adultos (carácter $105_{1}$ ); cresta medial de la bulla timpánica orientada ventro-medial o medialmente (carácter 1131); contorno de la cresta medial de la bulla timpánica recto o convexo (carácter 114); ausencia de margen ventral del proceso sigmoideo de la bulla timpánica (carácter 1171); ausencia de foramen elíptico (carácter 119) ); superficie medial de la salida del tubo de Eustaquio plana o convexa

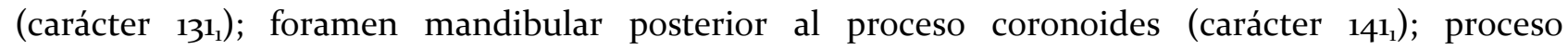
coronoides triangular más largo que alto (carácter 1433); presencia de una elevación postcoronoidea (carácter 1441); presencia de un foramen transverso en el axis (carácter 1491); proceso transverso bien desarrollado en la $7^{\circ}$ vértebra cervical (carácter 151 $)$; y cresta deltoidea del húmero reducida o ausente (carácter 1591).

El clado formado por los Cetotheriidae y los Balaenopteroidea $(\mathrm{GC}=\mathbf{2 2})$ está diagnosticado por las siguientes sinapomorfías ambiguas: premaxilar en la parte central del rostro continuo con el maxilar en vista lateral (carácter 7o); base del proceso postglenoideo en línea con el centro de la bulla timpánica (carácter 77o); ausencia de proceso superior en el periótico (carácter 101 1 ); húmero más corto que el radio y la ulna (carácter 160 $0_{1}$ ); y mano tetradáctila (carácter $16_{1}$ ). En particular, Caperea se recupera anidado en los Cetotheriidae y las sinapomorfías inequívocas que sostienen esta posición son las siguientes: proceso postglenoideo con una torsión en sentido horario del lado izquierdo y anti-horario del lado derecho (carácter $66_{1}$ ); y superficie lateral del proceso posterior compuesto del periótico forma parte de la pared lateral del cráneo (carácter 1091). Otra sinapomorfías ambiguas incluyen: márgenes laterales del proceso ascendente del maxilar paralelos (carácter 141); sutura parieto-escamosal en forma de cresta (carácter 57); y surco facial profundo con un borde 
anterior pronunciado en la mitad lateral del proceso posterior compuesto del periótico (carácter $\left.106_{1}\right)$.

Los Balaenidae se recuperan como un grupo con muy buen soporte ( $\mathrm{GC}=99$ ) lo cual es concordante con estudios filogenéticos previos (Bisconti, 2005, 2012; Marx, 2010), y están soportados por la siguiente sinapomorfía inequívoca: escamoso más alto dorso-ventralmente que largo ánteroposteriormente (carácter 56 $6_{1}$ ) (Fig. 5.4E). Otras sinapomorfías ambiguas son: superficie dorsal del rostro forma un arco suave interrumpido a nivel del vértex craneal por una superficie más plana (carácter $\mathbf{1}_{1}$ ); extremo anterior del proceso supraorbitario del frontal orientado posteriormente (carácter 25, reversión al estado o en Balaena mysticetus y Eubalaena australis); margen dorsal de la órbita localizado ventralmente al margen lateral del rostro (carácter $31_{1}$ ); ventana maxilar en el borde posterior de la placa infraorbitaria del maxilar (carácter 341); margen posterior del proceso zigomático del escamoso y extremo lateral del exoccipital confluyen y forman un borde lateral del cráneo continuo (carácter $4 \mathrm{O}_{1}$ ); parietales más altos dorso-ventralmente que largos ánteroposteriormente (carácter 471); extremo anterior del supraoccipital en línea con la mitad anterior o con el margen anterior del proceso supraorbitario del frontal (carácter $48_{2}$ ); proceso zigomático orientado ántero-lateralmente (carácter $5 \mathbf{2}_{2}$ ); extremo anterior del proceso zigomático del escamoso ubicado ventralmente al proceso postorbitario del frontal y separado de este por una distancia dorsoventral (carácter 542, con reversión al estado 1 en Eubalaena belgica, E. japonica, E. glacialis y E. australis); largo de la fosa escamosal menor a $3 / 4$ el ancho de la fosa temporal (carácter $61_{2}$ ); cresta occipital externa poco desarrollada o ausente (carácter $70_{0}$, ambiguo sólo en Balaenula balaenopsis); foramen pseudoval localizado dentro del escamoso y ubicado posteriormente (carácter 751); crestas basioccipitales divergen posteriormente (carácter $8 \mathrm{o}_{\mathrm{o}}$, ambiguo sólo en E. shinshuensis); proceso anterior del periótico redondeado (carácter $8_{5}$ ); presencia de una cresta delimitando la superficie de inserción del músculo tensor timpánico (carácter 912); proceso caudal timpánico triangular y orientado póstero-ventralmente (carácter 951); surco lateral de la bulla timpánica orientado ánteroventralmente (carácter 112 $)$ ); cresta del involucro retraída lateralmente (carácter 1151); lóbulo lateral de la bulla timpánica extendido posteriormente a la cresta del involucro (carácter $12 \mathrm{O}_{1}$, con reversión al estado o en Balaena mysticetus, E. glacialis, E. australis y E. japonica); extremo anterior de la cresta del involucro posterior al margen anterior de la bulla timpánica (carácter 1251); superficie dorsolateral del involucro formando un anillo continuo (carácter 126 $6_{1}$; superficie ántero-ventral de la bulla timpánica plana o levemente cóncava (carácter 130 $)$ (Fig. 5.4).

Dentro de los Balaenidae se recuperan dos clados: uno basal dentro de los balénidos formado por las formas miocenas Morenocetus y el Taxón A y otro formado por los balénidos más derivados, Balaenella, Balaenula, Balaena, y Eubalaena. 
El clado de los balénidos miocenos presenta un buen valor de soporte $(G C=71)$ y esta soportado por tres sinapomorfías inequívocas: exposición del escamoso en posición lateral al exoccipital es menor al 15\% de la distancia entre el plano sagital y el margen lateral del exoccipital (carácter $6 \mathrm{o}_{1}$ ); fosa del seno pterigoideo extendida anteriormente al foramen pseudoval (carácter 720); proceso anterior del periótico más corto que la pars coclearis (carácter 86 ) (Fig. 5.5).

El clado formado por Balaenella, Balaenula, Balaena, y Eubalaena se recupera también con un buen grado de soporte $(\mathrm{GC}=66)$, y está sustentado por las siguientes sinapomorfías ambiguas: proceso supraorbitario del frontal orientado ventralmente (carácter 291) y muy largo (más de 2 veces el largo del margen dorsal de la órbita) (carácter $3 \mathrm{O}_{2}$ ); nasales separados posteriormente a lo largo de la línea sagital por el proceso narial del frontal (carácter 39o); márgenes laterales del supraoccipital convexos (carácter 69o); tuberosidad ventro-lateral del proceso anterior hipertrofiada (carácter 90 ${ }_{1}$ ); proceso posterior compuesto del periótico orientado formando un ángulo recto con el eje del proceso anterior (carácter $107_{1}$, con reversión al estado o en Balaena mysticetus); y ausencia de lóbulo medial en la bulla timpánica (carácter 121 $)$ (Fig. 5.6). Dentro de este clado más inclusivo, se recuperó a Balaenella brachyrhynus como grupo hermano de un clado formado por Balaenula, Balaena y Eubalaena el cual esta soportado por dos sinapomorfías ambiguas: proceso postglenoideo orientado ventro-medialmente (en vista posterior) (carácter 642); y crestas transversales sobre la superficie dorsal del involucro bien definidas (carácter 127).

Las especies del género Balaenula se recuperan en un clado con un bajo valor de soporte $(G C=49)$ y diagnosticado por una sinapomorfía inequívoca: fosa glenoidea ubicada en línea con el proceso postorbitario y reducida (carácter 671 ) (Fig. 5.7). Por otro lado, las especies de los géneros Balaena y Eubalaena se recuperan como un clado con un bajo valor de soporte $(\mathrm{GC}=5)$ y diagnosticado por dos sinapomorfías ambiguas: presencia de un proceso piramidal robusto, (carácter 88 ) y lóbulo lateral y cresta del involucro proyectados de la misma forma posteriormente (carácter $\mathbf{1 2 0}_{\mathrm{o}}$ ). Dentro de este último grupo las relaciones están resueltas en dos clados: uno que incluye a las especies del género Balaena $(\mathrm{GC}=48)$, y otro que incluye a las especies del género Eubalaena $(\mathrm{GC}=24)$. Las relaciones internas dentro de cada clado no pudieron resolverse.

El clado Balaena está diagnosticado por una sinapomorfía inequívoca (escamoso orientado posteriormente; carácter 58 ), y por cinco sinapomorfías ambiguas: (superficie dorsal del rostro forma un arco continuo, carácter $\mathbf{1}_{2}$; proceso supraorbitario del frontal inclinado pósteroventralmente, carácter $28_{1}$; sutura parieto-escamosal en forma de cresta, carácter 57 ; apertura proximal del canal facial, meato auditivo interno sensu stricto y foramen perilinfático no alineados ántero-posteriormente, carácter 97; y foramen perilinfático y foramen endolinfático aprox. del mismo tamaño; carácter $100_{1}$ ) (Fig. 5.8). 
Por último, el clado Eubalaena esta diagnosticado por siete sinapomorfías ambiguas: nasales cortos en relación al ancho bizigomático (carácter 36 $6_{1}$; extremo anterior del proceso zigomático en posición ventral y en proximidad al proceso postorbitario del frontal (carácter 541); cresta escamosa lateral bien desarrollada y obstruyendo en vista lateral la visión de la sutura parieto-escamosal (carácter 592); presencia de una depresión cóncava en posición ántero-medial a la salida del tubo de Eustaquio (carácter 131 ); proceso coracoides de la escápula reducido a una rugosidad o protuberancia (carácter 156 ); ausencia de olecranon en el ulna (carácter 163 $)$ y presencia de callosidades en la cabeza (carácter 168 $)$ (Fig. 5.9).

Análisis bajo pesos implicados. En el análisis bajo pesos implicados mostró topologías similares en el árbol de consenso estricto con la exploración de las distintas constantes K. Se obtuvieron en todos los casos 5 árboles más parsimoniosos con un ajuste de 41,93, 26,49 y 17,87 (Goloboff fit) para un $\mathrm{K}=3, \mathrm{~K}=6$ y $\mathrm{K}=10$ respectivamente. Para el árbol de consenso el índice de consistencia es de 0.50 y el de retención es de o.71.

\subsubsection{Análisis de taxones inestables}

Los resultados del análisis del protocolo IterPCR no identificaron ni a Morenocetus ni al Taxón A como taxones inestables. Sin embargo, en este análisis se detectaron como taxones inestables Eubalaena shinshuensis y E. belgica, los cuales fueron podados en el árbol de consenso estricto elaborado bajo este análisis. La inestabilidad de estos taxones se debe a la presencia de varias entradas faltantes, las cuales se detallan a continuación:

\begin{tabular}{ll}
\hline \hline \multicolumn{1}{c}{ Taxón } & \multicolumn{1}{c}{ Caracteres con entradas faltantes } \\
\hline \hline Eubalaena shinshuensis & $54,57,59,71,106,131$, \\
& $148,156,157,163,166,168$ \\
Eubalaena belgica & $25,36,106,131,148,156,157$, \\
& $163,166,168$ \\
\hline
\end{tabular}

Cabe destacar que con el podado de estos dos taxones, las relaciones dentro del clado Eubalaena se resuelven con la recuperación de E. glacialis como taxón hermano del clado formado por E. japonica y E. australis.

\subsubsection{Ajuste estratigráfico}

Los resultados del análisis del ajuste estratigráfico muestran un valor de ajuste relativamente bajo para los 6 árboles filogenéticos analizados (Manhattan Stratigraphic Measure o MSM= 0,26; $\mathrm{GER}=0,85 ; P=0.0010)$. 


\subsection{Discusión}

Los resultados de los análisis filogenéticos obtenidos de la aplicación de dos diferentes metodologías (i.e. pesos iguales y pesos implicados), son consistentes entre sí en cuanto a la topología y las relaciones internas de los clados (Fig. 5·3).

La resolución de los grandes clados, tales como Mysticeti, Chaeomysticeti, Balaenidae y Balaenopteridae-Cetotheriidae coincide con los análisis filogenéticos previos de otros autores (e.g. Bisconti, 2005; Demeré et al., 2005; Bouetel \& Muizon, 2006; Steeman, 2007; Fitzgerald, 2010; Marx, 2010; Geisler et al., 2011; Fordyce \& Marx, 2012). Caperea se recuperó, tanto bajo pesos iguales como implicados, fuertemente anidado dentro de los Cetotheriidae con un buen soporte y no se identificó como un taxón inestable. Estos resultados coinciden con el análisis filogenético de Fordyce \& Marx (2012). Por el contrario, la mayoría de los análisis filogenéticos previos han propuesto a Caperea, o bien como taxón hermano de los Balaenidae conformando el clado Balaenoidea (e.g. Demeré et al., 2005; Bisconti, 2005, 2012; Bouetel \& Muizon ,2006; Steeman, 2007; Churchill et al., 2012), o como taxón hermano de los Balaenopteridae y Eschriichtidae (e.g. Sasaki et al., 2005; Demeré et al., 2008; Marx, 2010).

Los Balaenidae se recuperaron, con un buen valor de soporte, como grupo hermano de un clado mayor formado por Balaenopteroidea y Cetotheriidae. Esta posición de los balénidos difiere de algunos estudios previos en los cuales este grupo se recuperó en una posición basal dentro de los misticetos (Kimura \& Ozawa, 2002; Steeman 2007; Bisconti, 2008; Demeré et al., 2008; Geisler et al., 2011; Marx, 2010).

Dentro de los Balaenidae, Morenocetus se recuperó, junto con el Taxón A, como un clado basal a los restantes balénidos. Esta relación resultó estable y tiene un buen valor de soporte. Las sinapomorfías que sustentan esta relación son: corta exposición del escamoso en posición lateral al exoccipital, fosa del seno pterigoideo extendida anteriormente al foramen pseudoval y proceso anterior más corto que la pars coclearis. Morenocetus y del Taxón A retienen varios estados plesiomórficos para los Mysticeti tales como: proceso supraorbitario del frontal desarrollado principalmente en el plano lateral y con una leve inclinación ventral, ausencia de un proceso narial del frontal separando la porción posterior de los nasales, fosa del seno pterigoideo extendida anteriormente al foramen pseudoval; proceso anterior del periótico más corto que la pars coclearis; tuberosidad ventrolateral del proceso anterior roma, bulbosa y muy poco desarrollada; proceso posterior compuesto del periótico orientado póstero-lateralmente con respecto al eje longitudinal del proceso anterior; y presencia de un lóbulo medial de la bulla timpánica (ambiguo en Morenocetus).

El Taxón A se diferencia de Morenocetus en presentar procesos supraorbitarios del frontal 
más grandes y con una mayor inclinación póstero-ventral y en presentar una fenestra coclear de forma ovalada (Fig. 5.10).

La posición de Morenocetus, como el balénido más basal, es consistente con los resultados de Fordyce \& Marx (2012), pero difieren de los estudios de Bisconti (2000, 2005) y de los de Churchill et al. (2012) (Fig. 5.2). En el análisis de Bisconti (2000), Morenocetus se ubica como taxón hermano del clado formado por Balaenula astensis-B. balaenopsis. Las sinapomorfías propuestas por este autor y, que soportan esta relación, fueron revisadas posteriormente por Bisconti (2005) y sólo se mantuvieron tres: 1) pared posterior de la fosa temporal plana, 2) supraoccipital inclinado <6o con respecto al eje horizontal del cráneo, 3) bordes laterales del supraoccipital convexos. El primer carácter propuesto como sinapomórfico en Balaenula y en Morenocetus fue corregido en su codificación ya que, la pared posterior de la fosa temporal no es completamente plana. En el caso de la inclinación del supraoccipital en un ángulo menor a $60^{\circ}$, cabe mencionar que, tal como se dijo en el capítulo 4, este carácter está sujeto a variación ontogenética, al menos en E. australis, por lo que su valor taxonómico es cuestionable. Por último, en el caso del tercer carácter también fue corregida la codificación ya que en Morenocetus los bordes laterales del supraoccipital son rectos. En este contexto, la posición de Morenocetus como taxón hermano de Balaenula astensis-B. balaenopsis no tendría sustento.

Por otro lado, en los análisis de Bisconti (2005) y Churchill et al. (2012), la posición de Morenocetus dentro de los Balaenidae no se resuelve. Cabe destacar que en el análisis de bootstrap efectuado por Bisconti (2005; Fig. 8B), Morenocetus se recupera como taxón hermano del clado formado por Balaenella-Balaena, con un valor de soporte bajo. Las sinapomorfías que sustentarían esta relación no fueron especificadas.

Balaenella brachyrhynus se recupera como el taxón hermano de los restantes balénidos modernos (Balaenula, Balaena y Eubalaena), lo cual es consistente con los resultados de Fordyce \& Marx (2012) y Bisconti (2012). Balaenella es un género monotípico, conocido sólo por el ejemplar tipo de la especie. En esta tesis, el re-estudio del material tipo (NMB 42001) permitió la re-interpretación de algunos estados de caracteres incluidos por Bisconti (2005) en la descripción original. En este sentido, la orientación del cráneo propuesta por Bisconti (2005: Fig. 2-4) es incorrecta, y la reorientación propuesta en esta tesis (con base en los puntos anatómicos de los balénidos actuales) (Fig. 5.11), indica que:

1) La curvatura del rostro de NMB 42001 es similar a la observada en Eubalaena, o sea presenta una curvatura suave e interrumpida a nivel del vértex por una superficie horizontal. Esto se diferencia de la orientación propuesta por Bisconti (2005), en la cual el rostro resultaría casi recto. 
2) La nueva re-orientación del cráneo implica que la porción anterior del rostro no está preservada, con lo cual el largo total del cráneo sería mayor al estimado por Bisconti (2005).

3) La orientación del escamoso es anterior con respecto al eje sagital del cráneo, y no posterior.

4) El proceso supraorbitario del frontal se asemeja a la condición presente en Balaenula y Eubalaena y no presenta una inclinación póstero-ventral.

Asimismo, el re-estudio del ejemplar NMB42001 permitió constatar que lo que se interpretó en la descripción original como los nasales, en realidad corresponde a la proyección narial de los frontales, y los nasales no están preservados (Marx, F. com. pers.). Por este motivo en esta tesis los caracteres relacionados con la morfología de los nasales fueron codificados como entradas faltantes. Es importante destacar que la diagnosis original de este taxón estuvo basada en varios caracteres de los nasales, del tamaño del rostro y del cráneo. Por lo tanto, y considerando las re-interpretaciones expuestas anteriormente, será necesario a futuro efectuar una revisión de Balaenella.

En cuanto a la posición filogenética de Balaenella, los resultados obtenidos en esta tesis difieren de los estudios de Bisconti (2005) y Churchill et al. (2012) en los cuales este taxón se recupera formando un clado con Balaena. Estos autores proponen como sinapomorfías inequívocas soportando este clado:

- inclinación posterior del proceso lateral del maxilar

- extremo anterior del supraoccipital de forma cuadrangular

- ausencia de la porción distal de la placa infraorbitaria del maxilar

- fosa glenoidea ubicada posteriormente al ápex de la cresta nucal

- inclinación póstero-ventral del proceso supraorbitario del frontal

- inclinación posterior del escamoso

- presencia de una protrusión nucal en la unión del occipital, parietal y escamoso.

No obstante, el estudio anatómico comparado de balénidos extintos y actuales, así como también el análisis de las variaciones ontogenéticas de E. australis desarrollados en esta tesis, llevaron a re-definir y/o re-codificar seis de estos siete caracteres.

La inclinación del proceso lateral del maxilar (carácter 16 de este análisis), en contraposición con Bisconti (2005) y Churchill et al. (2012), fue codificado como faltante en Balaenella, ya que el holotipo carece de la porción distal del proceso lateral del maxilar.

El segundo carácter propuesto como sinapomórfico (extremo anterior del supraoccipital de forma cuadrangular), no fue incluido en el análisis filogenético de esta tesis ya que está lógicamente correlacionado con la telescopización del cráneo y, por lo tanto, su inclusión sería redundante.

En cuanto a la posición de la fosa glenoidea, Bisconti (2005: carácter 61) la definió tomando como referencia el ápex posterior de la cresta nucal. No obstante, los estudios realizados en esta tesis en Eubalena australis demostraron que la posición relativa de la fosa glenoidea y del ápex 
posterior de la cresta nucal, varía durante la ontogenia. En los neonatos la fosa glenoidea está ubicada en posición anterior a dicha cresta, en tanto que en los adultos ambas estructuras están alineadas. Por este motivo este carácter fue re-definido, y la fosa glenoidea fue posicionada tomando como punto de referencia el proceso supraorbitario del frontal (carácter 67).

Con respecto a la inclinación posterior del proceso supraorbitario del frontal y del escamoso, estos caracteres fueron re-codificados para Balaenella de acuerdo con la nueva orientación del cráneo propuesta en esta tesis (carácter 28 y 58 respectivamente).

Por último, la codificación para el carácter referido a la presencia de una protrusión nucal se modificó en esta tesis, ya que en Balaena mysticetus está ausente y B. montalionis esta región no está preservada (ob. pers).

El grupo formado por Balaenula astensis y B. balaenopsis se recupera como un clado basal al clado formado por Balaena y Eubalaena, resultados que difieren de los obtenidos en análisis previos (Bisconti 2000, 2005; Churchill et al., 2012). En el análisis filogenético de Bisconti (2000), Balaenula se recupera como el grupo hermano de Morenocetus, aspecto que ya fue discutido previamente dentro de esta sección. Posteriormente Bisconti (2005) propone que Balaenula es el grupo hermano de Eubalaena sobre la base de cinco sinapomorfías: depresión abrupta del premaxilar en la mitad anterior del rostro, rostro con una curvatura irregular e interrumpida a nivel del vértex del cráneo y superposición del parietal sobre el proceso supraorbitario del frontal, presencia de una cresta temporal y procesos supraorbitarios del frontal en posición perpendicular al eje sagital del cráneo. En relación al primer carácter (depresión abrupta del premaxilar) fue identificado como un carácter que varia durante la ontogenia, por lo cual no resulta útil (Churchill, et al., 2012). En referencia al carácter rostro con una curvatura suave e interrumpida en el vértex, también se observa en el Taxón A y en Balaenella (carácter 1 de esta tesis), con lo cual constituye una plesiomorfía para los Balaenidae. Para el tercer carácter (superposición del parietal sobre el proceso supraorbitario) el análisis morfológico comparado desarrollado en esta tesis, demostró que no hay diferencias en el grado de solapamiento del parietal sobre el frontal.

Por otro lado, en el análisis de Churchill et al. (2012), las relaciones internas de Balaenula (B. astensis, B. balaenopsis, Balaenula spp.) no están resueltas.

En resumen, a diferencia de los estudios de Bisconti (2000, 2005), los resultados obtenidos en esta tesis indican que Balaenula ocupa una posición intermedia entre los balénidos miocenos y los balénidos más derivados. Los caracteres que identifican a Balaenula son una combinación de caracteres primitivos (proceso superior en el periótico, proceso anterior del periótico más corto que la pars coclearis y pared posterior de la fosa temporal con una pendiente gradual o levemente cóncava) y derivados (tuberosidad ventro-lateral del proceso anterior bien desarrollada, aunque en una condición intermedia entre los balénidos miocenos y Eubalaena en cuanto a su extensión; 
proceso posterior compuesto del periótico en ángulo recto con el proceso anterior; ausencia de lóbulo medial en la bulla timpánica, crestas del involucro de la bulla timpánica bien desarrolladas, y mayor compresión dorso-ventral de la bulla timpánica). Esta diferencia en los resultados obtenidos entre esta tesis y los análisis previos, resulta de la inclusión y el estudio exhaustivo de los balénidos miocenos.

En lo que respecta a los linajes modernos, en esta tesis las ballenas arqueadas o Balaena y las ballenas francas o Eubalaena se recuperaron como dos clados, resultados consistentes con análisis filogenéticos previos (Bisconti, 2000, 2005; Rosenbaum et al., 2000; Gaines et al., 2005; Churchill et al., 2012). En ambos clados las relaciones internas entre las especies no pudieron ser resultas. En el caso de las especies de Balaena y de las especies actuales de Eubalaena (E. glacialis, E. japonica y E. australis), el análisis de IterPCR no las detectó como taxones inestables. Por el contrario, las especies extintas de Eubalaena (E. shinshuensis y E. belgica) fueron detectadas como inestables y podadas en el árbol de consenso estricto. La falta de resolución dentro de los clados Balaena y Eubalaena puede estar relacionada con la información insuficiente con que se cuenta de estas especies. En caso de los taxones inestables detectados, la falta de resolución estaría relacionada con la cantidad de entradas faltantes.

Churchill et al. (2012) propone 3 sinapomorfías inequívocas que diagnostican el clado Eubalaena: amplia superposición del parietal sobre el frontal; una cresta supramastoidea bien desarrollada que impide la visualización de la sutura escamoso/parietal en vista lateral y superficie anterior del supraoccipital en forma de domo. En el caso del primer carácter, el grado de superposición del parietal sobre el frontal es similar entre Morenocetus, el Taxón A, Balaenella, Balaenula, Balaena y Eubalaena, ya que en todos los casos la extensión anterior del parietal alcanza la mitad anterior del proceso supraorbitario, con lo cual este carácter es común a todos los balénidos. El segundo carácter (una cresta supramastoidea bien desarrollada) no es comprobable en $E$. shinshuensis ya que esta porción del escamoso no está preservada. En relación con el carácter superficie anterior del supraoccipital en forma de domo, en este estudio no se observan diferencias significativas en la forma del extremo anterior del supraoccipital entre Eubalaena y por ejemplo Balaena (en ambos casos es semicircular o redondeado, con una mayor o menor compresión transversal).

\section{Calibración estratigráfica del árbol}

El análisis del ajuste del cladograma con la información estratigráfica arrojó valores relativamente bajos de $\mathrm{MSM}=\mathbf{0 , 2 5}$ y $\mathrm{GER}=\mathbf{0}, 85$. Esto valores pueden estar relacionados con la presencia de un extenso linaje fantasma entre los balénidos miocenos y el linaje que conduce a los 
balénidos más derivados (Fig. 5.12). La extensión de este linaje fantasma ( $\sim 15 \mathrm{Ma})$ abarca desde el Mioceno temprano tardío (Burdigaliense) hasta el Plioceno temprano (Zancliense).

A esto se suma un extenso hiato temporal en el registro fósil de los balénidos que abarca más de la mitad de la historia evolutiva del grupo. Previo al desarrollo de esta tesis, el hiato temporal comprendía desde el Mioceno temprano hasta el Mioceno tardío/Plioceno temprano. La descripción del Taxón A en el Mioceno tardío temprano de la Fm. Puerto Madryn interrumpe este hiato, pero no acorta el linaje fantasma previamente mencionado (Fig. 5.12).

Las estimaciones más recientes de tiempos de divergencia de los balénidos, a partir de datos moleculares, sugieren una edad de $\sim 28$ Ma (Oligoceno tardío) (Sasaki et al., 2005; McGowen et al., 2009). Fordyce (2002) reportó la presencia de un posible balénido para el Oligoceno tardío de Nueva Zelanda, taxón que aún no ha sido descripto formalmente. Este registro sería consistente con los datos de divergencia sugeridos por los estudios moleculares, sin embargo, hasta tanto no se disponga de una descripción formal, el estatus de este registro debe evaluarse con precaución. 


\section{APÉNDICE}

\subsection{Listado de caracteres}

La descripción y detalle de la mayor parte de estos caracteres se encuentran disponibles online en Morphobank:

(http://www.morphobank.org/index.php/projects/viewMatrix/matrix_id/129o/streaming/o/project_i $\mathrm{d} / 578$; proyecto 578 ).

\section{Caja craneana (excluyendo el complejo tímpano-periótico)}

1. Curvatura de la superficie dorsal del cráneo en vista lateral: principalmente recto (o); curvatura suave interrumpida por el vértex craneal (1); arco continuo (2); superficie dorsal marcadamente cóncava debido a la presencia del melón (3).

2. Largo de la porción rostral del maxilar: menos que el ancho bizigomático (o); igual o mayor que el ancho bizigomático (1).

3. Borde lateral del maxilar anterior a la muesca antorbital o un punto homologo en el rostro en vista dorsal: cóncavo (o); recto (1); marcadamente convexo (2).

4. Ancho transversal del maxilar a la mitad del largo: marcadamente menor que el del premaxilar (o); aproximadamente igual o mayor que el del premaxilar (1).

5. Premaxilla en vista dorsal: porción anterior a la apertura nasal angosta o conserva el mismo ancho anteriormente (o); se ensancha en dirección anterior (1).

6. Incremento abrupto de la altura dorsoventral del premaxilar en el sector adyacente al extremo ántero-lateral del nasal: ausente (o); presente (1).

7. Premaxilar en la parte central del rostro en vista lateral: convexo y elevado sobre la maxila y formando una cara lateral evidente (o); aplanado y continuo o aproximadamente continuo con el maxilar (1).

8. Premaxilar en el sector adyacente y en el extremo posterior de la apertura nasal: no sobresale claramente al maxilar (o); premaxilar sobresale al maxilar (1).

9. Contacto medial del premaxilar en vista dorsal: contacta anteriormente a lo largo de la línea media (o); separado a lo largo de toda la extensión del rostro (1).

10. Proceso antorbital: ausente (o); presente y definido por un escalón separando claramente el extremo póstero-lateral del maxilar de su porción rostral anterior (1); presente como una proyección anterior evidente, lateral a la muesca antorbital (2).

11. Extremo póstero-lateral del maxilar y borde anterior del proceso supraorbitario del frontal en vista dorsal: maxilar muy cercano o por debajo del frontal (o); separado por una cuenca 
distinta al espacio para la recepción del lagrimal (1); maxilar oblitera el borde más anterior del proceso supraorbitario del frontal (2).

12. Espacio entre el proceso ascendente del maxilar dorsalmente y el proceso supraorbitario del frontal ventralmente: ausente (o); presente (1).

13. Extremo posterior del proceso ascendente del premaxilar: sin contacto con el frontal o contacta con el frontal sólo en su extremo más posterior (o); contacto robusto con el frontal (1).

14. Margen lateral del proceso ascendente del maxilar: extremos laterales convergentes con el proceso disminuyendo hasta un punto (o); márgenes laterales paralelos o divergentes posteriormente (1).

15. Proceso lateral del maxilar: ausente (o); presente y formando la muesca antorbital en vista dorsal (1).

16. Mitad lateral del proceso descendente del maxilar en vista lateral (Bisconti, 2005): anterior al proceso supraorbitario del frontal (o); por debajo del proceso supraorbitario del frontal (1).

17. Porción posterior de la superficie palatal del maxilar: paladar plano o levemente cóncavo (o); porción sagital del maxilar forma un surco longitudinal bordeado lateralmente por una canales longitudinales poco profundos (1); porción sagital forma un surco sin canales adyacentes (2).

18. Superficie palatal de la porción anterior del rostro: plana o levemente cóncava (o); presenta una quilla longitudinal pronunciada formada por el vómer y los márgenes mediales del maxilar a lo largo de la línea media del rostro (1).

19. Exposición del premaxilar en el paladar: presente y expuesto a lo largo de al menos 1/3 el largo del maxilar (o); limitada su exposición a menos de 1/3 el largo del maxilar (1).

20. Ventana palatal exponiendo el vómer: ausente (o); presente (1); exposición del vómer angosta y variable a lo largo de la línea media del rostro (2); vómer ampliamente expuesto a lo largo de la mayor parte o toda la línea media del rostro (3).

21. Forámenes y surcos nutricios en el paladar: ausente (o); presente (1).

22. Contorno de la sutura entre maxilar y palatinos: aproximadamente recto transversalmente o arqueado anteriormente (o); forma una "V" con la punta orientada posteriormente (1); márgenes anteriores de los palatinos forman dos "U" separadas y orientadas posteriormente (2).

23. Contorno del rostro en vista lateral: porción anterior de los nasales deprimida abruptamente (o); transición entre el extremo anterior del rostro y los nasales es suave (1).

24. Dientes en individuos adultos: presente (o); ausente o vestigial (1). 
25. Extremo anterior del proceso supraorbitario del frontal lateral al proceso ascendente del maxilar: orientado transversalmente o anteriormente (o); orientado posteriormente (1); lingüiforme y estrecho (2)

26. Borde posterior del proceso supraorbitario en vista dorsal: cóncavo (o); recto (1).

27. Proceso supraorbitario del frontal: horizontal (o); desciende gradualmente en dirección látero-ventral desde el vértex del cráneo (1); abruptamente deprimido por debajo del vértex con la pared lateral del cráneo (formada por el parietal y el frontal) sobre el proceso supraorbitario del frontal (2) como el estado 2 con la pared lateral del cráneo (formada sólo por el parietal) sobre el proceso supraorbitario del frontal (3).

28. Inclinación posterior del proceso supraorbitario del frontal en vista lateral (evidenciado en la inclinación del margen anterior del proceso): ausente (o); presente (1)

29. Desarrollo del proceso supraorbitario del frontal en vista lateral: expansión lateral con una inclinación ventral moderada (o); inclinado ventralmente (1).

30. Ancho del proceso supraorbitario (medido a línea recta a lo largo del margen posterior): igual o más corto que el largo ántero-posterior del proceso supraorbitario medido sobre la órbita (o); hasta dos veces el largo sobre la órbita (1); más de dos veces el largo sobre la órbita (2).

31. Borde dorsal de la órbita relativo al borde lateral del rostro, con el cráneo apoyado sobre una superficie horizontal: elevado sobre el borde lateral del rostro o aproximadamente en línea con el borde lateral del rostro (o); ubicado por debajo del borde lateral del rostro (1).

32. Contacto del yugal con el proceso zigomático del escamoso: ambos huesos superpuestos dorso-ventralmente (o); sin o con leve superposición (1).

33. Placa infraorbital del maxilar: ausente (o); presente (1).

34. Ventana maxilar que se origina del borde posterior de la placa infraorbital: ausente (o); presente (1).

35. Posición relativa del extremo más posterior del proceso ascendente del maxilar en vista dorsal: aproximadamente en línea transversal con o posterior al extremo posterior del

36. Largo de los nasales relativo al ancho bizigomático: entre 25 y 50\% del ancho bizigomático (o); menor al 25\% del ancho bizigomático (1); más del 50\% del ancho bizigomático (2).

37. Margen anterior de los nasales: aproximadamente recto o en forma de " $U$ " (o); forma una "W" orientada posteriormente (1); convergentes anteriormente hacia la línea sagital del cráneo y en punta con un espacio a cada lado entre el premaxilar y el nasal (2); convexo y forma una "M" (3).

38. Superficie dorsal de los nasales: plana (o); formando una quilla en dirección sagital (1).

39. Separación de la porción posterior de los nasales a lo largo del plano sagital por el proceso narial de los frontales: presente (o); ausente (1). 
40. Proceso zigomático del escamoso y exoccipital en vista dorsal: separados claramente por un ángulo (o); borde posterior del proceso zigomático y margen lateral del exoccipital confluentes y formando un margen lateral del cráneo continuo o casi continuo (1).

41. Cresta orbitotemporal: ubicado a lo largo del borde posterior del proceso supraorbitario con el origen del músculo temporal ubicado posterior o póstero-ventralmente (o); ausente o ubicada en la superficie dorsal del proceso supraorbitario con el origen del músculo temporal orientado póstero-dorsal o dorsalmente (1).

42. Superficie delimitada por la cresta orbitotemporal en el proceso supraorbitario del frontal: restringida al cuarto póstero-medial del proceso supraorbitario (o); en forma de " $U$ " y extendiéndose casi hasta el borde anterior del proceso supraorbitario (1); cubriendo la mitad o más de la superficie dorsal del proceso supraorbitario y casi alcanzando su extremo póstero-lateral (2).

43. Forma de la fosa temporal: larga ántero-posteriormente que ancha transversalmente o tan ancha como larga (o); más ancha que larga (1).

44. Pared posterior de la fosa temporal (Churchill, 2012): plana o con una pendiente gradual (o); cóncava (1).

45. Constricción intertemporal: más larga ántero-posteriormente que ancha transversalmente (o); como el estado 1 con la fosa temporal formando un óvalo parasagital grande (1); más ancho transversalmente que largo ántero-posteriormente (2).

46. Parietal e interparietal: extremo anterior extendido anteriormente sin sobrepasar el proceso postorbitario (o); extremo anterior en línea con el proceso supraorbitario (1).

47. Parietales en vista lateral: más largo ántero-posteriormente que alto dorso-ventralmente (o); más alto dorso-ventralmente que largo ántero-posteriormente (1).

48. Extensión anterior del supraoccipital en vista dorsal: posterior o en línea con el extremo anterior del proceso zigomático del escamoso (o); anterior al extremo anterior del proceso zigomático (1); en línea con la mitad anterior o con el extremo anterior del proceso supraorbitario del frontal (2).

49. Posición ántero-posterior del ápex posterior de la cresta nucal: posterior a los cóndilos (o); anterior o en línea con el margen posterior del cóndilo occipital (1).

50. Protuberancia nucal en la unión de la sutura parietal-escamoso-supraoccipital: ausente (o); presente (1).

51. Exposición del aliesfenoides en la fosa temporal: expuesto en la pared temporal del cráneo y contribuye a la fisura orbital (o); como el estado o pero con el aliesfenoides ampliamente expuesto y formando el margen ventral de un foramen amplio también delimitado por el 
escamoso y el parietal (1); expuesto en la pared temporal del cráneo pero no contribuye a la fisura orbital (2); no expuesto en la pared temporal del cráneo (3).

52. Orientación del proceso zigomático del escamoso: dirigido ántero-medialmente (o), dirigido anteriormente (1); dirigido ántero-lateralmente (2).

53. Proceso zigomático del escamoso en vista lateral: margen dorsal y ventral paralelos y convergentes anteriormente (o); proceso expandido dorso-ventralmente en dirección anterior y posterior formando entonces una constricción medial (1).

54. Extremo anterior del proceso zigomático del escamoso (modificado de Fordyce \& Marx, 2013; Churchill, 2012): ubicado enteramente en posición posterior al proceso postorbitario (o); ubicado ventral y en proximidad al proceso postorbitario (1); ubicado ventral al proceso postorbitario y separado por una distancia dorso-ventral (2).

55. Cresta supramastoidea del proceso zigomático del escamoso: presente (o); ausente (1).

56. Tamaño del escamoso incluyendo el proceso zigomático y postglenoideo: más largo ánteroposteriormente que alto dorso-ventralmente o aproximadamente tan alto como largo (o); marcadamente más alto que largo (1).

57. Sutura parieto-escamosal similar a una cresta: ausente (o); presente (1).

58. Orientación del escamoso: anteriormente o perpendicular al eje longitudinal del cráneo (o); posteriormente (1).

59. Prominencia escamosal o cresta escamosa lateral (Churchill et al., 2012): bien desarrollada sin impedir la visualización lateral de la sutura parietal-escamoso (o); ausente (1); bien desarrollada y obstruye parcialmente la visión de la sutura parietal-escamoso (2).

6o. Ancho transversal del escamoso lateral al exoccipital: igual o mayor que el 15\% de la distancia entre el plano sagital y el margen lateral del exoccipital (o); porción expuesta del escamoso es menor al $15 \%$ que esa distancia (1).

61. Largo de la fosa escamosa relativo al ancho transversal máximo de la fosa temporal medido en línea recta desde el punto más posterior de la cresta subtemporal al punto más posterior de la cresta nucal: largo de la fosa escamosal igual o mayor al ancho de la fosa temporal (o); largo de la fosa escamosa es $3 / 4$ el ancho de la fosa temporal o mayor (1); largo de la fosa escamosa es menor que $3 / 4$ el ancho de la fosa temporal (2).

62. Proceso postglenoideo en vista lateral: extremo ventral esta curvado anteriormente (o); margen anterior y posterior aproximadamente paralelos con el extremo del proceso orientado ventralmente (1); como el estado 1 pero con el extremo del proceso orientado posteriormente (2); proceso triangular con el extremo orientado posteriormente o ventralmente (3); proceso triangular con el margen anterior descendiendo pósteroventralmente y con el borde posterior descendiente ántero-ventralmente (4). 
63. Extensión ventral del proceso postglenoideo en vista lateral: extremo ventral del proceso postglenoideo aproximadamente en línea con o dorsal al extremo ventral del exoccipital (o); extendido ventral al extremo ventral del exoccipital (1).

64. Orientación del proceso postglenoideo en vista posterior: orientado ventralmente (o); orientado ventro-lateralmente (1); orientado ventro-medialmente (2).

65. Contorno del proceso postglenoideo en vista anterior o posterior: parabólico (o); como el estado o pero con el extremo lateral y medial paralelo o cóncavo (1); triangular (2); trapezoidal con el margen medial dirigido ventralmente (3).

66. Rotación del proceso postglenoideo en vista ventral: sin rotación o levemente transversal al eje sagital del cráneo (o); rotado en dirección horaria en el lado izquierdo y en dirección antihoraria en el lado derecho (1).

67. Posición de la fosa glenoidea en vista lateral (Churchill et al., 2012): posterior al proceso postorbitario (o); en línea con el proceso postorbitario y reducida (1).

68. Hendidura escamosal: ausente (o); presente (1).

69. Margen lateral del supraoccipital en vista dorsal: convexo (o); recto o cóncavo (1).

70. Cresta occipital externa en el supraoccipital: ausente o poco evidente (o); restringida a la mitad anterior del supraoccipital (1); restringida a una depresión en el centro del supraoccipital (2); presente y extendida a todo lo largo del supraoccipital (3).

71. Pterigoides en vista ventral: pterigoides expuestos parcial o ampliamente (o); palatinos casi cubriendo completamente los pterigoides y extendidos sobre los procesos hamulares (1).

72. Fosa del seno pterigoideo: extendida anterior al foramen oval o pseudoval (o); extremo anterior aproximadamente en línea o posterior al extremo anterior del foramen oval o pseudoval (1).

73. Lámina ventral del pterigoides: ausente o formando menos de la mitad del techo de la fosa pterigoidea (o); presente y cubriendo la mayor parte de la exposición ventral del aliesfenoides (1).

74. Forma de los hamulus pterigoideos: similar a un dedo (o); expandido en una placa aplanada dorso-ventralmente cubriendo parcialmente la fosa para el seno pterigoideo (1) reducido o casi ausente (2).

75. Posición del foramen pseudoval (= foramen oval externo): foramen localizado dentro del escamoso o entre el escamoso y el pterigoides y abriendo ántero-lateralmente o lateralmente (o); como el estado o pero con el foramen abriendo posteriormente (1); foramen ubicado dentro del pterigoides (2).

76. Fosa en el escamoso para la recepción del proceso sigmoideo de la bulla timpánica: presente (o); ausente (1). 
77. Base del proceso postglenoideo en vista ventral: en línea con el centro de la bulla timpánica (o); en línea o anterior con la mitad anterior de la bulla timpánica (1); posterior al centro de la bulla (2).

78. Margen ventral de la porción sagital del vómer en vista ventral: porción más posterior se proyecta más allá del borde posterior de los palatinos y es visible en vista ventral (o); completamente cubierto por los palatinos (1).

79. Crestas basioccipitales: angostas transversalmente (o); ancha y bulbosa (1)

8o. Ángulo formado por las crestas basioccipitales en vista ventral: divergen posteriormente (o); paralelo o subparalelo sin formar ángulo (1).

81. Extremo más posterior del exoccipital en vista dorsal o ventral: se extiende anterior al margen posterior del cóndilo occipital (o); en línea o posterior con el margen posterior del cóndilo (1).

\section{Hioides}

82. Contorno del estilohial en sección transversal: cilíndrico (o); aplanado (1)

83. Basihial y tirohial anquilosados: ausente (o); presente (1).

\section{Periótico}

84. Elongación medial y dorsal de la pars coclearis hacia la cavidad craneal: ausente (o); presente (1) presente pero sólo la parte anterior de la pars coclearis está elongada (2).

85. Proceso anterior en vista lateral: cuadrado (o); redondeado (1); en punta (2); margen anterior del proceso marcadamente cóncavo y en forma de "L" (3).

86. Largo del proceso anterior medido desde el margen anterior de la pars coclearis: más corto que el largo ántero-posterior de la pars coclearis (o); aproximadamente del mismo largo o más largo que la pars coclearis (1).

87. Surco ántero-externo: forma un surco oblicuo o vertical en la superficie lateral del proceso anterior inmediatamente anterior a la tuberosidad lateral (o); ausente (1).

88. Unión dorsal entre la pars coclearis y el área suprameatal extendida dorsalmente como un proceso piramidal robusto: ausente (o); presente (1).

89. Articulación del proceso anterior del periótico y la bulla timpánica: sin contacto o contacta con el osículo accesoria a través de la fovea epitubaria en el proceso anterior del periótico (o); osículo accesorio o región homologa en el periótico fusionado a la bulla (1).

90. Tuberosidad ventrolateral del proceso anterior: ausente o proyección roma y bulbosa (o); hipertrofiada (1); desarrollada como una plataforma ancha y orientada ántero-lateralmente articulando con el escamoso (2). 
91. Cresta bien desarrollada delimitando la superficie de inserción del músculo tensor timpánico en la superficie medial del proceso anterior: ausente (o); ausente pero la superficie de inserción conspicuamente excavada (1); presente (2).

92. Extremo ántero-medial de la pars coclearis en vista ventral: angular y proyectándose medialmente, como resultado la superficie ventral de la pars coclearis está aplanada ventralmente (o); liso y redondeado (1).

93. Surco promontorial en la superficie medial de la pars coclearis: presente (o); presente y profundamente excavado (1); ausente (2).

94. Proceso caudal timpánico del periótico en vista póstero-medial: bien separado de la cresta parotica (o); separación estrecha o en contacto (1).

95. Morfología de la cresta coclear posterior: desarrollado como una proyección posterior y triangular (o); como el estado o pero orientada póstero-ventralmente (1); como el estado o pero orientada póstero-dorsalmente (2); desarrollada como una proyección robusta y dirigida ventralmente (3); ausente o poco desarrollada (4).

96. Forma de la fenestra coclear: elíptica (o); circular (1); en forma de riñon (2).

97. Alineamiento ántero-posterior de la apertura proximal del canal facial, meato auditivo interno y apertura del acueducto coclear: presente (o); ausente (1).

98. Alineamiento ántero-posterior de la apertura del acueducto coclear (foramen perilinfático) y apertura del acueducto vestibular (foramen endolinfático): ausente (o); presente (1).

99. Septo prominente dividiendo los foraminas para los nervios vestibular y coclear dentro del meato auditivo interno: presente (o); ausente (1).

10o. Tamaño de la apertura del acueducto coclear (foramen perilinfático): más pequeño que la apertura del acueducto vestibular (o foramen endolinfático) (o); aproximadamente del mismo tamaño (1).

101. Proceso superior: presente como una cresta conspicua que forma la pared lateral de la fosa suprameatal (o); el margen lateral de la fosa suprameatal es bajo y redondeado o no está claramente definido (1).

102. Desarrollo de la cresta transversa: deprimida por debajo del anillo del meato auditivo (o); bien desarrollada y alcanzando la superficie cerebral de la pars coclearis (1).

103. Morfología de la apertura proximal del canal facial: aproximadamente circular (o); el borde anterior es continuo con el Hiato de Falloppi y con forma de fisura (1).

104. Tamaño de la apertura proximal del canal facial: no más de la mitad del tamaño del meato auditivo interno (o); más de la mitad del tamaño del meato auditivo interno (1).

105. Superficie de articulación del proceso posterior de la bulla timpánica y del periótico: sin fusionar (o); fusionado en adultos (1). 
106. Morfología del surco facial en la mitad distal del proceso posterior compuesto del periótico: ausente o surco poco profundo con borde anterior y posterior bien definido (o); surco bien marcado con margen anterior elevado (1); canal tubular profundo en "V" y parcialmente cerrado (2) .

107. Orientación del proceso posterior compuesto en vista ventral con el periótico in situ: orientado póstero-lateralmente con respecto al eje longitudinal del proceso anterior del periótico (o); orientado formando un ángulo recto con el eje del proceso anterior (1).

108. Forma del proceso posterior compuesto: cilíndrico o levemente cónico (o); aplanado (1); forma un tapón (2).

109. Exposición del proceso posterior compuesto en la pared lateral del cráneo: superficie externa del proceso posterior pequeña o no claramente definida (o); el proceso termina en una superficie distal que forma parte de la pared lateral del cráneo (1).

\section{Bulla timpánica}

110. Margen anterior de la bulla en vista dorsal o ventral: cuadrada (o); en punta o redondeada (1).

111. Posición del origen dorsal del surco lateral: ubicada a lo largo de los 2/3 posteriores del largo ántero-posterior de la bulla (o); localizada a aproximadamente 1/3 del largo ántero-posterior de la bulla (1).

112. Orientación del surco lateral: orientado ventralmente (o); orientado ántero-ventralmente (1).

113. Orientación de la cresta principal del lóbulo lateral de la bulla: orientada ventralmente (o); orientada ventro-medialmente o medialmente (1).

114. Contorno de la cresta principal de la bulla: cóncavo (o); recto o convexo (1).

115. Cresta del involucro en vista dorsal: surco del involucro coincide con el margen medial de la bulla, independientemente del grado de rotación de la bulla (o); cresta del involucro retraída lateralmente (1).

116. Extremo dorso-medial del proceso sigmoideo en vista anterior: separado del pedículo del martillo (o); confluente con el pedículo del martillo (1).

117. Margen ventral del proceso sigmoideo en vista lateral: presente (o); ausente con el margen lateral del proceso sigmoideo inclinado levemente hacia un sulcus en la superficie lateral de la bulla (1).

118. Forma del proceso cónico en vista lateral: bien desarrollado y convexo dorsalmente (o); reducido a una cresta baja o ausente (1).

119. Foramen elíptico: presente (o); ausente (1). 
120. Posición relativa del lóbulo lateral y medial o del lóbulo lateral y de la cresta del involucro: proyectados de la misma forma posteriormente (o); lóbulo lateral se proyecta más posteriormente (1).

121. Lóbulo medial de la bulla timpánica: presente como una prominencia o lóbulo en el involucro (o); ausente o indistinguible (1).

122. Cresta conectando el lóbulo medial y lateral de la bulla timpánica en vista posterior: presente (o); ausente (1).

123. Orientación de la cresta conectando el lóbulo medial o lateral de la bulla timpánica en vista posterior: aproximadamente paralelo al plano que conecta la superficie ventral del lóbulo medial y lateral (o); orientado en ángulo con respecto al plano que conecta la superficie ventral del lóbulo lateral y medial (1).

124. Lóbulo lateral de la bulla timpánica en vista posterior: más angosto que el lóbulo medial (o) lóbulo medial y lateral sub-iguales o el lóbulo medial más pequeño (1).

125. Extremo más anterior de la cresta del involucro: extendido anteriormente formando el punto más anterior de la bulla (o); en línea o posterior con el margen anterior de la bulla (1).

126. Superficie dorso-lateral del involucro: dividida en una parte anterior baja y una posterior elevada separada claramente por un escalón (o); forma un anillo continuo (1).

127. Crestas transversales sobre la superficie dorsal del involucro: poco desarrolladas o ausentes (o); bien definidas y profundas (1).

128. Desarrollo del surco timpánico: desarrollado como una línea débil (o); forma una cresta o $\operatorname{surco}(1)$.

129. Contorno y posición del anillo timpánico: forma una línea semicircular y curvada ventralmente bien separada de la intersección del proceso cónico y del proceso sigmoideo (o); forma una línea aprox. horizontal a o cercana al nivel de intersección del proceso cónico y sigmoideo (1).

130. Superficie ántero-ventral de la bulla timpánica: convexa transversalmente (o); aplanada o levemente cóncava (1).

131. Depresión cóncava transversalmente, en posición ántero-medial a la salida del tubo de Eustaquio: presente (o); ausente con la superficie medial de la salida del tubo de Eustaquio plana o convexa (1); ausente con el margen medial de la salida del tubo de Eustaquio reducida a una pared delgada (2).

132. Cresta o plataforma ántero-lateral: ausente (o); presente (1).

\section{Mandíbula}


133. Superficie medial de la parte central de la mandíbula: similar a la superficie lateral (o); aplanada con respecto a la superficie lateral (1).

134. Sínfisis mandibular: suturada o fusionada (o); no suturada (1).

135. Contorno de la parte posterior de la mandíbula en vista dorsal o ventral: sigue una línea recta o una curva simple (o); sigmoidal debido a que el cuello y el cóndilo están curvados lateralmente (1).

136. Rama horizontal de la mandíbula en vista dorsal o ventral: arqueada medialmente (o); recta (1); arqueada lateralmente (2).

137. Extremo anterior de la mandíbula: vertical o levemente torcido con el extremo ventral orientado medialmente (o); ápex de la mandíbula en una posición casi horizontal (1).

138. Rama horizontal de la mandíbula en vista lateral: alto de la rama permanece constante a todo su largo (o); arqueada dorsalmente (1) aumenta la altura ántero-posteriormente (2); constreñida dorso-ventralmente cerca del centro (3).

139. Foramen mandibular: altura dorso-ventral aprox. igual a la de la rama mandibular formando de esta forma la fosa mandibular (o); altura dorso-ventral aprox. la mitad o menor la altura de la rama mandibular (1).

140. Margen anterior del foramen mandibular: redondeado (o); triangular (1); sigmoidal con el margen dorsal del foramen desarrollado en un techo (2).

141. Posición relativa del margen anterior del foramen mandibular: en línea con el proceso coronoides (o); posterior al proceso coronoides (1).

142. Surco subcondilar: ausente (o); presente sólo medialmente (1); surco profundo en la superficie posterior separando el cóndilo y el proceso angular medialmente y lateralmente (2).

143. Proceso coronoides en vista lateral o medial: forma una placa ancha con el margen anterior convexo (o); fuertemente triangular y tan alto como largo (1); levemente triangular y más largo que alto (2); similar a un dedo y orientado posteriormente (3).

144. Elevación postcoronoidea: ausente (o); presente (1).

145. Posición del proceso angular: localizado por debajo del cóndilo y levemente anterior (o); proyectado posteriormente hasta un nivel posterior al cóndilo (1).

146. Orientación de la superficie articular del cóndilo mandibular: posterior (o); póstero-dorsal (1); dorsal con el cóndilo confluente con el proceso angular expandido dorso-ventralmente (2); dorsal con el cóndilo siendo más largo y desplazado del proceso angular (3).

147. Surco para la inserción del músculo milohyoide en la superficie ventro-medial de la mandíbula: ausente (o); presente (1). 


\section{Esqueleto postcraneano}

148. Altura en la base del proceso transverso del atlas: más de la mitad la altura de a superficie articular (o); igual o menor a la mitad la altura de la superficie articular (1).

149. Foramen transverso del axis: ausente (o); presente (1).

150. Vértebras cervicales: separadas o parcialmente separadas (o); fusionadas (1).

151. Proceso transverso bajo en la $7^{\circ}$ vértebra cervical: presente (o); ausente (1).

152. Orientación del proceso transverso de las vértebras lumbares: orientado ventro-lateralmente (o); orientado lateralmente y horizontalmente (1).

153. Forma del proceso transverso de las vértebras lumbares: esbelto y más ancho transversalmente que largo ántero-posteriormente (o); similar a una placa ancha y aprox. tan ancho transversalmente como largo ántero-posteriormente (1); más ancho que largo con una proyección conspicua en su borde anterior (2).

154. Esternón: compuesto de muchos huesos (o); compuesto de un hueso (1).

155. Proporciones de la escápula: largo ántero-posterior aprox. igual o menor a la altura dorsoventral máxima (o); largo ántero-posterior máximo excede la altura dorso-ventral máxima (1).

156. Proceso coracoides de la escápula (Churchill et al., 2012): presente (o); ausente (1); rugoso (2).

157. Acromion de la escápula (Churchill et al., 2012): presente (o); ausente (1) reducido a un pequeño reborde (2).

158. Fosa supraespinosa de la escápula: presente (o); ausente o casi ausente con el acromion localizado cerca del margen anterior de la escápula (1).

159. Cresta deltoide del húmero: presente (o); ausente o reducida a una rugosidad (1).

16o. Humero: más largo o del mismo largo que el radio y la ulna (o); más corto que el radio y la ulna (1).

161. Orientación de la cabeza del humero en vista lateral o medial: en ángulo (o); vertical (1).

162. Porción distal del húmero en vista lateral: epífisis distal más angosta que el eje (o); epífisis distal más ancha en comparación con el eje (1).

163. Olecranon en el cúbito: presente (o); ausente (1).

164. Mano: pentadáctila (o); tetradáctila (1).

\section{Caracteres blandos}

165.Aleta dorsal: ausente (o); presente (1).

166.Coloración, mancha dorsal: ausente (o); presente (1)

167. Coloración, macha ventral: ausente (o); presente en $<50 \%$ de la población (1); presenta en > del 50\% de la población (2).

168.Callosidades: ausente (o); presente (1). 


\subsection{Matriz de datos utilizada en el análisis filogenético.}

Zygorhiza kochii

Physeter catodon

Aetiocetus cotylalveus

Eomysticetus whitmorei

Morenocetus parvus

Taxon A

Balaena mysticetus

Balaena ricei

Balaena montalionis

Balaenella brachyrhynus

Balaenula astensis

Balaenula balaenopsis

Eubalaena australis

Eubalaena glacialis

Eubalaena japonica

Eubalaena belgica

Eubalaena shinshuensis

Balaenoptera bonaerensis

Caperea marginata

Cetotherium rathkii

Diorocetus hiatus

Eschrichtius robustus

Herpetocetus bramblei

Herpetocetus transatlanticus

Megaptera miocaena

Megaptera novaeangliae

Nannocetus eremus

Pelocetus calvertensis

Piscobalaena nana

Plesiobalaenoptera quarantellii

20

30

40

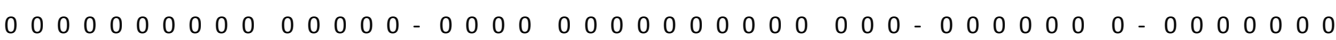

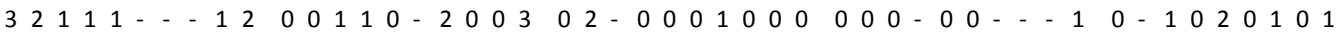
$\begin{array}{lllllllllllllllllllllllllllllllllllllllllllllllll}0 & 1 & 1 & 0 & 1 & 1 & 0 & 1 & 0 & 1 & 0 & 0 & 1 & 0 & 1 & 0 & 1 & 0 & 0 & 1 & 1 & 0 & 0 & 0 & 0 & 0 & 0 & 0 & 0 & 0 & 0 & 0 & 1 & 0 & 1 & 0 & 0 & 0 & 1 & 0 & 1 & 0 & 0 & 0 & 2 & 0 & 0 & 0 & 1\end{array}$

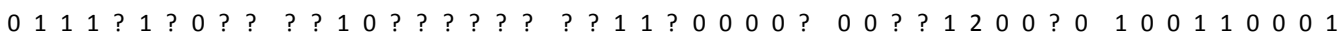

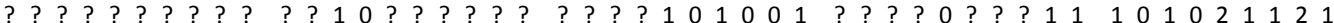

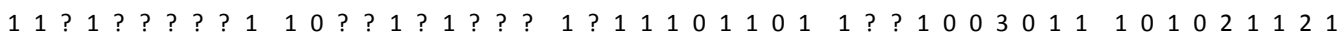
$\begin{array}{llllllllllllllllllllllllllllllllllllllllllllllllll}2 & 1 & 0 & 1 & 0 & 0 & 0 & 0 & 1 & 1 & 1 & 0 & 1 & 0 & 1 & 1 & 1 & 1 & 1 & 2 & 1 & 1 & 1 & 1 & 0 & 0 & 1 & 1 & 1 & 2 & 1 & 1 & 1 & 1 & 0 & 0 & 1 & 0 & 0 & 1 & 1 & 0 & 1 & 1 & 2 & 1 & 1 & 2 & 1\end{array}$ 21 ? 1 ? ? ? ? ? ? ? ? ? ? ? ? 11 ? ? 1 ? 11 ? ? 1 ? ? ? ? ? ? ? ? ? ? ? ? ? ? ? 112 ? 121 ? ? ? ? ? ? ? ? ? ? ? ? ? ? ? ? ? ? ? ? ? ? 11 ? ? 1111 ? ? ? ? ? 0001000 ? 110111211121

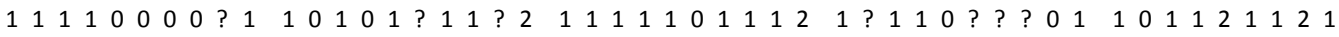

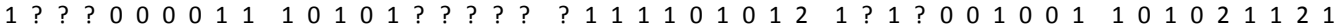

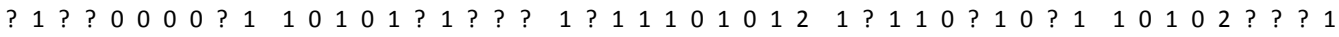

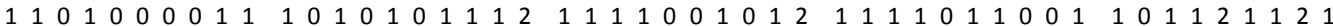

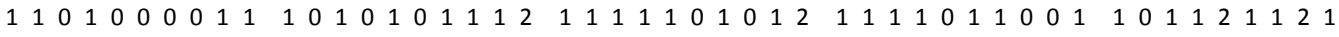
$\begin{array}{llllllllllllllllllllllllllllllllllllllllllllllllll}1 & 1 & 0 & 1 & 0 & 0 & 0 & 0 & 1 & 1 & 1 & 0 & 1 & 0 & 1 & 0 & 1 & 1 & 1 & 2 & 1 & 1 & 1 & 1 & 1 & 0 & 1 & 0 & 1 & 2 & 1 & 1 & 1 & 1 & 0 & 1 & 1 & 0 & 0 & 1 & 1 & 0 & 1 & 1 & 2 & 1 & 1 & 2 & 1\end{array}$ ? ? ? ? ? ? ? ? ? ? ? ? ? ? ? ? ? ? ? ? ? ? ? ? ? ? 100112 ? ? ? ? ? ? ? ? ? 1 ? 101111211 ? 1 1101 ? 000 ? ? ? ? 10 ? ? ? ? ? ? ? ? 11 ? ? 1 ? ? ? ? ? ? ? 01110 ? 1 ? 1 ? 1112 ? 12 ? $\begin{array}{lllllllllllllllllllllllllllllllllllllllllllllllll}0 & 1 & 1 & 1 & 0 & 0 & 1 & 0 & 1 & 1 & 1 & 1 & 1 & 1 & 1 & 0 & 1 & 1 & 1 & 3 & 1 & 1 & 1 & 1 & 1 & 1 & 2 & 0 & 0 & 1 & 0 & 1 & 1 & 0 & 0 & 1 & 0 & 0 & 1 & 0 & 1 & 2 & 1 & 1 & 2 & 1 & 0 & 1 & 1\end{array}$ $\begin{array}{lllllllllllllllllllllllllllllllllllllllllllllllllll}1 & 1 & 1 & 1 & 0 & 0 & 1 & 0 & 1 & 1 & 1 & 0 & 1 & 1 & 1 & 0 & 1 & 1 & 1 & 3 & 1 & 1 & 1 & 1 & 1 & 0 & 3 & 0 & 0 & 1 & 0 & 1 & 1 & 0 & 0 & 1 & 2 & 1 & 1 & 1 & 1 & 0 & 1 & 1 & 2 & 1 & 0 & 2 & 0\end{array}$ ? ? ? ? ? 0 ? ? ? ? 1 1 000111001 ? ? ? ? $0 \begin{array}{llllllllllllllllllllllllllll}1 & 1 & 0 & 0 & 1 & 0 & 0 & 1 & 0 & \text { ? } & 1 & 1 & 0 & 1 & \text { ? } & 0 & - & 0 & 0 & 2 & 1 & 0 & 2 & 0 & 0 & 0 & 1\end{array}$

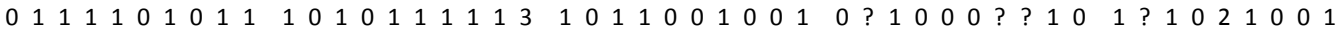
$\begin{array}{llllllllllllllllllllllllllllllllllllllllllllllllll}1 & 1 & 1 & 0 & 0 & 1 & 0 & 1 & 1 & 2 & 0 & 1 & 0 & 1 & 0 & 1 & 1 & 1 & 3 & 1 & 0 & 1 & 1 & 1 & 0 & 2 & 0 & 0 & 1 & 0 & 1 & 1 & 0 & 1 & 0 & 0 & 1 & 1 & 1 & 1 & 1 & 1 & 1 & 2 & 1 & 0 & 0 & 1\end{array}$ ? ? ? ? ? ? ? ? ? 1 ? ? ? ? 1 ? ? ? ? ? 1 ? ? 10 ? ? 00110 ? 1 ? ? ? ? ? ? 1 ? ? 11 ? ? ? ? 1 ? ? ? ? ? ? ? ? ? ? ? ? ? 1 ? ? ? ? ? ? ? ? ? ? ? ? 1 ? ? ? ? ? ? ? ? ? ? ? ? 1 ? ? 1120001

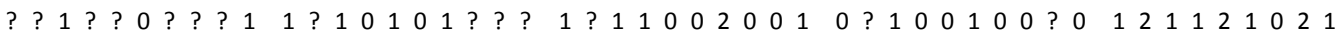
$\begin{array}{llllllllllllllllllllllllllllllllllllllllllllllllll}0 & 1 & 1 & 1 & 1 & 0 & 1 & 0 & 1 & 1 & 1 & 1 & 1 & 1 & 1 & 0 & 1 & 1 & 1 & 3 & 1 & 0 & 1 & 1 & 1 & 1 & 2 & 0 & 0 & 1 & 0 & 1 & 1 & 0 & 0 & 1 & 2 & 1 & 0 & 0 & 1 & 2 & 1 & 1 & 2 & 1 & 0 & 1 & 1\end{array}$ ? ? ? ? ? ? ? ? ? ? ? ? ? 1 ? ? ? ? ? ? ? ? ? ? 0001 ? ? ? ? ? ? ? ? ? ? ? ? 1 ? 10 ll 02 ? ? ? 1 $\begin{array}{llllllllllllllllllllllllllllllllllllllllllllllllll}0 & 2 & 1 & 1 & 0 & 1 & 0 & 1 & 1 & 1 & 0 & 1 & 0 & 1 & 0 & ? & 1 & 1 & 2 & 1 & 0 & 1 & 1 & 0 & 0 & 1 & 0 & 0 & 1 & 0 & 1 & 1 & 0 & 0 & 1 & 0 & 0 & ? & 0 & 1 & 2 & 1 & 0 & 2 & 1 & 0 & 0 & 0\end{array}$ $\begin{array}{lllllllllllllllllllllllllllllllllllllllllllllllll}0 & 1 & 1 & 1 & 1 & 0 & 1 & 0 & 1 & 1 & 1 & 0 & 0 & 1 & 1 & 0 & 1 & 1 & 1 & 3 & 1 & 2 & 1 & 1 & 0 & 0 & 1 & 0 & 0 & 1 & 0 & ? & 1 & 0 & 0 & 0 & 2 & 1 & - & 0 & 1 & 0 & 1 & 0 & 2 & 0 & 0 & 0 & 1\end{array}$ 011 ? 10101110 ? 11 ? ? ? ? ? ? 110 ? 2 ? ? ? 0 ? 1 ? ? ? ? ? ? ? ? ? ? 1 ? ?

50

Zygorhiza kochii

Physeter catodon

Aetiocetus cotylalveus

Eomysticetus whitmorei

Morenocetus parvus

Taxon A

Balaena mysticetus

Balaena ricei

Balaena montalionis

Balaenella brachyrhynus

Balaenula astensis

Balaenula balaenopsis

Eubalaena australis

Eubalaena glacialis

Eubalaena japonica

Eubalaena belgica

Eubalaena shinshuensis

Balaenoptera bonaerensis

Caperea marginata

Cetotherium rathkii

Diorocetus hiatus

Eschrichtius robustus

Herpetocetus bramble

Herpetocetus transatlanticus

Megaptera miocaena

Megaptera novaeangliae

Nannocetus eremus

Pelocetus calvertensis

Piscobalaena nana

Plesiobalaenoptera quarantellii
60

70

80

90

$\begin{array}{llllllll}0 & 0 & 0 & 0 & 0 & 0 & 0 & 0\end{array}$

$0 \begin{array}{llllllll}0 & 0 & 2 & 0 & 1 & 0 & 1 & 0\end{array}$

$\begin{array}{lllllllll}0 & 0 & 0 & 1 & 1 & 0 & 0 & 1\end{array}$

$0 \quad$ ? 1111001100

$\begin{array}{lllllllll}0 & 0 & 2 & 0 & 2 & \text { ? } & 1 & 0\end{array}$

$\begin{array}{llllllll}0 & 0 & 2 & 0 & 2 & 1 & 1 & 0\end{array}$

$\begin{array}{lllllllll}0 & 0 & 2 & 0 & 2 & 1 & 1 & 1\end{array}$

? ? ? ? ? ? 11

? ? ? ? ? ? 11

$\begin{array}{llllllll}1 & 0 & 2 & \text { ? ? ? } 10\end{array}$

$\begin{array}{lllllllll}0 & \text { ? } & 2 & 0 & 2 & 1 & 1 & 0\end{array}$

? ? 2002211 ?

$\begin{array}{lllllllll}0 & 0 & 2 & 0 & 1 & 1 & 1 & 0\end{array}$

$\begin{array}{lllllllllllllll}0 & 0 & 2 & 0 & 1 & 1 & 1 & 0\end{array}$

$\begin{array}{llllllll}0 & 0 & 2 & 0 & 1 & 1 & 1 & 1\end{array}$

$\begin{array}{lllllllllllllllll}0 & ? & 2 & 0 & 1 & 1 & 1 & 0\end{array}$

? ? ? ? ? ? 1 ?

$\begin{array}{llllllll}0 & 2 & 1 & 0 & 1 & 0 & 0 & 0\end{array}$

$1221-10001$

$\begin{array}{lllllllll}0 & \text { ? } & 1 & 0 & 1 & 0 & 0 & 1\end{array}$

$0 \quad$ ? 11001000

$\begin{array}{lllllllll}0 & 2 & 1 & 0 & 1 & 1 & 0 & 0 \& 1\end{array}$

$\begin{array}{lllllllll}0 & 1 & 1 & 0 & 1 & 0 & 0 & 0\end{array}$

? $1 \begin{array}{lllllllll}1 & 1 & 0 & 1 & 0 & 0\end{array}$

$\begin{array}{llllllll}0 & 3 & 1 & 0 & 1 & 1 & 0 & 0\end{array}$

$\begin{array}{llllllllllll}0 & 3 & 2 & 0 & 1 & 0 & 0 & 1\end{array}$

? ? 1101100 ?

$0 \begin{array}{lllllllllll}0 & 2 & 1 & 0 & 1 & 0 & 0 & 0\end{array}$

$\begin{array}{lllllllll}0 & 0 & 1 & 0 & 1 & 0 & 0 & 1\end{array}$

? ? ? ? ? ? ?

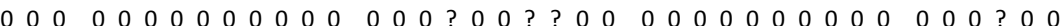

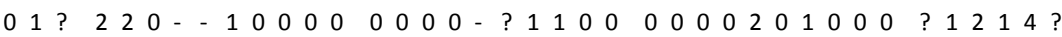

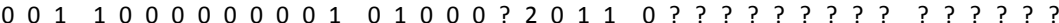

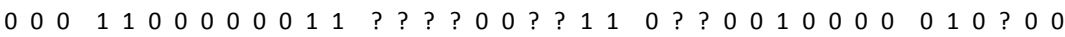
$\begin{array}{lllllllllllllllllllllllllllllllllllllll}0 & 0 & 1 & 2 & 2 & 1 & 0 & 1 & 0 & 0 & 0 & 1 & 0 & \text { ? } & 0 & 1 & \text { ? } & 1 & 1 & \text { ? } & \text { ? } & 1 & 0 & 1 & \text { ? } & \text { ? } & 0 & 1 & 0 & \text { ? } & 0 & 1 & 0 & 2 & 1 & 0 & 0 & 1 & 2\end{array}$ $0 \begin{array}{llllllllllllllllllllllllllllllllllllll} & 0 & 2 & 2 & 1 & 0 & 1 & 0 & 0 & 0 & 1 & 0 & \text { ? } & 0 & \text { ? } & \text { ? } & 1 & 1 & 1 & \text { ? } & 1 & 0 & 1 & 1 & 0 & 0 & 1 & 0 & 0 & 0 & 1 & 0 & \text { ? } & 1 & 0 & 0 & 1 & 0\end{array}$

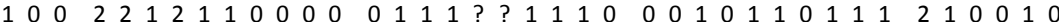

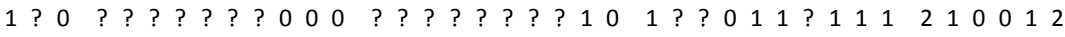
100 ? 2101 ? 00000 ? ? ? ? ? 1 ? ? 1001 ? ? ? ? ? ? ? ? ? ? ? ? ? ? ?

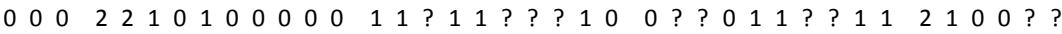
00002211210010000 ? 01 ? 11 ? ? 1000 ? ? ? ? 0 ? 0 ? 1 ? ? ? ? ? ? 000 ? 21 ? ? ? 1 ? ? ? ? 01 ? 1 ? ? ? 10010 ? ? ? ? ? ? ? ? ? ? ? ? ? ? $\begin{array}{llllllllllllllllllllllllllllllllllllllll}0 & 2 & 0 & 2 & 2 & 1 & 2 & 1 & 0 & 0 & 0 & 0 & 0 & 1 & 1 & 1 & 1 & 1 & 1 & 1 & 1 & 1 & 0 & 1 & 0 & 1 & 0 & 1 & 1 & 0 & 1 & 1 & 1 & 2 & 1 & 0 & 0 & 1 & 0\end{array}$ $\begin{array}{lllllllllllllllllllllllllllllllllllllll}0 & 2 & 0 & 2 & 2 & 1 & 2 & 1 & 0 & 0 & 0 & 0 & 0 & 1 & 1 & 1 & 1 & 1 & 1 & 1 & 1 & 1 & 0 & 1 & 0 & 1 & 0 & 1 & 1 & 0 & 1 & 1 & 1 & 2 & 1 & 0 & 0 & 1 & 0\end{array}$ $\begin{array}{lllllllllllllllllllllllllllllllllllllllll}0 & 2 & 0 & 2 & 2 & 1 & 2 & 1 & 0 & 0 & 0 & \text { ? } & 0 & 1 & 1 & 1 & 1 & 1 & 1 & 1 & 1 & 1 & 0 & 1 & 0 & 1 & 0 & 1 & 1 & 0 & 1 & 1 & 1 & 2 & 1 & 0 & 0 & 1 & 0\end{array}$ 02000221121 ? 00000011111111 ? 111000 ? ? ? ? ? ? ? ? ? ? ? ? 0 ? ? ? ? ? ? ? ? 0 ? 0 ? ? ? ? ? ? ? ? ? ? 1 ? ? ? ? ? ? ? ? ? ? ? ? ? ? ? $\begin{array}{llllllllllllllllllllllllllllllllllllllll}0 & 0 & 0 & 2 & 1 & 1 & 1 & 3 & 0 & 0 & 1 & 1 & 1 & 0 & 0 & 1 & 0 & 0 & 1 & 2 & 1 & 1 & 1 & 1 & 1 & 1 & 1 & 2 & 1 & 0 & 0 & 1 & 0 & 0 & 1 & 2 & 1 & 0 & 1\end{array}$ $\begin{array}{lllllllllllllllllllllllllllllllllllllll}0 & 1 & 1 & 0 & 4 & 1 & 2 & 1 & 1 & 0 & 1 & 1 & 3 & 0 & 1 & 1 & 2 & 2 & 1 & 1 & 1 & 1 & 1 & 1 & 0 & 1 & 2 & 3 & 1 & ? & 0 & 1 & 2 & \text { ? } & 0 & 0 & 0 & 4 & 1\end{array}$ $0 \begin{array}{llllllllllllllllllllllllllllllllllllll}0 & 0 & 1 & 3 & 1 & 0 & 1 & 1 & 0 & \text { ? } & 1 & 1 & 0 & 1 & 1 & 0 & 0 & 1 & 0 & 0 & 1 & 0 & 1 & \text { ? } & \text { ? } & 0 & \text { ? } & 1 & \text { ? } & 0 & 1 & 2 & 0 & 1 & 0 & 0 & 0\end{array}$ $0 \begin{array}{lllllllllllllllllllllllllllllllllllllll}0 & 0 & 1 & 3 & 1 & 1 & 2 & 0 & 0 & 0 & 1 & 1 & 0 & 1 & 1 & \text { ? } & 0 & 1 & 0 & 0 & 1 & 1 & 1 & \text { ? } & ? & 0 & 0 & 1 & 0 & 0 & 1 & 0 & 0 & 1 & 0 & \text { ? } & 0 & 1\end{array}$ $\begin{array}{llllllllllllllllllllllllllllllllllllllll}0 & 0 & 0 & 1 & 3 & 1 & 0 & 0 & 0 & 0 & 1 & 1 & 0 & 0 & 1 & 1 & 0 & 0 & 1 & 0 & 0 & 1 & 1 & 1 & 1 & 1 & 1 & 2 & 1 & 0 & 0 & 1 & 0 & 0 & 1 & 2 & 0 & 3 & 0\end{array}$

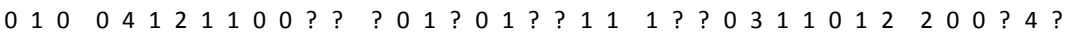

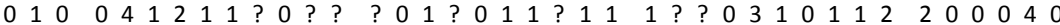

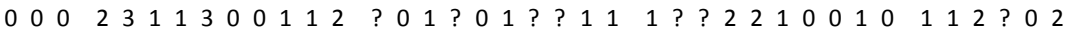
$\begin{array}{llllllllllllllllllllllllllllllllllllllll}0 & 1 & 0 & 2 & 1 & 1 & 1 & 3 & 0 & 0 & 1 & 1 & 1 & 0 & 1 & 1 & 0 & 0 & 1 & 2 & 0 & 1 & 1 & 1 & 1 & 1 & 1 & 3 & 1 & 0 & 0 & 1 & 0 & 0 & 1 & 2 & 1 & 0 & 0\end{array}$

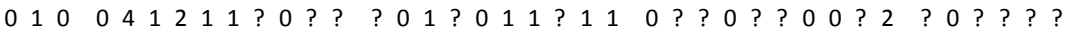
$\begin{array}{lllllllllllllllllllllllllllllllllllllll}0 & 0 & 0 & 1 & 3 & 1 & 1 & 2 & 0 & 0 & 0 & 1 & 0 & 0 & 1 & 1 & 0 & 0 & 1 & 0 & 0 & 1 & 1 & 1 & 1 & 1 & 0 & 0 & 1 & 0 & 0 & 1 & 2 & 2 & 1 & 0 & 0 & 0 & 1\end{array}$ $\begin{array}{lllllllllllllllllllllllllllllllllllllll}0 & 1 & 0 & 0 & 3 & 1 & 0 & 0 & 1 & 0 & 0 & 1 & 3 & 0 & 1 & 1 & 0 & 0 & 1 & 0 & 1 & 1 & 1 & 1 & \text { ? } & 1 & 0 & 0 & 1 & 0 & 0 & 1 & 0 & 0 & 1 & 0 & 0 & 2\end{array}$ ? ? ? ? ? ? ? ? ? ? ? 10 ? ? ? ? ? ? ? ? ? ? ? ? ? 1220001010111100 ? 


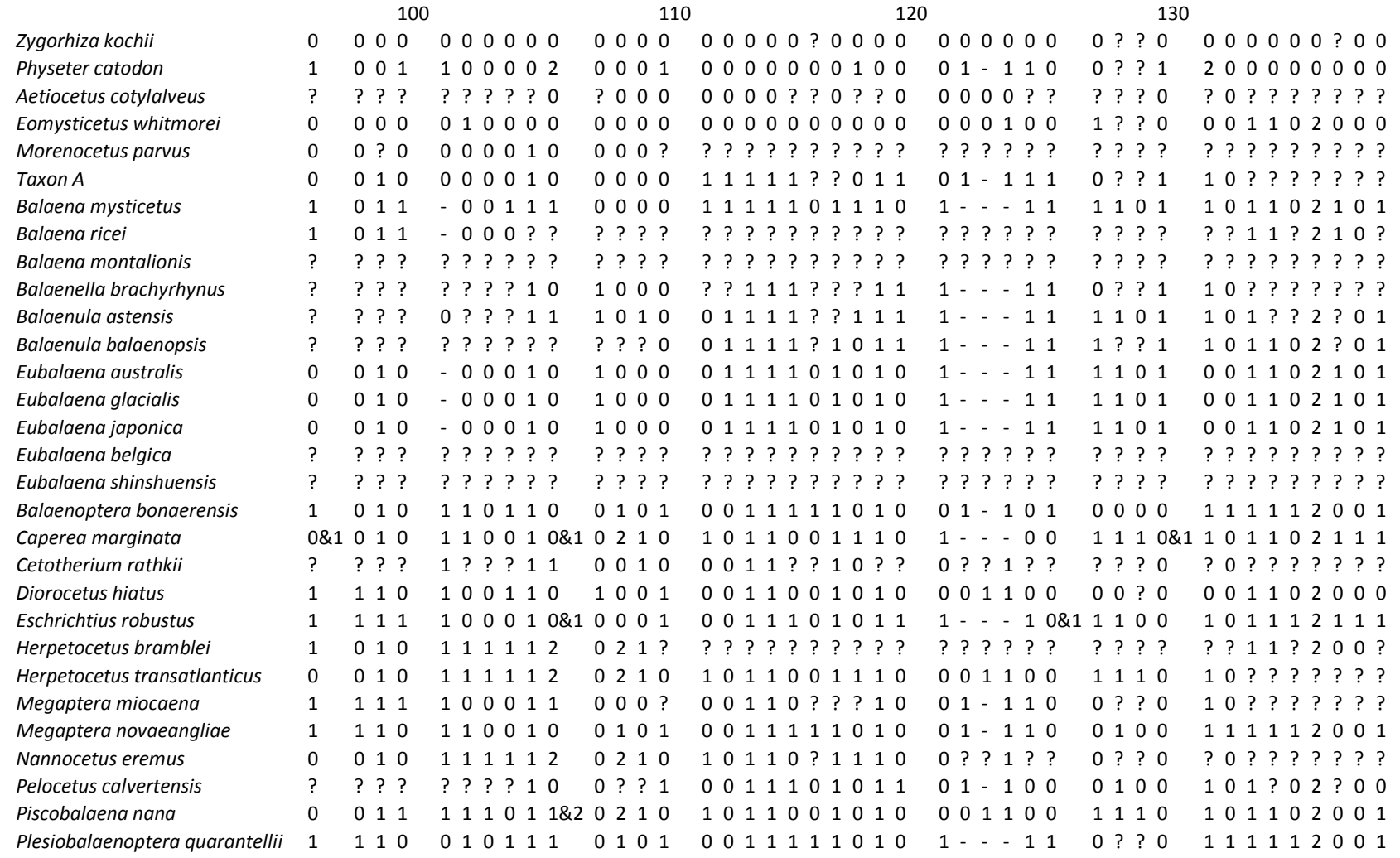

\begin{tabular}{|c|c|c|c|c|c|c|c|c|c|c|c|c|c|c|c|c|c|}
\hline & 14 & & & & & & & & & & & & & & & & \\
\hline Zygorhiza kochii & 0 & 00 & & 00 & 00 & 000 & 00 & 0 & 00 & & & 00 & 00 & 00 & $? \begin{array}{llll}0 & 0 & 0\end{array}$ & & \\
\hline Physeter catodon & & 00 & 00 & 00 & 00 & 000 & 0 & & 10 & 0 & 00 & 00 & 10 & 00 & $\begin{array}{lllll}0 & 1 & 0 & 0 & 1\end{array}$ & 0 & 0 \\
\hline Aetiocetus cotylalveus & $?$ & ? ? & ? ? & ? ? & ? ? ? & ? ? & 00 & ? & 12 & 20 & ? ? & ? ? & ? ? & ? ? & ? ? ? ? ? & ? ? & ? \\
\hline Eomysticetus whitmorei & & $0 ?$ & ? 0 & $0 ?$ & ? 10 & $0 ? 0$ & & D & 00 & & & 0 ? & ? 0 & 00 & $100 ? ?$ & $?$ & \\
\hline More & & ? ? & ? ? & ? ? & ? ? ? & ? ? ? & $?$ & 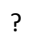 & ? ? & ? & ? ? & ? ? & ? ? & ? & ? ? ? ? ? & ? ? & ? \\
\hline Taxon A & ? & ? ? & ? ? & ? ? & ? ? ? & ? ? ? & & ? & ? ? & & & ? ? & ? ? & ? ? & ? ? ? ? & ? ? & 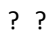 \\
\hline Balaena mys & & 11 & 12 & 10 & $\begin{array}{lll}0 & 3 & 1\end{array}$ & 101 & 1 & 1 & 10 & 1 & & 00 & 01 & 11 & 01100 & 00 & 0 \\
\hline Bala & & ? ? & ? ? & ? ? & ? ? 1 & 111 & 1 & 1 & 00 & 1 & 00 & 00 & 11 & 10 & $010 ?$ & ? ? & $?$ \\
\hline talionis & ? & ? ? & ? ? & ? ? & ? ? ? & ? ? & ? & ? & ? ? & ? & ? ? & ? ? & ? ? & ? & ? ? ? ? ? & ? ? & $?$ \\
\hline Balaenell & & ? ? & ? ? & ? ? & ? ? ? & ? ? & $?$ & ? & ? ? & ? & ? ? & ? ? & ? ? & & ? ? ? ? & ? ? & $?$ \\
\hline Balae & & ? 1 & 1 ? & $? 0$ & 031 & $1 ?$ & & ? & $?$ & 2 & & ? ? & ? ? & ? ? & ? ? ? ? & ? ? & 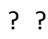 \\
\hline laenops & & $1 ?$ & ? 2 & 10 & 031 & & $?$ & ? & 1 ? & ? & & ? ? & ? ? & ? & ? ? ? ? ? & 2 & ? \\
\hline Eubalae & & 11 & 12 & 10 & 031 & 10 & 1 & 1 & 10 & 1 & & 22 & 11 & 10 & 01110 & 012 & 21 \\
\hline acialis & & 11 & 12 & & 031 & 10 & 1 & 1 & 10 & 1 & 01 & 10 & 11 & 10 & 01110 & 00 & 1 \\
\hline nica & & 11 & 12 & 10 & 031 & & & 1 & 1 & 1 & & 22 & 11 & 10 & 011 & & 2 \\
\hline Eubalc & ? & ? ? & ? ? & ? ? & ? ? ? & ? ? & $?$ & ? & ? ? & ? & ? ? & ? ? & ? ? & ? ? & ? ? ? ? & ? ? & ? \\
\hline inshuensis & ? & ? ? & ? ? & ? ? & ? ? ? & ? ? & ? & ? & ? ? & ? & ? ? & ? ? & ? ? & ? ? & ? ? ? ? & ? ? & ? ? \\
\hline bonaer & 2 & 12 & 21 & 10 & 000 & & & 1 & 1 ? & 1 & & 00 & & 11 & 11011 & -5 & 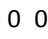 \\
\hline yinata & $1 \& 2$ & 11 & 12 & 10 & 011 & 11 & 1 & - & 11 & 1 & & 00 & 11 & 11 & 11011 & 10 & 0 \\
\hline rathkii & $?$ & ? ? & ? ? & ? ? & ? ? ? & ? ? & ? & ? & ? ? & ? & ? ? & ? ? & ? ? & ? ? & ? ? ? ? & ? ? & $?$ \\
\hline iatus & & 01 & 11 & 11 & 110 & $0 ?$ & & 1 & 10 & ? & & 00 & $1 ?$ & ? ? & ? ? 0 ? & 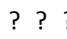 & ? \\
\hline bustus & 2 & 12 & 22 & 10 & $\begin{array}{lll}021 & 21\end{array}$ & 11 & 1 & 0 & 10 & 1 & 00 & 00 & 11 & 11 & $\begin{array}{lllll}0 & 1 & 0 & 1\end{array}$ & 10 & . \\
\hline bramblei & ? & ? ? & ? ? & ? ? & ? ? & $0 ?$ & ? & ? & ? ? & ? & & ? ? & ? ? & ? ? & ? ? ? ? & ? ? & 8 \\
\hline transatlo & & ? ? & ? ? & ? ? & ? ? & ? ? & ? ? & ? & ? ? & ? & ? ? & ? ? & ? ? & ? ? & ? ? ? ? ? & ? ? & ? ? \\
\hline jocaena & ? & ? ? & ? ? & & ? ? & ? ? & ? ? & ? & ? ? & ? & ? ? & ? ? & ? ? & ? ? & ? ? ? ? & ? ? & \\
\hline Megaptera novaeangliae & 2 & 12 & 21 & & 001 & 11 & 10 & 1 & & 1 & & 11 & & 11 & 011111 & 10 & \\
\hline eremus & & ? ? & ? ? & ? ? & ? ? & ? ? & ? ? & ? & ? ? & ? & ? ? & ? ? & ? ? & ? ? & ? ? ? ? ? & ? ? & ? ? \\
\hline Pelocetus calvertensis & 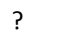 & & 21 & 10 & 00 & 01 & & 1 & 10 & ? & & 01 & 01 & & $01 ?$ ? ? & ? ? & $?$ \\
\hline na nana & 2 & & 12 & & 11 & 01 & & 1 & 11 & ? & & 00 & & & 110 ? ? & ? ? & : \\
\hline Pesiobalaenoptera quar & 2 & 12 & 21 & 10 & 00 & 01 & & ? & 1 & 0 & & ? & ? & & ? ? ? & ? & \\
\hline
\end{tabular}




\section{Capítulo 6}

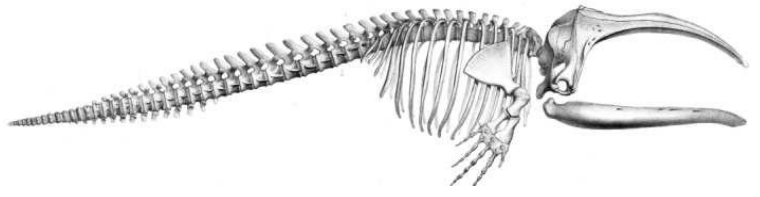

Aspectos Paleobiológicos de los balénidos miocenos e implicancias en la evolución de los misticetos

Buono, M. Evolución de los Balénidos del Mioceno de Patagonia 


\section{Capítulo 6}

\section{Aspectos paleobiológicos de los balénidos miocenos e implicancias en la evolución}

\section{de los misticetos}

Las innovaciones clave son novedades evolutivas, ya sean morfológicos y/o fisiológicos, que abren la posibilidad de explotar nuevos recursos y promueven las radiaciones adaptativas de los grupos (Hunter, 1998; Pagel, 2002). La evolución de los cetáceos estuvo marcada por la adquisición de innovaciones clave, como respuesta a las restricciones físicas impuestas por el medio acuático, que les permitieron el éxito evolutivo medido en términos de diversidad taxonómica y ecológica. Entre las principales innovaciones se encuentran el aumento de tamaño corporal, las adaptaciones al buceo, y las modificaciones en los órganos de los sentidos (Fordyce \& Muizon, 2001), las cuales serán abordadas a continuación.

Tamaño corporal. El tamaño corporal tiene una fuerte influencia en la biología de los organismos y ha sido correlacionado con numerosas variables metabólicas, fisiológicas y ecológicas (Schmidt-Nielsen, 1984; Damuth \& MacFadden, 1990). En la actualidad, los cetáceos presentan un rango de tamaño corporal (expresado como largo corporal sección 6.1.2) muy amplio, que abarca desde una masa corporal de 100 toneladas y $35 \mathrm{~m}$ de longitud corporal (la ballena azul Balaenoptera musculus) hasta los $50 \mathrm{~kg}$ de peso y los 1,5-2m de la marsopa común (Phocoena phocoena).

Tradicionalmente se ha interpretado como una tendencia macroevolutiva el incremento del tamaño corporal o gigantismo en los misticetos, y la disminución del tamaño corporal en el linaje de los odontocetos (McLeod et al., 1993; Fordyce \& Muizon, 20o1; Slater et al., 2010; Pyenson \& Sponberg, 2011). Estos cambios en el tamaño corporal han sido interpretados en respuesta a las 
demandas fisiológicas y/o ecológicas impuestas por el modo de vida marino pelágico. En el caso de las variables fisiológicas, se ha sugerido que el incremento en el tamaño corporal puede resultar una estrategia para afrontar la pérdida de calor en aguas de baja temperatura, dada la disminución de la relación área/volumen (Fordyce \& Barnes, 1994; Fordyce \& Muizon, 2001).

En lo que respecta a las variables ecológicas, el tamaño corporal se ha asociado por un lado con el desarrollo de estrategias antipredatorias (i.e. coexistencia con tiburones de grandes dimensiones Bianucci et al., 2000; Bisconti, 2003), y por otro con la adquisición de diferentes estrategias de alimentación (Slater et al., 2010). En un escenario evolutivo, la variación en la utilización de los recursos disponibles promueve la partición de nichos, y estimula la adquisición de especializaciones eco-morfológicas permitiendo la co-existencia de especies estrechamente emparentadas (Pierce et al., 2009 y referencias allí incluidas). En este contexto, la evolución de un tamaño corporal dispar entre misticetos y odontocetos puede asociarse con la adquisición de diferentes estrategias alimenticias como resultado de la ocupación de diferentes nichos ecológicos (Slater et al., 2010). De este modo, el gigantismo en los misticetos pudo estar asociado a la explotación de grandes volúmenes de presas pequeñas (zooplancton) con un alto valor energético, mientras que el menor tamaño corporal de los odontocetos (excepto en el cachalote Physeter catodon) sería más adecuado en la captura de presas móviles, rápidas y de mayor tamaño.

Adaptaciones al buceo. Otros aspectos fundamentales en el éxito evolutivo de los cetáceos son aquellos relacionados con su capacidad de buceo, esto es, la capacidad de desplazarse y permanecer largos períodos de tiempo debajo del agua. Tradicionalmente, el abordaje de esta temática en la literatura ha estado focalizado, principalmente, en estudios morfológicos del esqueleto axial y apendicular relacionados con los cambios en los modos de locomoción, control de la estabilidad del cuerpo, y adquisición de un perfil hidrodinámico. En este sentido, las modificaciones incluyen: el alargamiento de la columna vertebral y reducción de las espinas neurales, el acortamiento y fusión de vértebras, reducción de los miembros posteriores y de la cintura pélvica, y la transformación de los miembros anteriores en aletas con hiperfalangia (Thewissen et al., 2009). Estas modificaciones resultaron fundamentales en la adquisición de un perfil hidrodinámico, facilitando la locomoción y estabilización durante la natación. Las adaptaciones no sólo son evidentes a nivel macromorfológico, sino también a nivel micromorfológico en la estructura ósea. Las especializaciones estructurales del tejido óseo comunes a todos los tetrápodos acuáticos (i.e. aumento vs. disminución en la compactación y/o volumen del hueso) también han ocurrido a lo largo de la historia evolutiva de los cetáceos desde las primeras etapas (de Buffrénil et al., 1990; de Ricqlés \& Buffrénil, 2001; Gray et al., 2007; Talevi \& Fernández, 2012). 
Otras especializaciones vinculadas con el buceo son: aumento de la cantidad de mioglobina, el desarrollo de redes vasculares complejas o redes admirables, y el colapsamiento de los pulmones durante los períodos del buceo (Reidenberg, 2007). Estas modificaciones permiten afrontar las condiciones anaeróbicas (largos períodos de apnea) mediante un mayor almacenamiento de oxígeno en el sistema muscular, y a su vez la amortiguación de los cambios en la presión sanguínea. Todas estas especializaciones cuentan con una fuerte evidencia en el campo neontológico, pero no son contrastables en los taxones extintos.

Un tópico directamente vinculado con la respiración durante el buceo, y con un eventual correlato óseo, es la localización y tamaño de las narinas blandas (=blowhole) y musculatura asociada. Este aspecto no ha sido abordado previamente, ni en los taxones actuales ni en extintos, y será abordado en la sección 6.2. En esta sección se exploraran las estructuras blandas de la región nasal en el modelo neontológico (Eubalaena australis) con el fin de evaluar la presencia de correlatos óseo y su posterior exploración en las formas extintas.

Órganos de los sentidos. Los sistemas sensoriales son muy importantes en los animales ya que constituyen los canales de recepción y procesamiento de la información proveniente del medio que los rodea, actuando como barreras selectivas a los estímulos externos y considerando sólo aquellos más importantes. Los sistemas sensoriales están afectados por las características físicas del medio en el cual viven los animales, lo cual influye en la forma en la cual se recibe y se propaga la información (Wartzok \& Ketten, 1999). En el agua las restricciones físicas son muy distintas a las del medio aéreo, por lo cual, durante la transición de los cetáceos al medio acuático, los sistemas sensoriales estuvieron sujetos a profundas modificaciones.

En el medio acuático la comunicación química o quimiorrecepción (el olfato y el gusto) resulta menos eficiente ya que está afectada por una mayor difusión de las sustancias químicas en el agua (Wartzok \& Ketten, 1999; Hemilä \& Reuter, 2008). El olfato y el gusto tienen una marcada declinación en paralelo con la adaptación al medio acuático. En el caso del olfato se observa una tendencia a la reducción de los bulbos olfatorios y de los etmoturbinales, cuyo caso más extremo se observa en lo odontocetos, con ausencia de ambas estructuras (Cave, 1988; Dehnhardt, 2002; Oelschläger \& Oelschläger, 2008; Thewissen et al., 2011). La reducción del sistema gustativo se evidencia por la simplificación en la estructura de la lengua y una disminución en la cantidad de receptores gustativos, en comparación con los mamíferos terrestres (Pihlströn, 2008).

En este contexto, dadas las severas restricciones físicas impuestas por el medio acuático, los canales principales de comunicación sensorial en los cetáceos son el sistema visual y auditivo.

Las profundas modificaciones del sistema visual de los cetáceos involucran tanto al ojo como a las estructuras circundantes vinculadas con la protección del mismo. En líneas generales, el ojo de 
los cetáceos está modificado para aumentar la sensibilidad sin perder agudeza. Entre las modificaciones que hacen posible el mantenimiento de las capacidades visuales en un medio con condiciones físicas tan distintas al aéreo, se incluyen el aumento en la densidad de los fotorreceptores de la retina, un tapetum lucidum bien desarrollado, un aumento en la velocidad de contracción y relajación de la pupila y el desarrollo de una lente esférica (Dawson, 1980; Mass \& Supin, 2007). El ojo de los cetáceos también está sujeto a dos restricciones físicas importantes impuestas por la visión subacuática, que son el aumento de la presión y la disminución de la temperatura. En este sentido, las adaptaciones vinculadas con la protección mecánica del ojo son el engrosamiento de la esclera y de la córnea, el desarrollo de una red vascular compleja formando una red admirable en la parte posterior del ojo, músculos extraoculares muy desarrollados, y la presencia de grasa periorbital (Walls, 1942; Zhu et al., 2001; Mass \& Supin, 2007; Buono et al., 2012).

La evolución del sistema auditivo en los cetáceos implicó la pérdida de ciertos elementos involucrados con la audición aérea y la adquisición de nuevos elementos implicados en la audición acuática (Thewissen \& Hussain, 1993; Nummela et al., 2004). La mayor parte de los cambios implicaron una reorganización del oído externo y del oído medio, mientras que el oído interno permaneció casi sin cambios (Ketten, 1992, 2000; Nummela et al., 2004). Asimismo este proceso adaptativo también implicó la adquisición de diferentes especializaciones vinculadas con el rango de frecuencias de sonidos que emiten y reciben, e indican diferentes presiones selectivas en los odontocetos y misticetos. Los odontocetos están especializados en sonidos de alta frecuencia (2020okHz) mientras que los misticetos lo están en aquellos de baja frecuencia ( $12 \mathrm{~Hz}$ a $3 \mathrm{KhZ}$ ) (Fleischer, 1976; Ketten, 2000). Los sonidos de alta frecuencia son utilizados en los odontocetos para testear su ambiente y obtener una "imagen" de los objetos que los rodean, desarrollando un sistema de ecolocalización. Los sonidos son generados a través de un complejo de sacos aéreos asociados a la parte dorsal del pasaje nasal, que luego son enfocados y dirigidos al medio por una estructura grasa especializada, el melón (Fig. 6.1A) (Norris, 1969; Crandford et al., 1996). La recepción del sonido es llevada a cabo por la mandíbula a través de un cuerpo graso especializado (pan bone o fat body) que transmite las ondas sonoras al oído medio e interno (e.g. Norris, 1969; Ketten, 1992; Nummela et al., 2007; Yamato et al., 2012) (Fig. 6.1B-C). Las especializaciones vinculadas a la ecolocalización se conocen sólo para el linaje de los odontocetos (Ketten 1992; Fordyce \& Muizon, 2001).

Los misticetos emiten sonidos de muy baja frecuencia que utilizan en la cópula, las migraciones, y la alimentación. Por sus propiedades físicas los sonidos de baja frecuencia viajan largas distancias permitiendo la comunicación y la cohesión de los grupos, aún cuando estén separados (Payne \& McVay, 1971; Thompson et al., 1979, 1986). En los misticetos los mecanismos de generación del sonido eran desconocidos hasta los estudios de Reidenberg \& Laitman (2007). Estos autores demuestran la presencia de una serie de pliegues en la laringe, homólogos a las cuerdas 
vocales de los mamíferos terrestres, encargados de la generación de estos sonidos. Asimismo, los mecanismos de recepción del sonido también son poco conocidos en los misticetos y tradicionalmente se propuso que el canal auditivo externo estaba involucrado en esta función (Carte \& Macalister, 1868; Yamada, 1953). Sin embargo, estudios recientes en balenoptéridos reportan la presencia de cuerpos grasos en la región posterior de la mandíbula y en conexión con el complejo tímpano-periótico. Estos cuerpos grasos serían análogos a los observados en los odontocetos y estarían involucrados en la recepción de los sonidos de baja frecuencia a través de la mandíbula (Yamato et al., 2012) (Fig. 6.2). La presencia de esta estructura en otros grupos de misticetos, como los balénidos, no ha sido hasta el momento documentada.

En este contexto, con el objetivo de analizar si estas innovaciones claves estaban presentes en las formas más tempranas y basales de los balénidos, se seleccionaron los siguientes tópicos:

- Tamaño corporal: este tópico se abordó con la exploración del parámetro largo corporal.

- Adaptaciones al buceo: en particular se analizaron las modificaciones, tanto óseas como blandas, vinculadas con la región nasal.

- Órganos de los sentidos: se exploró la presencia de correlatos óseos que permitan la reconstrucción de los órganos blandos involucrados en la visión y en la audición.

Este capítulo está organizado de la siguiente manera:

Sección 6.1 Tamaño corporal

Sección 6.2 Morfología de la región nasal y respiración

Sección 6.3 Organos de los sentidos:

Sección 6.3.1 Ojo y estructuras periorbitales

Sección 6.3.2 Oído

Los objetivos específicos e hipótesis de trabajo en relación a cada uno de estos tópicos se detallan en las secciones correspondientes. Las tablas citadas en el texto se incluyen en un apéndice al final del capítulo.

Para poder abordar los objetivos específicos planteados se elaboró un protocolo de investigación que involucró 3 procedimientos básicos: la elección de un modelo neontológico de comparación (Eubalaena australis), la exploración en este modelo de las asociaciones entre las partes blandas y las estructuras óseos (búsqueda de correlatos óseos), y por último la búsqueda del correlato óseo en el taxón extinto (Witmer, 1997). 


\subsection{Tamaño corporal}

\subsubsection{Introducción}

El gigantismo se ha identificado como una de las tendencias macroevolutivas más importantes dentro de la historia de los misticetos (McLeod et al., 1993; Fordyce \& Barnes, 1994; Fordyce \& Muizon, 2001). La evolución de este carácter ha sido interpretada a través de dos escenarios evolutivos distintos. Por un lado Fitzgerald (2006) sugiere que el incremento del tamaño corporal (evaluado en este análisis en función del largo corporal) fue un evento gradual dentro de los misticetos, desde las formas basales de pequeño tamaño (e.g. misticetos dentados Aetiocetidae y Mammalodontidae), hasta las formas de mayor tamaño corporal correspondientes a los misticetos con barbas o Chaeomysticeti (Fitzgerald, 2006). Sobre la base de la optimización del tamaño corporal en el árbol filogenético (expresado en tres categorías de longitud: pequeño $<5 \mathrm{~m}$, grande 5$12 \mathrm{~m}$, y gigante $>12 \mathrm{~m}$ ), Fitzgerald (2010) propuso que la condición primitiva de los misticetos es un tamaño corporal grande, y que la reducción del tamaño corporal se adquirió secundariamente al menos dos veces en la historia evolutiva del grupo (i.e. Aetiocetidae y Mammalodontidae).

En lo referente a la evolución del tamaño corporal en los balénidos, los únicos antecedentes éditos son las contribuciones de Bisconti (2003, 2005). En estos estudios se efectuaron, en el contexto del análisis sistemático y filogenético de los balénidos, algunos comentarios sobre la evolución del tamaño corporal en este grupo. De este modo, Bisconti (2003, 2005) sugiere que la condición primitiva para los balénidos fue el tamaño corporal pequeño, basado en el pequeño tamaño del balénido más antiguo Morenocetus parvus, y que el gigantismo se habría desarrollada al menos dos veces en forma independiente en los linajes modernos de Eubalaena y de Balaena mysticetus.

En este contexto, el objetivo específico e hipótesis de trabajo planteada en esta sección es:

- Estimar la longitud corporal de los misticetos filtradores, y en particular de los balénidos miocenos, y analizarlo en un contexto evolutivo.

Hipótesis de trabajo: La tendencia al aumento del largo corporal, llegando al gigantismo, no ocurrió linealmente en la historia evolutiva de los balénidos.

\subsubsection{Materiales y métodos específicos}

La muestra seleccionada para efectuar las estimaciones del largo corporal (LC) incluye ejemplares de las siguientes especies: 


\section{Stem Cetacea o "arqueocetos":}

Maiacetus inuus: GSP-UM 3475 (Gingerich et al., 2009)

Rhodocetus kasrani: GSP-UM 3012 (Gingerich et al., 1994)

Dorudon atrox: CGM 42183; UM 101222 (Uhen, 2004)

Zygorhiza kochii: USNM 11962 (Kellog, 1936)

Basilosaurus cetoides: USNM 4674, 4675, 12261 (Kellog, 1936)

\section{Misticetos dentados}

Aetiocetus cotylalveus USNM 25210 (Demeré \& Berta, 2008).

Janjucetus hunderi: NMV P216929 (Fitzgerald, 2006)

Llanocetus denticrenatus: Fordyce (2003b)

\section{Misticetos con barbas}

Eomysticetus whitmorei: ChMPV4253 (Sanders \& Barnes, 2002)

\section{Balaenidae}

Morenocetus: MLP 5-11 y MLP 5-15

Taxón A: MPEF-PV-1122; CH-P33-01 y MPCNyO 290

Balaenula astensis: MSNT 12555 (Bisconti, 2000)

Balaena montalionis MSNT 12357 (Bisconti, 2000)

Balaenella brachyrhynus NMB 42001 (Bisconti, 2005)

Eubalaena shinshuensis SFMCV-o024 (Kimura et al., 2007; Kimura, 2009)

\section{Balaenopteroidea}

Diorocetus hiatus: USNM 16783 (Pyenson \& Sponberg, 2011)

Pelocetus calvertensis: USNM 11976 (Pyenson \& Sponberg, 2011)

\section{Cetotheriidae}

Piscobalaena nana: MNHN SAS 1623 (Bouetel \& Muizon, 2006)

Cetotherium rathkii: Gol'din et al. (2013a)

A los fines comparativos se incluyó la información del LC (el valor máximo) de los siguientes misticetos actuales (Perrin et al., 2009):

Eubalaena spp.: $18 \mathrm{~m}$

Balaena mysticetus: $20 \mathrm{~m}$

Balaenoptera spp:33m

Megaptera: $17 \mathrm{~m}$

Caperea: $7 \mathrm{~m}$

Eschrichtius robustus: $15 \mathrm{~m}$ 
La estimación del tamaño corporal de los cetáceos extintos representa un desafío aún no resuelto. La masa corporal es un valor extremadamente difícil de medir en cetáceos actuales con más de $100 \mathrm{~kg}$ (Gambell, 1970; Lockyer, 1976). A esto se suma que, las profundas diferencias en el patrón corporal (=bauplan) de los Neoceti con respecto a los stem cetáceos y a los mamíferos continentales, hacen que los modelos para las estimaciones de masa corporal utilizadas en estos últimos sean inaplicables a los Neoceti. Asimismo, la estimación del tamaño corporal de los cetáceos en función de la masa resulta riesgoso dada las significativas fluctuaciones estacionales, ontogenéticas y vinculadas con el período reproductivo que experimentan estos mamíferos (Pyenson y Sponberg, 2011). A modo de ejemplo cabe mencionar las fluctuaciones en la masa de tejido adiposo observadas en Eubalaena australis (Miller et al., 2011, 2012; Buono et al., 2012). Por este motivo, los modelos para estimar la masa corporal en los Neoceti son extremadamente escasos y poco confiables. No obstante un parámetro que resulta un buen proxy para abordar el tema del tamaño corporal es el largo corporal. En este sentido, la existencia de una fuerte correlación entre el LC y la masa corporal de los adultos, está bien documentada tanto en odontocetos como en misticetos (Mackintosh \& Wheeler, 1929; Nishiwaki, 1950; Gambell, 1970; Perrin, 1975; Lockyer, 1976; Uhen, 2004). La ventaja en la utilización del LC es que resulta prácticamente invariable a la pérdida de fluidos y a la distorsión que sufren los ejemplares fuera del agua. Asimismo, es el parámetro más extensamente reportado en la literatura, no sólo de los cetáceos sino también de otros vertebrados marinos (Teleósteos, elasmobranquios, reptiles marinos mesozoicos). Por lo anteriormente expuesto en esta tesis se estimaron los largos corporales totales.

En trabajo previos, la estimación del LC en los cetáceos se efectuó sobre la base de medidas del cráneo, como por ejemplo el largo condilobasal o el ancho de los cóndilos occipitales, o del esqueleto postcraneano (Marino et al., 2003, 2004; Uhen, 2004; Gingerich, 1998; Gingerich et al., 2001). Recientemente Pyenson \& Sponberg (2011) abordaron esta problemática a través del desarrollo de una metodología más rigurosa, que integra modelos de regresión con información filogenética. Esta metodología implementa modelos de Regresión Múltiple de Mínimos Cuadrados Parciales (partial Least Squares o PLS) controlados por efectos filogenéticos (análisis de contrastes independientes), lo cual incrementa la confiabilidad de los resultados obtenidos. Esta metodología será aplicada en esta tesis.

El método propuesto por Pyenson \& Sponberg (2011) consiste en:

1) Obtención de ecuaciones de regresión utilizando cinco medidas craneanas: ancho del rostro en la base, ancho bizigomático, ancho de los exoccipitales, ancho de los cóndilos occipitales y largo condilobasal. En el caso de que no se disponga de las cinco medidas, el mejor proxy para estimar el LC es el ancho bizigomático (ABZ). 
2) Las ecuaciones de regresión están ajustadas para cada nodo de la filogenia general de los misticetos de la siguiente manera:

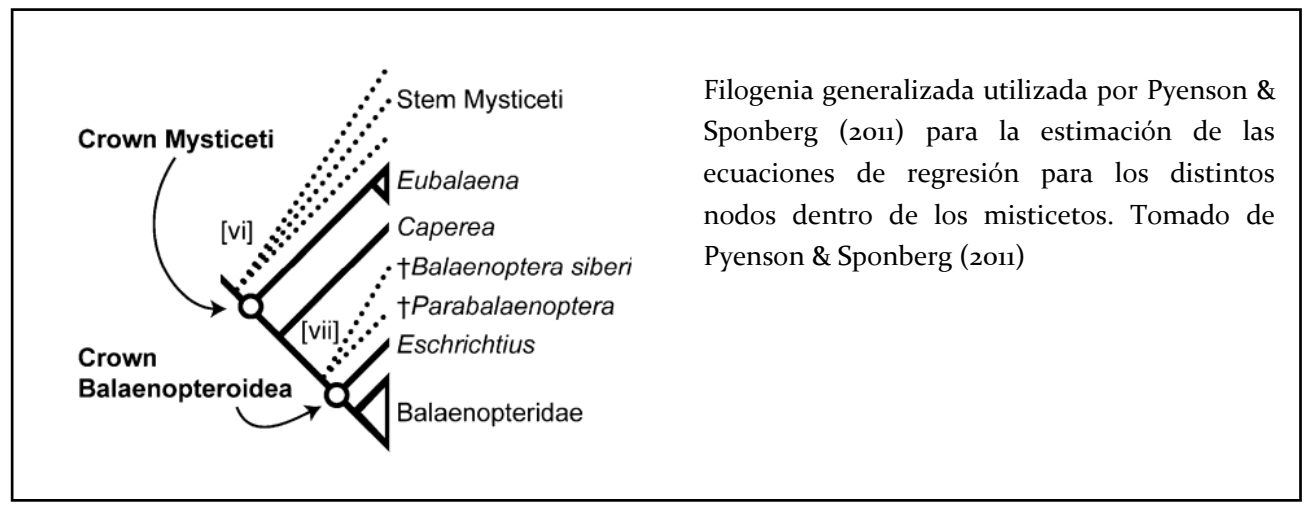

- $\quad$ Para el nodo stem Mysticeti la ecuación es la vi:

$$
\log (\mathrm{LC})=0.92 *(\log (\mathrm{ABZ})-1.72)+2.68
$$

- $\quad$ Para el nodo stem Balaenopteroidea la ecuación es la vii:

$$
\log (\mathrm{LC})=0.92 *(\log (\mathrm{ABZ})-\mathbf{1 . 6 4})+2.67
$$

La ecuación vi fue utilizada para estimar el LC en: Maiacetus inuus, Rhodocetus kasrani, Dorudon atrox, Zygorhiza kochii, Basilosaurus cetoides, Aetiocetus cotylalveus, Janjucetus hunderi, Eomysticetus whitmorei, Morenocetus, Taxón A, Balaenula astensis, Balaena montalionis, Balaenella brachyrhynus. La ecuación vii fue utilizada para estimar el LC en: Diorocetus hiatus, Pelocetus calvertensis, Piscobalaena nana y Cetotherium rathkii.

Debido a que algunas medidas necesarias para resolver las ecuaciones de regresión múltiple de PLS no pueden ser tomadas en los balénidos miocenos y en los otros misticetos analizados, se utilizará el ABZ para estimar el LC. Dicha medida fue obtenida por medición directa de los especímenes o tomada de la literatura. En aquellos casos donde sólo uno de los procesos zigomáticos está preservado, se efectuó la estimación del ABZ.

En el caso de los stem cetácea (Maiacetus inuus, Rhodocetus kasrani, Dorudon atrox, Zygorhiza kochii, Basilosaurus cetoides) se cuenta con información del LC de la literatura ya que hay varios especímenes con el esqueleto completo. A pesar de que la metodología utilizada en esta tesis para estimar el LC se aplica a los Neoceti, se puso a prueba la misma para los stem cetácea incluidos en el análisis para testear si los valores estimados se aproximan a los datos empíricos.

En Llanocetus el ABZ no está disponible ya que el holotipo está muy incompleto y sólo se preservaron porciones del basicráneo (Mitchell, 1989). Sin embargo, un nuevo espécimen, con el cráneo casi completamente preservado está en estudio, y el LC sugerido para el mismo sería de > 9m (Fordyce, 2003b; Fitzgerald, 2010). Dado que Llanocetus es el misticeto basal más antiguo (e.g. 
Steeman, 2007; Fitzgerald, 2010) y, por lo tanto, un taxón importante en la historia evolutiva de los misticetos, el valor de LC sugerido por Fordyce (2003b) será utilizado en esta tesis.

\subsubsection{Resultados}

Las estimaciones del LC para los taxones analizados se encuentran en la Tabla 6.1. En Mauicetus y Rodhocetus los LC obtenidos son 2,6 y 2,5m respectivamente (rango de 2-3m). En Dorudon, Zygorhiza y Basilosaurus los LC obtenidos son 4,5, 3,21 y 5,2m respectivamente. En estos taxones los LC estimados son próximos a los datos empíricos obtenidos de la literatura, excepto en Basilosaurus cetoides y, en menor medida, en Zygorhiza kochii. En el caso de Basilosaurus, la diferencia tan notable entre el LC estimado $(5,2 \mathrm{~m})$ y el dato empírico $(16,5 \mathrm{~m})$ puede estar relacionada con las características particulares que presenta este taxón en la columna vertebral. La columna vertebral de Basilosaurus está marcadamente alargada por la elongación de los cuerpos vertebrales y el cráneo es pequeño en comparación con el tamaño de la columna vertebral. Por este motivo, es probable que las medidas del cráneo no sean un buen proxy para estimar el LC. En el caso de Zygorhiza la diferencia entre el valor estimado (3,21m) y el dato empírico $(4,93 \mathrm{~m})$ puede estar relacionada con que el cráneo está levemente incompleto en la región donde se obtuvo el ABZ, y por lo tanto el LC está subestimado.

Para el caso de los misticetos basales dentados Aetiocetus y Janjucetus, el valor de LC obtenido es, en ambos casos, de $3 \mathrm{~m}$. En Janjucetus el valor estimado en este análisis es ligeramente menor al propuesto por Fitzgerald (2006; LC=3.5m)

En Eomysticetus whitmorei el LC estimado es de 4,4m. Sin embargo este valor puede estar subestimado por las características peculiares del cráneo de esta especie (i.e. cráneo angosto a nivel de la caja craneana, pero con un rostro muy largo; el largo condilobasal estimado es de 1,59m).

Para el caso de los balénidos miocenos los valores obtenidos rondan la media de 5,17 m, con un valor máximo de 5,7 m (Taxón A, MPEF-1122) y un valor mínimo de 4,15m en la cría del Taxón A (MPCNyO 290). En el ejemplar MLP 5-11 de Morenocetus y en el CH-P33-01 del Taxón A, los LC están ligeramente subestimados ya que ambos procesos zigomáticos no están completamente preservados.

En el caso de los balénidos pliocenos Balaenula astensis, Balaena montalionis y Balaenella los valores de LC estimados son de 6,6m, 7,2m y 7,9m respectivamente. En Balaenella el valor de LC está levemente subestimado, ya que los procesos zigomáticos están incompletos de ambos lados. Por otro lado, en Eubalaena shinshuensis el LC estimado fue de 12,5m.

En los cetotéridos Cetotherium rathkii y Piscobalaena nana el LC estimado fue de 3,6 y 4,6m respectivamente. En los balaenopteroideos Diorocetus y Pelocetus el LC estimado fue mayor, arrojando un valor de 6,4 y 9,4m respectivamente. 


\subsubsection{Discusión}

Los resultados de esta tesis sugieren que los balénidos miocenos presentaban un LC pequeño (<6m), no observándose mayores diferencias en el LC entre las formas del Mioceno temprano y las del Mioceno tardío. En el caso del Taxón A, el LC es similar entre el individuo adulto y subadulto. Esto es consistente con lo observado en los balénidos actuales donde individuos juveniles y subadultos ya presentan el largo corporal próximo al de un adulto (Best \& Schell, 1996; Kenney, 2009). Estas observaciones permiten inferir que, para el caso de Morenocetus (todos individuos subadultos), el LC obtenido sería próximo (o igual) al de un individuo adulto.

Los balénidos pliocenos (Balaenella, Balaenula astensis y Balaena montalionis) muestran un LC mayor a los balénidos miocenos, en un rango entre los 6-12 m. Estos resultados difieren de lo propuesto por Bisconti (2003, 2005) quien considera que Balaenula astensis, Balaenella brachyrhynus y Morenocetus, presentan un LC pequeño ( $\sim \mathrm{m})$. En el caso de Balaena montalionis el LC estimado en esta tesis es menor al obtenido en análisis previos (12m; Bisconti 2003; 7,2m de este análisis). Esto sugiere, a diferencia de Bisconti (2003), que algunas formas pliocenas de Balaena eran de un largo corporal menor a las formas actuales de este género (i.e. B. mysticetus). Por otro lado, Eubalaena shinshuensis presenta un valor de LC similar al de los representantes actuales de Eubalaena.

Cuando se compararon los LC de los balénidos extintos obtenidos en esta tesis con los datos estimados por Bisconti (2000, 2002, 2003), el mayor problema que se detectó es que la metodología empleada por este autor en la estimación del LG carece de un testeo riguroso. Para la estimación del LC en los balénidos extintos, Bisconti (2000, 2002, 2003) utilizó como parámetro el tamaño de la cabeza de Eubalaena (i.e. largo de la cabeza representa 1/3 del LC) (Tomilin, 1967). De esta forma, a partir de la estimación del largo del cráneo (el cual a su vez fue estimado a partir del largo del supraoccipital) se calculó el LC (Bisconti 2000, 2002, 2003). Esta metodología presenta dos problemas: 1) el largo del supraoccipital no es el mejor proxy para estimar el LC, sino el ABZ (Pyenson \& Sponberg, 2011); 2) no se cuenta con suficiente información empírica que sustente que la relación entre el largo de la cabeza vs resto del cuerpo (i.e. 1/3) observada en Eubalaena sea aplicable a la totalidad de los balénidos (por ejemplo en Balaena mysticetus la cabeza representa más de 1/3 del largo corporal; Rugh \& Shelden, 2009). Las diferencias observadas entre los resultados de este análisis y las estimaciones realizadas por Bisconti (2000, 2002, 2003), probablemente estén vinculadas con la diferencia en los métodos empleados. La metodología propuesta por Pyenson \& Sponberg (2011), y aplicada en esta tesis, es más rigurosa ya que integra modelos de regresión con información filogenética, lo cual aumenta la confianza de los resultados. Sin embargo es necesario continuar trabajando en el desarrollo de este tipo de metodologías y hacerlas extensivas a otros grupos de cetáceos, por ejemplo los arqueocetos, para de esta forma llegar a estimaciones que 
presenten el menor grado de error posible y que brinden una base más sólida para interpretar la evolución de este carácter en los Neoceti. Asimismo en este tipo de estimaciones se debe poner especial atención en la morfología esqueletaria de los taxones analizados, ya que en algunos casos (i.e. Basilosaurus y Eomysticetus), esta se dispara notablemente del plan corporal típico del resto del grupo.

La evolución al gigantismo fue una de las tendencias evolutivas más importantes dentro de los misticetos (Fordyce \& Barnes, 1994; MacLeod et al., 1993). En cuanto a la evolución de este carácter hay dos escenarios evolutivos propuestos: uno que sugiere una tendencia lineal de incremento del LC, desde los misticetos dentados de pequeño LC hasta los misticetos con barbas de mayor LC (Fitzgerald, 2006), y otro que propone que la condición primitiva para los misticetos es un LC grande y que el largo corporal pequeño evolucionó secundariamente en al menos dos linajes (Aetiocetidae y Mammalodontidae) (Fordyce \& de Muizon, 2001; Fitzgerald, 2010).

El mapeo de los LC obtenidos en esta tesis sobre el árbol evolutivo (i.e. cladograma calibrado estratigráficamente) permiten elaborar un escenario alternativo a los anteriormente mencionados (Fig. 6.3). Contrariamente a lo propuesto, la optimización del LC en un contexto más extenso, esto es ampliando el muestreo de las formas basales, indica que la explicación más parsimoniosa es que la condición primitiva dentro de los misticetos es un LC pequeño $(<6 \mathrm{~m})$, a pesar de que el registro más antiguo de los misticetos (Llanocetus) tiene un $\mathrm{LC}>6 \mathrm{~m}$. Asimismo, otros resultados que se desprenden de este análisis son:

1) La adquisición del gigantismo no siguió un patrón lineal y se adquirió al menos tres veces en forma independiente en la historia evolutiva de los cetáceos, resultados que nos permiten aceptar la hipótesis de trabajo planteada. La primera fue durante el Eoceno tardío en el Pelagiceti basal Basilosaurus cetoides, la segunda fue hacia finales del Mioceno dentro de los balénidos (en el ancestro Eubalaena-Balaena) y la tercera fue hacia finales del Plioceno en el ancestro de los Balaenoptera-Megaptera-Eschrichtius robustus. Como fue señalado por otros autores, durante el Mioceno no se registran misticetos con LC mayores a los 1om (Pyenson \& Sponberg, 2011);

2) Tanto en los Balaenidae como en los Balaenopteridae, se advierte al menos una reversión en B. montalionis y en B. bonaerensis.

3) Dentro de los cetotéridos no se registran formas gigantes y el único representante actual, Caperea marginata, presenta un LC $>6 \mathrm{~m}$;

4) Durante el Eoceno tardío se registra por primera vez la co-ocurrencia temporal de formas con un LC chico $(<6 \mathrm{~m})$, grande $(6-12 \mathrm{~m})$ y gigante $(>12 \mathrm{~m})$, con la presencia de los Pelagiceti basales (Zygorhiza, Dorudon, Basilosaurus) y del misticeto basal Llanocetus. Durante el Oligoceno y el Mioceno temprano se registran formas únicamente chicas, tales como Janjucetus, Aetiocetus, Eomysticetus y Morenocetus. El Mioceno medio-tardío estuvo otra vez marcado por la co-ocurrencia 
de formas con distintos rangos de LC, específicamente chicas (Taxón A, Cetotherium y Piscobalaena) y grandes (Diorocetus y Pelocetus). En los balenopteroideos la tendencia al aumento del LC ya estaba establecida en el Mioceno medio, más tempranamente que en los balénidos donde esta tendencia se observa recién en el Plioceno temprano (Fig. 6.3). El Mioceno medio representa el hiato más importante en el registro fósil de los balénidos, por lo cual habría que considerar que está última observación podría vincularse a un sesgo en el registro fósil. Durante el Plioceno temprano se registra la co-ocurrencia de balénidos grandes (<12m, como Balaenella y Balaenula) y gigantes $(E$. shinshuensis)

5) En lo que respecta específicamente a la evolución del LC de los balénidos, el escenario que surge a partir de los resultados obtenidos es el siguiente:

a) la condición primitiva dentro de los Balaenidae es un LC pequeño $(<6 \mathrm{~m})$, presente en los taxones basales Morenocetus y Taxón A, reteniendo de esta forma la condición ancestral de los Mysticeti;

b) a partir del Plioceno temprano se observa una tendencia al aumento del LC;

c) la primera aparición del gigantismo ocurre en el Plioceno temprano con Eubalaena shinshuensis;

d) durante el Plioceno se produjo la co-ocurrencia de formas de distintos LC (en un rango entre los 6 y los 12m), que culminó con la extinción de las formas más pequeñas hacia finales del Plioceno;

e) hasta el momento no hay evidencia de que en el Mioceno coexistieran balénidos de distintos LC.

Este escenario evolutivo difiere en algunos aspectos con el planteado por Bisconti (2003; 2005). Este autor sugiere que la evolución del LC en los balénidos estuvo marcada por la coocurrencia durante el Plioceno temprano de formas pequeñas y de formas gigantes, que culminó con la extinción de las formas pequeñas hacia finales del Plioceno y el advenimiento de formas gigantes. Como se mencionó previamente, los resultados de esta tesis sugieren que $B$. astensis y Balaenella presentan un LC mayor al previamente estimado y no se considera a estos taxones como balénidos pequeños, comparables a Morenocetus y al Taxón A, sino como un estadio de LC intermedio entre las formas basales y las formas modernas.

¿Cuáles son las ventajas evolutivas del gigantismo?. La respuesta a esta pregunta es un tema complejo de abordar, ya que el tamaño corporal esta relacionado con múltiples variables, entre ellas las metabólicas, fisiológicas y ecológicas (Schmidt-Nielsen, 1984; Damuth \& MacFadden, 1990). Entre los beneficios que se han propuesto para el aumento del tamaño corporal figuran: el incremento en el éxito de apareamiento, mayor longevidad y como estrategia antipredatoria (Hone \& Benton, 2005). Los resultados de esta tesis sugieren que el patrón de evolución del LC, no sólo de 
los balénidos sino también de los misticetos, es muy complejo, no lineal, y que el gigantismo ha ocurrido en los principales linajes, excepto en los cetotéridos, en más de una ocasión. El gigantismo representa un costo energético muy grande para los organismos ya que implica un aumento en la cantidad de alimento y agua consumida, se invierte mucha energía en la regulación térmica, y se prolongan los tiempos de desarrollo (pre y postnatal). Estos aspectos repercuten en tasas de evolución más bajas, limitando la habilidad de los organismos a afrontar cambios bruscos en el ambiente, y haciéndolos más susceptibles a la extinción (Hone \& Benton, 2005). En este contexto, la hipótesis antipredatoria ante la co-existencia con grandes tiburones propuesta por algunos autores (Bianucci et al., 2000; Bisconti, 2003) podría resultar en una sobresimplificación de una situación más compleja, que probablemente estuvo influenciada por una combinación de factores ecológicos y evolutivos. Futuros estudios que integren información neontológica, particularmente fisiológica, permitirán indagar este aspecto. 


\subsection{Morfología de la región nasal y}

\section{respiración}

\subsubsection{Introducción}

La región nasal es, junto con el oído, una de las regiones del cráneo que experimentó más cambios a lo largo de la historia evolutiva de los cetáceos. Las notables transformaciones del complejo nasal de los cetáceos, están muy bien documentadas en el registro fósil. Los principales cambios están relacionados con la migración de la fosa nasal, desde una posición anterior a una póstero-dorsal, con el consiguiente reacomodamiento de los huesos nasales, rostrales y occipitales (Forydce \& Muizon, 2001; Thewissen et al., 2009) (Fig. 6.4). Todas estas modificaciones permitieron optimizar los ciclos de respiración, ya que de esta forma los orificios nasales asoman rápidamente cuando el animal sale a la superficie a respirar. Esto evita un gasto de energía asociado con el levantamiento de la cabeza para eliminar el agua de la superficie (Heyning \& Mead, 1990; Reidenberg \& Laitman, 2008)

Dentro de este patrón general de modificación, los odontocetos presentan una mayor complejidad que los misticetos. En los primeros, además de la migración de las narinas, la región nasal presenta un complejo de estructuras blandas (i.e. sacos nasales alrededor del pasaje nasal y una estructura adiposa especializada, el melón) sin homólogo en otros grupos de mamíferos. Estas estructuras están involucradas en la producción y transmisión de sonidos de alta frecuencia utilizados durante el proceso de ecolocalización (Norris, 1968; Cranford et al., 1996; Cranford, 200o; Cranford \& Amundin, 2004) El complejo de sacos nasales rodea el pasaje nasal y se encarga de generar los sonidos de alta frecuencia, mientras que el melón los concentra y transmite al medio acuático. Asimismo los sacos nasales también se encargan de recapturar el aire circundante, que se utilizará en la próxima vocalización (Norris, 1968; 1969; Reidenberg \& Laitman, 2008) (Fig. 6.1). Los músculos faciales que rodean esta región están hipertrofiados e involucrados en el control del tamaño de los sacos aéreos, del diámetro del pasaje nasal, la forma del melón y en el cierre del pasaje nasal (Lawrence \& Schevill, 1956; Mead, 1975).

Por el contrario, en los misticetos la región nasal conserva el patrón típicamente mamaliano (Eschricht \& Reinhardt, 1866; Lawrence \& Schevill, 1956; Henry et al, 1983; Cave, 1988; Heyning \& Mead, 1990). Esto probablemente ha llevado a que no se explorara en detalle la morfología nasal de este grupo. En particular, es escaso el conocimiento de la miología de la región nasal (Carte \& 
Macalister, 1868; Allen, 1916; Schulte, 1926) y nulo el conocimiento de sus eventuales correlatos óseos. En este contexto, se plateó como objetivo de esta sección inferir la morfología de las estructuras blandas de la región nasal de los balénidos extintos y contribuir al conocimiento de la evolución del sistema respiratorio en este grupo.

Los objetivos específicos e hipótesis de trabajo de esta sección son:

1) Analizar los correlatos óseos y la posición de la apertura externa del pasaje nasal en la piel (blowhole) y de la narina externa ósea en balénidos actuales.

Hipótesis de trabajo 1: la posición del blowhole no tiene correlato óseo en la fosa nasal.

2) Evaluar si durante la evolución de los misticetos el desplazamiento postero-dorsal de la narina ósea estuvo acompañado por un cambio en la localización del blowhole.

Hipótesis de trabajo 2: la morfología del complejo nasal de los misticetos, incluídos los balénidos, se mantuvo estable y conservó el patrón mamaliano a lo largo de la historia evolutiva del grupo (i.e el blowhole se posiciona ántero-ventralmente dentro de la narina ósea).

3) Analizar la correlación entre el tamaño de la fosa nasal (medido en ancho y largo) y el tamaño del cráneo (medido en ancho y largo)

Hipótesis de trabajo 3: el tamaño de la fosa nasal no está correlacionada con el tamaño del cráneo.

\subsubsection{Materiales y métodos específicos}

Para la exploración de la anatomía de la región nasal se pudieron analizar como modelos neontológicos Eubalaena australis (ejemplares 4-10 y 03-11), Caperea marginata (NMNZ TMP o11345) y Balaenoptera bonaerensis (CNPMAMM 750) (capítulo 2).

Para la exploración de la región nasal de los misticetos se seleccionaron 19 especies, 12 extintas y 7 con representantes actuales. En el caso de los misticetos extintos se seleccionaron sólo aquellos con el cráneo completo o casi completo, y en los balénidos, dado que ni en Morenocetus ni el Taxón A esta preservada la región nasal, se aproximó a este tema mediante la exploración del balénido plioceno Balaenella brachyrhynus (NMB 42001).

El protocolo desarrollado para alcanzar los objetivos propuestos incluyó: la disección de la región nasal de Eubalaena australis, y la caracterización de las estructuras blandas alojadas en la fosa nasal; exploración de los correlatos entre las estructuras blandas y la morfología de la fosa nasal; 
análisis comparativo con los misticetos actuales Caperea y Balaenoptera bonaerensis; y el análisis de la correlación entre la localización del blowhole y los parámetros morfométricos de la fosa (i.e. largo y ancho de la fosa). Cumplido con este protocolo se procedió a la exploración del correlato óseo en los representantes extintos de los misticetos.

La homología de los músculos nasales entre los odontocetos y misticetos es difícil de establecer dadas las profundas modificaciones en la región nasal en el primero de estos grupos (Lawrence \& Schevill, 1956; Mead, 1975; Huggenberger et al., 2009). Esa situación se complica aún más cuando se tratan de establecer homologías entre los músculos de los cetáceos y de los mamíferos terrestres. En este contexto, en esta tesis se utilizó el criterio topológico propuesto por Carte \& Macalister (1868) para la identificación y nominación de los músculos nasofaciales. Este criterio ha sido adoptado en trabajos posteriores de la musculatura de los misticetos (Allen, 1916; Schulte, 1926). Sin embargo, en futuros estudios es recomendable considerar la inervación e irrigación en la identificación de los músculos, y de esta forma testear de forma adecuada las homologías entre los músculos nasofaciales de los cetáceos y de los mamíferos terrestres, así como también entre misticetos y odontocetos.

Debido a la gran cantidad de términos disponibles en la literatura sobre las estructuras de la región nasal en los cetáceos y para evitar confusiones, se presentan en la Tabla 6.2 (Apéndice) los términos, definición y referencias de cada una de las estructuras analizadas.

La descripción de las estructuras osteológicas asociadas al pasaje nasal se describieron en el capítulo 4 .

El análisis morfométrico se llevo a cabo mediante el análisis de cuatro medidas craneales: largo de la fosa nasal (LFN; medida desde el margen anterior de los nasales hasta el extremo más anterior de los premaxilares donde estos comienzan a confluir hacia el plano sagital del cráneo y donde la superficie de los mismos cambia de cóncava a convexa); ancho de la fosa nasal (AFN; tomada a nivel donde se registra el ancho máximo de la fosa), largo condilobasal (LCB; desde el extremo más anterior del rostro hasta el punto más posterior de los cóndilos occipitales) y ancho bizigomático (ABZ; entre los extremos más laterales de ambos procesos zigomáticos del escamoso) (Fig. 6.5). Las cuatro variables fueron logaritmizadas (base 10) para convertir la relación entre esas variables de una función exponencial $(\mathrm{Y}=\mathrm{aWb})$ a una función lineal ( $\log \mathrm{Y}=\log \mathrm{a}+\mathrm{b} \log \mathrm{W})$ y reducir la dispersión asociada con el alto valor de los datos. Se efectuó un análisis de regresión del eje mayor reducido o estandarizado (SMA, "standarized major axis") ya que se considera uno de los métodos más apropiados para aproximaciones alométricas (Warton et al., 2006)

El software utilizado en los análisis estadístico es el PAST v. 2.17 (Hammer et al., 2001). 


\subsubsection{Resultados}

\subsubsection{Anatomía de la región nasal en Eubalaena australis.}

El pasaje nasal se define como todo el corredor de aire entre los blowholes y las narinas internas. Los blowholes constituyen la apertura externa del aparato respiratorio en la piel. Dicho orificios son pares, simétricos, y ubicados sobre la superficie dorso-posterior de la cabeza, a cada lado del plano sagital del cráneo (a $440 \mathrm{~mm}$ del extremo anterior del rostro en el ejemplar 03-11 y al 630 mm en el ejemplar 04-10) (Fig. 6.6 A). Los blowholes se ubican a nivel de la mitad posterior de la fosa nasal (fosa en la superficie dorsal del cráneo, formada por el premaxilar, el vómer, el nasal y el septo nasal), donde esta presenta su ancho máximo. En vista dorsal, los blowholes están definidos por un margen interno o medial y un margen externo o lateral que son semicirculares con la superficie cóncava orientada lateralmente, y ambos están separados medialmente por un surco en la piel. En algunos especímenes se observan pelos en posición posterior a los blowholes (Fig. 6.6B). Por debajo de la capa de tegumento que cubre el blowhole hay una capa de grasa muy gruesa ubicada en posición anterior al margen externo del blowhole. Esta capa de grasa presenta una estructura más firme y fibrosa que la grasa que cubre el resto del cuerpo y forma una protuberancia redondeada sobre la superficie dorsal de la cabeza, en posición anterior al margen externo del blowhole (Fig. 6.7). Cada blowhole desemboca ventralmente dentro de un vestíbulo que conecta póstero-ventralmente con la cámara nasal (Tabla 6.2). El vestíbulo se define como la cavidad generada por la apertura del blowhole, la cual está ubicada inmediatamente debajo de éste último, para el pasaje del aire hacia el pasaje nasal ventral (Tabla 6.2). La superficie interna del vestíbulo está cubierta de un epitelio negro, delgado y levemente plegado, el cual se vuelve rosado hacia la porción póstero-ventral del pasaje nasal. El espacio de cada vestíbulo está ocupado por una masa de tejido, correspondiente a las válvulas nasales (Fig. 6.8). Dichas válvulas están formadas de tejido conectivo, grasa y musculatura nasal y están cubiertas por un epitelio negro el cual es continuo con la pared ventral y lateral del pasaje nasal.

En la porción posterior del pasaje nasal, en posición cercana a las narinas internas y sobre la superficie dorso-lateral de los palatinos, se ubica una masa de tejido altamente vascularizado que cubre la pared del pasaje nasal (Fig. 6.8). Macroscópicamente este tejido es similar a la red admirable oftálmica presente en el ojo de E. australis (Buono et al., 2012). Histológicamente, este tejido está compuesto por una compleja red de vasos de arterias, arteriolas y capilares embebidas en tejido conectivo (Fig. 6.9).

Musculatura nasofacial. En E. australis se identificaron los cuatro músculos nasales (m. dilator de las narinas, $\mathrm{m}$. constrictor de las narinas, $\mathrm{m}$. retractor y $\mathrm{m}$. depresor alae nasi) descriptos por Carte \& Macalister (1868, P: 238-239) en Balaenoptera acutorostrata. Un músculo nasal 
adicional, no descripto para esta última especie, se encontró en E. australis (denominado aquí como M. dilator de las narinas profundo) (Fig. 6.10; 6.11; 6.12).

M. dilator de las narinas superficial (Fig. 6.11 A, B): es el músculo más superficial ya que se encuentra inmediatamente por debajo de la capa de grasa subcutánea. Es un músculo muy delgado y se origina posteriormente en la superficie anterior del proceso descendente del maxilar, y en dirección anterior, a lo largo de la superficie lateral del maxilar vía una aponeurosis muy ancha. Las fibras se desarrollan en dirección medial por delante del blowhole y se insertan a lo largo de la superficie del premaxilar. Las fibras musculares de este músculo tienen una disposición irregular y están superpuestas una sobre la otra.

M. constrictor de las narinas (Fig. 6.11 A, D): se origina ventralmente en todo el margen lateral de la fosa nasal; las fibras de desarrollan en dirección dorsal y se insertan vía una aponeurosis en la capa de grasa que se encuentra por debajo del margen externo del blowhole.

M. dilator de las narinas profundo (nuevo nombre) (Fig. $6.11 \mathrm{~A}, \mathrm{C}$ ): este músculo se desarrolla en el plano medio entre el $\mathrm{m}$. dilator y contrictor de las narinas. Es un músculo delgado que se origina posteriormente en la región póstero-dorsal del maxilar y premaxilar. Desde esta región, las fibras se desarrollan ántero-dorsalmente y se apoyan sobre la superficie lateral del $\mathrm{m}$. constrictor de las narinas para insertarse finalmente, vía una aponeurosis en la capa de grasa, en la línea sagital de la cabeza, anteriormente al blowhole.

M. retractor alae nasi (Fig. 6.11 A, E; 6.12): es un músculo pequeño situado en el margen posterior del blowhole y las fibras están orientadas dorso-ventralmente. Se ancla medialmente en el margen posterior del cartílago nasal medial. Las fibras corren oblicuamente en dirección mediolateral ocupando la superficie posterior del cartílago nasal lateral y se inserta lateralmente vía una aponeurosis sobre el músculo constrictor de las narinas.

M. depresor alae nasi (Fig. 6.12): es el músculo nasal más grande y profundo y ocupa toda la superficie ventral de la fosa nasal y una pequeña porción del pasaje nasal dorsal. Se origina del extremo anterior de la fosa nasal sobre toda la superficie medial y ventral del premaxilar. Las fibras corren posteriormente y están orientadas oblicuamente en dirección ántero-dorsal. Se inserta medialmente vía una aponeurosis en el cartílago nasal medial y posteriormente en la grasa y piel que recubre la válvula nasal. La separación entre el $\mathrm{m}$. constrictor de las narinas y el $\mathrm{m}$. depresor alae nasi no puede distinguirse ya que las fibras están interdigitadas.

\subsubsection{Análisis morfométrico}

Las medidas utilizadas en el análisis morfométrico se presentan en la Tabla 6.3. Los resultados del análisis de regresión "SMA" muestran una correlación positiva entre el largo del 
cráneo (LCB) y el tamaño de la fosa nasal (LFN y AFN; r=0.90 y r=0.92 respectivamente), y entre el ancho del cráneo (ABZ) y el tamaño de la fosa nasal (LFN y AFN; $r=0.82$ y r=0.94 respectivamente) (Tabla 6.4 y 6.5). De los cuatro análisis de correlación, el ABZ-AFN muestran el valor de correlación más alto $(\mathrm{r}=0.94)$. Los resultados del análisis de regresión muestran una relación alométrica positiva entre LCB y el AFN ( $b=1.28$; la pendiente es significativamente distinta de 1 a un $p<0.05$ ). Por el contrario, el ABZ y del AFN muestran una relación isométrica $(b=1.15 ; p=0.15)$. El LFN muestra un incremento isométrico tanto con el LCB como con el ABZ (Fig. 6.13).

\subsubsection{Discusión}

\section{Aspectos morfológicos del complejo nasal en los misticetos}

Como resultado de la exploración y análisis de la anatomía blanda del modelo neontológico seleccionado, Eubalaena australis, surgieron algunos aspectos interesantes en relación con la morfología conocida en los balenoptéridos y en el cetotérido Caperea. Las principales diferencias que se pueden puntualizar son aquellas vinculadas con las estructuras para expeler el agua del pasaje nasal durante la respiración, y la inserción y/o disposición de los músculos nasales. En relación al primer aspecto uno de los desafíos que enfrentan los cetáceos durante la respiración es mantener el agua fuera del pasaje nasal. Para ello desarrollaron una serie de estructuras tales como las válvulas nasales, surcos, crestas y/o protuberancias alrededor de los blowholes. Las válvulas nasales sellan los blowholes impidiendo la entrada de agua al pasaje nasal, y no se observaron diferencias en la morfología de estas estructuras en los tres grupos taxonómicos analizados (balénidos, balenoptéridos y cetotéridos). En relación con las otras estructuras para la deflexión del agua, en los balénidos los blowholes se ubican sobre una protuberancia muy desarrollada formada por grasa y musculatura, lo cual, junto con un rostro muy arqueado, favorece que los blowholes tengan una posición alta en la cabeza (Fig. 6.7). Además presentan un surco medial entre ambos blowholes y una cresta anterior que ayuda a expeler el agua de la superficie dorsal de la cabeza. En los balenoptéridos, que presentan un rostro plano que favorece la acumulación de agua con mayor facilidad, la protuberancia tiene un desarrollo menor en comparación con los balénidos. Sin embargo, en este grupo se observan una serie de crestas en "V" sobre la superficie dorsal del rostro, localizadas anteriormente a los blowholes, que favorecen que el agua se escurra de la cabeza en forma eficiente. En Caperea, cuyo rostro tiene un arqueamiento intermedio entre los balénidos y los balenoptéridos, los blowholes se ubican sobre una protuberancia de grasa y musculatura de menor desarrollo que en los balénidos. Al igual que en este último grupo, hay un surco poco pronunciado entre los blowholes. En este contexto, un patrón común a los representantes de los tres grupos principales de misticetos, es la presencia de grasa por debajo del blowhole formando una protuberancia. 
A pesar de que la organización general de los músculos nasales es similar entre los balénidos y los balenoptéridos, existen algunas diferencias. En los balenoptéridos el $\mathrm{m}$. constrictor se origina en el extremo anterior de la fosa temporal y sobre la superficie dorsal del maxilar. Su inserción anterior se ubica sobre la superficie dorsal del cartílago mesorostral y la posterior en el margen externo del blowhole y sobre la superficie dorsal del maxilar (Carte \& Macalister, 1868, P: 239). Por el contrario, en Eubalaena australis el origen de este músculo está restringido al premaxilar y se inserta en el margen externo del blowhole. En los balenoptéridos el m. constrictor se desarrolla en dirección ántero-posterior (a diferencia de E. australis que es dorso-ventral), en posición lateral a los blowholes y forma una estructura convexa en vista dorsal; como resultado este músculo no forma una protuberancia acentuada por debajo de los blowholes como la observada en E. australis. Por otro lado en los balenoptéridos el $\mathrm{m}$. retractor alae nasi se origina de la porción antero-lateral del frontal, las fibras se dirigen anteriormente y se insertan en los cartílagos nasales. En E. australis este músculo está restringido a los cartílagos nasales y nunca se inserta en el frontal. El m. dilator de las narinas superficial y el m. depresor alae nasi tienen una disposición similar en ambos taxones.

Las diferencias observadas en los sitios de inserción de la musculatura nasal entre balénidos y balenoptéridos pueden estar vinculadas con la anatomía dispar que presenta el cráneo de estos dos grupos. En los balenoptéridos el rostro es plano, con un maxilar ancho y un proceso ascendente del maxilar pronunciado brindando una superficie amplia de anclaje para el $\mathrm{m}$. constrictor. Por el contrario, en los balénidos, el rostro está comprimido transversalmente y arqueado; como resultado el maxilar es muy angosto y la superficie mayor de inserción para el m. constrictor está en el premaxilar.

Por otro lado, el m. dilator profundo identificado en Eubalaena australis no fue reportado por Carte \& Macallister (1868) en Balaenoptera acustorostrata. Esto puede estar relacionado con que no se haya podido identificar en la disección, ya que se trata de un músculo muy delgado, o que este músculo no esté presente en los balenoptéridos. Nuevos estudios donde se explore en detalle la miología nasal de los balenoptéridos, así como también de Caperea marginata, ayudarán a resolver esta problemática.

En Eubalaena australis durante la respiración cada blowhole cambia desde un contorno en forma de media luna (cuando está cerrada) a un contorno oval (cuanto está abierto). El margen interno del blowhole permanece rígido, debido a la presencia de los cartílagos nasales, mientras que el margen externo se mueve libremente para abrir y cerrar el blowhole. La capa de grasa que se encuentra por debajo del margen externo del blowhole tiene una estructura firme y fibrosa y brinda soporte y anclaje a los músculos nasales implicados en los movimientos de apertura y cierre del blowhole.

En Eubalaena australis el movimiento del blowhole se produce por la acción de cinco 
músculos nasales. Por un lado la apertura de la parte dorsal del pasaje nasal (el blowhole y el vestíbulo) se produce por la contracción del $\mathrm{m}$. dilator de las narinas superficial y $\mathrm{m}$. dilator de las narinas profundo, los cuales traccionan del margen externo del blowhole látero-ventralmente. La apertura de la porción ventral del pasaje nasal se produce por la contracción del $\mathrm{m}$. depresor alae nasi, el cual tracciona la válvula nasal anteriormente. La acción simultánea de estos tres músculos permite la dilatación del lumen del pasaje nasal durante los ciclos de inhalación y exhalación. El cierre del pasaje nasal se produce por la relajación del músculo depresor alae nasi y por la contracción del $\mathrm{m}$. constrictor de las narinas y $\mathrm{m}$. retractor alae nasi. La relajación del $\mathrm{m}$. depresor alae nasi permite que la válvula nasal vuelva a su posición dentro del lumen del pasaje nasal. Asimismo, la contracción simultánea del $\mathrm{m}$. constrictor y del $\mathrm{m}$. retractor alae nasi comprime el margen interno y externo del blowhole, cerrando el pasaje nasal, sellando el blowhole y evitando la entrada de agua mientras el animal se sumerge.

Otro resultado destacado del análisis de Eubalaena australis, es la presencia de un tejido fuertemente vascularizado revistiendo el pasaje nasal. La estructura macro y microscópica de este tejido es semejante a las redes admirables. Estas últimas son complejos de redes vasculares formadas por arterias, venas o ambas que rodean o cubren parcialmente al ojo, paladar, encéfalo, tórax, foramen mandibular, seno pterigoideo, oído y columna vertebral (Nagel et al., 1968; Geisler \& Luo, 1998; Pfeiffer \& Kinkead, 1990; Buono et al., 2012; Ford et al., 2013). Hasta el desarrollo de esta tesis, la presencia de una red admirable revistiendo el pasaje nasal no había sido identificada en ningún otro misticeto.

La función de las redes admirables ha sido ampliamente discutida en la literatura, y se ha sugerido que actúan en la modulación y amortiguación de las fluctuaciones en el flujo sanguíneo hacia el sistema nervioso central durante el buceo, como reservorio de oxígeno y/o para regular la temperatura corporal (Geisler \& Luo, 1998; Ninomiya \& Yoshida, 2007; Ford et al., 2013). Teniendo en cuenta que en los misticetos, a diferencia de lo que ocurre en los mamíferos terrestres, el calentamiento del aire que entra al pasaje nasal no involucra los etmoturbinales, ya que están muy reducidos, otra estructura debe cumplir con esta función. En este contexto se propone que una de las funciones del tejido vascular que reviste el pasaje nasal en Eubalaena australis sea el calentamiento del aire, o que, como otras redes admirables, sirva como reservorio del aire excedente que es movilizado durante el colapsamiento de los pulmones. Las hipótesis aquí planteadas requerirán de futuros estudios, especialmente microanatómicos y fisiológicos, para su contrastación.

\section{Aspectos evolutivos del complejo nasal de los misticetos}

Los resultados del estudio de la morfología de la región nasal (blanda y ósea) permitieron 
localizar la posición del blowhole en la fosa nasal. Tanto en Eubalaena australis, Caperea marginata, como en Balenoptera bonaerensis el blowhole está localizado en la mitad posterior de la fosa nasal, donde esta presenta su ancho máximo. Dado que esta muestra abarca representantes de los tres grandes clados de misticetos con representantes actuales, en el marco de esta tesis se asume que esta condición es representativa de los misticetos. Con base en lo anteriormente expuesto se rechazó la hipótesis de trabajo 1 y se considera que el ancho máximo de la fosa nasal es un buen correlato de la posición del blowhole.

En los cetáceos es de amplio conocimiento que la narina externa ósea migró pósterodorsalmente en el cráneo a lo largo de la evolución. La narina ósea migró desde una posición anterior, típicamente mamaliana, en los paquicétidos, ambulocétidos y remingtonocétidos, hasta una posición póstero-dorsal en los Pelagiceti (Thewissen \& Bajpai, 2001; Thewissen et al., 2009) (Fig. 6.4). Asimismo, dentro de los misticetos el grado de retracción de las narinas es variable. En los misticetos basales Janjucetus y Aetiocetus weltoni, y en los balenopteroideos Diorocetus hiatus y Aglaocetus patulus, la narina externa ósea está más retraída que en los basilosauridos, con el margen posterior de la misma ubicado en posición anterior a las muescas anterorbitales. Esta condición es extensiva a los balénidos extintos (Balaenella NMB 42001) y a los taxones actuales (Eubalaena y Balaena) así como también a Caperea. Algunos cetotéridos (e.g. Piscobalaena nana), los balenoptéridos y los escríctidos, presentan una condición de retracción de la narina externa ósea más pronunciada aún, con el margen posterior de la misma ubicado al mismo nivel o posterior a las muescas anterorbitales.

Además de un cambio en la posición de la narina externa ósea, otro aspecto relevante a mencionar es el cambio en la morfología de esta estructura a lo largo de la historia evolutiva de los misticetos. En este sentido, el proceso de retracción de la narina ósea estuvo acompañado por el desarrollo de una fosa nasal profunda y elongada en la superficie dorsal del cráneo. El primer grupo en el que se registra el desarrollo de la fosa nasal es en los basilosauridos, en los cuales la fosa es profunda y su contorno en vista dorsal es en forma de lágrima (angosta anteriormente y ancha posteriormente), condición que se mantiene y acentúa más en los misticetos.

En contraposición con el amplio conocimiento sobre la migración de la narina ósea en el cráneo de los misticetos, la posición relativa del blowhole dentro de la fosa nasal no había sido previamente indagada. La posición póstero-dorsal del blowhole dentro de la fosa nasal de los misticetos descripta en esta tesis se contrapone con la regla aceptada como invariante, no sólo en los mamíferos sino también en los amniotas. En este sentido se ha propuesto que en los amniotas la narina externa blanda se ubica anterior o ántero-ventral dentro de la narina externa ósea (Witmer, 2001). En este contexto, si tal como lo indican los resultados de esta tesis en los balénidos, balenoptéridos y cetotéridos, el ensanchamiento posterior de la narina ósea coincide y marca (= 
correlato óseo) el emplazamiento del blowhole, entonces es posible explorar este carácter en un marco evolutivo. La exploración de este correlato en los grupos analizados sugiere que la migración posterior de la narina externa ósea y la formación de la fosa nasal, estuvo acompañada del desplazamiento póstero-dorsal del blowhole dentro de la fosa nasal, condición ya adquirida en los primeros cetáceos completamente acuáticos (basilosauridos del Eoceno medio-tardío). Sobre esta base se rechaza la segunda hipótesis de trabajo planteada.

La retracción y dorsalización de las narinas externas óseas y del blowhole podría estar relacionada con la optimización de los ciclos respiratorios. Por un lado permite la respiración minimizando el gasto energético implicado en elevar la cabeza fuera del agua y por otro acorta significativamente la longitud del pasaje nasal, permitiendo una ventilación más rápida.

Como se mencionó anteriormente, dentro del crown Mysticeti, la retracción de la narina ósea y del blowhole es más acentuada en los balenoptéridos, que en los balénidos y cetotéridos (Caperea). Los balénidos y Caperea presentan un diseño corporal (i.e. contorno poco hidrodinámico, aletas pectorales y caudal grandes) que ha sido relacionado con un modo de natación de baja velocidad y vinculado con la alimentación por filtración pasiva (Webb, 1984; Webb \& de Buffrenil, 1990; Woodward et al., 2006). Por el contrario el diseño corporal de los balenoptéridos (e.g. cuerpos muy hidrodinámicos, aletas pectorales y caudal reducidas) ha sido asociado con un método de natación más rápido, que resulta eficiente para la alimentación por filtración activa o engullido (Fish \& Battle, 1995; Woodward et al., 2006). Las evidencias reunidas permiten elaborar como hipótesis, que la retracción más acentuada en los balenoptéridos esté vinculada con alcanzar una mayor eficiencia en la respiración durante los ciclos de natación rápida característicos de estos misticetos, especialmente durante las maniobras de alimentación. Esta hipótesis requerirá de evidencias futuras para su contrastación.

\section{Análisis morfométrico}

De todos los parámetros morfométricos analizados, el de mayor interés es el ancho máximo de la fosa nasal. Como se describió anteriormente, el espacio entre el blowhole y la fosa nasal está ocupado por la musculatura que acciona las válvulas de apertura y cierra del blowhole, por lo tanto el ancho máximo de la fosa nasal no es sólo un correlato de la posición del blowhole sino también del tamaño de los músculos que accionan sobre esta estructura. De este modo, un aumento del ancho de la fosa nasal podría vincularse a un mayor desarrollo de la musculatura nasal y, por lo tanto, a un aumento del tamaño del blowhole. De las variables analizadas es, precisamente, el ancho de la fosa nasal el que mostró una correlación más alta con el largo $(\mathrm{r}=\mathrm{0}, 93)$ y el ancho del cráneo $(\mathrm{r}=\mathrm{0}, 94)$ (Tabla 6.4; 6.5; Fig. 6.13), con lo cual se acepta la tercera hipótesis de trabajo planteada. Asimismo, el 
análisis morfométrico muestra una relación alométrica positiva entre el ancho de la fosa nasal y el largo del cráneo (Tabla 6.4).

Los resultados obtenidos en esta tesis indican que el ensanchamiento de la fosa nasal a lo largo de la evolución de los misticetos estaría relacionado con el mayor desarrollo de los músculos nasales, particularmente de los que abren y cierran el blowhole, sugiriendo así un incremento en el tamaño relativo de esta última estructura. Esto último pudo estar vinculado a los cambios en los requerimientos fisiológicos relacionados con el aumento en el tamaño corporal, como así también con la adquisición de un buceo más eficiente. El mayor problema que enfrentan los animales de respiración pulmonar durante el buceo, es la disminución en la tensión arterial del oxígeno (hipoxia) y el aumento en la tensión arterial del dióxido de carbono (hipercapnia). Este problema se resuelve capturando mayor cantidad de oxígeno y usándolo de forma más eficiente (Blix \& Folkow, 1983). En este contexto un blowhole de mayor tamaño posibilitó, no sólo un incremento en el volumen de aire intercambiado durante la respiración, sino también una ventilación más rápida de los pulmones, reduciendo de esta forma los riesgos de hipoxia y de hipercapnia. La contrastación de estas hipótesis requerirá el desarrollo de líneas de investigación futuras. 


\section{3 Órganos de los sentidos}

\subsubsection{Ojo}

\subsubsection{Introducción}

Las capacidades visuales se pueden medir en términos de sensibilidad (esto es la capacidad de ver en condiciones de baja luminosidad) y de agudeza (capacidad de resolver detalles finos de la imagen), las cuales dependen de la estructura, tamaño y propiedades ópticas del ojo (Walls, 1942; Humphries \& Ruxton, 2002). La sensibilidad visual está determinada por el número $f$, el cual depende de la longitud focal (distancia desde el punto posterior de la lente hasta la retina; $l_{\mathrm{f}}$ ) y del diámetro de la pupila dilatada (Dpd) $\left(f=l_{f} / \mathrm{Dpd}\right)$. La agudeza visual está vinculada con la distancia focal $\left(l_{\mathrm{f}}\right)$ y la distancia entre las células fotorreceptoras de la retina $(\mathrm{dr})\left(\mathrm{R}=l_{\mathrm{f}} / 2 \mathrm{~d}_{\mathrm{r}}\right)$ (Humphries \& Ruxton, 2002).

En el caso de las formas extintas, las aproximaciones posibles al tema de las capacidades visuales están limitadas a la reconstrucción del globo ocular (largo, ancho y distancia focal) a través de la búsqueda de correlatos óseos. En los reptiles y en las aves extintas los anillos escleróticos se han utilizado como un buen proxy para reconstruir el globo ocular, y de esta manera estimar parámetros visuales (e.g. Motani et al., 1999; Fernández et al., 2005; Schmitz, 2009; Herrera, 2012). Los mamíferos carecen de anillos escleróticos y, por lo tanto, la estimación de parámetros visuales en taxones extintos se efectuó a partir del análisis del tamaño de la órbita y del foramen óptico, los cuales resultaron buenos indicadores (Kay \& Kirk, 2000). En los cetáceos estas aproximaciones no son del todo válidas debido a que la pared posterior de la órbita está abierta. En el caso particular de los misticetos, las contribuciones que abordaron este tema son escasas, entre las que se destacan Fitzgerald (2006), Demeré \& Berta (2008) y Marx (2010). En estos estudios las inferencias en cuanto al tamaño del globo ocular se efectuaron sobre la base de la relación entre el tamaño de la órbita y el ancho bizigomático del cráneo. Sin embargo, estos estudios carecen de un análisis anatómico detallado de la región orbital, donde se explore la existencia de correlatos entre las estructuras óseas y las blandas.

Los objetivos específicos e hipótesis de trabajo de esta sección son:

1) Explorar la anatomía ósea y blanda de la región orbital de E. australis con el fin de buscar correlatos óseos que permitan reconstruir el globo ocular y el nervio óptico en los balénidos miocenos y en otros misticetos extintos. 
Hipótesis de trabajo 1: la órbita y el canal óptico son correlatos óseos válidos del tamaño del globo ocular y del nervio óptico respectivamente.

2) Analizar los resultados obtenidos en el contexto de la historia evolutiva de los balénidos.

Hipótesis de trabajo 2: en los balénidos, al igual que en todos los misticetos, hubo una tendencia a la reducción del globo ocular y del nervio óptico, indicando una disminución de las capacidades visuales a lo largo de la historia evolutiva del grupo.

\subsubsection{Materiales y métodos específicos}

Para estudiar la morfología del ojo y estructuras periorbitales de E. australis in situ y explorar la presencia de correlatos óseos, se diseccionó la zona orbital de los siguientes ejemplares: 01-09,04-09, 01-10, 02-10, 03-10, 04-10, 02-11 y 03-11 (Capítulo 2). Asimismo para los estudios anatómicos y morfométricos del globo ocular, se analizaron 32 muestras de ojos (26 provenientes de crías, 4 de adultos y dos de individuos de largo corporal desconocido) que fueron colectadas en su mayoría y donadas para su estudio por el programa de Monitoreo Sanitario Ballena Franca Austral a lo largo de 7 años (2003; 2006-2011) y algunas por la tesista. Las muestras fueron congeladas en una cámara fría a $20{ }^{\circ} \mathrm{C}$ en el Centro Nacional Patagónico, y se estudiaron congeladas para evitar el colapso y/o deterioro de algunas estructuras del ojo. La información obtenida de Eubalaena australis fue comparada con aquella disponible en la literatura del balénido Balaena mysticetus (Zhu et al., 2001), así como también con la proveniente de otros misticetos diseccionados por la tesista (i.e. Caperea marginata y Balaenoptera physalus; capítulo 2)

Para los estudios histológicos se utilizó una muestra de ojo (o80910-PV-Ea o6), la cual fue cortada transversalmente (i.e. plano vertical que corta a través del eje longitudinal del ojo in situ y lo separa en una sección anterior y otra posterior) para realizar cortes delgados de diversas estructuras intraoculares (córnea, iris, esclera, lente, retina y coroide). Los procedimientos de fijación y coloración de las muestras histológicas fueron detallados en el capítulo 2. La terminología utilizada en esta sección sigue la propuesta por Zhu et al. (2001) y la Nomina Anatómica Veterinaria (2012). En la Fig. 2.1 se muestran los planos de orientación del cuerpo de los balénidos que serán utilizados para orientar las estructuras del ojo in situ.

Con el objetivo de determinar si el tamaño de la órbita se relaciona con el tamaño del globo ocular, se tomaron en dos ejemplares (o71210-PV-Ea02; 082210-PV-Ea 11) las siguientes medidas: largo del globo ocular (LGO), alto del globo ocular (AlGO); largo de la órbita (LO) y alto de la órbita (AO). Por otro lado, con el objetivo de determinar la relación entre el tamaño del globo ocular y la córnea con el tamaño corporal (medido como el largo corporal) se obtuvieron cinco medidas de 29 ejemplares que incluyen: ancho del globo ocular (AnGO), largo del globo ocular (LGO), alto del 
globo ocular (AlGO), largo de la córnea (LCO) y alto de la córnea (AlCO) (Fig. 6.14). Estas variables fueron logaritmizadas (base 10) para convertir la relación entre esas variables de una función exponencial $(\mathrm{Y}=\mathrm{aWb})$ a una función lineal $(\log \mathrm{Y}=\log \mathrm{a}+\mathrm{b} \log \mathrm{W})$ y reducir la dispersión asociada con el valor alto de los datos. Se efectuó un análisis de regresión del eje mayor reducido o estandarizado (SMA, "standarized major axis") ya que se considera uno de los métodos más apropiados para aproximaciones alométricas (Warton et al., 2006).

Para explorar uno de los parámetros visuales en Eubalaena australis, esto es la sensibilidad visual, se estimó el número $f$ en el ejemplar cría 071210-PV-Ea 02, a través de la relación entre la longitud focal o distancia nodal posterior (PND) y el diámetro de la pupila dilatada (Humphries \& Ruxton, 2002) (Fig. 6.14) . Debido a que el ojo de los cetáceos es emétrope en el agua, el largo focal se midió desde el centro de la lente hasta la retina (Mass \& Suppin, 2002; 2007). El diámetro de la pupila dilatada se estimó como el 90\% del diámetro de la lente (Hughes, 1977).

Los análisis estadísticos fueron efectuado en el programa PAST versión 2.17 (Hammer et al., 2001).

\subsubsection{Resultados}

\subsection{Anatomía del ojo y estructuras periorbitales de}

\section{Eubalaena australis.}

Posición del ojo. En Eubalaena australis, como en otros misticetos, los ojos están ubicados lateralmente en la cabeza por detrás de la comisura de la boca. Al igual que en Balaena mysticetus (Zhu et al., 2001), el globo ocular está protruido y ubicado por fuera de la órbita (formado en E.australis por el frontal, el yugal, el lagrimal, el maxilar y el escamoso) (Fig. 6.15). Las medidas del globo ocular y de la órbita obtenidas en dos ejemplares (o71210-PV-Ea o2 y o82210-PV-Ea 11) muestran que el largo ántero-posterior y el alto dorso-ventral del globo ocular representan un 50 y un $44 \%$ en o71210-PV-Ea o2 y un 52 y un 67\% en o82210-PV-Ea 11, respectivamente del tamaño de la órbita (Tabla 6.6), lo cual sugiere que el tamaño de estas dos estructuras no están relacionadas.

Estructuras periorbitales. El globo ocular está rodeado por el párpado dorsal y el ventral lo cuales forman el margen de la apertura palpebral. La apertura palpebral es la apertura del ojo y representa 1/3 del largo de la fisura palpebral, de la misma forma que se observa en Balaena mysticetus (Zhu et al., 2001) (Fig. 6.16A). La piel por encima del globo ocular es más clara y marca el sitio de desarrollo de las callosidades (Fig. 6.16B). El párpado dorsal está delimitado por un surco dorsal mientras que el párpado ventral está delimitado por un surco ventral menos acentuado, y ambos están orientados ántero-posteriormente. En algunos ejemplares se observa un tercer surco, menos pronunciado, en el párpado dorsal (Fig. 6.16C). En sección medial, la piel es delgada en los 
párpados y gruesa en los surcos. Rodeando la fisura palpebral y por debajo de la piel de los párpados se observan las fibras del $\mathrm{m}$. orbicularis oculi las cuales están embebidas en la capa de grasa subcutánea (Fig. 6.17). Una vez retirados los párpados y la musculatura palpelbral, queda expuesto el globo ocular el cual se encuentra rodeado por tres capas de grasa. Dichas capas se corresponden con aquellas descriptas en B. mysticetus (Zhu et al., 2001), pero se observan algunas diferencias en el grosor de las mismas entre los adultos y las crías así como también dentro de estas dos categorías de edad analizadas. La capa externa está muy desarrollada y rodea el globo ocular y la órbita; la capa media se ubica entre el $\mathrm{m}$. retractor bulbi y los otros músculos extraoculares, y la capa interna se ubica entre el $\mathrm{m}$. retractor bulbi y la vaina que recubre al nervio óptico (Fig. 6.15; 6.18). En las crías la capa externa se dispone alrededor de la órbita formando una estructura circular que rodea el ojo, y presenta variaciones en el grosor entre los especímenes analizados. Asimismo, la estructura macroscópica de esta capa de grasa es firme, lo cual se relaciona con la abundante cantidad de fibras colágenas y la ausencia de adipocitos que caracteriza la dermis de E. australis (Reeb et al., 2007) (Fig. 6.18 A-B). Más profundamente dentro de la capa externa, la grasa tiene una coloración rosada debido a un aumento en la cantidad de vasos sanguíneos. La capa interna está presente en algunas crías, como una capa muy delgada de grasa entre el $\mathrm{m}$. retractor bulbi y la vaina que rodea al nervio óptico, la cual se inserta lateralmente en la esclera del globo ocular y medialmente en el m. retractor bulbi. Esta capa presenta una estructura más laxa que la capa externa, lo cual puede estar relacionado con la presencia de menor cantidad de fibras colágenas y una mayor cantidad de adipocitos (Fig. 6.18 C-D). Asimismo el grosor de la capa interna no es uniforme, y se dispone en forma de depósitos aislados alrededor del $\mathrm{m}$. retractor bulbi. La capa media está presente sólo en tres crías (091410-PV-Ea 19; 071910-PV-Ea 01; 102710-PV-Ea33). El grosor relativo de la capa de grasa interna y media sumadas es menor a la mitad del grosor de la capa externa.

En los adultos, debido a que no pudieron realizarse disecciones in situ, no pudo constatarse la presencia de la capa externa de grasa periorbital. Con respecto a la capa media e interna sólo se observaron bien desarrolladas en un ejemplar (o80310-PV-Ea 05). En este individuo la capa interna es gruesa y rodea la vaina del nervio óptico, y se inserta lateralmente sobre la esclera del globo ocular (Fig.6.19). La capa media está incompleta, ya que parte se perdió durante el proceso de extracción del globo ocular, y se inserta lateralmente en la superficie medial de la conjuntiva palpebral. Estas dos capas de grasa presentan una estructura laxa al igual que en las crías. Llamativamente, en los otros adultos analizados (o91410-PV-Ea 19; 071910-PV-Ea 01; 102710-PV-Ea33), estas capas de grasa son muy delgadas y están poco desarrolladas.

Globo ocular. En E. australis el globo ocular está comprimido látero-medialmente: el largo ántero-posterior y el alto dorso-ventral es mayor al ancho látero-medial. El valor promedio para 
AnGO: LGO y AnGO: AlGO es o.61 en ambos casos.

La membrana conjuntiva bulbar es una membrana delicada y muy delgada $(\sim 0.20 \mathrm{~mm}$ en o81709-PV-Ea) que cubre la superficie lateral del globo ocular y forma un anillo negro (o gris en algunos individuos) alrededor de la córnea que se denomina membrana conjuntiva bulbar pigmentada (Fig. 6.20 A, C). Por fuera de este anillo oscuro, la conjuntiva bulbar se inserta fuertemente en la superficie de la esclera y es de coloración roja debido a una alta vascularización. A $\sim 17$ mm (en 081709-PV-Ea 09) de la unión entre la córnea y la esclera, la conjuntiva bulbar es más gruesa y se refleja como conjuntiva palpebral, la cual recubre los párpados internamente (Fig. 6.2oB).

La córnea es más larga ántero-posteriormente (LCO) que alta dorso-ventralmente (AlCO), con una media de AlCO: $\mathrm{LCO}=0.71$ (Fig. 6.20C). La superficie externa de la misma está levemente curvada en vista dorsal, y como en otros cetáceos, es más gruesa en la periferia que en el centro (grosor de la córnea en el centro: 1.1 mm; grosor de la córnea en la periferia: $2.4 \mathrm{~mm}$; ejemplar 071210PV-Ea 02). Histológicamente, la capa externa de epitelio que forma la córnea se perdió durante el proceso de fijación (sólo se observa en algunos sectores) pero la capa más interna, correspondiente a la capa de Bowman, pudo ser identificada (grosor $\sim 15 \mu \mathrm{m}$ ). El grosor del estroma es menor hacia el centro $\sim 860 \mu$ m de la córnea que en la periferia $(\sim 1,730 \mu \mathrm{m})$ y contiene un gran número de fibras de colágeno que se disponen en forma paralela a la superficie de la córnea. La membrana de Descement no fue identificada. Hacia la periferia, la córnea se une con la esclera en el limbus.

La esclera es el carácter más llamativo del ojo de E. australis. En dirección lateral rodea la córnea, mientras que en dirección medial rodea la cámara vítrea y la salida del nervio óptico (Fig. 6.20C). En corte transversal (Fig. 6.21), la esclera es delgada hacia la zona de unión con la cornea (6.5 mm en 091410-PV-Ea 19 y 3 mm en 071210-Pv-Ea 02) pero más gruesa en dirección medial, donde se une con la vaina del nervio óptico (grosor=34 mm en o91410-PV-Ea 19, y 24 mm en 071210-Pv-Ea 02). La esclera esta irrigada por abundantes vasos sanguíneos que se ramifican a otras estructuras del ojo (Ninomiya \& Yoshida, 2007). En sección sagital a través del disco óptico (lugar de entrada del nervio óptico al globo ocular) se observan numerosos vasos sanguíneos que corresponden a las arterias ciliares posteriores cortas, mientras que hacia la superficie lateral del globo ocular se identifican las arterias ciliares posteriores largas. En sección transversal, una de las arterias ciliares posteriores largas se ubica en el margen dorsal del globo ocular, mientras que la otra se ubica en el margen ventral (Fig. 6.21). Histológicamente la esclera está formada de una capa interna de tejido conectivo denso, que aumenta de grosor en dirección medial, formada por una gran cantidad de fibras colágenas embebidas en la sustancia propia (Fig. 6.22A). Estas fibras están muy empaquetadas y dispuestas en diferentes direcciones una con otras, lo cual le otorga a la esclera una estructura firme y contribuye a darle forma al globo ocular. La capa más externa, la lámina episcleralis, está formada por tejido conectivo laxo con mayor cantidad de vasos sanguíneos. Se observan además gran 
cantidad de células pigmentarias en el estroma esclero-corneal del limbo.

En el ángulo iridocorneal (AIC) el estroma presenta una red de trabéculas y espacios de fontana cubiertos por una capa de endotelio muy delgado (Fig. 6.22B). Este sistema de trabéculas y espacios es responsable de drenar el humor acuoso hacia el AIC.

El iris es una membrana delgada, elástica y negra que se ubica entre la cámara anterior y el lente. La apertura central forma la pupila, la cual es aproximadamente esférica. Histológicamente el iris está formado desde la periferia hacia el centro, por una capa externa, el estroma, el m. esfínter de la pupila, el m. dilatador de la pupila y el epitelio interno del iris (Fig. 6.22C). La capa externa consiste en su mayoría en melanocitos que aumentan en cantidad hacia el margen de la pupila. El estroma presenta grandes cantidades de vasos sanguíneos, correspondientes a las arterias del iris (Ninomiya \& Yoshida, 2007), así como también melanocitos embebidos en tejido conectivo laxo. Entre el estroma y el epitelio interno del iris se ubica el $\mathrm{m}$. dilatador de la pupila, el cual está bien desarrollado (espesor=8o $\mu \mathrm{m}$ ) El m. esfínter de la pupila no pudo ser identificado. El epitelio interno del iris está ubicado hacia la cámara vítrea y está formado principalmente por melanocitos.

El cuerpo ciliar es una estructura triangular que conecta la coroides con la periferia del iris, y está formado por los procesos ciliares y los músculos ciliares. Histológicamente el cuerpo ciliar está formado por un epitelio ciliar interno y un estroma externo. El epitelio ciliar interno consta de una capa interna delgada $(\sim 15 \mu \mathrm{m})$ y despigmentada, y de una capa externa gruesa $(\sim 30 \mu \mathrm{m})$ con abundantes melanocitos. El estroma es grueso y está formado por tejido conectivo con gran cantidad de vasos sanguíneos, que corresponden con las arterias del iris provenientes del círculo arterial mayor (Ninomiya \& Yoshida, 2007). Hacia el lumen de la cámara vítrea, hay numerosos pliegues formados por el epitelio ciliar y estroma, que corresponden a los procesos ciliares (Fig. 6.22B). Los músculos ciliares no pudieron ser identificados.

El lente o cristalino (Fig. 6.21) es esférico y está suspendido entre el iris y la cámara vítrea por el ligamento suspensorio del lente. Histológicamente, la lente está formada desde la periferia hacia el centro, por una cápsula externa, por el epitelio del lente (que sólo se encuentra en la región lateral) y por el núcleo. La cápsula externa y el epitelio del lente se perdieron durante el proceso de fijación de la muestra. El núcleo está formado por la sustancia cristalina, que en corte transversal consiste en fibras elongadas y dispuestas en forma paralela en dirección látero-medial.

La cámara vítrea (Fig. 6.21) es más alta dorso-ventralmente que ancha látero-medialmente y está ocupada por el humor acuoso.

En los cetáceos la retina está formada por 7 capas (espesor $230 \mu \mathrm{m}$ ), las cuales fueron identificadas en su totalidad en Eubalaena australis. La coroide es una membrana que se encuentra entre la retina y la esclera. El estroma de esta membrana está compuesto de abundantes vasos sanguíneos que corresponden a las arterias coroidales (ramificaciones de las arterias ciliares 
posteriores cortas) y por otro a las venas coroidales (Ninomiya \& Yoshida, 2007). Asimismo, en el estroma de la coroide hay abundantes melanocitos embebidos en el tejido conectivo. El tapetum lucidum está bien desarrollado y tiene una coloración gris azulada.

El nervio óptico atraviesa la pared lateral del cráneo a través del foramen óptico, el cual en Eubalaena australis no está completamente cerrado por hueso, sino por cartílago. En el punto de entrada al cráneo, el nervio óptico sólo está rodeado de una vaina fibrosa y desde allí se desarrolla en dirección lateral a lo ancho de la superficie ventral del proceso supraorbitario del frontal, dentro del canal óptico. En su recorrido por el canal óptico, el nervio está rodeado por otras estructuras, tales como la red admirable oftálmica, tejido adiposo y los músculos extraoculares del globo ocular (Fig. 6.22E). En el punto donde el nervio óptico sale del globo ocular, denominado disco óptico, está envuelto por la esclera y en menor medida por la red admirable oftálmica. El diámetro del nervio óptico en la salida del globo ocular es de $5.90 \mathrm{~mm}$ en 091410-Pv-Ea19 y $3.1 \mathrm{~mm}$ en o82110-PV-Ea 10.

La red admirable oftálmica está formada por una red de arterias y venas de diferentes calibres embebidas en abundante tejido conectivo (Fig. 6.22D). La red admirable oftálmica forma una estructura en forma de cono alrededor del nervio óptico antes que éste atraviese el globo ocular a través de la esclera (Fig. 6.20).

\subsection{Análisis morfométrico}

Las medidas obtenidas del globo ocular de los 29 especímenes analizados se detallan en la Tabla 6.7 y los resultados del análisis de regresión en encuentran en la Tabla 6.8 y en la Fig. 6.23. De las tres medidas analizadas del globo ocular, el largo $(\mathrm{r}=0.93)$ y el alto del globo ocular $(\mathrm{r}=0.92)$ mostraron una buena correlación con el largo corporal, mientras que el ancho del globo ocular mostró una menor correlación ( $\mathrm{r}=0.79$ ). Por el contrario, el largo de la córnea vs el largo corporal presenta una baja correlación ( $\mathrm{r}=0.49)$, y en el caso del alto de la córnea $v s$ el largo corporal la relación no es significativa. Los resultados del análisis de regresión muestran una relación alométrica negativa entre el tamaño del globo ocular vs el largo corporal y entre el tamaño de la córnea $v s$ el tamaño corporal.

\subsection{Estimación del número $f$}

Las medidas de la lente utilizadas (i.e. largo y alto) para la estimación del parámetro $f$ en el ejemplar 071210-Pv-Ea o2 se detallan en la Tabla 6.7. El número $f$ obtenido es 2 y 1,81 dependiendo del diámetro de la lente que se utilice (i.e. el largo o el alto). 


\subsubsection{Discusión}

\section{Aspectos morfológicos del ojo y estructuras periorbitales de}

\section{Eubalaena australis.}

La exploración de la anatomía e histología del globo ocular de E. australis permitió constatar la presencia de caracteres comunes con otros misticetos, particularmente con la especie estrechamente emparentada Balaena mysticetus, tales como una esclera gruesa, la ausencia de músculos ciliares, la presencia de una red admirable oftálmica, una coroides y un tapetum lucidum bien desarrollados.

Las implicancias funcionales de una esclera gruesa, un carácter presente también en tiburones, tortugas marinas y en otros mamíferos marinos, permanece aún sin resolverse. Algunos autores proponen que ayuda a prevenir la deformación del globo ocular, producto de las altas presiones a las cuales están sometidos durante las secuencias de buceo, o por los movimientos de retracción del globo ocular dentro de la órbita (Dawson, 1980; Kastelein et al., 1990; Zhu et al., 2001; Bjerager et al., 2003). Otra explicación posible es que una esclera gruesa contribuya a formar un globo ocular no esférico (en forma de copa), que permita mantener rígida la periferia y prevenir la deformación de la córnea en situaciones de presiones diferenciales. Esta hipótesis, basada principalmente en el análisis de la morfología ocular de Dermochelys coriacea (tortuga laúd), puede ser plausible para los cetáceos (Brudenall et al., 2008).

Como en otros cetáceos, en Eubalaena australis la irrigación del ojo está bien desarrollada, particularmente la red admirable oftálmica. La presencia de esta red admirable en el ojo de los cetáceos ha sido ampliamente citada en la literatura (Zhu et al., 2001; Bjerager et al., 2003; Mass \& Supin, 2007), pero su función no ha sido del todo esclarecida. Bjerager et al. (2003) sugiere que, teniendo en cuenta el gran desarrollo de los vasos sanguíneos y la posición de esta red admirable, esta pueda estar involucrada en brindar la presión necesaria para permitir el movimiento del globo ocular hacia afuera. Sin embargo esta hipótesis ha sido cuestionada, ya que el tamaño de la red admirable no es suficiente como para permitir la protrusión del ojo, y los vasos sanguíneos no tienen la estructura anatómica o el mecanismo de bombeo necesario para provocar la protrusión y retracción del globo ocular (Ninomiya \& Yoshida, 2007). Otra función probable de la red admirable oftálmica es que, como otras red admirables del cuerpo de los cetáceos, intervenga en la modulación y amortiguación de las fluctuaciones en el flujo de sangre al sistema nervioso central, así como también actuar como reservorio de oxígeno durante los períodos de buceo (Nagel et al., 1968; Geisler \& Luo, 1998). Una hipótesis reciente, que se desprende de un análisis detallado del sistema vascular del ojo de los cetáceos, sugiere que la red admirable oftálmica, así como también todo el sistema 
vascular del ojo, actúan como un sistema termorregulatorio. Este sistema actuaría en el mantenimiento de temperatura óptima para el funcionamiento de los fotorreceptores de la retina, ante condiciones de bajas temperaturas y altas presiones durante el buceo. Asimismo mantener una temperatura adecuada del globo ocular puede prevenir cambios en la estructura laxa del tejido graso periorbital y, de esta forma, contribuir a los movimientos del globo ocular (Ninomiya \& Yoshida, 2007). En este contexto, es probable que en E. australis la red admirable oftálmica actúe como un sistema de termorregulación para mantener una temperatura apropiada de funcionamiento de los fotorreceptores (contribuyendo a un mejor rendimiento visual), y una estructura laxa de las capas internas de grasa periorbital, lo cual facilitaría los movimientos del globo ocular.

Los estudios histológicos del ojo de los cetáceos, así como también de otros mamíferos marinos, son escasos en la literatura. En particular Hatfield et al. (2003) realizó un estudio anatómico y funcional del ángulo iridocorneal (AIC) del ojo de algunas especies de mamíferos acuáticos y terrestres, como el manatí (Trichechus manatus), el delfín piloto (Globicephala macrorhynchus), el hipopótamo (Hippopotamus amphibius), y el elefante africano (Loxodonta africana). Los resultados de este estudio muestran que en las formas acuáticas (en el manatí, en el delfín piloto y en el hipopótamo), el AIC presenta espacios de Fontana grandes. Asimismo en el manatí y en el delfín piloto se observa un aumento en la vascularización dentro del AIC, a diferencia del hipopótamo y del elefante africano donde ésta es menor o moderada. El patrón del AIC en Eubalaena australis es consistente con el observado en los mamíferos acuáticos, en la presencia de grandes espacios de Fontana así como también en la gran vascularización. En los mamíferos acuáticos, y en particular en los cetáceos, el mayor desarrollo de los espacios de Fontana y la mayor vascularización ha sido vinculado con un aumento en el flujo y en la producción de humor acuoso, lo cual influye en la presión intraocular (Hatfield et al., 2003). Las variaciones en la presión intraocular del ojo pueden ser mecanismos tendientes a regular la presión osmótica interna, responder a cambios en las presiones externas durante los períodos de buceo, y como un método alternativo de acomodación del lente, debido a la ausencia de musculatura ciliar en los cetáceos (Hatfield et al., 2003).

Entre los resultados más interesantes del análisis del modelo neontológico Eubalaena australis, se encuentran la posición del ojo con respecto a la órbita, y el desarrollo de las estructuras periorbitales (grasa). Como se mencionó previamente, en E. australis el ojo está ubicado por fuera de la órbita y rodeado de capas de grasa (interna, media y externa) las cuales presentan variaciones en su estructura y grosor relativo, entre y dentro de los distintos estadios ontogenéticos analizados. En relación al primer aspecto, la capa externa de grasa es de estructura firme mientras que las capas internas son de estructura más laxa tanto en las crías como en los adultos. En cuanto al grosor relativo, la capa media e interna están poco desarrolladas en las crías y presentan variaciones en los adultos. Un globo ocular protuido de la órbita también se observa en el balénido Balaena mysticetus 
(Zhu et al., 2001), así como también en el cetóterido Caperea marginata. Por otro lado, tanto en Balaena mysticetus, Caperea marginata como en Balaenoptera physalus, el globo ocular esta rodeado de grasa periorbital dispuesta en diferentes capas.

El tejido adiposo tiene múltiples funciones en los cetáceos, como la termorregulación, el control de la flotabilidad, contribuir a una forma corporal hidrodinámica y como reservorio de energía (Struntz et al., 2004). En los misticetos, la capa de grasa subcutánea del cuerpo puede dividirse en una capa interna y una capa externa, las cuales se diferencian en su estructura y composición histológica (Ackman et al., 1975; Lockyer et al., 1984; Aguilar \& Borrell, 1990). La capa superficial es metabólicamente inerte y tiene una función estructural, mientras que las capas internas son metabólicamente activas y están involucradas en el metabolismo de lípidos (Aguilar \& Borrell, 1990; Klanjscek et al., 2007; Struntz et al., 2004). En el caso de la grasa periorbital, entre las funciones sugeridas se encuentran la protección mecánica del globo ocular (durante la retracción o compresión/expansión del globo ocular durante el buceo) y /o el aislamiento térmico, para mantener una temperatura óptima para los fotorreceptores. En este contexto, es probable que la capa de grasa externa tenga un rol estructural, mientras que las capas internas por un lado intervengan en la generación de un espacio flexible para acomodar la expansión y/o compresión de las estructuras periorbitales durante la acomodación del globo ocular, y por otro sean metabólicamente activas y estén relacionadas con la termorregulación.

La hipótesis de una función de aislamiento térmico de las capas internas de grasa periorbital se relaciona con las diferencias en el grosor de estas capas que se observan entre las crías de $B$. mysticetus y las de E. australis. La comparación de crías de estas dos especies con largos corporales similares muestra que la cantidad de grasa periorbital es mucho más abundante en las crías de $B$. mysticetus (Zhu et al., 2001 Figura 5: 735) que en las de E. australis. B. mysticetus se distribuye en aguas circumpolares en el Hemisferio Norte (entre $\operatorname{los} 80^{\circ}$ y $\operatorname{los} 60^{\circ}$ latitud N) y realiza movimientos estacionales dentro de esa latitud, por consiguiente las crías nacen en aguas polares de muy bajas temperaturas (Rugh \& Shelden, 2009). Por el contrario las crías de E. australis nacen en aguas templadas del Hemisferio Sur, y permanecen los primeros meses de vida en estas aguas creciendo y almacenando reservas antes de la migración hacia las zonas de alimentación en las altas latitudes $\left(60^{\circ} \mathrm{S}\right)$ (Best et al., 1993; Best, 1994; Kenney, 2009). En este contexto la variación observada en la cantidad de grasa periorbital entre las crías de estas dos especies puede estar relacionada con la diferencia en el rango latitudinal donde viven (Buono et al., 2012).

Otra característica llamativa de la grasa periorbital de Eubalaena australis y, que también apoya la hipótesis de una función termorregulatoria de las capas internas, es el patrón de depositación de las mismas. De las crías analizadas sólo en la de mayor tamaño corporal se observó la capa interna y media, siendo la capa interna de mayor grosor que la media. Esto último indica que 
la capa interna puede ser una de las primeras en ser depositada. Estas observaciones sugieren que ciertas restricciones físicas impuestas por el ambiente, como la temperatura del agua, pueden ser determinantes en el desarrollo de este tejido dinámico.

Por otro lado, las diferencias observadas en el grosor de las capas de grasa periorbital entre individuos adultos de Eubalaena australis, podrían estar vinculadas con el sexo, estado nutricional o reproductivo de los individuos (Buono et al., 2012). El ciclo reproductivo de E. australis representa un costo energético muy alto para las hembras, las cuales dependen de su reservas de energía en forma de grasa corporal y proteínas en los músculos (Oftedal, 1993; 2000). Los estudios de Valenzuela et al. (2010) sugieren que las variaciones interanuales en las concentraciones de los isótopos estables de carbono y nitrógeno en las madres y sus crías podrían estar asociadas a diferentes niveles de estrés nutricional. De este modo, las hembras, para afrontar las demandas energéticas que implican la gestación y/o la lactancia, deben movilizar sus propias reservas de energía. El grosor de la capa de grasa subcutánea corporal de los adultos analizados (información provista por el Programa de Monitoreo Sanitario Ballena Franca Austral de Península Valdés), muestra que aquellas hembras con menor cantidad de grasa periorbital (o70910-PV-Ea o1 y 091410-PV-Ea 19) también presentan una capa de grasa subcutánea más delgada. A pesar que se desconoce el estatus reproductivo de estas hembras al morir, la diferencia en la cantidad de grasa periorbital observada sugiere que las hembras estaban en diferentes tiempos del ciclo reproductivo, y que debieron metabolizar sus reservas de lípidos en respuesta a diferentes demandas energéticas. Si bien esta hipótesis necesita ser testeada en un futuro, es consistente con el patrón de la distribución estructural y no-estructural de la grasa observada en los cetáceos esto es, la capa superficial de grasa es metabólicamente inerte, mientras que las capas más internas son metabólicamente activas (Aguilar \& Borrell, 1990; Klanjscek et al., 2007; Struntz et al., 2004).

El menor desarrollo de las capas de grasa observado en algunos ejemplares de E. australis implicaría una disminución en sus propiedades de aislamiento térmico, impidiendo el calentamiento de la retina y del nervio óptico, y afectando en última instancia la visión. Sin embargo, en el caso de E. australis, la disminución de la grasa periorbital no introduce un trade off con respecto al rendimiento visual ya que esta disminución se producen cuando los individuos habitan las aguas templadas de Península Valdés.

Del análisis del modelo neontológico, así como de la comparación con otros misticetos actuales, se deduce que la órbita y el foramen/canal óptico dan una información muy pobre sobre las estructuras blandas que albergan. De este modo debe rechazarse la hipótesis de trabajo 1 planteada al inicio de esta sección. El globo ocular esta protruido de la órbita y rodeado de estructuras metabólicamente activas que varían durante el ciclo de vida del animal. Del mismo modo, el nervio óptico está rodeado de una serie de estructuras blandas y, tanto la superficie ventral del canal óptico 
como el foramen óptico, están cerrados por cartílago de difícil preservación en formas extintas. Como resultado, la órbita y el canal/foramen óptico no representan correlatos óseos claros con las estructuras blandas y por lo tanto no resultan buenos proxies para la reconstrucción del globo ocular y del nervio óptico. Consecuentemente, tampoco permitirían, a diferencia de lo que ocurre con los mamíferos terrestres, la estimación de las capacidades visuales en las formas extintas.

\section{Análisis alométrico}

En los vertebrados la agudeza visual está relacionada con el tamaño del ojo esto es, ojos más grandes pueden albergar mayor cantidad de células fotorreceptivas en la retina, incrementando de esta forma la capacidad de resolución del ojo (Walls, 1942). Asimismo los estudios alométricos entre el tamaño del ojo y el tamaño corporal sugieren que existe una correlación positiva entre estas dos variables (Hughes, 1977; Burton, 1998, 2006; Kiltie, 2000; Zhu et al., 2001; Howland et al., 2004).

De los resultados de esta tesis se desprende que, en Eubalaena australis, existe una correlación positiva entre el tamaño del globo ocular y el largo corporal. Estos resultados son consistentes con aquellos obtenidos para Balaena mysticetus, aunque los valores de correlación entre el alto del ojo y el largo corporal, y entre largo del ojo y el largo corporal son mayores en E. australis que en B. mysticetus (Zhu et al, 2001 P: 745, Figura 13) (Tabla 6.8). En E. australis, así como también en otros misticetos, el tamaño del globo ocular está influenciado en gran medida por la esclera, la cual esta notablemente engrosada. Burton (2006) sugiere que, en los misticetos, si se excluye la esclera del valor de la masa del globo ocular, reduciéndolo sólo a las estructuras que están en relación con la visión, el tamaño del ojo resulta notablemente reducido en comparación con otros mamíferos. En este contexto, en E. australis el crecimiento del globo ocular, considerando el ancho, el largo y el alto, está influenciado por el engrosamiento de la esclera y, por lo tanto, no implica necesariamente un aumento en el poder de resolución del ojo (o sea un aumento en la cantidad de fotorreceptores o una mayor distancia focal).

Por otro lado, no sólo el tamaño absoluto del ojo tiene importancia en las capacidades visuales (Wall, 1942), sino también el largo del ojo o largo axial (considerado en esta contribución como ancho del globo ocular debido a la posición anatómica del ojo en la cabeza de Eubalaena australis). En los vertebrados, el largo axial está relacionado con el largo focal (distancia córnea/lente vs retina): a mayor largo focal mayor tamaño de la imagen en la retina (Walls, 1942). El globo ocular de E. australis, así como de otros cetáceos, es aplanado medio-lateralmente (en forma de copa), y este aplanamiento conlleva a una disminución en el largo axial y, por lo tanto, a una disminución del poder de resolución de la retina. Los cetáceos han resuelto este problema aumentando el poder de refracción de la lente mediante la adquisición de una lente esférica o elíptica, lo cual provee de una 
amplia superficie convexa y, consecuentemente, de un aumento del poder refractivo (Mass \& Supin, 2007).

En Eubalaena australis las variables del tamaño del globo ocular (el ancho, el alto y el largo) muestran un incremento alométrico negativo con el aumento del largo corporal (Fig. 6.23), lo cual se corresponde con el patrón observado en la mayoría de los tetrápodos (Emerson \& Bramble, 1993; Burton, 2006). Considerando el tamaño corporal que alcanzan los misticetos, es lógico asumir que el ojo no puede crecer isométricamente con el largo corporal, dado que este tipo de crecimiento llevaría al desarrollo de estructuras imposibles de albergar en la cabeza.

Por otro lado, el tamaño de la córnea presenta una baja correlación con el largo corporal, y la relación entre estas dos variables también muestra una alometría negativa. Estos resultados sugieren que, a diferencia del globo ocular, la córnea no aumenta mucho de tamaño durante el crecimiento del animal. Este patrón es coincidente con el conocido para otros grupos de tetrápodos, tan distantes filogenéticamente como los ictiosaurios y los humanos (Goddé-Jolly \& Dufier, 1994; Sprague Eutis, 1995; Fledelius \& Christensen, 1996; Fernández et al., 2005).

\section{Estimación del parámetro $f$}

El valor de $f$ estimado para el ojo de Eubalaena australis $(f=2 ; f=1,81$ según el diámetro de la lente utilizado Tabla 6.7), sugiere que este presenta una sensibilidad visual baja. Estos valores son similares a otros tetrápodos acuáticos, como Chelonia mydas ( $f=2.4$, Mäthger et al., 2007) y Dermochelys coriácea $(f=2.3$, Brudenall et al., 2008), pero mayores a los conocidos en el pez Makaira nigricans (pez marlín; $f=1.6$, Fritsches et al., 2005). Entre los mamíferos marinos, los únicos datos disponibles sobre el parámetro $f$ corresponden a Mirounga spp. (Elefante marino, $f=1.18-1.48$; Humphries \& Ruxton, 2002). En el caso de Eschrichtius robustus (ballena gris) y Delphinapterus leucas (beluga) se pudo estimar el párametro $f$ a partir de datos disponibles en la literatura del largo focal y del diámetro de la lente (Mass \& Supin, 1997; 2002). Los valores de $f$ obtenidos son 2.56 y 1.97 (para el largo ántero-posterior y el alto dorso-ventral de la lente respectivamente) en E. robustus; y 1.90 y 1.67 (para el largo ántero-posterior y el alto dorso-ventral de la lente respectivamente) para $D$. leucas.

El parámetro $f$ debe interpretarse con cuidado, ya que depende del tamaño de la lente, la cual es una estructura muy frágil y de difícil preservación, y en la mayoría de los casos las medidas son obtenidas de especímenes congelados, con lo cual se altera el tamaño de la lente por los efectos del descongelamiento. 


\section{Reconstrucción del globo ocular y evolución de la visión en los}

\section{misticetos extintos}

En los misticetos extintos las estimaciones de las capacidades visuales se efectuaron en base al tamaño y posición de la órbita, utilizándose indistintamente órbita como sinónimo de ojo (Fitzgerald, 2006; Demeré \& Berta, 2008; Marx, 2010). Fitzgerald (2006) sugiere que, a lo largo de la evolución de los misticetos, se observa una tendencia a la lateralización y reducción de las órbitas, desde los misticetos dentados y basales (Janjucetus y Aetiocetus) con órbitas grandes y orientadas ántero-lateral o dorso-lateralmente, hasta los misticetos con barbas (=Chaeomysticeti), con órbitas pequeñas y laterales. Esta tendencia a la reducción de las órbitas ha sido asociada con la evolución del sistema de alimentación por filtración, durante el cual la visión habría perdido importancia. En contraposición, Marx (2010) analizó la relación entre el largo de la órbita y el ancho bizigomático (LO/ABZ) y propuso un escenario evolutivo distinto al de Fitzgerald (2006). Según Marx (2010) la presencia de órbitas grandes es una condición sinapomórfica para los misticetos dentados (Janjucetus y Mammalodon), en tanto que las órbitas chicas son la condición primitiva para los misticetos.

Como se indicó anteriormente, el tamaño de la órbita es un correlato muy grosero del tamaño del ojo y, consecuentemente, no es un buen estimador de las capacidades visuales. Por lo tanto, los caracteres que pueden ser explorados mediante su mapeo en una filogenia son el tamaño de la órbita y su posición relativa en el cráneo, sin que estos estén vinculados directamente con la evolución de las capacidades visuales, o al menos no tan directamente. La optimización del carácter tamaño de la órbita (=LO/ABZ) sobre el árbol evolutivo obtenido en esta tesis, sugiere un escenario consistente con la propuesta de Marx (2010) (Fig. 6.24). En este sentido, la ampliación del muestreo taxonómico incluyendo arqueocetos sugiere que la condición primitiva para los misticetos es órbitas pequeñas en relación con el tamaño del cráneo ( LO/ABZ o,1-0,25). El agrandamiento de las órbitas (LO/ABZ >0,25) en Janjucetus, Aetiocetus y en Mammalodon, indica que este carácter se dio al menos dos veces en el linaje que condujo a los misticetos dentados (uno en el clado de Mammalodon+Janjucetus y otra en Aetiocetus). Dentro de los Chaeomysticeti la reducción más extrema de las órbitas se observa en los representantes actuales de los Balaenidae (Eubalaena y Balaena) y de los Balaenopteridae (Balaenoptera, Megaptera y Eschrichtius) donde la relación LO/ABZ es <0,1. En el caso de los balénidos miocenos la relación LO/ABZ es o,23 y o,22 para Morenocetus y el Taxón A respectivamente, valores ligeramente mayores a la obtenidos para los balénidos actuales.

En relación con la posición de la órbita, si bien en todos los misticetos con barbas predomina una posición lateral, hay algunas diferencias entre los balénidos, balenopteroideos y cetotéridos. En 
los balénidos se observa una conspicua diferencia en la posición de las órbitas entre Morenocetus y los restantes balénidos. En Morenocetus la órbita se ubica en una posición alta en el cráneo, aproximadamente a la mitad de la distancia vertical entre el vértex del cráneo y la base del proceso postglenoideo. (Fig. 4.14). En el Taxón A la órbita tienen una posición levemente más baja con respecto a Morenocetus (a 2/3 aproximadamente de la altura entre el vértex y la base del proceso postglenoideo) (Fig. 4.23). En Balaenella, Balaenula astensis, en los representantes actuales de Eubalaena y en Balaena mysticetus las órbitas se ubican aproximadamente a 2/3 de la distancia entre el vértex del cráneo y la base del proceso postglenoideo. En los balenoptéridos, escríctidos y en Caperea las órbitas están ubicadas aproximadamente en la mitad del alto (1/2) entre el vértex del cráneo y la base del proceso postglenoideo. Es interesante destacar que, los estudios ontogenéticos Eubalaena australis desarrollados en esta tesis (Capítulo 4) permitieron determinar que la posición de la órbita no varía durante la ontogenia.

Cuando la altura en la cual se ubica la órbita en el cráneo es optimizada sobre el árbol filogenético surge que (Fig. 6.25):

1) la condición primitiva en los misticetos es órbitas altas, ubicadas al mismo nivel que la superficie dorsal del cráneo (relación 1/1) (presente en los stem cetacea y en los misticetos basales)

2) las órbitas en una posición ventral (relación 2/3) sería una condición sinapomorfica para el clado formado por los balénidos, los cetotéridos y los balenoptéridos. La condición de Morneocetus (i.e. órbitas a mitad de altura, 1/2) es autapormófica dentro de los balénidos, y aparece en forma paralela al menos dos veces, una en los cetotéridos (Caperea) y otra en los balenoptéridos.

En resumen, si bien los resultados obtenidos en esta sección llevan a rechazar la hipótesis de trabajo 2, ya que en los misticetos no habría una relación tan directa entre el tamaño de la órbita/ canal y foramen óptico y las capacidades visuales, la exploración del tamaño de la órbita y su posición relativa en el cráneo brinda las primeras aproximaciones a este tema. 


\subsubsection{Oído}

\subsubsection{Introducción}

Una de las modificaciones anatómicas de los cetáceos en la transición a la vida acuática fue la modificación del sistema auditivo. A diferencia de lo que ocurre con la visión, la evolución del oído en los cetáceos está mejor documentada en el registro fósil, ya que hay evidencias osteológicas de los cambios anatómicos producidos en las estructuras asociadas a esta región. El registro fósil documenta que la adquisición de una audición acuática fue un evento evolutivo relativamente rápido (menos de 10 millones de años) y que, antes de alcanzar la morfología actual, el sistema auditivo atravesó distintas caminos (Thewissen \& Hussain, 1993; Nummela et al., 2004). La mayor parte de las modificaciones y/o reorganizaciones se produjeron en el oído externo y el oído medio mientras que el oído interno permaneció casi sin cambios (Ketten, 1992; 2000) (Fig. 6.26).

En los misticetos, el oído externo está muy reducido. El pabellón auditivo está ausente y sólo se conserva el canal auditivo externo, el cual es estrecho y presenta en su extremo medial una estructura denominada tapón céreo. Medialmente el canal termina en la membrana timpánica, la cual está muy modificada en una estructura engrosada y en forma de cono (conocida en la literatura como "glove finger") (Lillie, 1910; Fraser \& Purves, 1960) (Fig. 6.27; 6.28).

El oído medio contiene la cavidad timpánica y los huesecillos del oído medio (martillo, yunque y estribo) los cuales están dentro de la bulla timpánica (Fig. 6.26B). En los misticetos los huesecillos son grandes y macizos, y con excepción de un pedicelo del martillo, no están fusionados a la bulla timpánica. Asimismo la unión entre ellos es móvil, lo cual se relaciona con la audición de bajas frecuencias. La cavidad del oído medio está ocupada por una mucosa fibrosa, el corpus cavernosum, el cual es un tejido expandible y muy inervado por ramas del nervio trigémino (V) (Ketten, 2000).

El oído interno esta contenido dentro del periótico y presenta una estructura similar a la de los restantes mamíferos, reconociéndose dos partes: una porción auditiva o cóclea y una porción vestibular o canales semicirculares. La cóclea es un espiral óseo lleno de fluido, ubicado dentro de la pars coclearis del periótico, y dividido por membranas en tres cámaras: la escala media o ducto coclear, la escala timpánica y la escala vestibular. Estas cámaras son tubos paralelos llenos de fluido que forman un espiral en torno a un eje óseo, el mediolus, que alberga ramas del nervio VIII. El diámetro del espiral es mayor en la base (vuelta basal) y se angosta hacia el ápex (vuelta apical); el número de vueltas varía entre las especies. En los cetáceos, considerando el cráneo en posición anatómica, el ápex de la cóclea apunta en dirección ventral, a diferencia de los mamíferos terrestres donde está orientada anteriormente (Ketten, 2000). La escala vestibular y la escala timpánica rodean 
el ducto coclear el cual alberga el Órgano de Corti. El ducto coclear es un canal membranoso que está rodeado por la membrana basilar y la membrana vestibular (membrana de Reissner's) y ocupado por líquido endolinfático. Este último fluye entre el ducto coclear y el saco endolinfático vía el ducto endolinfático, el cual está contenido dentro de un canal óseo, el acueducto vestibular. La escala timpánica y la escala vestibular están ocupadas de líquido perilinfático, el cual fluye a través del ducto perilinfático, que está contenido en un ducto óseo, el acueducto coclear.

La membrana basilar es un componente importante de las características de resonancia de la cóclea, y es la estructura indicada para el estudio de rango de frecuencias de audición. Las frecuencias más altas se codifican en la base del espiral de la cóclea, donde la membrana es angosta y gruesa, mientras que hacia el ápex del espiral, donde la membrana es más ancha y delgada, se codifican las frecuencias bajas (Ketten \& Wartzok, 1990; Ketten, 2000). La membrana basilar está suspendida de dos láminas óseas que están dentro del ducto coclear, la lámina primaria o interna y la lámina secundaria o externa. Estas láminas están muy poco desarrolladas en los misticetos en comparación con los odontocetos. La configuración de la membrana basilar y de las láminas óseas determinan tres configuraciones de cócleas: Tipo I y Tipo II, exclusivas de los odontocetos, y Tipo M en misticetos (Ketten, 1992, 2000; Wartzok \& Ketten, 1999) (Fig. 6.29). La cóclea tipo I es baja, presenta < de 2 vueltas y está asociada a rangos de frecuencia de $>100 \mathrm{kHz}$ (típica de marsopas y delfines de agua dulce). La cóclea Tipo II es más alta y presenta $>$ de 2 vueltas y está asociada a rangos de frecuencia entre $40-80 \mathrm{kHz}$ (en delfines oceánicos). Estos dos tipos de cóclea se caracterizan por presentar una membrana basilar rígida y canales óseos muy desarrollados donde se ancla esta membrana, todas adaptaciones a sonidos de alta frecuencia (ultrasónicos). El Tipo M es una cóclea ancha, con las vueltas superpuestas una sobre otra, con una membrana basilar ancha y delgada, y láminas óseas reducidas (Ketten, 1992, 2000; Wartzok \& Ketten, 1999). Estas especializaciones son adaptaciones a sonidos de baja frecuencia (infrasónicos) que utilizan para comunicarse a través de largas distancias.

En todos los misticetos la porción vestibular, relacionada con el equilibrio, es sustancialmente más pequeña que la porción coclear, condición no observada en ningún otro mamífero. La única excepción a esta regla se encuentra en los balénidos Balaena mysticetus y en Eubalaena glacialis (Ketten, 1994). Esta reducción del sistema vestibular podría estar vinculada a la ausencia de movimientos de la cabeza, como resultado de la fusión y el acortamiento de la región cervical. Esto ocasionaría una diminución en la entrada de estímulos hacia el sistema vestibular, y por ende una reducción de los receptores vestibulares.

Modelos para estudiar rangos de frecuencias en misticetos extintos. Los estudios de las capacidades auditivas de los misticetos extintos son escasos (Geisler \& Luo, 1996; Steeman, 2009; Fleischer, 1976). En el análisis del oído interno del cetotérido Herpetocetus se efectúa la 
reconstrucción de la membrana basilar sobre la base de la medición del espacio interlaminar, el cual se utiliza como una aproximación del ancho de la membrana, y por lo tanto un indicador del rango de audición (Geisler \& Luo, 1996). Sin embargo, Ketten (2000) propone que esta metodología debe emplearse con cuidado ya que el espacio interlaminar no es igual al ancho de la membrana, lo cual contribuye a sobreestimar los valores obtenidos. No obstante, el estudio de la morfología de la cóclea, esto es el número y grado de superposición de las vueltas, puede servir como primera aproximación para identificar oídos especializados en bajas y en altas frecuencias.

En los balénidos extintos no hay estudios previos donde se explore la morfología del oído interno. En el caso de los balénidos actuales, la información disponible sobre la anatomía del oído interno en Eubalaena glacialis, indica que presentan un rango de audición de $10 \mathrm{~Hz}-22 \mathrm{kHz}$ (i.e. sonidos de muy baja frecuencia) (Parks, et al., 2007).

Los objetivos específicos e hipótesis de trabajo de esta sección son:

1) Analizar las estructuras blandas asociadas con el oído y sus correlatos óseos en Eubalaena australis.

Hipótesis de trabajo 1: la depresión en el meato auditivo y los recesos en la superficie ventral del pterigoides y del basioccipital, indican el punto de inserción de la membrana timpánica y la extensión del seno pterigoideo respectivamente.

2) Reconstruir la cóclea del los balénidos miocenos y poder inferir aspectos de la audición en estos balénidos.

Hipótesis de trabajo 2: la morfología de la cóclea de los balénidos miocenos indica que las modificaciones del sistema auditivo para los sonidos de baja frecuencia se adquirieron tempranamente en la historia del grupo.

\subsubsection{Materiales y Métodos específicos}

Para el estudio de las estructuras del oído interno de los balénidos se efectuaron reconstrucciones tridimensionales de la cóclea a partir de tomografías computadas axiales de los siguientes ejemplares (ver detalle en Capítulo 2):

1) Eubalaena australis: neonato (CNPMAMM 748); cría (S/N colección CNPMAMM); adulto (S/N colección CNPMAMM)

2) Taxón A: adulto (MPEF-PV-1122)

Asimismo, a los fines comparativos, se efectuó la reconstrucción tridimensional de la cóclea de Balaenoptera bonaerensis (cría; CNPMAMM 750) y de Balaenoptera spp. (S/N, colección del 
CNPMAMM).

En el caso de Morenocetus (MLP 5-11), la tomografía no mostró una buena contrastación del hueso y del sedimento, razón por la cual no fue posible explorar en detalle la morfología del oído interno.

El análisis de las estructuras blandas asociadas al oído se llevó a cabo en el modelo neontológico Eubalaena australis, a través de la disección anatómica del ejemplar neonato 03-11 (capítulo 2). Dichas observaciones se complementaron con la resonancia magnética y tomografía axial computada (TAC) del ejemplar. Asimismo se analizaron varios complejos tímpano-perióticos de crías y adultos de esta especie (Capítulo 2).

Se efectuaron mediciones de la cóclea en las imágenes $2 \mathrm{D}$ de las tomografías computadas, a partir del corte paramodiolar de la misma (donde se observan las vueltas de la cóclea y el mediolus), siguiendo la metodología propuesta por Parks et al., (2007) y Ketten et al., (1998) (Fig. 6.30). Las medidas son:

1) Diámetro basal: ancho máximo a nivel de la última vuelta o la base del espiral

2) Alto axial: es el alto del eje axial de la espiral de la cóclea

3) Radios de cada vuelta: radio de cada vuelta de la cóclea

El número de vueltas de la cóclea se estimó a partir de los modelos 3D (Parks et al., 2007). Los marcadores anatómicos utilizados para determinar el comienzo y el final del espiral fueron: el comienzo del espacio laminar (o "laminar gap") cerca de la base de la primer vuelta y el ápex del eje axial de la cóclea respectivamente (Geisler \& Luo, 1996).

Para la reconstrucción tridimensional del complejo tímpano-periótico y de la cóclea se utilizó el programa OsiriXv 5.6 32-bit (Rosset \& Spadola, 2004).

\subsubsection{Resultados}

\section{Morfología del oído de Eubalaena australis}

Oído externo. Como sucede en los todos los cetáceos, en Eubalaena australis no hay pabellón auditivo externo y la apertura externa del canal auditivo está marcada por un orificio muy pequeño en la superficie de la piel, ubicado en la parte posterior de la cabeza. Dicho orificio comunica con un canal, el canal auditivo externo, que se proyecta látero-medialmente hacia el oído medio, dentro de la capa de grasa subcutánea. En los misticetos el canal es muy angosto cerca de la superficie de la cabeza y luego se ensancha notablemente en dirección medial (Lillie, 1910; Fraser \& Purves, 1960). En el caso de E. australis, la morfología completa del canal no pudo ser determinada, ya que parte del canal se perdió durante la disección. Sin embargo, la porción preservada muestra que el canal está recubierto internamente por epitelio negro, el cual desaparece medialmente. 
Asimismo, el diámetro del canal se incrementa en dirección medial y en principio es hueco, pero hacia la porción más cercana a la membrana timpánica el lumen está ocupado por el tapón céreo (Fig. 6.31). En el extremo medial del canal se encuentra la membrana timpánica, la cual apoya dorsalmente sobre una depresión de forma ovalada en la superficie ventral del meato auditivo externo (la cual está recubierta de un tejido, probablemente conectivo, muy suave al tacto) y ventralmente contacta con la bulla timpánica, a través del anillo timpánico. Como en todos los misticetos, la membrana timpánica está formada por dos porciones: una de estructura fibrosa y de forma triangular, el ligamento timpánico, y otra en forma de saco o embudo, la membrana timpánica sensu stricto ("glove finger") (Fig. 6.32; 6.33). El ligamento timpánico, es un pliegue de la membrana timpánica que se proyecta desde el interior de la misma y se inserta dorsalmente en el anillo timpánico de la bulla, y ventralmente sobre el manubrio del martillo (Fig. 6.32 C). El ligamento timpánico es homólogo a la porción fibrosa de la membrana timpánica de los mamíferos terrestres (Purves, 1966). La membrana timpánica s.s. es una estructura en forma de saco elongado (Fig. 6.32 A-B) $(\mathrm{L}$ máximo=1.55 cm; Ancho máximo=2.2cm) con su extremo medial cóncavo, en el cual comunica con la cavidad timpánica, y su extremo lateral convexo, el cual se comunica con el meato auditivo externo. La membrana timpánica sensu stricto se inserta sobre la superficie externa e interna de la bulla timpánica. Externamente se inserta en el anillo timpánico de la bulla formado por el proceso sigmoideo de la bulla, el proceso cónico y el pedicelo posterior de la bulla timpánica (Fig. 6.32 A-B). Dentro de la bulla, el área de inserción de la membrana timpánica está formada por un surco semicircular profundo, que se extiende desde el extremo posterior del proceso sigmoideo hasta el extremo posterior del proceso cónico. La estructura histológica de la membrana no fue analizada, pero macroscópicamente pudieron diferenciarse dos capas: una superficial de estructura más delgada y laxa, y una interna de mayor grosor y de consistencia más firme. La superficie interna de la bulla timpánica está recubierta por una continuación del tejido que forma la membrana timpánica (Fig. 6.32C).

En la disección de la región auditiva de Eubalaena australis no se identificó ningún cuerpo graso en posición análoga al cuerpo graso identificado por Yamato et al. (2012) en Balaenoptera acutorostrata, esto es, en posición lateral al complejo tímpano-periótico entre la fosa glenoidea y la cara lateral de la mandíbula.

Oído medio. La bulla timpánica alberga la cavidad timpánica donde se encuentran el martillo, el yunque y el estribo (Fig.6.34). Estos huesecillos son grandes y macizos como es característico de todos los misticetos, y se disponen látero-medialmente dentro de la cavidad timpánica entre el proceso sigmoideo de la bulla y el foramen oval. El martillo es el huesecillo más grande y se fusiona al proceso sigmoideo de la bulla a través del proceso gracialis, excepto en 
neonatos donde la fusión es incompleta. La cabeza del martillo contacta ventralmente con el periótico a través de la fosa malear, la cual es más conspicua en las crías que en los adultos, y dorsomedialmente con el yunque a través de una unión móvil. El yunque contacta, a través de una unión móvil, con el estribo, el cual se apoya sobre el foramen oval.

Oído interno. La cóclea de E. australis tiene 2.5 vueltas en los tres estadios ontogenéticos analizados (neonato, cría y adulto) (Tabla 6.9). Dentro de la pars coclearis la cóclea está ubicada con el ápice dirigido ventro-lateralmente y la base dirigida dorso-medialmente. En los tres estadios ontogenéticos analizados, la vuelta basal está más separada de la vuelta media (cría distancia $=\sim 753 \mu \mathrm{m}$; adulto distancia $=\sim 773 \mu \mathrm{m}$; neonato $=\sim 600 \mu \mathrm{m})$, mientras que la vuelta media y la vuelta apical están fuertemente enrolladas, sin dejar espacio entre ellas (Fig. 6.35). En cuanto a la forma de la cóclea, la relación alto axial/ $\mathbf{n}^{\circ}$ de vueltas se incrementa desde el neonato $(1,46)$ al adulto $(2,1)$ mientras que la relación altura axial/diámetro basal muestra el mismo valor para el neonato, la cría y el adulto (o.51).

La membrana basilar y las láminas óseas sólo fueron identificadas en las imágenes de resonancia magnética; las láminas óseas son muy delgadas, casi indistinguibles.

Seno pterigoideo. El seno pterigoideo es un tejido de tipo trabecular que se desarrolla en la región auditiva, en posición lateral al complejo tímpano-periótico, dentro de la fosa para el seno pterigoideo. Dicho seno se extiende posteriormente sobre la superficie ventro-lateral del basioccipital hasta las crestas basioccipitales, y lateralmente cubre casi toda la superficie ventral del periótico. El largo máximo de extensión posterior es de $8.4 \mathrm{~cm}$. La estructura del tejido es de tipo laxa, altamente vascularizada con espacio o trabéculas que son evidentes en las imágenes de tomografía computada (Fig. 6.36). El seno pterigoide está conectado ántero-medialmente con la red admirable que rodea el encéfalo, la cual a su vez está conectada con la red admirable oftálmica del ojo.

\section{Reconstrucción del oído en los balénidos extintos}

Con respecto a las estructuras del oído externo se pudo identificar que el meato auditivo externo presenta la misma orientación y morfología general que en E. australis. En el extremo medial del meato auditivo externo, sobre su superficie ventral, se identifica, tanto en Morenocetus como en el Taxón A, una depresión de contorno oval cuyo textura lisa difiere notoriamente del tejido óseo circundante. Esta depresión coincide con el emplazamiento (y tamaño absoluto) de la membrana timpánica en Eubalaena australis.

Con respecto al oído interno se reconstruyó la cóclea del Taxón A (Fig. 6.37). La misma es semejante a la de E. australis en el números de vueltas y en la orientación del ápice. La cóclea 
presenta 2.5 vueltas, y el ápice está orientado ventro-lateralmente, mientras que la base del espiral está orientada dorso-medialmente. La entrada del nervio VIII (vestibulococlear) también sigue el mismo curso que en E. australis. La principal diferencia entre la cóclea de estos taxones se observa en la separación de las vueltas. En el Taxón A la vuelta basal está separada de la vuelta media por una distancia menor que en E. australis $(\sim 464 \mu \mathrm{m}$ del Taxón A en contraposición con los $\sim 773 \mu \mathrm{m}$ en $E$. australis). Asimismo, la vuelta media y apical presentan una mayor separación en el Taxón A (566 $\mu \mathrm{m})$ en comparación con E. australis, donde la separación entre las vueltas es indistinguible.

La relación alto axial $/ \mathrm{n}^{\circ}$ de vueltas es de 1.51, mientras que la relación altura axial/diámetro basal es de 0.57 .

Los canales semicirculares están ubicados hacia la cara medial de la pars coclearis, en posición dorso-anterior a la cóclea, cercano a la posición del foramen endolinfático (acueducto vestibular).Se identificaron sólo dos canales (el dorsal y el posterior).

Por otro lado, la exploración de la fosa pterigoidea en el Taxón A indica que el seno pterigoideo tenía una desarrollo y extensión posterior comparable al de Eubalaena australis.

\subsubsection{Discusión}

La exploración de la anatomía de la región auditiva de Eubalaena australis permitió identificar correlatos óseos de algunas estructuras blandas implicadas en la audición.

En lo que respecta al oído externo, la membrana timpánica y el tejido conectivo que la reviste, recesan la porción ventro-medial del meato auditivo externo y, de esta forma, brindan un buen correlato óseo de la posición y del tamaño de la membrana timpánica en las formas extintas. La exploración de este correlato en Morenocetus y en el Taxón A indica que, en los representantes más tempranos de los balénidos, la membrana timpánica tiene un desarrollo y posicionamiento comparable al de los balénidos actuales.

En referencia al oído interno, el análisis de individuos de Eubalaena australis de diferentes estadios ontogenéticos indicó que la macroestructura de la cóclea (i.e. número de vueltas 2,5 y forma) no varía durante la ontogenia. La cóclea del Taxón A es idéntica a la de E. australis en cuanto al número de vueltas (i.e. 2,5), así como también a la de Balaenoptera, Eubalaena glacialis, Balaenoptera physalus, y en el stem cetácea Dorudon. Pero difiere de la condición observada en Balaena mysticetus (2,25 vueltas), Parietobalaena palmeri (2,3 vueltas), Herpetocetus (3 vueltas), Megaptera (2 vueltas), Balaenoptera musculus (2,25 vueltas), y del stem cetácea Zygorhiza (2 vueltas) (Tabla 6.9) (Ketten, 1992; Geisler \& Luo, 1996; Wartzok \& Ketten, 1999; Parks et al., 2007). Por otro lado, la cóclea del Taxón A difiere de la de E. australis en presentar una mayor separación entre la vuelta apical y medial, o sea un enrollamiento menor. La morfología coclear caracterizada por 2 o 
más vueltas superpuestas (cóclea tipo M), estaría indicando una especialización para la audición en bajas frecuencias, comparable a la de algunos balénidos actuales, como Eubalaena.

El estudio comparativo de otros parámetros de la cóclea, tales como el alto y ancho, muestra algunas observaciones interesantes. En el caso de Eubalaena australis las medidas del alto y el ancho de la cóclea sugieren que, a lo largo de la ontogenia, estas medidas cambian en forma proporcional (hay un incremento en ambas medidas de $\sim 20 \%$ entre cada estadio ontogenético o sea entre neonato /cría y entre cría/adulto), lo cual contribuye a mantener la forma de la cóclea estable a lo largo del desarrollo. Esto se evidencia en los valores de la relación alto axial/diámetro basal, los cuales se mantienen iguales en los tres estadios ontogenéticos (Tabla 4.5). Por otro lado, el alto y el diámetro basal de la cóclea del Taxón A son similares a las del neonato de E. australis, y difieren de las crías y adultos de E. australis así como también de otros misticetos y stem cetácea (Ketten, 1992; Wartzok \& Ketten, 1999) (Tabla 6.9).

En síntesis, en esta tesis se han podido abordar sólo algunos aspectos descriptivos del oído. Esto se debe a que, en los misticetos actuales son escasos los estudios neontológicos en lo que se haya podido establecer una relación entre una determinada morfología coclear y las capacidades auditivas (por ejemplo cual es la relación entre el número de vueltas y la longitud del espiral de la cóclea con los rangos de frecuencia que pueden oír). Más escasa aún es la información sobre la morfología del oído interno de los stem cetácea y de los misticetos extintos. Los resultados de esta tesis brindan por primera vez detalles de la morfología de la cóclea del balénido actual Eubalaena australis incluyendo distintos estadios ontogenéticos, así como también la primera descripción anatómica de la cóclea de un balénido Mioceno. Esta información constituye un punto de partida para el desarrollo de futuras líneas de trabajo. 


\section{APÉNDICE}

Tabla 6.1. Resultados de las ecuaciones de regresión para la estimación del largo corporal en los stem cetácea y misticetos extintos analizados. Abreviaturas: ABZ, ancho bizigomático; e, estimado; LC, largo corporal.

\begin{tabular}{|c|c|c|c|c|c|}
\hline Especie & $\mathrm{N}^{\circ}$ de espécimen & $\overline{\mathrm{ABZ}(\mathrm{mm})}$ & $\begin{array}{l}\text { LC } \\
\text { estimado } \\
(\mathbf{m})\end{array}$ & LC real(m) & Referencia \\
\hline Maiacetus inuus & GSP-UM 3475 & 279 & 2,6 & 2,6 & $\begin{array}{c}\text { Gingerich et al. } \\
(2009)\end{array}$ \\
\hline Rodhocetus kasrani & GSP-UM 3012 & 260 & 2,5 & $2-3$ & $\begin{array}{c}\text { Gingerich et al. } \\
\text { (1994) }\end{array}$ \\
\hline Dorudon & $\mathrm{CGM}_{42183}$ & 500 & 4,6 & $4,58 \#$ & Uhen (2004) \\
\hline Zygorhiza kochii & USNM 11962 & 336 & 3,21 & 4,93 & Kellog (1936) \\
\hline Basilosaurus cetoides & USNM 4674 & 576 & 5,2 & 16,5 & Kellog (1936) \\
\hline Aetiocetus cotylalveus & USNM 25210 & 316 & 3 & & $\begin{array}{c}\text { Demeré \& Berta } \\
\quad(2008)\end{array}$ \\
\hline Janjucetus hunderi & NMV P216929 & 350 & 3 & & $\begin{array}{c}\text { Pyenson \& } \\
\text { Sponberg (2011) }\end{array}$ \\
\hline Eomysticetus whitmorei & $\mathrm{ChMPV}_{4253}$ & 480 & 4,4 & & $\begin{array}{c}\text { Sanders \& } \\
\text { Barnes (2002) }\end{array}$ \\
\hline \multirow[t]{2}{*}{ Morenocetus parvus } & MLP 5-11 & 570 & 5,2 & & \\
\hline & MLP 5-15 & e620 & 5,6 & & \\
\hline \multirow[t]{3}{*}{ Taxón A } & MPEF-PV-1122 & 640 & 5,7 & & \\
\hline & $\mathrm{CH}-\mathrm{P}_{33-\mathrm{O}}$ & 570 & 5,2 & & \\
\hline & $\mathrm{MPCNyO} 290$ & 450 & 4,15 & & \\
\hline Balaenula astensis & MSNT I 12555 & e820 & 6,6 & & Bisconti (2000) \\
\hline Balaena montalionis & MSNT 12357 & e750 & 7,2 & & Bisconti (200o) \\
\hline Balaenella brachyrhynus & NMB 42001 & egoo & 7,9 & & \\
\hline Eubalaena shinshuensis & SFMCV-0024, & e149o & 12,5 & & $\begin{array}{l}\text { Kimura et } \\
\text { al.(2007) } \\
\text { Kimura (2009) }\end{array}$ \\
\hline Diorocetus hiatus & USNM 16783 & 616,5 & 6,4 & & $\begin{array}{c}\text { Pyenson \& } \\
\text { Sponberg (2011) }\end{array}$ \\
\hline Pelocetus calvertensis & USNM 11976 & 930 & 9,4 & & $\begin{array}{c}\text { Pyenson \& } \\
\text { Sponberg (2011) }\end{array}$ \\
\hline Piscobalaena nana & $\begin{array}{c}\text { MNHN SAS } \\
1623\end{array}$ & 433 & 4,6 & & $\begin{array}{c}\text { Bouetel \& } \\
\text { Muizon (2006) }\end{array}$ \\
\hline Cetotherium rathkii & - & 333 & 3,6 & & $\begin{array}{c}\text { Gol'din et al. } \\
(2013) \\
\end{array}$ \\
\hline \multicolumn{6}{|c|}{$\begin{array}{l}\text { \# Este valor corresponde a otro espécimen (UM 101222) donde el ABZ no estaba disponible para analizar. Sin embargo el CBL de UM } 101222 \\
\text { y el utilizado en la estimación (CGM 42183) presentan el mismo CBL (largo cóndilobasal) con lo cual las medidas son comparables, porque } \\
\text { se trataría de individuos de tamaños similares. }\end{array}$} \\
\hline
\end{tabular}


Tabla 6.2. Principales términos anatómicos de las estructuras blandas y óseas de la región nasal de los cetáceos utilizados en esta tesis.

\begin{tabular}{|c|c|c|c|}
\hline $\begin{array}{c}\text { Término } \\
\text { anatómico }\end{array}$ & Sinónimo & Definición & Referencia \\
\hline Pasaje nasal & & $\begin{array}{l}\text { El pasaje de aire completo entre el "blowhole" y las } \\
\text { narinas internas incluyendo el vestíbulo y la cámara } \\
\text { nasal. Puede dividirse en pasaje nasal dorsal y } \\
\text { ventral }\end{array}$ & Esta tesis \\
\hline "Blowhole" & $\begin{array}{l}\text { Narina blanda } \\
\text { "fleshy nostril" }\end{array}$ & $\begin{array}{l}\text { Apertura externa del aparato respiratorio en la piel, } \\
\text { formada por un margen interno y por un margen } \\
\text { externo }\end{array}$ & $\begin{array}{l}\text { Mead \& Fordyce (2009) } \\
\text { p:156; Witmer (2001) }\end{array}$ \\
\hline Vestíbulo & vestíbulo & $\begin{array}{l}\text { Cavidad generada con la apertura del } \\
\text { "blowhole" para el pasaje de aire, ubicada } \\
\text { inmediatamente debajo del blowhole }\end{array}$ & $\begin{array}{l}\text { Henry et al. (1983) y esta } \\
\text { tesis }\end{array}$ \\
\hline Cámara nasal & $\begin{array}{l}\text { cámara } \\
\text { olfatoria, } \\
\text { cavidad nasal }\end{array}$ & $\begin{array}{l}\text { Receso en el pasaje nasal que contiene } \\
\text { los turbinales }\end{array}$ & $\begin{array}{l}\text { Thewissen et al. (2011), } \\
\text { p:5 }\end{array}$ \\
\hline Narinas internas & $\begin{array}{l}\text { coanas, narinas } \\
\text { posteriores }\end{array}$ & $\begin{array}{l}\text { Apertura interna o posterior del pasaje } \\
\text { nasal formada por el pterigoides y el vómer }\end{array}$ & Mead \& Forydce (2009) \\
\hline Válvula nasal & & $\begin{array}{l}\text { Estructura blanda, en forma de válvula } \\
\text { formada por tejido conectivo y adiposo y } \\
\text { por los músculos nasales que ocluyen el pasaje nasal }\end{array}$ & $\begin{array}{l}\text { Heyning \& Mead (1990), } \\
\text { p: } 69 .\end{array}$ \\
\hline Fosa Nasal & - & $\begin{array}{l}\text { Fosa en la superficie dorsal del cráneo, formada por } \\
\text { el premaxilar, el vómer, el nasal y el septo nasal, que } \\
\text { alberga las estructuras blandas del pasaje nasal } \\
\text { dorsal (principalmente los músculos nasales) }\end{array}$ & Esta tesis \\
\hline $\begin{array}{l}\text { Narina externa } \\
\text { ósea }\end{array}$ & - & $\begin{array}{l}\text { Apertura externa del aparato respiratorio asociada } \\
\text { con los nasales y los premaxilares }\end{array}$ & Mead \& Fordyce (2009) \\
\hline
\end{tabular}


Tabla 6.3. Listado de especímenes analizados y medidas utilizadas en el análisis morfométrico de la región nasal. Abreviaturas: LCB, largo condilobasal; LFN, largo de la fosa nasal; AFN, ancho de la fosa nasal y ABZ , ancho bizigomático. Medidas en mm.

\begin{tabular}{|c|c|c|c|c|c|c|}
\hline Especie & LCB & ABZ & LFN & AFN & Referencia & $\begin{array}{c}\mathrm{N}^{\circ} \\
\text { de espécimen }\end{array}$ \\
\hline Janjucetus & 490 & 310 & 140 & 40 & Fitzgerald (2006) & I"NMV P216929 \\
\hline Aetiocetus cotylalveus & 630 & 278 & 143 & 55 & Demeré \& Berta (2008) & USNM 25210 \\
\hline Aetiocetus weltoni & 646 & 322 & 174 & 57 & Demeré \& Berta (2008) & UCMP 122900 \\
\hline Eomysticetus whitmorei & 1316 & 467 & 150 & 58 & Sanders \& Barnes (2002) & ChMPV4253 \\
\hline Joumocetus & 720 & - & 163 & 60 & Kimura \& Hasegawa (2010) & GMNH-PV-2401 \\
\hline Pelocetus calvertensis & 1920 & 972 & 552 & 144 & - & USNM 11976 \\
\hline Aglaocetus patulus & 1595 & 775 & 500 & 215 & - & USNM 23690 \\
\hline Diorocetus hiatus & 1310 & 533 & 319 & 100 & - & USNM 16783 \\
\hline Piscobalaena & 1018 & 385 & 278 & 74 & Boutel \& Muizon (2006) & MNHN SAS 1617 \\
\hline Titanocetus & 1046 & 282 & 303 & 61 & Bisconti (2006) & $\begin{array}{c}\text { MGB 1CMC172 } \\
9073\end{array}$ \\
\hline Miocaperea pulchra & 1010 & 560 & 116 & 54 & Bisconti (2012) & SMNS 46978 \\
\hline Balaenoptera acutorostrata & 1128 & 596 & 298 & 121 & True (1904) & USNM 20931 \\
\hline Balaenoptera physalus & 2582 & 1387 & 540 & 231 & True (1904) & USNM 16039 \\
\hline Balaenoptera borealis & 3386 & 1634 & 765 & 280 & Andrews (1916) & AMNH 34871 \\
\hline Eubalaena & 3310 & 2040 & 786 & 434 & - & USNM 23077 \\
\hline Balaenella & - & 900 & 219 & 173 & Bisconti (2005) & NMB 42001 \\
\hline Caperea marginata & 1210 & 705 & 250 & 147 & - & $\begin{array}{c}\text { NMNZ } \\
\text { MM002235 }\end{array}$ \\
\hline Eschrichtius robustus & 2607 & 1168 & 578 & 283 & Andrews (1914) & AMNH 34260 \\
\hline Megaptera & 3060 & 1850 & 720 & 390 & - & USNM 21492 \\
\hline
\end{tabular}

Tabla 6.4. Resultados del análisis de regresión (SMA) para las variables de la fosa nasal (variables Y) vs el largo del cráneo (variable X). Todas las variables están en $\log _{10}$.Abreviaturas: $a$, ordenada al origen; $b$, pendiente; $\mathrm{n}$, número de ejemplares; $p$ : probabilidad; $\mathrm{r}$, coeficiente de correlación de Pearson.

\begin{tabular}{cccccccc}
\hline \hline Variable Y & $\mathbf{n}$ & $\boldsymbol{b}$ & $\boldsymbol{P}(\boldsymbol{b}=\mathbf{1})$ & $\boldsymbol{a}$ & $\mathbf{r}$ & $\begin{array}{c}\boldsymbol{p} \text { (no } \\
\text { corr)* }\end{array}$ & Alometría \\
\hline \hline Largo de la fosa nasal & 18 & 1.08 & 0.49 & -0.89 & 0.90 & $<0.05$ & NO \\
Ancho de la fosa nasal & 18 & 1.28 & $<0.05$ & -1.94 & 0.93 & $<0.05$ & + \\
\hline \hline
\end{tabular}

*Probabilidad de que las dos variables no estén correlacionadas 
Tabla 6.5. Resultados del análisis de regresión (SMA) para las variables de la fosa nasal (variables Y) vs el ancho bizigomático (variable X). Todas las variables están en $\log _{10}$. Abreviaturas: $a$, ordenada al origen; $b$, pendiente; $\mathrm{n}$, número de ejemplares; $p$, valor de probabilidad de no correlación; $\mathrm{r}$, coeficiente de correlación de Pearson.

\begin{tabular}{cccccccc}
\hline \hline Variable Y & $\mathbf{n}$ & $\boldsymbol{b}$ & $\boldsymbol{P}(\boldsymbol{b}=\mathbf{1})$ & $\boldsymbol{a}$ & $\mathbf{r}$ & $\begin{array}{c}\boldsymbol{p}(\text { no } \\
\text { correlación) }^{*}\end{array}$ & Alometría \\
\hline \hline Largo de la fosa nasal & 18 & 0.97 & 0.82 & -0.25 & 0.82 & $<0.05$ & $\mathrm{NO}$ \\
Ancho de la fosa nasal & 18 & 1.15 & 0.13 & -1.17 & 0.94 & $<0.05$ & $\mathrm{NO}$ \\
\hline \hline
\end{tabular}

*Probabilidad de que las dos variables no estén correlacionadas

Tabla 6.6. Medidas comparativas del globo ocular y de la órbita de los especímenes de Eubalaena australis analizados. Abreviaturas: LGO, largo del globo ocular; AlGO, alto del globo ocular; LO, largo de la órbita; AO, alto de la órbita. Medidas en milímetros

\begin{tabular}{lcccc}
\hline \hline \multicolumn{1}{c}{$\mathbf{N}^{\circ}$ de ejemplar } & LGO & AlGO & LO & AO \\
\hline \hline 071210-PV-Eao2 & 50 & 49 & 100 & 110 \\
082210-PV-Ea 11 & 55 & 54 & 105 & 80 \\
\hline
\end{tabular}

Tabla 6.7. Medidas del ojo de los especímenes utilizados en el análisis de regresión. Largo corporal en metros, el resto de las medidas en milímetros. Abreviaturas: A, adulto; AL, alto de la lente; AlCO, alto de la córnea; AlGO, alto del globo ocular; AnGO, ancho del globo ocular; C, cría; LC, largo corporal; LCO, largo de la córnea; LF, largo focal; LGO, largo del globo ocular; LL, largo de la lente; NI, número de identificación

\begin{tabular}{|c|c|c|c|c|c|c|c|c|c|}
\hline NI & LC & Edad & AnGO & LGO & AlGO & $\mathrm{AlCO}$ & LCO & $\mathbf{L L}$ & $\mathbf{A L}$ \\
\hline 102710-PV-Ea 33 & 11.9 & A & 46 & 72 & 70 & 17 & 30 & & \\
\hline 080310-PV-Ea 05 & 14.9 & A & 59 & 74 & 77 & 24 & 35 & & \\
\hline 070910-PV-Ea 01 & 12.7 & A & 50 & 69 & 73 & 24 & 35 & & \\
\hline 091410-PV-Ea 19 & 12.5 & A & 46 & 73 & 71 & 21 & 32 & & \\
\hline 092706-PV-Ea 11 & 7.7 & $\mathrm{C}$ & 46 & 66 & 64 & 27 & 38 & & \\
\hline 081809-PV-Ea 21 & 5.8 & $\mathrm{C}$ & 44 & 57 & 53 & 21 & 32 & & \\
\hline 092410-PV-Ea 24 & 7.4 & $\mathrm{C}$ & 31 & 59 & 57 & 23 & 33 & & \\
\hline
\end{tabular}




\begin{tabular}{|c|c|c|c|c|c|c|c|c|c|c|}
\hline 072309-PV-Ea 07 & 5.9 & $\mathrm{C}$ & 41 & 66 & 64 & 21 & 35 & & & \\
\hline 082810-Pv-Ea 16 & 6.0 & $\mathrm{C}$ & 39 & 61 & 58 & 24 & 32 & & & \\
\hline 071610-Pv-Ea 03 & 6.5 & $\mathrm{C}$ & 38 & 61 & 59 & 22 & 35 & & & \\
\hline 081709-PV-Ea 19 & 6.7 & $\mathrm{C}$ & 44 & 60 & 58 & 22 & 29 & & & \\
\hline 090109-PV-Ea 40 & 6.2 & $\mathrm{C}$ & 35 & 61 & 56 & 20 & 33 & & & \\
\hline 081209-PV-Ea 18 & 8.0 & $\mathrm{C}$ & 41 & 68 & 67 & 22 & 32 & & & \\
\hline 092807-PV-Ea 19 & 6.9 & $\mathrm{C}$ & 33 & 59 & 56 & 22 & 30 & & & \\
\hline 101807-PV-Ea 41 & 7.8 & $\mathrm{C}$ & 41 & 64 & 65 & 24 & 32 & & & \\
\hline 080203-Pv-Ea 02 & 5.7 & $\mathrm{C}$ & 29 & 52 & 52 & 21 & 29 & & & \\
\hline 071210-PV-Ea 02 & 4.9 & $\mathrm{C}$ & 33 & 50 & 49 & 20 & 26 & 10 & 11 & 18 \\
\hline 091309-Pv-Ea 48 & 5.2 & $\mathrm{C}$ & 28 & 56 & 55 & 20 & 28 & & & \\
\hline 101207-PV-Ea 37 & 7.2 & $\mathrm{C}$ & 37 & 61 & 60 & 20 & 26 & & & \\
\hline 170809-PV-Ea 20 & 5.8 & $\mathrm{C}$ & 28 & 55 & 51 & 23 & 29 & & & \\
\hline 082110-PV-Ea 10 & 5.2 & $\mathrm{C}$ & 34 & 55 & 50 & 21 & 30 & & & \\
\hline 081910-PV-Ea 09 & 6.3 & $\mathrm{C}$ & 38 & 59 & 56 & 22 & 28 & & & \\
\hline 090210-PV-Ea 17 & 7.3 & $\mathrm{C}$ & 46 & 63 & 60 & 22 & 33 & & & \\
\hline 092510-PV-Ea 24 & 6.1 & $\mathrm{C}$ & 34 & 56 & 53 & 18 & 24 & & & \\
\hline 081707-PV-Ea 09 & 5.3 & $\mathrm{C}$ & 31 & 55 & 50 & 20 & 30 & & & \\
\hline 082210-PV-Ea 11 & 4.9 & $\mathrm{C}$ & 34 & 55 & 54 & 22 & 28 & & & \\
\hline 101407-Pv-Ea 39 & 7.7 & $\mathrm{C}$ & 38 & 64 & 60 & 20 & 27 & & & \\
\hline 062909-Pv-Ea 01 & 5.5 & $\mathrm{C}$ & 31 & 60 & 54 & 21 & 30 & & & \\
\hline 082410-Pv-Ea 12 & 4.1 & $\mathrm{C}$ & 25 & 48 & 44 & 17 & 25 & & & \\
\hline
\end{tabular}

Tabla 6.8. Resultados del análisis de regresión (SMA) para las variables del ojo (variables Y) vs el largo corporal (variable X). Todas las variables están $\log _{10}$. Abreviaturas: $a$, ordenada al origen; $b$, pendiente; $C$, diferencia estadística no significativa; $n$, número de ejemplares; $p$, probabilidad; $r$, Coeficiente de correlación de Pearson.

\begin{tabular}{|c|c|c|c|c|c|c|c|}
\hline \multirow[b]{2}{*}{ Variable- Y } & \multicolumn{4}{|c|}{ Análisis de Regresión } & \multicolumn{3}{|c|}{ Correlación } \\
\hline & $\mathbf{n}$ & $b$ & $p(b=1)$ & $a$ & $\underset{\text { correlación) }}{p(\text { no }}$ & $\mathbf{r}$ & Alometría \\
\hline $\begin{array}{l}\text { Largo del globo } \\
\text { ocular }\end{array}$ & 29 & 0.41 & $<0.001$ & 1.44 & $<0.001$ & 0.93 & - \\
\hline $\begin{array}{l}\text { Alto del globo } \\
\text { ocular }\end{array}$ & 29 & 0.44 & $<0.001$ & 1.40 & $<0.001$ & 0.92 & - \\
\hline $\begin{array}{l}\text { Ancho globo } \\
\text { ocular }\end{array}$ & 29 & 0.65 & $<0.001$ & 1.02 & $<0.001$ & 0.79 & - \\
\hline
\end{tabular}




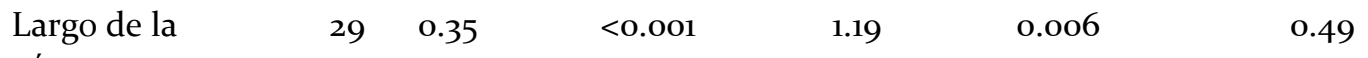
córnea

Alto de la córnea $\quad 29 \quad 0.33$

$<0.001$

1.05

$0.14(\mathrm{NS})^{\mathrm{c}}$

0.29

*Probabilidad de que las dos variables no estén correlacionadas

Tabla 6.9. Medidas de la cóclea e índices calculados en los especímenes de Eubalaena australis,

Taxón A (MPEF-PV 1122) y Balaenoptera spp. analizados. Las medidas están en milímetros.

\begin{tabular}{|c|c|c|c|c|c|c|c|c|c|c|}
\hline \multirow[b]{2}{*}{ Espécimen } & \multirow[b]{2}{*}{$\begin{array}{c}\mathrm{N}^{\circ} \\
\text { vueltas }\end{array}$} & \multirow[b]{2}{*}{$\begin{array}{l}\text { Alto } \\
\text { axial }\end{array}$} & \multirow[b]{2}{*}{$\begin{array}{c}\text { Diámetro } \\
\text { basal }\end{array}$} & \multirow[b]{2}{*}{$\begin{array}{c}\text { alto } \\
\text { axial/ } \\
\mathbf{n}^{\circ} \text { de } \\
\text { vueltas }\end{array}$} & \multirow[b]{2}{*}{$\begin{array}{c}\text { altura axial/ } \\
\text { diámetro } \\
\text { basal }\end{array}$} & \multicolumn{5}{|c|}{$\begin{array}{l}\text { Radios en corte } \\
\text { paramodiolar }\end{array}$} \\
\hline & & & & & & $\begin{array}{c}1 / 2 \\
\pi\end{array}$ & $\begin{array}{c}3 / 2 \\
\pi\end{array}$ & $\begin{array}{c}5 / 2 \\
\pi\end{array}$ & $\begin{array}{c}7 / 2 \\
\pi\end{array}$ & $\begin{array}{c}9 / 2 \\
\pi\end{array}$ \\
\hline $\begin{array}{l}\text { Eubalaena australis } \\
\text { (neonato } \\
\text { CNPMAMM 748) }\end{array}$ & 2,5 & 3,65 & 7,09 & 1,46 & 0,51 & 0,5 & 1,71 & 2,01 & 4,12 & 2,96 \\
\hline $\begin{array}{l}\text { Eubalaena australis } \\
\text { (cría S/N) }\end{array}$ & 2,5 & 4,45 & 8,73 & 1,78 & 0,51 & 0,42 & 1,87 & 2,55 & 3,33 & 4,49 \\
\hline $\begin{array}{l}\text { Eubalaena australis } \\
\text { (adulto } \mathrm{S} / \mathrm{N} \text { ) }\end{array}$ & 2,5 & 5,25 & 10,36 & 2,1 & 0,51 & 0,47 & 2,35 & 2,98 & 6,43 & 3,83 \\
\hline Taxón A (MPEF-1122) & 2,5 & 3,77 & 6,57 & 1,51 & 0,57 & 0,27 & 1,86 & 0,23 & 3,8 & 2,76 \\
\hline $\begin{array}{l}\text { Balaenoptera bonaerensis } \\
\text { (cría CNPMAMM } 75^{\circ} \text { ) }\end{array}$ & 2,5 & 5,02 & 8,85 & 2,01 & 0,57 & 0,49 & 2,7 & 2,49 & 5,24 & 3,42 \\
\hline $\begin{array}{l}\text { Balaenoptera spp. } \\
\text { (adulto } \mathrm{S} / \mathrm{N} \text { ) }\end{array}$ & 2,5 & 6,25 & 10,68 & 2,5 & 0,58 & 0,61 & 3,36 & 3,58 & 5,96 & 4,42 \\
\hline Eubalaena glacialis* & 2,5 & 6,7 & 9,67 & 2,68 & 0,57 & - & - & - & - & - \\
\hline $\begin{array}{l}\text { Parietobalaena } \\
\text { Palmeri* }^{*}\end{array}$ & 2,3 & 6,6 & 13,5 & 2,87 & 0,49 & - & - & - & - & - \\
\hline Herpetocetus* & 3 & 9,8 & 12 & 3,3 & 0,9 & - & - & - & - & - \\
\hline Zygorhiza* & 2 & 6,75 & 10,5 & 3,38 & 0,64 & - & - & - & - & - \\
\hline
\end{tabular}

*Datos obtenidos de la literatura (Ketten, 1992, Geisler \& Luo, 1996; Wartzok \& Ketten, 1999) 


\section{Capítulo 7}

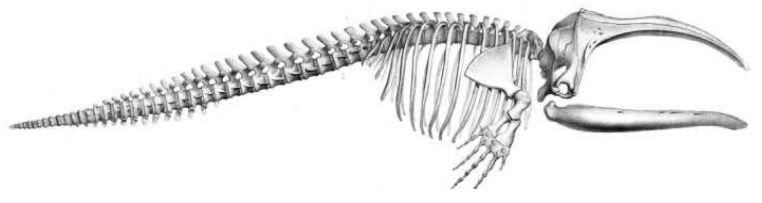

\section{Conclusiones}

Buono, M. Evolución de los Balénidos del Mioceno de Patagonia 


\section{Capítulo 7 Conclusiones}

Conforme con los objetivos planteados y el desarrollo del protocolo de trabajo, se pudo obtener información neontológica que permitió interpretar en forma más integral las evidencias del registro paleontológico. Las discusiones de cada uno de los tópicos abordados se desarrollaron en cada capítulo. A continuación se detallan las conclusiones de este trabajo de tesis.

\section{Capítulo 4: Anatomía y sistemática paleontológica}

En este capítulo los objetivos, hipótesis de trabajo y conclusiones fueron:

1) Objetivo: Efectuar la descripción osteológica del cráneo y mandíbula de ejemplares de distintos estadios ontogenéticos del balénido actual Eubalaena australis, que se utilizará como modelo neontológico para efectuar comparaciones con los balénidos miocenos.

Hipótesis de trabajo: la morfología craneal y mandibular brinda parámetos no vinculados al tamaño que permiten diferenciar estadios ontogenéticos relativos.

Conclusión:

- De la exploración osteológica del cráneo y mandíbula de neonatos, crías y adultos de Eubalaena australis se concluye que el cráneo de los neonatos y crías se diferencia del de los adultos en parámetros independientes del tamaño y del cierre relativo de las suturas, lo cual permite aceptar la hipótesis de trabajo planteada. Entre las variaciones que se identifican están: apertura transversal de la ventana maxilar, fosa 
para el martillo poco acentuada, desarrollo de crestas y surcos en la superficie dorsal del periótico y bulla timpánica comprimida transversalmente.

2) Objetivo: Analizar los caracteres diagnósticos de la familia Balaenidae así como también del género Eubalaena y de la especie E. australis

Hipótesis de trabajo: Los caracteres identificados como diagnósticos de la familia Balaenidae, y particularmente del género Eubalaena y de la especie E. australis, en publicaciones anteriores son insuficientes.

Conclusión:

- El análisis sistemático de los balénidos desarrollado en esta tesis permitió determinar que los caracteres identificados como diagnósticos de los Balaenidae, Eubalaena y E. australis en estudios previos son insuficientes. Por este motivo se aceptó la hipótesis de trabajo planteada y se elaboró una diagnosis enmendada de la familia, género y especie.

3) Objetivo: Realizar el estudio y re-descripción del holotipo y material referido de Morenocetus parvus Cabrera (1926) del Mioceno temprano de Chubut (Formación Gaiman).

Hipótesis de trabajo: El ejemplar MLP 5-15 y el holotipo (MLP 5-11) de Morenocetus parvus son asignables a la misma entidad taxonómica.

Conclusión:

- El re-estudio anatómico y sistemático de Morenocetus parvus permitió aceptar la hipótesis de trabajo planteada y, por lo tanto, determinar que es una entidad taxonómica válida representada por dos ejemplares subadultos (MLP 5-11, holotipo y MLP 5-15, material referido).

4) Objetivo: Estudio anatómico detallado y de taxonomía alfa de los nuevos registros de balénidos recuperados de la Formación Puerto Madryn (Mioceno Tardío; Península Valdés; Chubut).

Hipótesis de trabajo: Los ejemplares MPEF-PV-1122, CH-P33-01, y MPCNyO 290 colectados en niveles de la Formación Puerto Madryn (Mioceno tardío) representan un nuevo taxón.

Conclusiones:

- Los ejemplares MPEF-PV-1122, CH-P33-01, y MPCNyO 290 recuperados de la Formación Puerto Madryn presentan una combinatoria única de caracteres que no permite referirlo a ningún taxón conocido, con lo cual se acepta la hipótesis de 
trabajo planteada, y se asignan a un nuevo género y especie (Taxón A) de balénidos. Los tres ejemplares representan distintos estadios de la serie ontogenética: adulto (MPEF-PV-1122), subadulto (CH-P33-01) y juvenil (MPCNyO 290).

- La presencia en el adulto del Taxón A (MPEF-PV-1122) de ciertos caracteres, tales como un proceso ascendente del maxilar aproximadamente triangular y corto ánteroposteriormente, una bulla timpánica de aspecto globoso sin una marcada compresión dorso-ventral, y superficie dorsal del periótico sin crestas ni surcos, se interpretan como rasgos paedomórficos.

5) Objetivo: Descripción de los ejemplares de balénidos del Mioceno de Paraná (Entre Ríos). Hipótesis de trabajo: en la Formación Paraná (Mioceno tardío) se registran los mismos taxones que en la Formación Gaiman y Puerto Madryn.

Conclusión:

- Las diferencias observadas entre el ejemplar MACN-PV 13221 (Fm. Paraná) y el Taxón A (Fm. Puerto Madryn) no permitieron asignarlos a un mismo taxón, por lo cual se rechazó la hipótesis de trabajo planteada. Los balénidos miocenos de la Fm. Paraná no pudieron ser identificados a niveles específicos ni genéricos, debido a la condición fragmentaria del espécimen.

\section{Capítulo 5: Análisis filogenético}

En este capítulo los objetivos, hipótesis de trabajo y conclusiones fueron:

1) Objetivo: Analizar la posición filogenética de los Balaenidae dentro de los Mysticeti.

Hipótesis de trabajo: los balénidos son un grupo monofilético y hermano del clado formado por los Cetotheriidae y Balaenopteroidea.

Conclusiones:

- Los resultados del análisis filogenético, tanto en el análisis de pesos implicados como pesos iguales, permitieron aceptar la hipótesis de trabajo planteada, concluyendo que los Balaenidae son un grupo monofilético bien soportado y hermano del clado formado por los Balaenopteroidea y Cetotheriidae.

- Caperea marginata se recupera con buenos valores de soporte profundamente anidado dentro de los cetotéridos. De esta forma constituye el único representante actual de este clado. 
2) Objetivo: Analizar la posición filogenética de los balénidos del Mioceno de Patagonia dentro de los Balaenidae.

Hipótesis de trabajo: Morenocetus y el nuevo Taxón A forman un clado basal de balénidos.

Conclusiones:

- Los balénidos miocenos (Morenocetus y Taxón A) conforman un clado de posición basal dentro de los balénidos. El soporte de este clado es adecuado y ninguno de los dos taxones fue hallado como inestables. Por lo tanto se acepta la hipótesis de trabajo planteada.

- El re-estudio del holotipo de Balaenella brachyrhynus de NMB42001 permite concluir que el estatus sistemático de este taxón debe ser re-evaluado.

- Balaenella y Balaenula se posicionan como sucesivos taxones hermanos de los balénidos modernos (Balaena y Eubalaena)

- Las relaciones dentro de los clados modernos (Balaena y Eubalaena) no lograron resolverse.

- La calibración estratigráfica del cladograma indica la presencia de un extenso linaje fantasma entre los balénidos miocenos y los balénidos más derivados (Balaenella, Balaenula, Balaena y Eubalaena). La extensión de este linaje fantasma ( $\sim 15 \mathrm{Ma})$ abarca desde el Mioceno temprano tardío (Burdigaliense) hasta el Plioceno temprano (Zancliense).

- El hallazgo del Taxón A del Mioceno tardío de Patagonia, interrumpe el hiato temporal entre Morenocetus y los balénidos más derivados, pero no acorta el linaje fantasma previamente mencionado.

\section{Capítulo 6: Aspectos paleobiológicos de los balénidos miocenos e implicancias en la evolución de los misticetos}

\subsection{Tamaño corporal}

En esta sección el objetivo, hipótesis de trabajo y conclusiones fueron:

1) Objetivo: Estimar la longitud corporal de los misticetos filtradores, y en particular de los balénidos miocenos, y analizarlo en un contexto evolutivo.

Hipótesis de trabajo: La tendencia al aumento del largo corporal, llegando al gigantismo, no 
ocurrió linealmente en la historia evolutiva de los balénidos.

Conclusiones:

Los resultados de esta sección permitieron aceptar la hipótesis de trabajo y las conclusiones que se desprenden de este análisis son:

- La condición primitiva para los misticetos es un largo corporal pequeño $(<6 \mathrm{~m})$, condición que retienen las formas basales de Chaeomyticeti o misticetos con barbas.

- En lo misticetos el incremento en el largo corporal o tendencia al gigantismo no siguió un patrón lineal y se adquirió al menos dos veces en forma independiente, una en los Balaenidae y otra en los Balaenopteridae y Eschrichtiidae. Dentro de los cetotéridos no se registran formas gigantes.

- Los balénidos más antiguos y más basales corresponden a formas de largo corporal pequeño $(<6 \mathrm{~m})$.

- En los balénidos, se registra desde el Plioceno una tendencia al aumento del largo corporal. El registro más temprano de gigantismo ocurre en el Plioceno temprano con Eubalaena shinshuensis.

\subsection{Morfología de la región nasal y respiración}

En esta sección los objetivos, hipótesis de trabajo y conclusiones fueron:

1) Objetivo: Analizar los correlatos óseos y la posición de la apertura externa del pasaje nasal en la piel (blowhole) y la narina externa ósea en balénidos actuales.

Hipótesis de trabajo: la posición del blowhole no tiene correlato óseo en la fosa nasal.

Conclusiones:

La exploración de la anatomía ósea y blanda de la región nasal de Eubalaena australis permitió rechazar la hipótesis de trabajo planteada y concluir que:

- El análisis morfológico de la región nasal en los modelos neontológicos analizados, balénidos (Eubalaena australis), cetotéridos (Caperea) y balenoptéridos (Balaenoptera bonaerensis), indica que comparten un patrón general con diferencias menores en las estructuras para la deflexión del agua y en la organización de la musculatura nasal.

- En los tres grandes clados de misticetos filtradores con representantes actuales (balénidos, balenoptéridos y cetotéridos), el ancho máximo de la fosa nasal coincide con el emplazamiento del blowhole. Por consiguiente este parámetro puede ser utilizado como correlato óseo de la apertura de la narina blanda. 
2) Objetivo: Evaluar si durante la evolución de los misticetos el desplazamiento póstero-dorsal de la narina ósea estuvo acompañado por un cambio en la localización del blowhole.

Hipótesis de trabajo: la morfología del complejo nasal de los misticetos, incluidos los balénidos, se mantuvo estable y conservó el patrón mamaliano a lo largo la su historia evolutiva del grupo (i.e el blowhole se posiciona ántero-ventralmente dentro de la narina ósea).

\section{Conclusiones:}

Los resultados obtenidos en relación a este objetivo permitieron rechazar la hipótesis de trabajo planteada y se concluye que:

- El proceso de retracción de la narina ósea estuvo acompañado por el desarrollo de una fosa nasal profunda y elongada en la superficie dorsal del cráneo, condición ya presente en los Pelagiceti basales.

- Contrariamente a lo que se ha postulado como una regla prácticamente invariable para los amniotas (Witmer, 2001), en los misticetos la apertura carnosa (= fleshy nostril $=$ blowhole) dentro de la narina externa ósea (= fosa nasal) se ubica en posición póstero-dorsal y no ántero-ventral.

- La exploración de este correlato en un marco filogenético indica que la migración posterior de la narina externa ósea estuvo acompañada por el desplazamiento póstero-dorsal del blowhole dentro de la fosa nasal. Esta migración ya estaría presente en las formas más basales de Pelagiceti a partir del Eoceno Medio-tardío.

3) Objetivo: Analizar la correlación entre el tamaño de la fosa nasal (medido en ancho y largo) y el tamaño del cráneo (medido en ancho y largo)

Hipótesis de trabajo: el tamaño de la fosa nasal no está correlacionada con el tamaño del cráneo.

Conclusiones:

- Hay una correlación positiva entre el aumento del tamaño del cráneo y el aumento del tamaño del blowhole.

- Se hipotetiza que el cambio en la posición y el aumento en el tamaño relativo del blowhole estaría vinculado con un aumento en la eficiencia de la respiración durante el buceo.

Cabe mencionar que la exploración anatómica de la región nasal de Eubalaena australis permitió por primera vez identificar caracteres morfológicas, con implicancias fisiológicas, como es una red admirable revistiendo el pasaje nasal. Se propone como hipótesis para futuros trabajos que 
esta rete podría estar presente en los cetotéridos y balenoptéridos, y que podría intervenir en el calentamiento del aire que entra al pasaje nasal. Futuros trabajos permitirán poner a prueba esta hipótesis.

\section{3 Órganos de los sentidos}

\subsubsection{Ojo y estructuras periorbitales}

Los objetivos, hipótesis de trabajo y conclusiones correspondientes a esta sección fueron:

1) Objetivo: Explorar la anatomía ósea y blanda de la región orbital de E. australis con el fin de buscar correlatos óseos que permitan reconstruir el globo ocular y el nervio óptico en los balénidos miocenos y en otros misticetos extintos.

Hipótesis de trabajo: la órbita y el canal óptico son correlatos óseos válidos del globo ocular y del nervio óptico respectivamente.

\section{Conclusiones:}

La exploración de la anatomía del ojo y estructuras periorbitales de Eubalaena australis permitió rechazar la hipótesis de trabajo planteada y se concluye que:

- La órbita no es un buen correlato óseo del tamaño del globo ocular. El globo ocular es mucho menor que la órbita, está protruido y rodeado de estructuras metabólicamente activas (grasa), cuyo desarrollo varía en la ontogenia y en distintos períodos del ciclo vital del animal. Asimismo, el canal y el foramen óptico no resultan buenos proxies, ya que el nervio óptico está rodeado en su recorrido por estructuras blandas, como la red admirable oftálmica y los músculos extraoculares, y además están cerrados por cartílago.

- La anatomía del globo ocular y estructuras periorbitales de E. australis muestra un patrón similar al observado en otros misticetos, tales como una esclera gruesa, la ausencia de músculos ciliares, la presencia de una red admirable oftálmica y una coroides, un tapetum lucidum bien desarrollados y grasa periorbital.

- Se hipotetiza que en Eubalaena australis la capa de grasa periorbital externa cumple un rol estructural, mientras que las capas internas intervienen en la generación de un espacio flexible para acomodar la expansión y/o compresión de las estructuras periorbitales durante la acomodación del globo ocular, y por otro son metabólicamente activas y están relacionadas con la termorregulación.

- En Eubalaena australis hay una correlación positiva entre el tamaño del globo ocular y el largo corporal. Las variables del tamaño del globo ocular (medidas en ancho, el 
alto y el largo) presentan un incremento alométrico negativo con el aumento del largo corporal. Por el contrario, la córnea presenta una baja correlación con el largo corporal, y la relación entre estas dos variables presenta una alometría negativa, lo cual sugiere que la córnea no aumenta mucho de tamaño durante el crecimiento del animal. La estimación del parámetro visual $f$ para el ojo de Eubalaena australis sugiere que este presenta una sensibilidad visual baja.

2) Objetivo: Analizar los resultados obtenidos en el contexto de la historia evolutiva de los balénidos.

Hipótesis de trabajo: en los balénidos, al igual que en todos los misticetos, hubo una tendencia a la reducción del globo ocular y del nervio óptico, indicando una disminución de las capacidades visuales a lo largo de la historia evolutiva del grupo.

\section{Conclusiones:}

- Dado que no hay un correlato claro entre la órbita/canal/foramen óptico y el globo ocular/nervio óptico, no pueden explorarse las capacidades visuales en los taxones extintos, con lo cual no puede contrastarse la hipótesis de trabajo planteada. El único carácter que puede analizarse en un contexto evolutivo es el tamaño relativo y la posición de las órbitas, sin que ello implique una interpretación de la evolución de las capacidades visuales de los misticetos.

- En los misticetos, la condición primitiva es órbitas relativamente pequeñas (en relación al tamaño cráneo). El agrandamiento de las órbitas se dió al menos dos veces independientemente en el linaje que condujo a los misticetos dentados (uno en el clado de Mammalodon+Janjucetus y otra en el clado de Aetiocetus+Chonecetus). Dentro de los Chaeomysticeti o ballenas con barbas hay una reducción marcada de las órbitas en los representantes actuales de los Balaenidae y de los Balaenopteridae.

- En cuanto a la posición de las órbitas, en los misticetos la condición primitiva es órbitas altas, ubicadas al mismo nivel que la superficie dorsal del cráneo. Las órbitas en una posición ventral es una condición sinapomórfica para el clado formado por los balénidos, los cetotéridos y los balenoptéridos. La condición de Morenocetus (i.e. órbitas a mitad de altura, 1/2) es autapormófica dentro de los balénidos, y aparece en forma paralela al menos dos veces, una en los cetotéridos (Caperea) y otra en los balenoptéridos.

\subsubsection{Oído}

Los objetivos, hipótesis de trabajo y conclusiones correspondientes a esta sección fueron: 
1) Objetivo: Analizar las estructuras blandas asociadas con el oído y sus correlatos óseos en Eubalaena australis.

Hipótesis de trabajo: la depresión en el meato auditivo y los recesos en la superficie ventral del pterigoides y del basioccipital, indican el punto inserción de la membrana timpánica y la extensión del seno pterigoideo respectivamente.

Conclusión:

La exploración del la anatomía de la región auditiva de Eubalaena australis permitió aceptar la hipótesis de trabajo planteada y concluir que:

- La depresión en el meato auditivo externo y los recesos en la superficie ventral del pterigoides y del basioccipital, marcan el punto inserción de la membrana timpánica y la extensión posterior del seno pterigoideo respectivamente. Estas estructuras tienen un desarrollo comparable en Eubalaena australis y en los balénidos miocenos.

2) Objetivo: Reconstruir la cóclea del los balénidos miocenos y poder inferir aspectos de la audición en estos balénidos.

Hipótesis de trabajo: la morfología de la cóclea de los balénidos miocenos indica que las modificaciones del sistema auditivo para los sonidos de baja frecuencia se adquirieron tempranamente en la historia del grupo.

Conclusiones:

El estudio de la morfología de la cóclea de los balénidos del Mioceno tardio (Taxón A) permitió aceptar la hipótesis de trabajo planteada y se concluye que:

- La cóclea del Taxón A presenta el mismo patrón morfológico general, o sea tipo M, que el de Eubalaena australis (i.e. 2,5 vueltas y superposición entre las mismas), sugiriendo una adaptación a las bajas frecuencias, comparables con algunos balénidos actuales.

- En Eubalaena australis la estructura general de la cóclea (i.e. número de vueltas y la forma) no varía durante la ontogenia. 


\section{Bibliografía}

Abel, O. 1941. Vorläufige mitteilungen uber die revision der fossilen mystacoceten aus dem tertiär belgiens. Bulletin du Muséee d'Histoire naturelle de Belgique 17:1-29.

Aceñolaza, F. G. 200o. La Formación Paraná (Mioceno medio): estratigrafía, regional y unidades equivalentes. Serie Correlación Geológica 14:9-28.

Ackman, R. G., J. H. Hingley, C. A. Eaton, J. C. Sipos, y E. D. Mitchell. 1975. Blubber fat deposition in Mysticeti whales. Canadian Journal of Zoology 53:1332-1339.

Acosta Hospitaleche, C. 2003. Paraptenodytes antarcticus (Aves: Sphenisciformes) en la Formación Puerto Madryn (Mioceno tardío temprano), provincia de Chubut, Argentina. Revista Española de Paleontología 18:179-183.

Acosta Hospitaleche, C. 2007. Revisión sistemática de Palaeospheniscus (Simpson) nov. comb. (Aves, Spheniscidae) de la Formación Gaiman (Mioceno Temprano), Chubut, Argentina. Ameghiniana 44:417-426.

Acosta Hospitaleche, C., C. Tambussi, M. Donato, y M. A. Cozzuol. 2007a. A new Miocene penguin from Patagonia and its phylogenetic relationships. Acta Palaeontologica Polonica 52:299-314.

Acosta Hospitaleche, C., C. Tambussi, y M. T. Dozo. 2007b. Dendrocygna Swinson (Anseriformes) en el Mioceno tardío de la Formación Puerto Madryn (Argentina): anatomía de la pelvis. Actas de las XXIII Jornadas Argentinas de Paleontología de Vertebrados P:4.

Acosta Hospitaleche, C., L. N. Castro, C. Tambussi, y R. Scasso. 2008. Palaeospheniscus patagonicus (Aves, Spheniscidae): new discoveries from the Early Miocene of Argentina. Journal of Palaeontology 82:565-575

Agnolin, F., y S. Lucero. 2004. Registros de cetáceos del Mioceno Tardío de Entre Ríos, Argentina. Revista de Biología Marina y Oceanografía 39:107-110. 
Aguilar, A., y A. Borrell. 1990. Patterns of lipid content and stratification in the blubber of fin whales (Balaenoptera physalus). Journal of Mammalogy 71:544-554.

Allen, J. A. 1908. The North Atlantic right whale and its near allies. Bulletin of the American Museum of Natural History 24:277-329.

Allen, G. M. 1916. The whalebone whales of New England. Memoirs of the Boston Society of Natural History 8:105-322.

Ameghino, F. 1906. Les formations sédimentaires du Crétacé supérieur et du Tertiaire de Patagonia, avec un paralèlle entre leurs faunes mammalogiques et celles de l'ancien continent. Anales del Museo Nacional de Buenos Aires 15:568pp.

Andrews, R. C. 1914. The California gray whale (Rhachianectes glaucus Cope): Its history, habits, external anatomy, osteology and relationship. Monographs of the Pacific Cetacea. Memoirs of the American Museum of Natural History, New Series 1:227-287.

Andrews, R. C. 1916. The Sei whale (Balaenoptera borealis Lesson): history, habits, external anatomy, osteology and relationship. Monographs of the Pacific Cetacea. Memoirs of the American Museum of Natural History, New Series 1:289-388.

Anthony, R. L. F. 1926. Les affinites des Cetaces. Annales de I'Institut Océanographique. Monaco. N.S. 3:93-134.

Ardolino, A. 1981. El vulcanismo cenozoico del borde suroriental de la meseta de Somuncurá. $8^{\circ}$ Congreso Geológico Argentino, Buenos Aires. Actas 3:7-23.

Árnason, U., y A. Gullberg. 1994. Relationship of baleen whales established by cytochrome b gene sequence comparison. Nature 367:726-728.

Arratia, G., y A. L. Cione. 1996. The fish fossil record of southern South America. Münchener Geowissenschaft Abhanlungen 30A:9-72.

Bacha, W. J., L. M. Wood, y G. Delhon. 1991. Atlas color de histología veterinaria. Editorial Intermédica, Buenos Aires, $\mathfrak{1}^{\underline{a}}$ Edición. 
Bajpai, S., y P. D. Gingerich. 1998. A new Eocene archaeocete (Mammalia, Cetacea) from India and the time of origin of whales. Proceeding of the National Academy of Sciences USA 95:15464-68.

Bajpai, S., y J. G. M. Thewissen. 2000. A new, diminutive Eocene whale from Kachchh (Gujarat, India) and its implications for locomotor evolution of cetaceans. Current Science 79:1478-1482.

Bajpai, S., J. G. M. Thewissen, y R. W. Conley 2011. Cranial anatomy of Middle Eocene Remingtonocetus (Cetacea, Mammalia) from Kutch, India. Journal of Paleontology 85:703-718.

Bannister, J. 2009. Baleen whales. En: Encyclopedia of marine mammals. Perrin, W. F., Thewissen J. G. M., y Würsig, B., editors. San Diego, CA. Elsevier P:8o-89.

Barnes, L. G. 1977. Outline of eastern North Pacific fossil cetacean assemblages. Systematic Zoology 25:321-343.

Barnes, L. G., M. Kimura, H. Furusawa, y H. Sawamura. 1995. Classification and distribution of Oligocene Aetiocetidae (Mammalia; Cetacea; Mysticeti) from western North America and Japan. Island Arc 3:392-431.

Barreda, V. D., y L. Palazzesi. 2007. Patagonian vegetation turnovers during the Paleogene-Early Neogene: origin of arid-adapted floras. The Botanical Review 73:31-50.

Bebej, R. M., M. Ul-Haq, I. S. Zalmout, y P. D. Gingerich. 2012. Morphology and function of the vertebral column in Remingtonocetus domandaensis (Mammalia, Cetacea) from the Middle Eocene Domanda Formation of Pakistan. Journal of Mammalian Evolution 19:77-104.

Bergqvist, L. P., C. J. Drehmer, A. M. Ribeiro, y E. V. Oliveira. 1999. Aquatic mammal fossils from Brazil: A review. Revista Universidade Guarulhos, Geociências 4:28-32.

Berta, A., J. L. Sumich, K. M. Kovacs, P. A. Folkens, y P. J. Adam. 20o6. Marine Mammals. Evolutionary Biology. Second Edition. Elsevier 512pp.

Best, P. B., R. Payne, V. Rowntree, J. T. Palazzo, y M. D. Both. 1993. Long-range movements of South Atlantic right whales Eubalaena australis. Marine Mammal Science 9:227-234. 
Best, P. B. 1994. Seasonality of reproduction and the length of gestation in southern right whales, Eubalaena australis. Journal of Zoology 232:175-189.

Bianucci, G., M. Bisconti, W. Landini, T. Storai, M. Zuffa, S. Giuliani, y A. Mojetta. 20oo. Trophic interaction between white shark, Carcharodon carcharias, and cetaceans: a comparison between Pliocene and recent data from central Mediterranean Sea. Proceedings of the 4th Meeting of the European Elasmobranch Association, Livorno P:27-30.

Bisconti, M. 2000. New description, character analysis and preliminary phyletic assessmentof two Balaenidae skulls from the Italian Pliocene. Palaeontographia Italica 87:37-66.

Bisconti, M. 2002. An early Late Pliocene right whale (genus Eubalaena) from Tuscany (Central Italy). Bollettino della Società Paleontologica Italiana 41:83-91.

Bisconti, M. 2003. Evolutionary history of Balaenidae. Cranium 20:9-50.

Bisconti, M. 2005. Skull morphology and phylogenetic relationships of a new diminutive balaenid from the lower Pliocene of Belgium. Palaeontology 48:793-816.

Bisconti, M. 2006. Titanocetus, a new baleen whale from the middle Miocene of northern Italy (Mammalia, Cetacea, Mysticeti). Journal of Vertebrate Paleontology 26:344-354.

Bisconti, M. 2008. Morphology and phylogenetic relationships of a new eschrichtiid genus (Cetacea: Mysticeti) from the Early Pliocene of northern Italy. Zoological Journal of the Linnean Society 153:161-186.

Bisconti, M. 2010. A new balaenopterid whale from the late Miocene of the stirone river, northern Italy (Mammalia, Cetacea, Mysticeti). Journal of Vertebrate Paleontology 30:943-958.

Bisconti, M. 2012. Comparative osteology and phylogenetic relationships of Miocaperea pulchra, the first fossil pygmy right whale genus and species (Cetacea, Mysticeti, Neobalaenidae). Zoological Journal of the Linnean Society 166:876-911.

Bjerager, P., S. Heegaard, y J. Tougaard. 2003. Anatomy of the eye of the Sperm whale (Physeter macrocephalus). Aquatic Mammal 29:31-36. 
Blainville, H. M. D. 1816. Prodrome d'une nouvelle distribution systematique du règne animal. Bulletin de Science. Société Philomátique, Paris 8:113-20.

Blix, A. S., y B. Folkow. 1983. Cardiovascular Adjustments to Diving in Mammals and Birds. Comprehensive Physiology, 2011. Supplement 8: Handbook of Physiology, The Cardiovascular System, Peripheral Circulation and Organ Blood Flow P:917-945.

Bouetel, V. 2005. Phylogenetic implications of skull structure and feeding Behavior in balaenopterids (Cetacea, Mysticeti). Journal of Mammalogy 86:139-146.

Bouetel, V., y C. de Muizon. 2006. The anatomy and relationships of Piscobalaena nana (Cetacea, Mysticeti), a Cetotheriidae s.s. from the early Pliocene of Peru. Geodiversitas 28:319-395.

Brandt, J. F. 1872. Uber eine neue Classification der Bartenwale (Balaenoidea) mit Berucksichtigung der untergegangenen Gattungen derselben. Bulletin d L'Academie Imperiale des Sciences de St. Petersbourg 26:113-130.

Brisson, M. J. 1762. Regnum animale in classes IX distributum, sive synopsis methodical sistens generalem animalium distributionem in classes IX, \& duarum primarum classium, quadripedum scilicet \& cetaceorum, particularum divisonem in ordines, sectiones, genera, \& species. Editio altera auctior [Second edition]. Theodorum Haak, Lugduni Batavorum [Leiden] $\mathrm{P}: 296$.

Brudenall, D. K., I. R. Schwab, y K. A. Fritsches. 2008. Ocular morphology of the Leatherback sea turtle (Dermochelys coriacea). Veterinary Ophthalmology 11:99-110.

Brunner, S. 1998. Skull development and growth in the southern fur seals Arctocephalus forsteri and A. pusillus doriferus (Carnivora: Otariidae). Australian Journal of Zoology 46:43-66.

Buono, M. R., M. S. Fernández, y Y. Herrera. 2012. Morphology of the eye of the southern right whales (Eubalaena australis). Anatomical Record 295:355-68.

Buono, M. R., y M. A. Cozzuol. 2013. A new beaked whale (Cetacea, Odontoceti) from the Late Miocene of Patagonia, Argentina. Journal of Vertebrate Paleontology 33:986-997. 
Buono, M., M. T. Dozo, F. G. Marx, y R. E. Fordyce. 2013. A Late Miocene potential neobalaenine mandible from Argentina sheds light on the origins of the living pygmy right whale. Acta Palaeontologica Polonica. En prensa. doi: http://dx.doi.org/10.4202/app.2012.0122.

Burton, R. F. 1998. Biology by numbers: an encouragement to quantitative thinking. Cambridge: Cambridge University Press P:157-178.

Burton, R. F. 2006. A new look at the scaling of size in mammalian eyes. Journal of Zoology 269:225232.

Cabrera, A. 1926. Cetáceos fósiles del Museo de La Plata. Revista del Museo de la Plata 29:363-411.

Camacho, H. H., y J. A. Fernández. 1956. La transgresión patagoniense en la costa atlántica entre Comodoro Rivadavia y el valle inferior del río Chubut. Revista de la Asociación Geológica Argentina 11:23-45.

Capellini, G. 1872. Resoconto della Riunione Straordinaria della Società Italiana di Scienze Naturali a Siena nel Settembre 1872. Atti della Società Italiana di Scienze Naturali 15:219.

Capellini, G. 1904. Balene fossili toscane. II. Balaena montalionis. Memorie della Regia Accademia delle Scienze dell'Istituto di Bologna 6 1:45-57.

Carte, E., y A. Macalister. 1868. On the Anatomy of Balaenoptera rostrata. Philosophical Transactions of the Royal Society (B) 158:210-261.

Cave, A. J. E. 1988. Note on olfactory activity in mysticetes. Journal of Zoology 214:307-311.

Caviglia, S. E., y R. E. Jorge. 1980. Preaulophyseter gualichensis General. et sp. nov. (Cetacea; Physeteridae) en el Terciario marino de Río Negro, República Argentina. Actas del Segundo Congreso Argentino de Paleontología y Bioestratigrafía y Primer Congreso Latinoamericano de Paleontología 2:363-368.

Churchill, M., A. Berta, y T. Deméré. 2012. The systematics of right whales (Mysticeti: Balaenidae). Marine Mammal Science 28:497-521. 
Cifelli, R. L. 1982. The petrosal structure of Hyopsodus with respect to that of some other ungulates, and its phylogenetic implications. Journal of Paleontology 56:795-805.

Cione, A. L. 1978. Aportes paleoictiológicos al conocimiento de la evolución de las paleotemperaturas en el área austral de América del Sur durante el Cenozoico. Aspectos zoogeográficos y ecológicos conexos. Ameghiniana 15:183-208.

Cione, A. L. 1986. A new Megascyliorhinus (Chondrichthyes, Galeomorphii) from the middle Tertiary of Patagonia. Journal of Vertebrate Paleontology 6:105-112.

Cione, A. L., y M. A. Cozzuol. 1990. Reidentification of Portheus patagonicus Ameghino, 1901, a supposed fish from the middle Tertiary of Patagonia, as a delphinoid cetacean. Journal of Paleontology 64:451-453.

Cione, A. L., E. P. Tonni. 1995. Chronostratigraphy and "Land mammal-ages" in the Cenozoic of southern South America: principles, practices and the "Uquian" problem. Journal of Paleontology 69:135-159.

Cione, A. L., M. M. Azpelicueta, M. Bond, A. Carlini, J. Casciotta, M. A. Cozzuol, M. de la Fuente, Z. Gasparini, F. Goin, J. Noriega, G. Scillato-Yané, L. Soibelzon, E. Tonni, D. Verzi, y M. G. Vucetich. 200o. Miocene vertebrates from Entre Ríos province, Argentina. Serie Correlación Geológica 14:191-238.

Cione, A. L., y M. M. Azpelicueta. 2002. An oplegnathid fish from the Miocene of Patagonia. Geobios $35: 367-373$.

Cione, A. L., M. M. Azpelicueta, J. R. Casciotta, y M. T. Dozo. 2005. Tropical freshwater teleosts from Miocene beds of Eastern Patagonia, Southern Argentina. Geobios 38:29-42.

Cione, A. L., J. Mennucci, L. Pérez, y M. J. Barla. 20o8. Megascyliorhinus trelewensis (Neoselachi) in the upper Miocene of Paraná, central-eastern Argentina. Misceláena INSUGEO 17:41-48.

Cione, A. L., M. A. Cozzuol, M. T. Dozo, y C. Acosta Hospitaleche. 2011. Marine vertebrate assemblages in the southwest Atlantic during the Miocene. Biological Journal of the Linnean Society 103:423-440. 
Cope, E. D. 1869. Systematic synopsis. En: On the cetaceans of the western coast of North America. Scammon, C. M., editor. Proceedings of the Academy of Natural Sciences of Philadelphia 21:1363.

Cozzuol, M. A. 1985. The odontoceti of the "Mesopotamiense" of the Paraná River Ravines. Systematic Review. Investigations on Cetacea 17:39-54.

Cozzuol, M. A., G. Humbert Lan, P. Puerta, M. A. Ferreiro, y R. Taylor. 1990. Hallazgos recientes de vertebrados marinos en el área de Puerto Madryn y Valle Inferior del río Chubut, Chubut, Argentina. Ameghiniana 26:242.

Cozzuol, M. A. 1993. Mamíferos acuáticos del Mioceno tardío de Argentina. Sistemática, evolución y biogeografía. Tesis doctoral. Universidad Nacional de La Plata, Facultad de Ciencias Naturales y Museo, La Plata 148pp.

Cozzuol, M. A. 1996. The record of the Aquatic Mammals in Southern South America. Munchner Geowissenschaftliche Abhandlungen (A) 30:321-342.

Cozzuol, M. A. 2001. A "northern" seal from Miocene from Argentina: implications for phocid phylogeny and biogeography. Journal of Vertebrate Paleontology 21:415-421.

Cranford, T. W., M. Amundin, y K. S. Norris. 1996. Functional morphology and homology in the odontocete nasal complex: implications for sound generation. Journal of Morphology 228:223285 .

Cranford, T. W. 200o. In search of impulse sound sources in odontocetes. En: Hearing by whales and dolphins. Au, W.W.L., Popper, A. N., Fay, R. R., editors. New York. Springer P:109-155.

Cranford, T. W., y M. Amundin. 2004. Biosonar pulse production in odontocetes: the state of our knowledge. En: Echolocation in bats and dolphins. Thomas, J. A., Moss, C., Vater, M., editors. Chicago. University Press P:26-59.

Cuvier, G. 1823. Recherches sur les ossemens fossiles, où l'on rètablit les caractères de plusieurs animaux dont les révolutions du globe ont détruit les espéces. Paris: Dufour et d'Ocagne P:308-396. 
Damuth, J., y B. J. MacFadden. 1990. Body Size in Mammalia Paleobiology: Estimation and Biological Implications. Cambridge University Press 391pp.

Darwin, C. 1846. Geological observations of coral reefs, volcanic islands and on South America. Londres 279pp.

Dawson, W. W. 1980. The cetacean eye. En: Cetacean behavior. Herman, L. M., editor. New York. John Wiley and Sons P:53-100

de Buffrénil, V., A. de Ricqlès, C. Ray, y D. Domning. 1990. Bone histology of the ribs of the archaeocetes (Mammalia: Cetacea). Journal of Vertebrate Paleontology 10:455-466.

Dehnhardt, G. 2002. Sensory systems. En: Marine mammal biology. Hoelzel, R., editor. Oxford, UK. Blackwell Publishing Company P:116-141.

Dellman, H. D. 1994. Histología Veterinaria. Editorial Acribia, Zaragoza, España.

del Río, C. J. 1988. Bioestratigrafía y Cronoestratigrafía de la Formación Puerto Madryn (Mioceno Medio), provincia del Chubut, Argentina. Anales de la Academia Ciencias Exactas, Físicas y Naturales, Buenos Aires 40:231-254.

del Río, C. J. 1990. Composición, origen y significado paleoclimático de la malacofauna "Entrerriense" (Mioceno medio) de la Argentina. Anales de la Academia Nacional de Ciencias Exactas, Físicas y Naturales 42:207-226.

del Río, C. J. 1991. Revisión sistemática de los bivalvos de la Formación Paraná (Mioceno medio), provincia de Entre Ríos, Argentina. Monografías de la Academia Nacional de Ciencias Exactas, Físicas y Naturales 7:11-90.

del Río, C. J. 200o. Malacofauna de las Formaciones Paraná y Puerto Madryn (Mioceno marino, Argentina): su origen, composición y significado bioestratigráfico. En: Aceñolaza, F.G., Herbst, R., (Eds.), El Neógeno de Argentina: Serie Correlación Geológica, vol. 14:77-101.

del Río, C. J. 2004. Tertiary Marine Molluscan Assemblages of Eastern Patagonia (Argentina): a Biostratigraphic Análisis. Journal of Paleontology 78:1097-1122. 
del Río, C. J., S. A. Martínez, y R. A. Scasso. 2001. Nature and origin of spectacular marine Miocene Shell beds of Northeastern Patagonia (Argentina): paleoecological and bathymetric significance. Palaios 16:3-25.

Deméré, T. A., A. Berta, y M. R. McGowen. 2005. The taxonomic and evolutionary history of fossil and modern balaenopteroid mysticetes. Journal of Mammalian Evolution 12:99-143.

Deméré, T., y A. Berta. 2008. Skull anatomy of the Oligocene toothed mysticete Aetiocetus weltoni (Mammalia; Cetacea): implications for mysticete evolution and functional anatomy. Zoological Journal of the Linnean Society 154:308-352.

Deméré, T. A., M. R. McGowen, A. Berta, y J. Gatesy. 2008. Morphological and molecular evidence for a stepwise evolutionary transition from teeth to baleen in mysticete whales. Systematic Biology 57:15-37.

de Ricqlès, A., y V. de Buffrénil. 2001. Bone histology, heterochronies and the return of tetrapods to life in water: where are we? En: Secondary adaptation to life in water. Mazin, J.-M., de Buffrénil, V., editors.Verlag Dr. Friedrich Pfeil, München P:289-306.

Desmoulins, A. 1822. Baleine. Dictionnaire Classique d'Histoire Naturelle P:155-165.

D’Orbigny, A. 1842. Voyage dans l’Amérique méridionale. P. Bertrand, Paris p. 188.

Dozo, M. T., P. Bouza, A. Monti, L. Palazzesi, V. Barreda, G. Massaferro, R. A. Scasso, y C. P. Tambussi. 2010. Late Miocene continental biota in Northeastern Patagonia (Península Valdés, Chubut, Argentina). Palaeogeography, Palaeoclimatology, Palaeoecology 297:100-109.

Ekdale, E. G., A. Berta, y T. A. Deméré. 2011. The comparative osteology of the petrotympanic complex (ear region) of extant baleen whales (Cetacea: Mysticeti). PloSOne 6(6) doi:10.1371/journal.pone.0021311.

Ellerman, J. R., y T. C. S. Morrisson-Scott. 1951. Checklist of Palaearctic and Indian Mammals 1758 to 1946. Trustees British Museum (Nat. Hist.), London 81opp.

Emerson, S. B., y D. M. Bramble. 1993. Scaling, allometry, and skull design. En: Functional and 
Evolutionary mechanisms (Volume 3). Hanken, J., y Hall, B. K., editors. The University of Chicago Press: Chicago and London P: 384-421.

Escapa, I. H., y D. Pol. 2011. Dealing with incompleteness: new advances for the use of fossils in phylogenetic analysis. Palaios 26:121-124.

Eschricht, D. F., y J. Reinhardt. 1866. On the Greenland right whale (Balaena mysticetus). En: Recent Memoirs on the Cetacea. Flower, W. H., editor. Ray Society, London, Vol. 40:143pp.

Fernández, M. S., F. Archuby, M. Talevi, y R. Ebner. 2005. Ichthyosaurian eyes: paleobiological information content in the sclerotic ring of Caypullisaurus (Ichthyosauria, Opthalmosauria). Journal of Vertebrate Paleontology 25:330-337.

Feruglio, E. 1949. Descripción geológica de la Patagonia 2. Yacimientos Petrolíferos Fiscales, Buenos Aires 349pp.

Fish, F. E., y J. M. Battle. 1995. Hydrodynamic design of the humpback flipper. Journal of Morphology 225:51-6o.

Fitzgerald, E. M. G. 2006. A bizarre new toothed mysticete (Cetacea) from Australia and the early evolution of baleen whales. Proceeding of the Royal Society of London. Ser. B 273:2955-63.

Fitzgerald, E. M. G. 2010. The morphology and systematics of Mammalodon colliveri (Cetacea: Mysticeti), a toothed mysticete from the Oligocene of Australia. Zoological Journal of the Linnean Society 158:367-476.

Fitzgerald, E. M. G. 2011. Archaeocete-like jaws in a baleen whale. Biology letters 8:94-6.

Fledelius, H. C., y A. C. Christensen. 1996. Reappraisal of the human ocular growth curve in fetal life, infancy, and early childhood. British Journal of Ophthalmology 80:918-921

Fleischer, G. 1976. Hearing in extinct cetaceans as determined by cochlear structure. Journal of Paleontology 50:133-152.

Flower, W. H. 1865. Notes on the skeletons of whales in the principal museums of Holland and 
Belgium, with descriptions of two species apparently new to Science 1864:384-420.

Flower, W. H. 1867. Description of the skeleton of Inia geoffrensis and the skull of Pontoporia blainvillei, with remarks on the systematic position of these animals in the Order Cetacea. Transactions of the Zoological Society of London 6:87-116.

Flower, W. H. 1883a. On whales, past and present, and their probable origin. Nature 28:199-202.

Flower, W. H. 1885. List of specimens of Cetacea in the Zoological Department of the British Museum. British Museum (Natural History), London, UK 36pp.

Flynn, J. J., y C. C. Swisher. 1995. Cenozoic South American Land Mammal Ages: correlation to global geochronologies. En: Geochronology, time scales and global stratigraphic correlation. Berggren, W. A., Kent, D. V., y Aubry, M. P., editors. Society of Economic Mineralogists and Geologists Special Publication, Vol. 54:317-333.

Ford, T. J., A. J. Werth, y J. C. George. 2013. An intraoral thermoregulatory organ in the bowhead whale (Balaena mysticetus), the corpus cavernosum maxillaris. Anatomical Record 296:701-8.

Fordyce, R. E. 1980. Whale evolution and Oligocene southern ocean environments. Palaeogeography, Palaeoclimatology, Palaeoecology 31:319-336.

Fordyce, R. E. 1989. Origins and evolution of Antarctic marine mammals. En: Origins and evolution of the Antarctic biota. Crame, J. A., editor. Geological Society Special Publication 47:269-281.

Fordyce, R. E. 1992. Cetacean evolution and Eocene/Oligocene environments. En: EoceneOligocene climatic and biotic evolution. Prothero, D. R., Berggren, W. A., editors. Princeton, NJ: Princeton University Press P:368-381.

Fordyce, R. E., L. G. Barnes, y N. Miyazaki. 1994. General aspects of the evolutionary history of whales and dolphins. The Island Arc P:373-391.

Fordyce, R. E., y C. de Muizon. 2001. Evolutionary history of cetaceans: a review. En: Secondary adaptations of tetrapods to life in water. Mazin, J.-M., y de Buffrenil, V., editors. Proceeding of the International Meeting, Poitiers, 1996. Munich: Verlag Dr. Friederich Pfeil P:169-233 
Fordyce, R. E. 2002. Oligocene origin of skim-feeding right whales: a small archaeic balaenid from New Zealand. Journal of Vertebrate Paleontology 22:54(a).

Fordyce, R. E. 2003a. Cetacea evolution and Eocene-Oligocene oceans revisited. En: From Greenhouse to Icehouse. The Marine Eocene-Oligocene Transition. Prothero, D. R., Ivany, L. C., y Nesbitt, E., editors. Columbia University Press, New York P:154-170 .

Fordyce, R. E. 2003b. Early crown-group Cetacea in the southern ocean: the toothed archaic mysticete Llanocetus. Journal of Vertebrate Paleontology 23:50A.

Fordyce, R. E. 2009a. Cetacean evolution. En: Encyclopedia of Marine Mammals. Perrin, W. F., Thewissen, J. G. M., Würsig, B., editors. San Diego. Elsevier P:201-207.

Fordyce, R. E. 20o9b. Cetacean fossil record. En: Encyclopedia of marine mammals. Perrin, W. F., Thewissen, J. G. M., Würsig, B., editors. San Diego, CA. Elsevier P:207-215.

Fordyce, R. E., y F. G. Marx. 2012. The pygmy right whale Caperea marginata: the last of the cetotheres. Proceedings. Biological sciences / The Royal Society, 280(1753), 20122645.

Fraser, F. C., y P. E. Purves. 1960. Hearing in cetaceans. Bulletin of the British Museum (Natural History), Zoology 7 1:14opp.

Frenguelli, J. 1927. El Entrerriense del Golfo Nuevo en el Chubut: Córdoba. Boletín de la Academia Nacional de Ciencias de Córdoba 29:119-170.

Frenguelli, J. 1935. El perfil de Gaiman (Chubut). Notas del Museo de La Plata, Geología 1:177-192.

Fritsches, K. A., R. W. Brill, y E. J. Warrant. 2005. Warm eyes provide superior vision in swordfishes. Current Biology 15:55-58.

Gaines, C. A., M. P. Hare, S. E. Beck, y H. C. Rosenbaum. 2005. Nuclear markers confirm taxonomic status and relationships among highly endangered and closely related right whale species. Proceedings. Biological Sciences / The Royal Society 272:533-42.

Gambell, R. 1970. Weight of a sperm whale, whole and in parts. South African Journal of Science 
66:225-27.

García, E. 1970. Ostracodes du Miocene de la Republique Argentine (Entrerriense de la Peninsule Valdez). IV Colloque Africain de Micropaleontologie, Abidjan, Côte D'Ivoire P:391-417.

Gatesy, J., J. H. Geisler, J. Chang, C. Buell, A. Berta, R. W. Meredith, M. S. Springer, y M. R. McGowen. 2013. A phylogenetic blueprint for a modern whale. Molecular Phylogenetics and Evolution 66:479-506.

Geisler, J. H., y Z. Luo. 1996. The petrosal and inner ear of Herpetocetus sp. (Mammalia: Cetacea) and their implications for the phylogeny and hearing of archaic mysticetes. Journal of Paleontology 70:1045-1066.

Geisler, J. H., y Z. Luo. 1998. Relationships of Cetacea to terrestrial ungulates and the evolution of cranial vasculature in Cete. En: The Emergence of Whales. Thewissen, J. G. M., editor. New York: Plenum P:163-212.

Geisler, J. H., y M. D. Uhen. 2003. Morphological support for a close relationship between hippos and whales. Journal of Vertebrate Paleontology 23:991-96.

Geisler, J. H., y M. D. Uhen. 2005. Phylogenetic relationships of extinct cetartiodactyls: results of simultaneous analyses of molecular, morphological, and stratigraphic data. Journal of Mammalian Evolution 12:145-6o.

Geisler, J. H., y J. M. Theodor. 2009. Hippopotamus and whale phylogeny.Nature 458:E1-4

Geisler, J. H., M. R. McGowen, G. Yang, y J. Gatesy. 2011. A supermatrix analysis of genomic, morphological, and paleontological data from crown Cetacea. BMC Evolutionary Biology 11:33pp.

Geraci, J. R., y V. J. Lounsbury. 1993. Specimen and data collection. En: Marine Mammals Ashore: A Field Guide for Strandings. Geraci, J. R., y Lounsbury, V. J., editors. Texas A\&M Sea Grant Program, Galveston P:175-228.

Gill, T. 1871. Synopsis of the primary subdivisions of the cetaceans. Communications of the Essex 
Institute 6:121-126.

Gill, T. 1873. On the genetic relations of the cetaceans and the methods involved in discovery. American Naturalist 7:19-29.

Gingerich, P. D., y D. E. Russell. 1981. Pakicetus inachus, a new archaeocete (Mammalia, Cetacea) from the earlymiddle Eocene Kuldana Formation of Kohat (Pakistan).Contribution Museum of Paleontology University of Michigan 25:235-46.

Gingerich, P. D., S. M. Raza, M. Arif, M. Anwar, y X. Zhou. 1994. New whale from the Eocene of Pakistan and the origin of cetacean swimming. Nature 368:844-47

Gingerich, P. D., M. Arif, W. C. Clyde. 1995. New archaeocetes (Mammalia, Cetacea) from the middle Eocene Domanda Formation of the Sulaiman Range, Punjab (Pakistan). Contribution Museum of Paleontology University of Michigan 29:291-330.

Gingerich, P. D. 1998. Paleobiological perspectives on Mesonychia, Archaeoceti, and the origin of whales. En: Emergence of Whales: Evolutionary Patterns in the Origin of Cetacea. Thewissen, J. G. M., editor. Plenum, New York P:423-449.

Gingerich, P. D., M. U. Haq, I. S. Zalmout, I. H. Khan, y M. S. Malakani. 20o1. Origin of whales from early artiodactyls: hands and feet of Eocene Protocetidae from Pakistan. Science 293:22392242.

Gingerich, P. D., M. U. Haq, W. von Koenigswald, W. J. Sanders, B. H. Smith, y I. S. Zalmout. 2009. New protocetid whale from the Middle Eocene of Pakistan: Birth on land, precocial development, and sexual dimorphism. PLoS One 4:e4366

Goddé-Jolly, D., y J.-M. Dufier. 1994. Oftalmología pediátrica. Masson, Barcelona P:479

Gol'din, P., D. Startsev, y T. Krakhmalnaya. 2013a. The anatomy of Cetotherium riabinini Hofstein, 1948, a baleen whale from the late Miocene of Ukraine. Acta Palaeontológica Polonica. En Prensa. http://dx.doi.org/10.4202/app.2012.0107

Gol'din, P., y E. Zvonok. 2013b. Basilotritus uheni, a new cetacean (Cetacea, Basilosauridae) from the 
Late Middle Eocene of Eastern Europe. Journal of Paleontology 87:254-268.

Goloboff, P. A. 1993. Estimating character weights during tree search. Cladistics 9:83-91.

Goloboff, P. A., J. S. Farris, M. Källersjö, B. Oxelman, M. J. Ramírez, y C. A. Szumik. 2003. Improvements to resampling measures of group support. Cladistics 19:324-332.

Goloboff, P. A., J. S. Farris, y K. Nixon. 2008a. TNT, a free program for phylogenetic analysis. Cladistics 24:774-786.

Goloboff, P. A., J. S. Farris, y K. Nixon. 20o8b. TNT: Tree Analysis Using New Technology, version 1.1 (Willi Hennig Society edition). Available at http://www.zmuc.dk/public/phylogeny/tnt. Acceso Diciembre 2012.

Goloboff, P. A., J. M. Carpenter, J. S. Arias, D. Rafael, y M. Esquivel. 2008c. Cladistics Weighting against homoplasy improves phylogenetic analysis of morphological data sets. Cladistics 24:758-773.

Gondar, D. 1975. La presencia de cetáceos Physeteridae en el Terciario Suprior ('Rionegrense') de la Provincia de Rio Negro. Actas del Primer Congreso Argentino de Paleontología y Biostratigrafía Tucumán, Argentina 2:349-354.

Gray, J. E. 1825. Outline of an attempt at the disposition of the Mammalia into tribes and families with a list of the genera apparently appertaining to each tribe. Philosophical Annals 26:337-344.

Gray, J. E. 1843. List of mammalian hitherto recorded as found in New Zealand. En: Travels in New Zealand; with contributions to the geography, geology, botany, and natural history of that country Diffenback, editor. J. Murray, London, Vol.2.

Gray, J. E. 1864a. On the Cetacea which have been observed in the seas surrounding the British Islands. Proceedings of the Zoological Society of London 1864:195-248.

Gray, J. E. 1864b. Notes on the Whalebone-Whales; with a Synopsis of the Species. The Annals and Magazine of Natural History 14:345-353. 
Gray, J. E. 1865. Notes on the whales of the Cape. Proceeding of the Zoological Society of London. 1865:357-359.

Gray, J. E. 1866. Catalogue of Seals and Whales in the British Museum. Taylor and Francis P:402.

Gray, J. E. 1868. Synopsis of the species of whales and dolphins in the Collection of the British Museum. London, B. Quaritch P: 1-10.

Gray, J. E. 1873. Remarks on some of the species in the foregoing paper. Annals and Magazine of Natural History (Series 4) 11:107-112.

Gray, J.E. 1874. On the bladebones of Balaena hectori and Megaptera novaezelandiae. Annals and Magazine of Natural History 4:56-58

Gray, N. M., K. Kainec, S. Madar, L. Tomko, y S. Wolfe. 2007. Sink or swim? Bone density as a mechanism for buoyancy control in early cetaceans. Anatomical Record 290:638-53.

Haller, M. J. 1978. Estratigrafía de la región al poniente de Puerto Madryn, Provincia de Chubut, República Argentina. Actas del VI Congreso Geológico Argentino, Buenos Aires 1:285-297.

Haller, M. J., y J. E. Mendía. 1980. Las sedimentitas del ciclo Patagoniano en el litoral atlántico norpatagónico. Coloquio "R. Wichmann" (Buenos Aires, 28 octubre, 1980). Asociación Geológica Argentina. En: Mendía, J. E., y Bayarsky, A. Estratigrafía del Terciario en el valle inferior del río Chubut. VIII Congreso Geológico Argentino (San Luis, 20-26, septiembre, 1981). Actas III: 593-606.

Haller, M. J., A. J. Monti, y C. M. Meister. 2001. Hoja Geológica 4363-I Península Valdés, Provincia del Chubut. Programa Nacional de Cartas Geológicas de la República Argentina, 1:250.ooo. Boletín N²66, pp. 1-34; 1 mapa. Servicio Geológico Minero Argentino. Buenos Aires. 2001. Península Valdés Provincia del Chubut Boletín del Servicio de Geología y Minería Nacional 184:41pp.

Hammer, Ø., D. A. T. Harper, y P. D. Ryan. 2001. PAST: Paleontological statistics software package for education and data analysis. Palaeontologia electronica $\quad$ 4:9.

Hatfield, J.R., Samuelson, D. A., Lewis, P.A., Chisholm, M. 2003. Structure and presumptive function of the iridocorneal angle of the West Indian manatee (Trichechus manatus), short-finned pilot 
whale (Globicephala macrorhynchus), hippopotamus (Hippopotamus amphibius), and the African elephant (Loxodonta africana). Veterinary Ophthalmology 6:35-43

Hemilä, S., y T. Reuter. 2008. The physics and biology of olfaction and taste. Sensory evolution on the threshold: adaptations in secondarily aquatic vertebrates. University of California Press, Berkeley P:29-33.

Henry, R. W., J. T. Haldiman, T. F. Albert, W. G. Henk, Y. Z. Abdelbaki, y D. W. Duffield. 1983. Gross anatomy of the respiratoy system of the bowhead whale, Balaena mysticetus. The Anatomical Record 207:435-449.

Herbst, R. 2000. La Formación Ituizangó (Plioceno). Estratigrafía y distribución. En "El neógeno Argentino" INSUGEO. Serie de correlación geológica 14:181-190.

Herrera, L. Y. 2012. Análisis morfológico y paleobiológico de Cricosaurus araucanensis (Gasparini y Dellapé) (Crocodyliformes: Metriorhynchidae). Tesis Doctoral. Universidad Nacional de La Plata, Argentina P:326.

Heyning, J. E., J. G. Mead. 1990. Evolution of the nasal anatomy of cetaceans. En: Sensory abilities of cetaceans: laboratory and field evidence. Thomas, J. A., Kastelein, R. A., editors. New York: Plenum P:67-8o.

Hilgen, F. J., L.J. Lourens, y J. A. Van Dam. 2012. The Neogene Period. En: The Geologic Time Scale. Elsevier: Boston P:923-978.

Hone, D. W. E., y M. J. Benton. 2005. The evolution of large size: how does Cope's Rule work? Evolution 20:4-6.

Howland, H. C., S. Merola, y J. R. Basarab. 2004. The allometry and scaling of the size of vertebrate eyes. Vision Research 44:2043-2065

Huggenberger, S., M. A. Rauschmann, T. J. Vogl, y H. H. A. Oelschläger. 20o9. Functional morphology of the nasal complex in the harbor porpoise (Phocoena phocoena 1.). Anatomical Record 292:902-20. 
Hughes, A. 1977. The topography of vision in mammals of contrasting life style: comparative optics and retinal organization. En:. The visual system in vertebrates, Vol. VII/5. Crescitelli, F. editor. Berlin: Springer Verlag P:613-756.

Humphries, S., y G. D. Ruxton. 2002. Why did some ichthyosaurs have such large eyes? The Journal of Experimental Biology 205:43-441.

Hunter, J. P. 1998. Key innovations and the ecology of macroevolution. Trends in Ecology and Evolution 13:31-36

Johnston, C., T. Deméré, A. Berta, J. Yonas, y J. St. Leger. 2009. Observations on the musculoskeletal anatomy of the head of a neonate gray whale (Eschrichtius robustus). Marine Mammal Science 26:186-194.

Kaliszewska, Z., J. Seger, V. J. Rowntree, S. Barco, R. Benegas, P. Best, M. Brown, R. J. Brownell, A. Carribero, R. Harcourt, A. Knowlton, K. MarshallTilas, N. J. Patenaude, M. Rivarola, C. M. Schaeff, M. Sironi, W. Smith, y T. K. Yamada. 2005. Population histories of right whales (Cetacea: Eubalaena) inferred from mitochondrial sequence diversities and divergences of their whale lice (Amphipoda: Cyamus). Molecular Ecology 14:3439-3456.

Kastelein, R. A., R. C. V. J. Zweypfennig, y H. Spekreijse. 1990. Anatomical and histological characteristics of the eyes of a month-old and an adult harbor porpoise (Phocoena phocoena). En: Sensory abilities of Cetaceans. Thomas. J. A., y Kastelein, R. A., editors. New York: Plenum $P: 463-480$.

Kasuya, T. 1973. Systematic Consideration of Recent Toothed Whales Based on the Morphology of the Tympano-periotic Bone. Scientific Reports of the Whales Research Institute 25: 1-103.

Kay, R. F., y E. C. Kirk. 200o. Osteological evidence for the evolution of activity pattern and visual acuity in primates. American Journal of Physical Anthropology 113:235-262.

Kellog, R. 1936. A Review of the Archaeoceti. Carnegie Institution ofWashington Special Publication 482:1-366. 
Kenney, R. D. 2009. Right whales: Eubalaena glacialis, E. japonica and E. australis. En: Encyclopedia of marine mammals. Perrin, W. F., Thewissen, J.G.M., Würsig, B., editors. San Diego, CA: Elsevier P:962-969.

Ketten, D. R., y D. Wartzok. 1990. Three-dimensional reconstructions of the dolphin ear. En: Sensory abilities of cetaceans. Kastelein, R., editor. New York: Plenum Press P:81-105

Ketten, D. R. 1992. The marine mammal ear: specializations for aquatic audition and echolocation. En: The evolutionary biology of hearing. Webster, D., Fay, R. R., Popper, A. N., editors. New York: Springer-Verlag P:717-754.

Ketten, D. R. 1994. Functional analyses of whale ears: adaptations for underwater hearing. I.E.E.E. Proceedings Underwater Acoustics 1:264-270.

Ketten, D. R., M. W. Skinner, G. Wang, M. W. Vannier, G. A. Gates, y J. G. Neely. 1998. In vivo measures of cochlear length and insertion depth of nucleus cochlear implant electrode arrays. Annals of Otology Rhinology \& Laryngololy 107:16pp.

Ketten, D. R. 200o. Cetacean ears. En: Hearing by whales and dolphins. Fay, R. R., editor. New York: Springer-Verlag P:43-108.

Kiltie, R. A. 200o. Scaling of visual acuity with body size in mammals and birds. Functional Ecology $14: 226-234$.

Kimura, T. 2002. Feeding strategy of an Early Miocene cetothere from the Toyama and Akeyo Formations, central Japan. Paleontological Research 6:179-189.

Kimura, T., y T. Ozawa. 2002. A New Cetothere (Cetacea: Mysticeti) From the Early Miocene of Japan. Journal of Vertebrate Paleontology 22:684-702.

Kimura, T., N. Ken, F. Takashi, y Y. Hasegawa. 2007. A new species of Eubalaena (Cetacea: Mysticeti: Balaenidae) from the Gonda Formation (latest Miocene-Early Pliocene) of Japan. Bulletin of Gunma Museum of Natural History 11:15-27.

Kimura, T. 2009. Review of the fossil balaenids from Japan with a re-description of Eubalaena 
shinshuensis (Mammalia, Cetacea, Mysticeti). Quaderni del Museo di Storia Naturale di Livorno 22:3-21.

Kimura, T., y Y. Hasegawa. 2010. A new baleen whale (Mysticeti: Cetotheriidae) from the Earliest Late Miocene of Japan and a reconsideration of the phylogeny of cetotheres. Journal of Vertebrate Paleontology 30:577-591.

Klanjscek, T., R. M. Nisbet, H. Caswell, y M. G. Neubert. 2007. A model for energetic and bioaccumulation in marine mammals with applications to the right whale. Journal of Applied Ecology 17:2233-2250.

Kraus, S. D., K. E. Moore, y C. A. Price, et al. 1986. The use of photographs to identify individual North Atlantic right whales (Eubalaena glacialis). En: Right whales: past and present status, Reports of the international whaling commission (Special Issue 10). Brownell, R. L. Jr., Best, P. B., Prescott, J.H., editors. International Whaling Commission, Cambridge P:145-151.

Lambertsen, R., N. Ulrich, y J. Straley. 1995. Frontomandibular stay of Balaenopteridae: a mechanism for momentum recapture during feeding. Journal of Mammalogy 76:877-899.

Lambertsen, R. H., y R. J. Hintz. 2004. Maxillomandibular cam articulation discovered in North Atlantic minke whale. Journal of Mammalogy 85:446-452.

Lambertsen, R. H., K. J. Rasmussen, W. C. Lancaster, y R. J. Hintz. 2005. Functional Morphology of the mouth of the bowhead whale and its implications for conservation. Journal of Mammalogy $86: 342-352$.

Landon, D. B., C. A. Waite, R. O. Peterson, y L. D. Mech. 1998. Evaluation of age determination techniques for gray wolves. Journal of Wildlife Management 62:674-682.

Lawrence, B., y W. E. Schevill. 1956. The functional anatomy of the delphinid nose. Bulletin of the Museum of Comparative Zoology 114:103-151.

Lesson, R. P. 1828. Cétacés. Volume 1 in complement des oeuvres de Buffon ou Histoire Naturelle des animaux rares découverts par les naturalist et les voyageurs depuis la mort de Buffon. Paris. 
Lillie, D. G. 1910. Observations on the anatomy and general biology of some members of the larger Cetacea. In Proceedings of the Zoological Society of London 80:769-792.

Linnaeus, C. 1758. Systema Naturae per regna tria naturae, secundum classis, ordines, genera, species cum characteribus, differentiis, synonymis, locis. 1oth edition, Volume 1. Laurentii Salvii, Stockholm, Sweden.

Lockyer, C. 1976. Body weights of some species of large whales. Journal du Conseil /Conseil Permanent International pour l'Exploration de la Mer 36:259-273.

Lockyer, C. H., L. C. McConnell, y T. D. Waters. 1984. The biochemical composition of fin whale blubber. Canadian Journal of Zoology 62:2553-2562.

Luo, Z-X., y P. D. Gingerich. 1999. Terrestrial Mesonychia to aquatic Cetacea: transformation of the basicranium and evolution of hearing in whales. University of Michigan Museum of Paleontology. Papers in Paleontology 31:1-98.

Lydekker, R. 1893. Cetacean skull from Patagonia. Anales del Museo de La Plata, Paleontología Argentina 2:14pp.

Lydekker, R. 1894. Cetacean skulls from Patagonia. Anales del Museo de la Plata 2:1-13.

Mackintosh, N. A., y J. F. G. Wheeler. 1929. Southern blue and fin whales. Discovery Reports 1:257-510.

Madar, S. I. 2007. The postcranial skeleton of early Eocene pakicetid cetaceans. Journal of Paleontology 81:176-200.

Malumián, N., y V. Masiuk. 1973. Asociaciones Foraminiferológicas fósiles de la República Argentina. V Congreso Geológico Argentino (Buenos Aires), Actas 3:433-453.

Malumián, N., 1999. La sedimentación en la Patagonia extraandina. En Geología Argentina. R. Caminos, editor. Anales del Instituto de Geología y Recursos Minerales 29:557-578.

Marino, L., M. D. Uhen, N. D. Pyenson, y B. Frolich. 2003. Reconstructing cetacean brain evolution 
using computed tomography. Anatomical Record 272B:107-117.

Marino, L., D. McShea, y M. S. Uhen. 2004. The origin and evolution of large brains in toothed whales. Anatomical Record 281A:1247-1255

Martínez, S., 1994. Bioestratigrafía (invertebrados) de la Formación Camacho (Mioceno, Uruguay). Tesis de doctorado inédita. Universidad de Buenos Aires, Argentina 346pp.

Martínez, S., y C. del Río. 2002. Las provincias malacológicas miocenas y recientes del Atlántico sudoccidental. Anales de Biología 24:121-130.

Marx, F. G. 2010. The More the Merrier? A large cladistic analysis of mysticetes, and comments on the transition from teeth to baleen. Journal of Mammalian Evolution 18:77-100.

Marx, F. G., M. R. Buono, R. E. Fordyce, y R. W. Boessenecker. 2013. Juvenile morphology: a clue to the origins of the most mysterious of mysticetes? Naturwissenschaften 100:257-61.

Masiuk, V., D. Becker, y A. García Espiasse. 1976. Micropaleontología y Sedimentología del pozo YPF. ChPV. es-1 (Península de Valdés) República Argentina, Importancia y Correlaciones. ARPEL, XXIV Reunión a nivel de expertos, Buenos Aires 2opp.

Mass, A. M., AYa. Supin. 1997. Ocular anatomy, retinal ganglion cell distribution, and visual resolution in the gray whale, Eschrichtius gibbosus. Aquatic Mammals 23:17-28.

Mass, A. M., y AYa. Supin. 2002. Visual field organization and retinal resolution of the beluga, Delphinapterus leucas. Aquatic Mammals 28:241-250.

Mass, A. M. y AYa. Supin. 2007. Adaptive features of aquatic mammals' eye. The Anatomical Record: 290:701-715.

Mäther, L. M., L. Litherland, y K. A. Fritsches. 2007. An anatomical study of the visual capabilities of the green turtle, Chelonia mydas. Copeia 1:169-179.

McGowen, M. R., M. Spaulding, y J. Gatesy. 2009. Divergence date estimation and a comprehensive molecular tree of extant cetaceans. Molecular Phylogenetics and Evolution 53:891-906. 
McLeod, S. A., F. C. Jr Whitmore, y L. G. Barnes. 1993. Evolutionary relationships and classification. En: The Bowhead whale. Burns, J. J., Montague, J. J., y Cowles, C. J., editors. The Society for Marine Mammalogy, Special Publication P:45-70.

Mead, J. G. 1975. Anatomy of the External Nasal Passages and Facial Complex in the Delphinidae (Mammalia : Cetacea). Smithsonian Contributions to Zoology 207:1-35.

Mead, J. G., y R. L. Brownell. 2005. Order Cetacea. Mammalian Species of the World P:723-743.

Mead, J. G., R. E. Fordyce. 2009. The therian skull. A lexicon with emphasis on the odontocetes. Smithsonian Contributions to Zoology 627:1-248.

Mendía, J. E., y A. Bayarsky. 1981. Estratigrafía del Terciario del valle inferior del río Chubut. Actas 8 Congreso Geológico Argentino 3:593-603.

Miller, G. S. 1923. The telescoping of the cetacean skull. Smithsonian Miscellaneous Collection 76:1-71.

Miller, C., D. Reeb, P. Best, A. Knowlton, M. Brown, y M. Moore. 2011. Blubber thickness in right whales Eubalaena glacialis and Eubalaena australis related with reproduction, life history status and prey abundance. Marine Ecology Progress Series 438:267-283.

Miller, C., P. Best, W. Perryman, M. Baumgartner, y M. Moore. 2012. Body shape changes associated with reproductive status, nutritive condition and growth in right whales Eubalaena glacialis and E. australis. Marine Ecology Progress Series 459:135-156.

Mitchell, E. D. 1989. A new cetacean from the Late Eocene La Meseta Formation, Seymour Island, Antarctic Peninsula. Canadian Journal of Fisheries and Aquatic Sciences 46:2219-2235.

Montgelard, C., F. M. Catzeflis, y E. Douzery. 1997. Phylogenetic relationships of Artiodactyls and Cetaceans as deduced from the comparison of cytochrome $b$ and ${ }_{12} \mathrm{~S}$ rRNA mitochondrial sequences. Molecular Biology and Evolution. 14:550-559.

Moreno, F. P. 1892. Lijeros apuntes sobre dos géneros de cetáceos fósiles de la República Argentina. Revista del Museo de La Plata 3:393-400. 
Motani, R., B. M. Rothschild, y W. Jr. Wahl. 1999. Large eyeballs in diving ichthyosaurs. Nature 402:747.

Muller, O. F. 1776. Balaena glacialis. Zoologiae Danicae Prodromus auclort 7 pp.

Nagel, E. L., P. J. Morgane, W. L. McFarland y R. E. Galliano. 1968. Rete mirabile of dolphin: its pressure-dampening effect on cerebral circulation. Science 161:898-90o

Ninomiya, H., y E. Yoshida. 2007. Functional anatomy of the ocular circulatory system: vascular corrosion casts of the cetacean eye. Veterinary Ophthalmology10:231-238.

Nishiwaki, M. 1950. The body weight of whales. The Scientific Reports of the Whales Research Institute 4:184-209.

Nomina Anatómica Veterinaria. 2012. $5^{\circ}$ edición 4:184-209.

Noriega, J., A. L. Cione, y F. G. Aceñolaza. 2007. Shark tooth marks on Miocene balaenopterid cetacean bones from Argentina. Neues Jahrbuch für Geologie und Paläontologie 245:185-192.

Noriega, J. I., y F. L. Agnolin. 2008. El registro paleontológico de las Aves del "Mesopotamiense" (Formación Ituzaingó; Mioceno tardío-Plioceno) de la provincia de Entre Ríos, Argentina. Temas de la Biodiversidad del Litoral fluvial argentino III . INSUGEO, Miscelánea 17:271-290.

Noriega, J., y G. Cladera. 2008. First record of an extinct marabou stork in the Neogene of South America. Acta Palaeontologica Polonica 53:593-60o.

Noriega, J., C. Tambussi, M. Cozzuol. 2008. New material and the phylogenetic position of Cayaoa bruneti Tonni, an early Miocene anseriform (Aves) from Patagonia, Argentina. Neues Jahrbuch für Geologie und Paläontologie, Abhandlungen 249:271-28o

Norris, K. S. 1968. The evolution of acoustic mechanisms in odontocete cetaceans. En: Evolution and environment. Drake, E. T., editor. New Haven: Yale University Press P:297-324.

Norris, K. S. 1969. The echolocation of marine mammals. En: The biology of marine mammals. 
Andersen, H. T., editor. New York: Academic Press P:391-423.

Norman, R. J., y F. C. Fraser. 1938. Giant fishes, whales and dolphins. Putnam, London, U.K. P:376pp.

Novacek, M. J. 1993. Patterns of diversity in the mammalian skull. The skull 2 566pp.

Nummela, S., J. G. M. Thewissen, S. Bajpai, S. T. Hussain, y K. Kumar. 2004. Eocene evolution of whale hearing. Nature 430: 776-778.

Nummela, S., J. G. M. Thewissen, S. Bajpai, T. Hussain, y K. Kumar. 2007. Sound transmission in archaic and modern whales: anatomical adaptations for underwater hearing. Anatomical Record 290:716-33

Oelschläger, H. H. A., y J. S. Oelschläger. 2008. Brain. En: Encyclopedia of marine mammals, Second edition. Perrin, W. F., Wursig B., y Thewissen, J. G. M., editors. Elsevier, Amsterdam, Netherlands P:134-149.

Oftedal, O. T. 1993. The adaptation of milk secretion to the constraints of fasting in bears, seals, and baleen whales. Journal of Dairy Science 76:3234-3246.

Oftedal, O. T. 200o. Use of maternal reserves as a lactation strategy in large mammals. ProceedingsNutrition Society of London 59:99-106.

O'Leary, M. A., y M. D. Uhen. 1999. The time of origin of whales and the role of behavioral changes in the terrestrial-aquatic transition. Paleobiology 25:534-56.

O'Leary, M. A., y J. Gatesy. 2008. Impact of increased character sampling on the phylogeny of Cetartiodactyla (Mammalia): combined analysis including fossils. Cladistics 24:397-442.

Pagel, M. D. 2002. Novelty and key innovations. En: Encyclopedia of evolution. Vol. 2. Pagel, editor. Oxford University Press P:827-830.

Palazzesi, L., y V. Barreda. 2004. Primer registro palinológico de la Formación Puerto Madryn, Mioceno de la provincia del Chubut, Argentina. Ameghiniana 41:355-362. 
Palmer, T. S. 1904. Index generum mammalium: a list of the genera and families of mammals. North American Fauna 23:984pp.

Parks, S. E., D. R. Ketten, J. T. O’Malley, y J. Arruda. 2007. Anatomical predictions of hearing in the North Atlantic right whale. Anatomical Record 290:734-44.

Payne, R. S., y S. McVay. 1971. Songs of humpback whales. Science 173:585-597.

Payne, R., O. Brazier, E. M. Dorsey, J. S. Perkins, V. J. Rowntree, y A. Titus. 1983. External features in southern right whales (Eubalaena australis) and their use in identifying individuals. En: Communication and Behavior of Whales. AAAS Selected Symposia Series 76. Payne, R. editor. Westview Press, Colorado P: 371-445.

Pérez, L. M., A. L. Cione, M. Cozzuol, y A. N. Varela. 2011. A sperm whale (Cetacea: Physeteroidea) from the Paraná Formation (Late Miocene) of Entre Ríos, Argentina. Environment and taphonomy. Ameghiniana 48:648-654.

Perrin, W. F. 1975. Variation of Spotted and Spinner Porpoise (Genus Stenella) in the Eastern Tropical Pacific and Hawaii. Bulletin of the Scripps Institution of Oceanography 21:1-206

Perrin, W. F., J. G. M. Thewissen, y B. Würsig. 2009. Encyclopedia of marine mammals. $2^{\circ}$ Edición. San Diego, CA: Elsevier 1352pp.

Pfeiffer, C. J., y T. P. Kinkead. 1990. Microanatomy of retia mirabilia of bowhead whale foramen magnum and mandibular foramen. Acta Anatómica 139:141-150.

Picasso, M., C. Tambussi, y M. T. Dozo. 2009. Neurocranial and brain anatomy of a Late Miocene eagle (Aves, Accipitridae) from Patagonia. Journal of Vertebrate Paleontology 29:831-836.

Pierce, S. E., K. D. Angielczyk, y E. J. Rayfield. 2009. Shape and mechanics in thalattosuchian (Crocodylomorpha) skulls: implications for feeding behaviour and niche partitioning. Journal of Anatomy 215:555-576.

Pihlström, H. 2008. Comparative anatomy and physiology of chemical senses in aquatic mammals. En:. Sensory evolution on the threshold: Adaptations in secondarily aquatic vertebrates. 
Thewissen, J. G. M., y Nummela, S., editors. University of California Press, Berkeley, CA P:95111.

Pivorunas, A. 1979. The feeding mechanisms of baleen whales. American Scientist 67:432-440.

Pol, D., y M. A. Norell. 2001. Comments on the Manhattan Stratigraphic. Measure. Cladistics 17:285289 .

Pol, D., y I. H. Escapa. 2009. Unstable taxa in cladistic analysis: identification and the assessment of relevant characters. Cladistics 25:515-527.

Pritchard, G. B. 1939. On the discovery of a fossil whale in the older tertiaries of Torquay, Victoria. Victorian Naturalist 55:151-59.

Purves, P. E. 1966. Anatomy and physiology of the outer and middle ear in cetaceans. En: Whales, Dolphins, and Porpoises. Norris K. S., editor. Berkeley, Calif. University of California Press. $\mathrm{P}: 320-380$.

Pyenson, N. D., y S. N. Sponberg. 2011. Reconstructing Body Size in Extinct Crown Cetacea (Neoceti) Using Allometry, Phylogenetic Methods and Tests from the Fossil Record Journal of Mammalian Evolution 18:269-288.

Reidenberg, J. S. 2007. Anatomical adaptations of aquatic mammals. Anatomical Record 290:507513.

Reidenberg, J. S., y J. T. Laitman. 2007. Discovery of a low frequency sound source in Mysticeti (baleen whales): anatomical establishment of a vocal fold homolog. Anatomical Record 290:745-59.

Reidenberg, J. S., y J. T. Laitman. 2008. Sisters of the sinuses: cetacean air sacs. Anatomical Record 291:1389-96.

Rice, D. W. 1998. Marine Mammals of the World: Systematics and Distribution. Society for Marine Mammalogy Special Publication Number 4. Allen Press, Lawrence, Kansas.

Ridewood, W. G. 1923. Observations on the skull in foetal specimens of whales of the genera 
Megaptera and Balaenoptera. Philosophical Transactions of the Royal Society of London, B 211:209-272.

Riva Rossi, C. M. 1997. Presencia de Pseudopercis semifasciata (Pisces, Pinguipedidae) en el Mioceno medio de Península Valdés. Ameghiniana 34:540.

Riva Rossi, C. M., A. E. Gosztonyi, y M. A. Cozzuol. 20oo. A Miocene cusk-eel (Ophidiiformes: Ophidiidae) from Península Valdés, Argentina. Journal of Vertebrate Paleontology 20:645-650.

Rosenbaum, H. C., R. L. Brownell, M. W. Brown, et al. 2000. World-wide genetic differentiation of Eubalaena: Questioning the number of right whale species. Molecular Ecology 9:1793-1802

Rosset, A., y L. Spadola. 2004. OsiriX: an open-source software for navigating in multidimensional DICOM images. Journal of Digital Imaging 17:205-216.

Roston, R. A., D. Lickorish, y E. a Buchholtz. 2013. Anatomy and age estimation of an early blue whale (Balaenoptera musculus) fetus. Anatomical Record 296:709-22.

Rowntree, V. J. 1996. Feeding, distribution, and reproductive behavior of cyamids (Crustacea: Amphipoda) living on humpback and right whales. Canadian Journal of Zoology 74:103-109.

Rugh, D. J., y K. E. W. Shelden. 2009. Bowhead whale (Balaena mysticetus). En: Encyclopedia of marine mammals. Perrin, W. F., Thewissen, J. G. M., Würsig, B., editors. San Diego, CA: Elsevier P:131-133.

Sanders, A. E., y L. G. Barnes. 2002. Paleontology of the late Oligocene Ashley and Chandler Bridge formations of South Carolina 3: Eomysticetidae, a new family of primitive Oligocene mysticetes (Mammalia: Cetacea), from South Carolina, USA. En: Cenozoic mammals of land and sea: tributes to the career of Clayton E. Ray. Emry, R. J., editor. Smithsonian Contributions to Paleobiology 93: 313-356.

Sasaki, T., N. Okada, M. Nikaido, H. Hamilton, M. Goto, H. Kato, N. Kanda, L. A. Pastene, Y. Cao, R. E. Fordyce, y M. Hasegawa. 2005. Mitochondrial phylogenetics and evolution of Mysticete whales. Systematic Biology 54: 77-90. 
Scasso, R., C. Del Rí. 1987. Ambientes de sedimentación, bioestratigrafía y proveniencia de la secuencia marina del Terciario superior de la región de Península Valdés, Chubut. Revista de la Asociación Geológica Argentina 42:291-321.

Scasso, R. A., y L. N. Castro. 1999. Cenozoic phosphatic deposits in North Patagonia, Argentina: Phosphogenesis, sequence-stratigraphy and paleoceanography. Journal of South American Earth Sciences 12:471-487.

Scasso, R., J. M. McArthur, C. del Río, S. Martínez, M. F. Thirlwall. 2001. 87Sr/86Sr Late Miocene age of fossil molluscs in the "Entrerriense" of the Valdés Peninsula (Chubut, Argentina). Journal of South American Earth Sciences 14:319-329.

Scheffer, V. B. y D. W. Rice. 1963. A list of the marine mammals of the world. United States Fish and Wildlife Service Special Scientific Report Fisheries 431:1-12.

Schlegel, H. 1841. Abhandlungen aus dem Gebiete der Zoologie und vergleichenden Anatomie. 1 Heft. A. Arnz \& Company, Leiden, Netherlands

Schmitz, L. 2009. Quantitative Estimates of Visual Performance Features in Fossil Birds. Journal of Morphology 270: 759-773.

Schmidt-Nielsen, K. 1984. Scaling: Why is animal size so important? Cambridge University Press, Cambridge 237pp.

Schulte, H. V. W. 1916. Monographs of the Pacific Cetacea. The Sei whale (Balaenoptera borealis Lesson). Part 2: Anatomy of a foetus of Balaenoptera borealis. Memoirs of the American Museum of Natural History, New York 1: 380-502.

Siddall, M. 1998. Stratigraphic fit to phylogenies: A proposed solution. Cladistics 14:201-208.

Simpson, G. G. 1935. Early and Middle Tertiary geology of the Gaiman Region, Chubut, Argentina. America Museum Novitates 775:1-29.

Simpson, G. G. 1945. The principles of classification, and a classification of mammals. Bulletin of the American Museum of Natural History 85:1-350. 
Sironi, M., S. D. Kraus, E. V. Nordheim, V. J. Rowntree, y C. T. Snowdon. 2005. Age estimation of North Atlantic right whales (Eubalaena glacialis) by allometric measurements on photographs. Paper SC/57/BRG7 presentado a la International Whaling Commission Scientific Committee 14pp.

Slater, G. J., S. a Price, F. Santini, y M. E. Alfaro. 2010. Diversity versus disparity and the radiation of modern cetaceans. Proceedings Biological Sciences / The Royal Society 277:3097-3104

Sprague Eutis, H. 1995. Postnatal development. En: Pediatric Ophthalmology and strabismus. Wright K. W., editor. Mosby, St. Louis. P:45-52.

Steeman, M. E. 2007. Cladistic analysis and a revised classification of fossil and recent mysticetes. Zoologycal Journal of the Linnean Society 150:875-894.

Steeman, M. E. 2009. A new baleen whale from the Late Miocene of Denmark and early mysticete hearing. Palaeontology 52:1169-1190.

Struntz, D. J., W. A. Mclellan, R. M. Dillaman, J. E. Blum, J. R. Kucklick, y D. A. Pabst. 2004. Blubber development in bottlenose dolphins (Tursiops truncates). Journal of Morphology 259:7-20.

Talevi, M., y M. S. Fernández. 2012. Unexpected skeletal histology of an ichthyosaur from the Middle Jurassic of Patagonia: implications for evolution of bone microstructure among secondary aquatic tetrapods. Naturwissenschaften 99:241-244.

Thewissen, J. G. M., ed. 1998. The Emergence of Whales. NewYork: Plenum Press 479pp.

Thewissen, J. G. M., y S. Bajpai. 2001. Whale Origins as a Poster Child for Macroevolution. BioScience 51:1037-1049.

Thewissen, J. G. M., y S. T. Hussain. 1993. Origin of underwater hearing. Nature 361: 444-445.

Thewissen, J. G. M., y S. T. Hussain. 2000. Attockicetus praecursor, a new remingtonocetid cetacean from marine Eocene sediments of Pakistan. Journal of Mammalian Evolution 7:133-46.

Thewissen, J. G. M., S. T. Hussain, y M. Arif. 1994. Fossil evidence for the origin of aquatic locomotion 
in archaeocete whales. Science 263:210-212.

Thewissen, J. G. M., S. I. Madar, S. T. Hussain. 1996. Ambulocetus natans, an Eocene cetacean (Mammalia) from Pakistan. Courier Forschungsinstitut Senckenberg 191:1-86.

Thewissen, J. G. M., E. M. Williams, L. J. Roe, y S. T. Hussain. 2001. Skeletons of terrestrial cetaceans and the relationship of whales to artiodactyls. Nature 413:277-278.

Thewissen, J. G. M., L. N. Cooper, M. T. Clementz, S. Bajpai, y B. N. Tiwari. 2007. Whales originated from aquatic artiodactyls in the Eocene epoch of India. Nature 450:1190-1195.

Thewissen, J. G. M., L. N. Cooper, J. C. George, y S. Bajpai. 2009. From Land to Water: the Origin of Whales, Dolphins, and Porpoises. Evolution: Education and Outreach 2:272-288.

Thewissen, J. G. M., J. George, C. Rosa, y T. Kishida. 2011. Olfaction and brain size in the bowhead whale (Balaena mysticetus). Marine Mammal Science 27:282-294.

Thompson, D. W. 1890. On the systematic position of Zeuglodon. Study Museum of Zoology 9:1-8.

Thompson, T. J., H. E. Winn, y P. J. Perkins. 1979. Mysticete sounds. En: Behavior of marine animals, current perspectives in research. Vol. 3. Cetaceans. Winn, H. E., Olla, B. L., editors. New York: Plenum Press P:403-431.

Thompson, P. O., W. C. Cummings, y S. J. Ha. 1986. Sounds, source levels, and associated behavior of humpback whales, southeast Alaska. The Journal of the Acoustical Society of America 80:735739 .

Tomilin, A. G. 1962. Order Cetacea. Mammals of eastern Europe and northern Asia 79:158-164.

Tomilin, A. G. 1967. Cetacea (Vol. XIX). En: Mammals of the USSR and adjacent countries. Heptner, V.G., editor. Jerusalem: Israel Program for Scientific Translations 756pp.

Trevisan, L. 1941. Una nuova specie di Balaenula Pliocenica. Palaeontographia Italica 40:1-13.

True, F. W. 1904. The whalebone whales of the western North Atlantic compared with those occurring 
in European waters with some observations on the species of the North Pacific. Smithsonian Contributions to Knowledge 33:332pp.

Turner, W. M. 1913. The right whale of the North Atlantic, Balaena biscayensis: Its skeleton described and compared with that of the Greenland right whale Balaena mysticetus. Transactions of the Royal Society of Edinburgh 48:899-992.

Uhen, M. D. 1998. Middle to Late Eocene Basilosaurines and Dorudontines. En: The emergence of whales. Thewissen JGM, editor. New York: Plenum Press P:29-61.

Uhen, M. D. 2004. Form, function, and anatomy of Dorudon atrox (Mammalia, Cetacea): An archaeocete from the middle to late Eocene of Egypt. The University of Michigan Museum of Paleontology Papers on Paleontology 34:1-222.

Uhen, M. D. 2008. New protocetid whales from Alabama and Mississippi, and a new cetacean clade, Pelagiceti. Journal of Vertebrate Paleontology 28:589-593.

Uhen, M. D. 2010. The Origin(s) of Whales. Annual Review of Earth and Planetary Sciences 38:189-219.

Uhen, M. D. 2013. Cetacea: Online Systematics Archive. http:// http://paleodb.org/bridge.pl

Uliana, M. A., y K. T. Biddle. 1988. Mesozoic-Cenozoic paleogeographic and geodynamic evolution of southern South America. Revista Brasileira de Geociências 18:172-19o.

Valenzuela, L. O., M. Sironi, y V. Rowntree. 2010. Interannual variation in the stable isotope differences between mothers and their calves in southern right whales (Eubalaena australis). Aquatic Mammals 36:138-147.

Van Beneden, P. J. 1872. Les baleines fossiles d'Anvers. Bulletin de l'Academie Royal de Belgique 34:620.

Van Beneden, P. J. 1878. Description des ossements fossiles des environs d'Anvers. Balénides. Annales du Musée Royal d'Histoire Naturelle du Belgique (Atlas) 42:1-38.

Van Beneden, P. J. 1880. Description des ossements fossiles des environs d'Anvers. Cétacés Genres 
Balaenula, Balaena et Balaenotus. Annales du Muse'e Royal d'Histoire Naturelle de Belgique 4:83pp.

Van Beneden, P. J., y P. Gervais. 1880. Ostéographie des cétacés vivants et fossiles: comprenant la description et l'iconographie du squelette et du système dentaire de ces animaux ainsi que des documents relatifs à leur histoire naturelle. Arthus Bertrand, Paris.

Vélez-Juarbe, J., J. I. Noriega, y B. S. Ferrero. 2012. Fossil Dugongidae (Mammalia, Sirenia) from the Parana Formation (late Miocene) of Entre Ríos Province, Argentina. Ameghiniana 49:585-593.

Vermeij, G. J., y R. Dudley. 200o. Why are there so few evolutionary transitions between aquatic and terrestrial ecosystems? Biological Journal of the Linnean Society 70:541-554.

Vogl, W., y H. D. Fisher. 1981. The internal carotid artery does not directly supply the brain in the Monodontidae (order Cetacea). Journal of Morphology 170:207-14.

Vucetich, M. G., C. M. Deschamps, A. I. Olivares, y M. T. Dozo. 2005. Capybaras, size, shape and time: a model kit. Acta Palaeontologica Polonica 50:259-272.

Walls, G. L. 1942. The vertebrate eye and its adaptive radiation. Cranbrook, Bloomfield Hills, Michigan $\mathrm{P}: 785$.

Walmsley, R. 1938. Some observations on the vascular system of a female fetal finback. Carnegie Institution of Washington, Contributions to Embryology 164:109-178, 5 pls.

Walsh, B. M., y A. Berta. 2011. Occipital ossification of balaenopteroid mysticetes. Anatomical Record 294:391-8.

Warton, D. I., I. J. Wright, D. S. Falster, y M. Westoby. 2006. Bivariate line-fitting methods for allometry. Biological reviews of the Cambridge Philosophical Society 81: 259-291.

Wartzok, D., y D. R. Ketten. 1999. Marine mammal sensory systems. En: Reynolds J.E.III, Rommel S.A., editors. Biology of marine mammals.Washington: Smithsonian Institution Press P:117-175.

Webb, P. W. 1984. Body form, locomotion, and foraging in aquatic vertebrates. American Zoology 
24:107-120.

Webb, P. W., y V. de Buffrenil. 1990. Locomotion in the biology of large aquatic vertebrates. Transactions of the American Fisheries Society 119:629-641.

Werth, A. 20oo. Feeding in marine mammals. En: Feeding: form, function, and evolution in tetrapod vertebrates. Schwenk, K., editor. Academic Press, San Diego, California P:487-526.

Westgate, J. W., y F. C. Whitmore, Jr. 2002. Balaena ricei, a new species of bowhead whale from the Yorktown Formation (Pliocene) of Hampton, Virginia. En: Cenozoic mammals of land and sea: Tribute to the career of Clayton E. Ray. Emry R.J., editor. Smithsonian Contributions to Paleobiology 93: 295-312.

Wills, M. A. 1999. Congruence between stratigraphy and phylogeny: randomization tests and the gap excess ratio. Systematic Biology 48:559-580.

Witmer, L. 1997. The evolution of the anteorbital cavity of Archosaurs: a study in soft-tissue reconstruction in the fossil record with an analysis of the function of pneumaticity. Journal of Vertebrate Paleontology 17:1-81.

Witmer, L. M. 2001. Nostril position in dinosaurs and other vertebrates and its significance for nasal function. Science 293:850-853.

Woodward, B. L., J. P. Winn, y F. E. Fish. 2006. Morphological specializations of baleen whales associated with hydrodynamic performance and ecological niche. Journal of Morphology 267:1284-1294.

Wyss, A. R. 1994. The evolution of body size in phocids: some ontogenetic and phylogenetic observations. En: Berta, A.B., Demeré, T.A., editors. Proceedings of the San Diego Society of Natural History. San Diego, CA 29:69-75.

Yamada, M. 1953. Contribution to the anatomy of the organ of hearing of whales. Scientific Report Whales Research Institute 8:1-79.

Yamato, M., D. R. Ketten, J. Arruda, S. Cramer, y K. Moore. 2012. The auditory anatomy of the minke 
whale (Balaenoptera acutorostrata): a potential fatty sound reception pathway in a baleen whale. Anatomical Record 295:991-8.

Yrigoyen, M. 1969. Problemas estratigráficos del Terciario de Argentina. Ameghiniana, 6:315-329.

Zinsmeister, W., L. G. Marshall, R. Drake, G. Curtis. 1981. First radioisotope (potassium argon) age of marine Neogen Río Negro Beds in northeastern Patagonia, Argentina. Science 212:440.

Zhu, Q., D. J. Hillmann, W. G. Henk. 20o1. Morphology of the eye and surrounding structures of the bowhead whale, Balaena mysticetus. Marine Mammal Science 17:729-750. 